\title{
ECOLOGICAL GENOMICS OF DIVERGENCE, ADMIXTURE, AND FITNESS IN THE SMALLMOUTH BASS (Micropterus dolomieu)
}

A Dissertation
Presented to
The Faculty of the Graduate School
at the University of Missouri-Columbia
In Partial Fulfillment
of the Requirements for the Degree
Doctor of Philosophy
by
JOE C. GUNN
Dr. Lori S. Eggert, Dissertation Supervisor
JULY 2021


The undersigned, appointed by the dean of the Graduate School, have examined the dissertation entitled:

\section{ECOLOGICAL GENOMICS OF DIVERGENCE, ADMIXTURE, AND FITNESS IN THE SMALLMOUTH BASS (Micropterus dolomieu)}

Presented by Joe C. Gunn, a candidate for the degree Doctor of Philosophy, and hereby certify that, in their opinion, it is worthy of acceptance.

Professor Lori S. Eggert

Professor Don E. Tillitt

Professor Elizabeth G. King

Professor Mitchell D. Weegman 


\section{DEDICATION}

For my former self, who decided long ago that I would do this. And for all the teachers I've had who made me believe I could.

"I will not be afraid because I understand...And understanding is happiness" - A.C.C. 


\section{ACKNOWLEDGMENTS}

Thank you to my PhD advisor, Dr. Lori Eggert, for seeing potential in me five years ago that I did not see myself. Even as she was just getting ready for her own joyous freedom (retirement), she took me in and gave me the opportunity to fulfill a lifelong goal and to find my passion for conservation, research, and teaching. I have grown every day under her guidance to be a better writer, speaker, problem-solver, and thinker. Maybe the most important thing to me is that she has taught me what it means to be a good teacher, which is what I hope to do for the rest of my life. Thanks for seeing the conservation geneticist in me even though I had barely taken a genetics course before graduate school. Thanks for indulging me but reining me in on my lofty ideas; thanks for putting up with my various annoying habits (whistling and foot-tapping, to name a few); thanks for the good times, the lab lunch gatherings, and the Eggert Lab holiday parties over the years; thanks for the tough love when I needed it, especially when perfectionism in writing got in the way of getting my work done; and thanks for always being there for a good chat, either about science or about life. I am honored to have been your last graduate student.

I would also like to thank the members of my dissertation committee, Libby King, Don Tillitt, and Mitch Weegman, who have pushed me all the way through this journey. Thank you to Don for welcoming me into his lab at the Columbia Environmental Research Center when I first came to Mizzou and for introducing me to new techniques and ways of thinking. His help and advice have been steadfast over the past five years; I know exactly who to go to if I need something fish-related. Thank you to Mitch for showing me the power of Bayesian computation and for teaching me about the true value of conservation. And thank you for challenging me to reach a level of mathematical and 
statistical understanding that I never imagined. Thank you to Libby for all you've done for me over the years, from welcoming me into your lab, to teaching me everything I know about coding and running statistical models in $R$, to planting the initial confidence in me that I could teach.

During my time in graduate school, I have had the pleasure of collaborating with a number of kind, brilliant, and hard-working researchers from multiple institutions, all of whom have shown me the commitment, perseverance, and self-reflection it takes to be a good scientist. Many of them are authors on chapters in this dissertation, including Andrew Taylor (University of Central Oklahoma), Shannon Brewer (Oklahoma State University), Jim Long (Oklahoma State University), Leah Berkman (Missouri Department of Conservation), Jeff Koppelman (Missouri Department of Conservation), Michael Moore (University of Missouri), Eddie Sterling (U.S. Fish and Wildlife Service), Taylor Volkers (University of Missouri), and my PhD advisor, Lori Eggert (University of Missouri). I have worked with several others on auxiliary projects that have made me a more well-rounded biologist, including Jessica Kansman (Penn State University), Jacob Cianci-Gaskill (University of Missouri), Sarah Clements (University of Missouri), Tom Anderson (Southern Illinois University), Katy Klymus (U.S. Geological Survey), Tabitha Finch (University of Vermont), and Noah Sitati (World Wide Fund for Nature).

I would consider all these people to be my mentors, because I could not have accomplished the work I have done, nor could I have yet known the elation of publishing, without them. I want to give a special thanks to Andrew Taylor and Jim Long, who have helped to cultivate in me a true passion for Smallmouth Bass and for the conservation of sport fishes in general. Both of them have spent a lot of hours with me pondering the 
complexities of Smallmouth Bass diversity and discussing potential new avenues to explore in the study of their evolution. I hope we will get to go fishing together and continue to collaborate in the future. A sincere thank you to Jeff Koppelman, who took me on my first field collection trip well before I fully understood what I was doing; I've learned a lot over the years about how and where to fish for the elusive Smallmouth Bass. Finally, a special thanks to Leah K. Berkman, who has always been there to help me work through tough questions and who has been the most consistent voice of reason in the usual chaos of research. And finally, thanks to Jeff Quinn (Arknasas Game and Fish Commission) and Charlie Gagen (Arkansas Tech University), who shared and helped to procure samples with me for various projects.

Thank you to all in the Eggert Lab family, past and present, who have taught me so much, supported me in the lowest of times, and have given me some of the most enjoyable years of my life. Dr. Jake Burkhart, Chelsea Titus, Kathryn Storey, Zack Miller, Sabrina Michael, Damien Yves Saint Hall, Dr. Rachel Munds, Dr. Austin Lynn, Dr. Ellee Cook, Dr. Arianne Messerman, Dr. Freya Rowland, Kaitlin Sulkowski, Madison Wilkins, Christine Sholy, Molly Garrett, John Orech, Emily Smith, Taylor Volkers, and anyone else I may have missed amid the emotions of writing this. I thank all of them for being my friends; I thank them now and forever for all they are doing and will do for the betterment of species and the world.

Thank you especially to Kris Budd, the one lab member I intentionally left off the Eggert Lab list above. Since I am overloaded with memories of all we went through, I find that there is not much I can say to explain how much her friendship has meant to me. Kris, you are the most intelligent person, most talented scientist, and most skilled writer I 
know, and I would trust you with all my data. Thanks for teaching me everything I know about genetics; thanks for enabling my coffee overconsumption; thanks for all the maps (any map in this dissertation is thanks to Kris); thanks for bringing in dogs all the time; thanks for being on my level of obsession when it came to decorating the office door for the holidays; and thanks for all the great times.

Thank you to Paul Petrowski, Makenzie Mabry, Troy Rowan, Harly Durbin, Bob Schnabel, Jared Decker, and the entire RCSS Support Staff at the University of Missouri for the many, many times they helped me through difficult (or, in most cases, probably very simple) bioinformatic troubleshooting. I appreciate your patience. Additionally, thank you to all the faculty, lecturers, and participants at the La Kretz Institute for Conservation Science at the University of California, Los Angeles, whose week-long conservation genomics workshop got my project ideas and computational skills off the ground. The fourth chapter of this dissertation would not have been possible without any of them.

Special thank you to Christian Perez for always listening to my venting about the stresses of research, but especially for never letting me win in tennis. I am a better scientist, person, and tennis player because of him. Thank you to Sarah Clements for taking me to Louisiana to catch plovers and avocets, even though I used quite a bit of my time there to take naps on the beach. Thanks for turning me into a bird person. Thanks to Lauren Sullivan for quasi-adopting me into her lab just before the COVID-19 pandemic, for all the help in statistics and modeling, and for keeping me caffeinated. Thanks to Rick Horton, Mike Thomas, Zach Morris, Joe Chilton, Damien Hall, Mischa Schultz, and any others who helped me catch fish for my projects from time to time. Thanks to Kathryn 
Storey, Jacob Bouchier, Allison Bramanti, and Erika Schneider for all the great memories and for letting me stay with you all those times. Finally, thank you to John and Janice Faaborg and one-eyed Rita (their dog), who have been a lot like family to me ever since they recruited me as a house-sitter. Equal thanks to Candi Galen and Shelly Ossana for letting me get to know their family through housesitting and tutoring. Thanks for all the "staycations" in your beautiful homes.

Thanks to all my volleyball people, especially those who have become my lifelong friends. I could never have made through this experience if it were not for all the times at the Deuce, Stephens College Open Gym, Jeff City Open Gym, Forum Church Open Gym, and all the tournaments around Missouri.

And thank you to the many teachers I was lucky to have at Rock Bridge High School and William Jewell College who invested energy in making me a better person and showing me how to have self-confidence. Thank you Mary Dix for teaching me how to write; thank you Stephanie Harman for introducing me the exhilaration and wonder of science; thank you Barbara Phillips for teaching me the power of language; thank you Dan Ware for showing me how to work hard always; thank you Dr. Jennifer Moody for your wisdom and reason, which got me through tough times at Jewell; thank you Paul Klawinski for your mentorship in research and your advice on how to be a good teacher; thank you Gary Armstrong for your challenging me to think and to question. I couldn't have done this $\mathrm{PhD}$ without the lessons given to me by each of you.

Finally, thank you to my mom, Marla, and my dad, Greg, who have housed, loved, fed, and supported me despite all my anxiety-induced antics over the past five years. I think my parents always knew I wanted to go to graduate school, but I'm not sure 
they anticipated me living with them through all of it. Thank you for raising me and encouraging me to be the best I could be, and for forgiving me and loving me when I was not. I love you both. Thank you to my brother Andy for being the one who truly motivated me to pursue a PhD. I couldn't just let him hold his graduate degree over me for the rest of my life. You also got married while I was deep in the trenches of writing all of this; I am sorry if I projected any of my stress on you, and I wish you and Megan great happiness in your life together. Thanks to Hazel and Sam (the dogs), who seem to have always been happy to see me.

To everyone I have listed here, and to everyone else who has been a part of this adventure with me, I will appreciate you always. 


\section{TABLE OF CONTENTS}

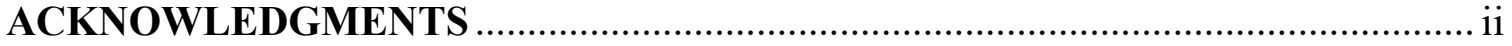

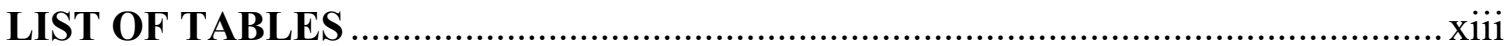

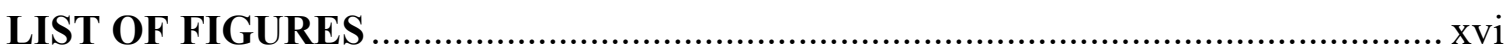

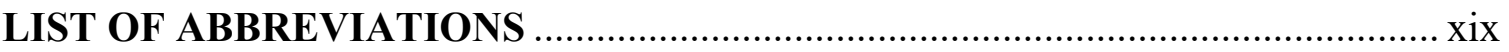

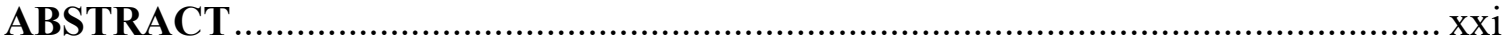

CHAPTER 1 - Using genetics and genomics to understand divergence, admixture, and fitness of Smallmouth Bass (Micropterus dolomieu) in the Central Interior Highlands .... 1

Ecological Genetics, Genomics, and Admixture ............................................. 1

Divergence and diversity in the central interior highlands.............................. 6

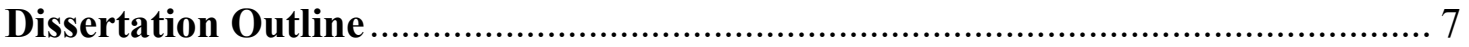

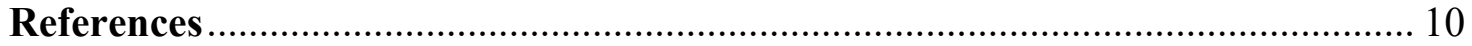

CHAPTER 2 - Integrating taxonomy, natural history and ecology into the study of evolution and local adaptation in the Smallmouth Bass (Micropterus dolomieu): A framework for advancing conservation and management of a popular sportfish ............ 13

The Allure and Plight of the Smallmouth Bass ............................................. 13

Evolution in the Smallmouth Bass Lineages .................................................. 16

A Framework for Integrating Natural History and Ecology with Evolution........ 18

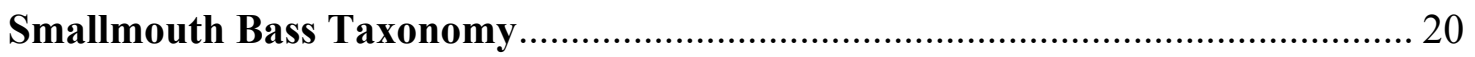

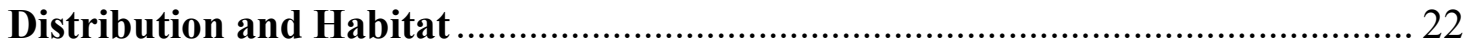

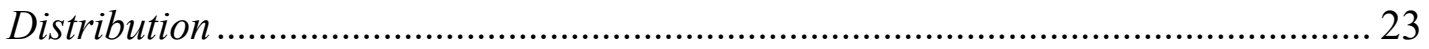

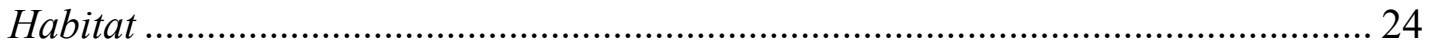

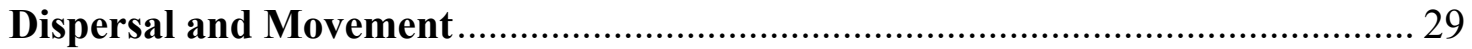

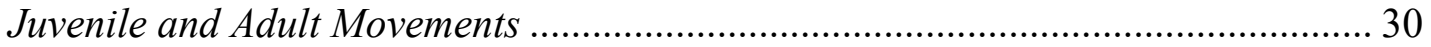

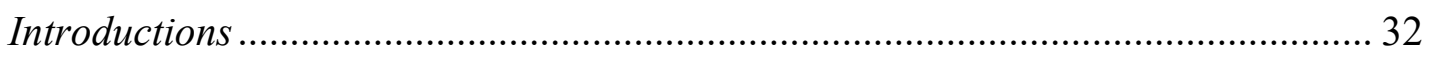




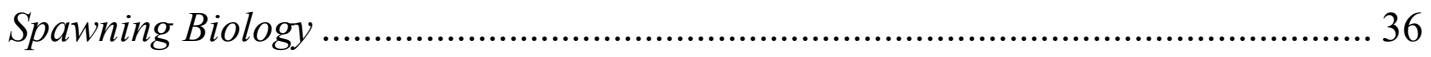

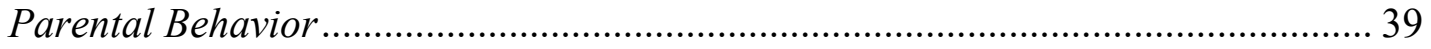

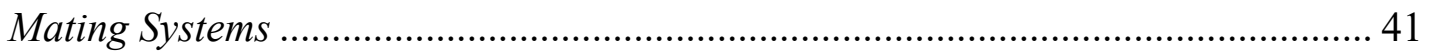

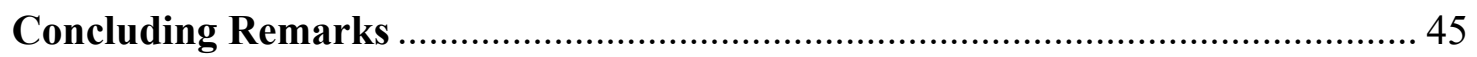

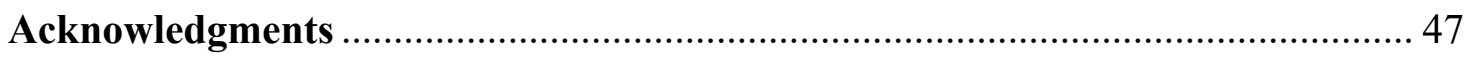

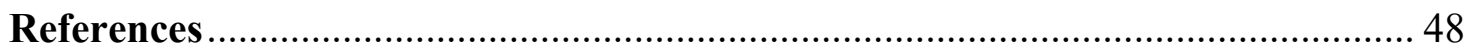

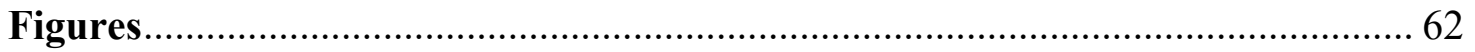

CHAPTER 3 - Complex patterns of genetic and morphological differentiation in the Smallmouth Bass subspecies (Micropterus dolomieu dolomieu and M. d. velox) of the

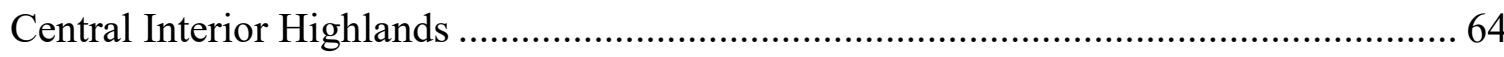

Abstract

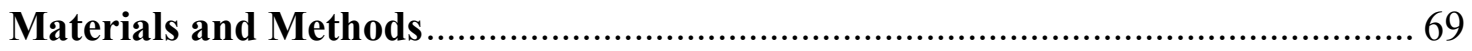

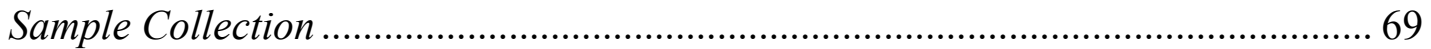

Microsatellite Genotyping and Genotyping Error ........................................... 70

Hardy-Weinberg Equilibrium, and Linkage Disequilibrium ................................ 71

Analysis of Genetic Diversity and Differentiation ............................................... 71

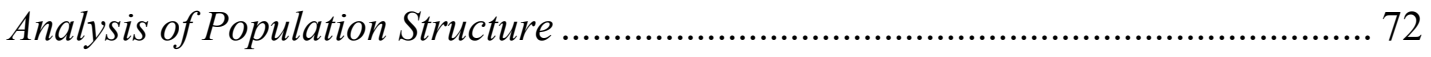

Analysis of Morphological Differentiation ......................................................... 73

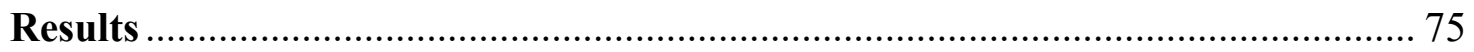

Sample Collection and Genotyping Error ...................................................... 75

Hardy-Weinberg Equilibrium and Linkage Disequilibrium .................................. 76

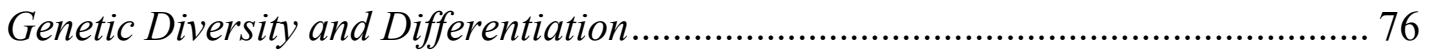

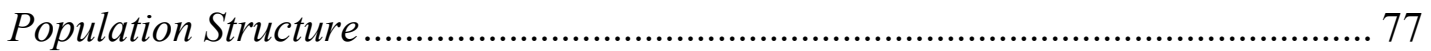

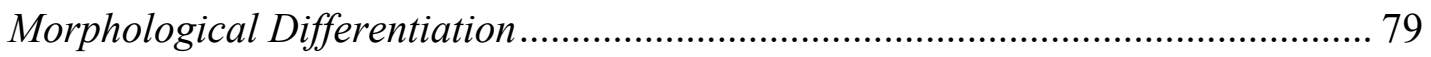

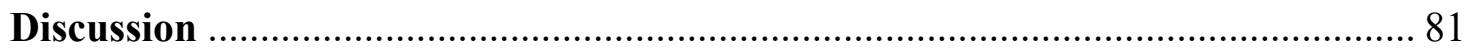




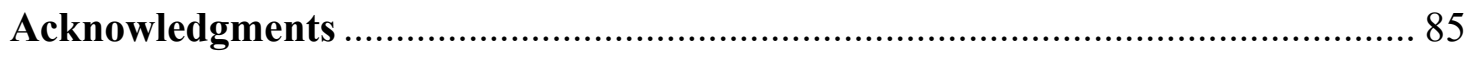

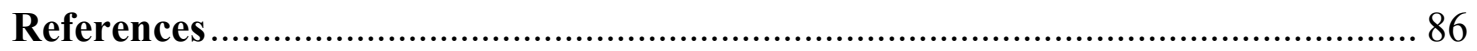

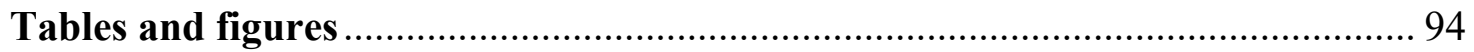

CHAPTER 4 - Lineage diversification, local adaptation, and historic and anthropogenic secondary contact have shaped Smallmouth Bass (Micropterus dolomieu) diversity in the

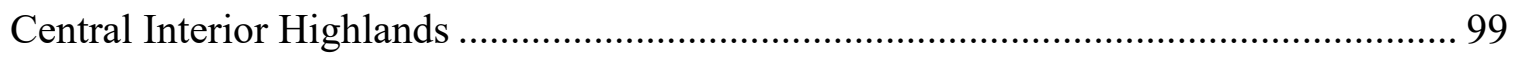

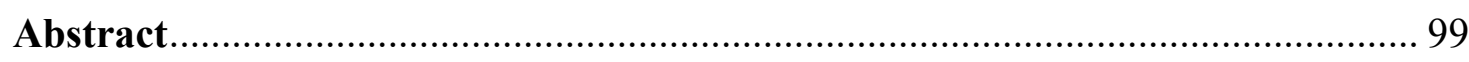

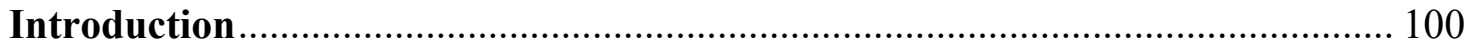

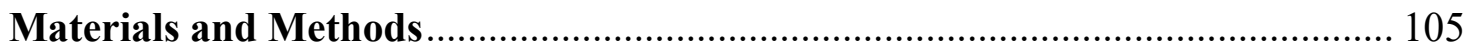

Sample Collection and Genomic DNA Preparation ........................................... 105

Library Preparation and Sequencing ............................................................ 106

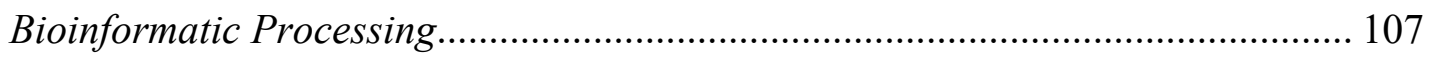

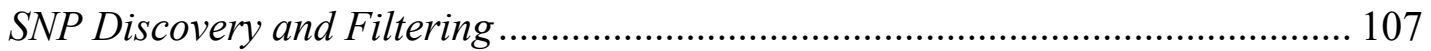

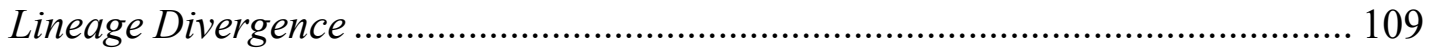

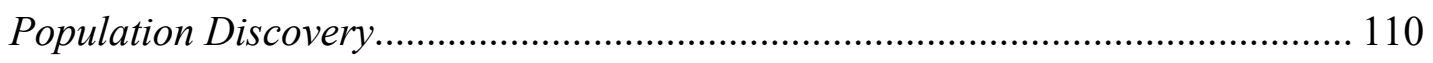

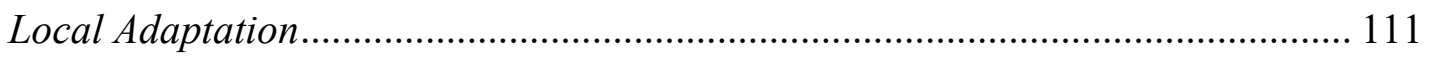

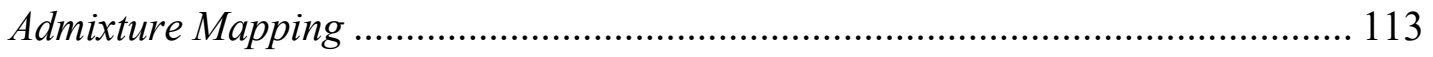

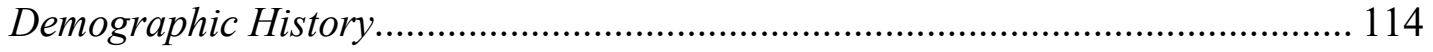

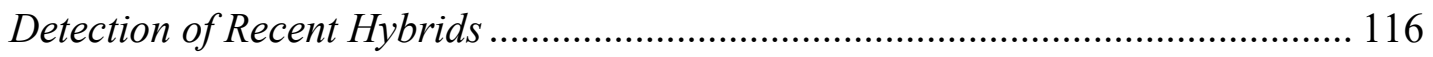

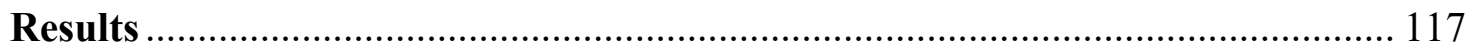

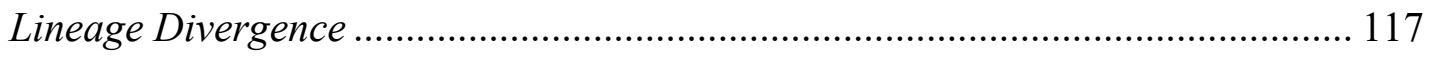

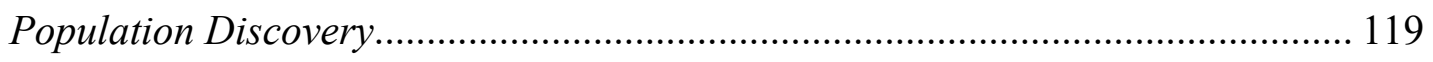

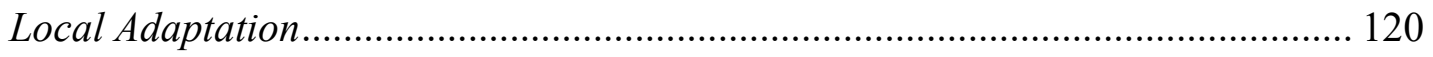

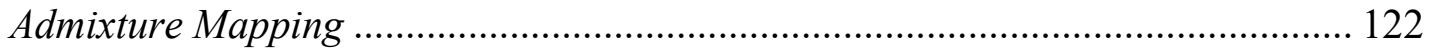

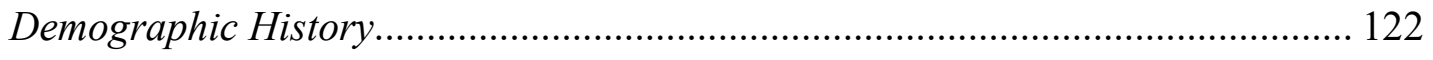

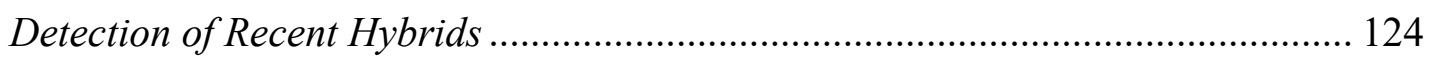

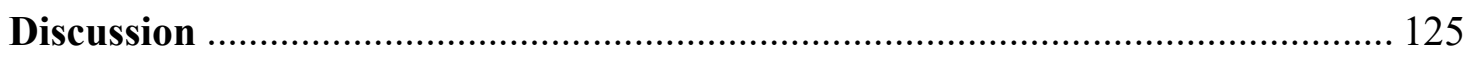


Conclusions.

Acknowledgments

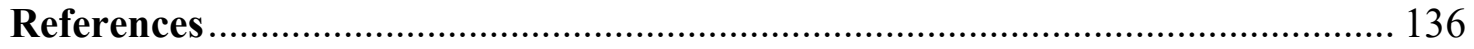

Tables and figures

CHAPTER 5 - Admixture affects individual growth and body condition of the Neosho Smallmouth Bass (Micropterus dolomieu velox) in two Ozark rivers.

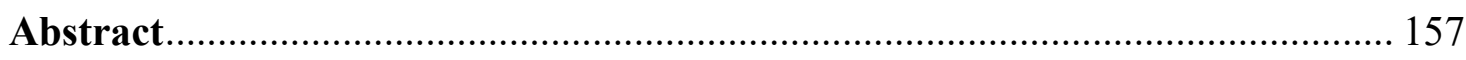

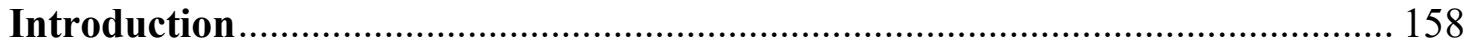

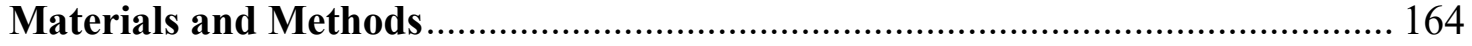

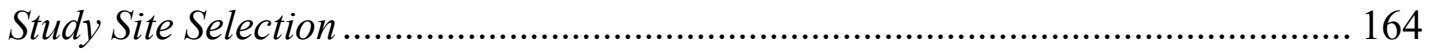

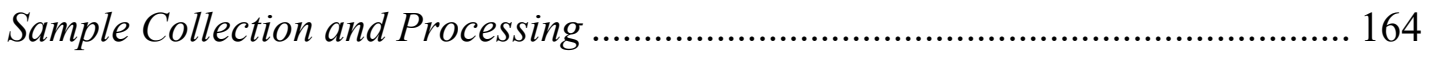

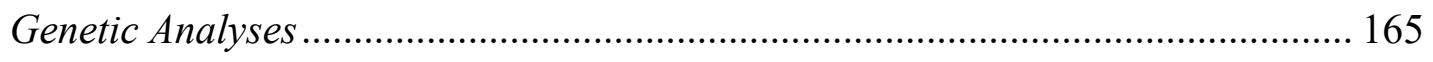

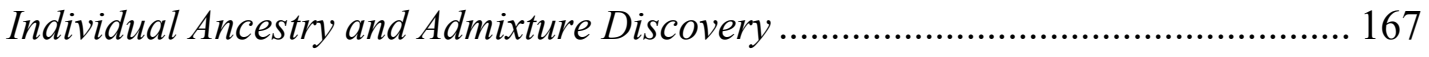

Age Estimation using Sagittal Otoliths ............................................................... 168

Geographic Distribution of Admixture ......................................................... 170

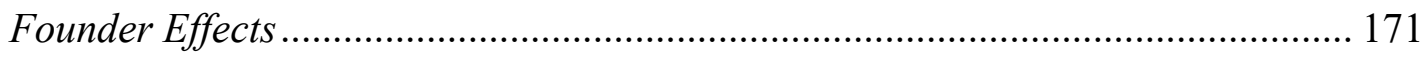

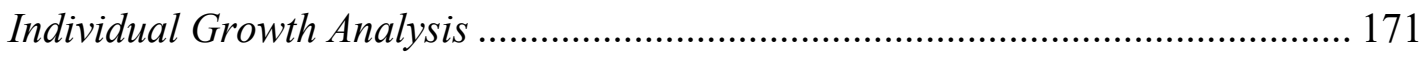

Heterozygosity-Fitness Correlation ............................................................ 172

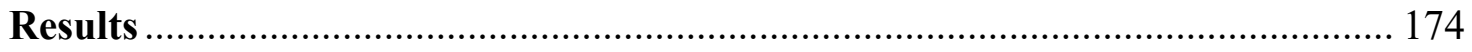

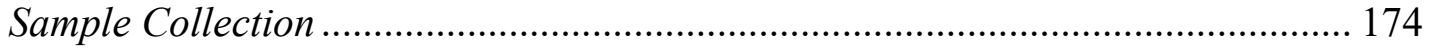

Hardy-Weinberg Equilibrium and Genotyping Error ..................................... 174

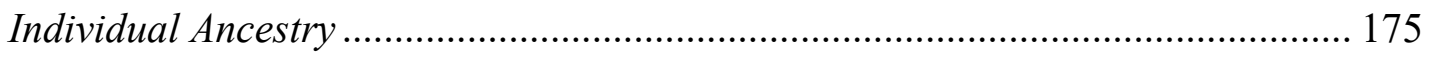

Geographic Distribution of Admixture .......................................................... 175

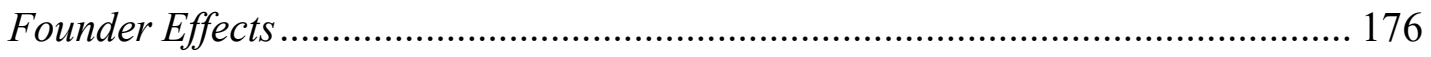

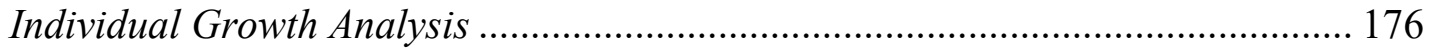

Heterozygosity-Fitness Correlation ............................................................ 178

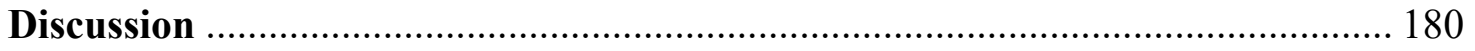




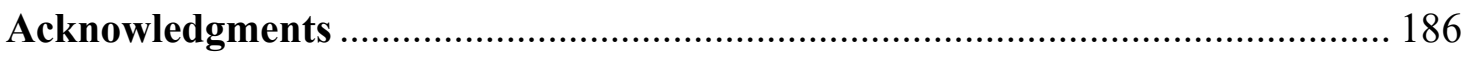

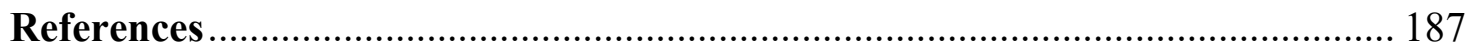

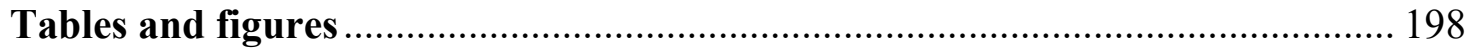

CHAPTER 6 • Genetic and Morphological Patterns, Ecological and Evolutionary Processes, and Fitness Consequences in the Conservation of the Smallmouth Bass

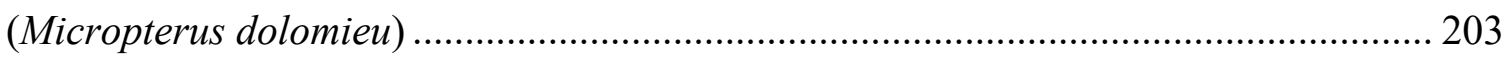

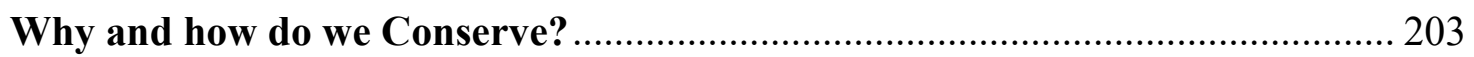

Brief Overview of Dissertation Findings.................................................. 206

Genetic and Morphological Patterns................................................................ 206

Ecological and Evolutionary Processes .......................................................... 208

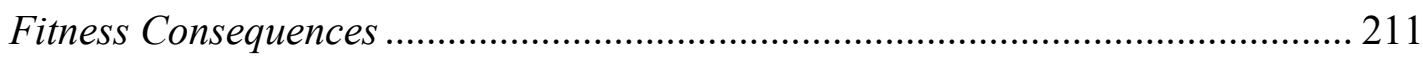

Open Questions and Future Directions ..................................................... 212

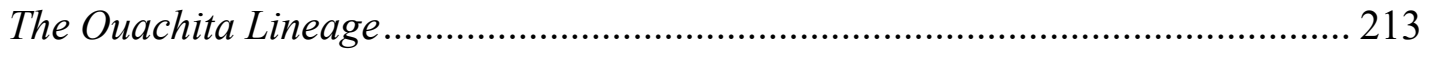

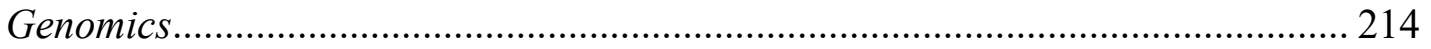

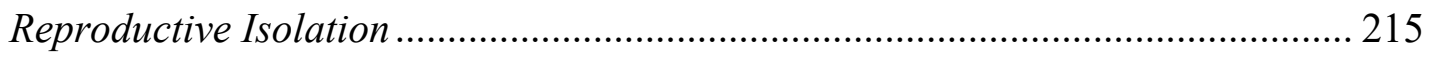

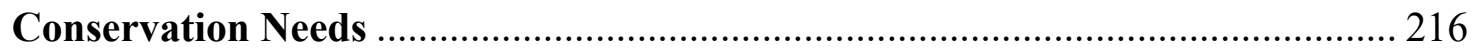

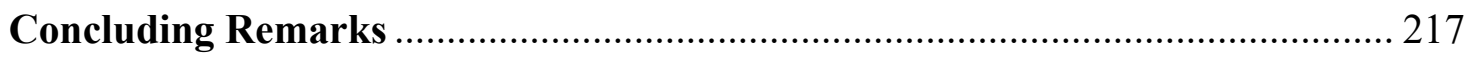

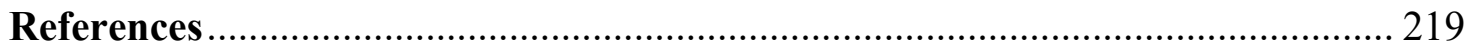

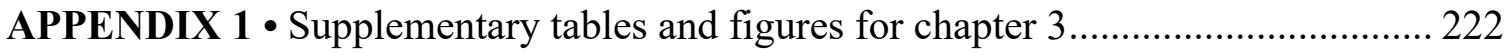

APPENDIX 2 • Supplementary tables and figures for chapter 4 ............................... 238

APPENDIX 3 • Supplementary tables and figures for chapter 5 .............................. 257

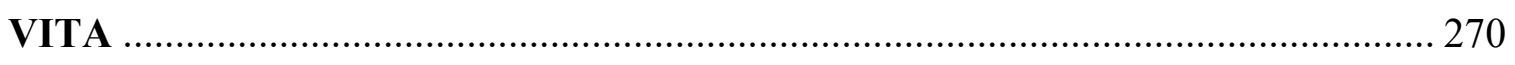




\section{LIST OF TABLES}

Table 3.1. Sampling sites for 838 Smallmouth Bass (Micropterus dolomieu) and Spotted Bass (Micropterus punctulatus) samples

Table 3.2. Raw and adjusted trait means of standard length (SL), orbital length (OL), head length (HL), and body depth (BD) for Neosho and Northern Smallmouth Bass samples assessed by (a) taxonomic range, and (b) genetic assignment

Table 4.1. Sampling sites and associated sample sizes for 91 Smallmouth Bass and 4 Spotted Bass from three river drainages (Missouri River tributaries (MRT), White River drainage (WRD), and Arkansas River Basin (ARB)), and one Tennessee Lake-strainstocked lake population (LAKE)

Table 4.2. Admixed populations (Adm. Pop), their inferred parent populations, and parameters inferred from two-population tests in MIXMAPPER

Table 4.3. Best-fitting $(\triangle \mathrm{AIC}=0)$ two-population demographic models, likelihood, $\mathrm{AIC}$, and parameters output from $\delta a \delta i$. Descriptions of all models are given in Table A2.1, and definitions of model parameters are given in Table A2.2

Table 5.1. (a) Rivers and associated sample sizes $(N)$ for Northern Smallmouth Bass samples used to calculate cluster membership in STRUCTURE. (b) Rivers, distance from Deep Ford Access (DFA), starting (1) and ending (2) easting (East) and northing (North) coordinates, and sample sizes $(N)$ for 10 groups of samples in our study populations of interest, Big Sugar Creek and the Elk River

Table 5.2. Individual growth parameters from von Bertalanffy growth models within Big Sugar Creek and the Elk River for (a) sexes, and (b) admixture status groups (Neosho, Northern, Admixed). $L_{\infty}$ is theoretical average maximum length $(\mathrm{mm}), K$ is the Brody growth coefficient (rate at which total length (TL) approaches $L_{\infty}$, and $t_{0}$ is theoretical age at which length is $0 \mathrm{~mm}$

Table A1.1. Metadata for Neosho and Northern Smallmouth Bass and Spotted Bass samples, including source ID, source name, site, date collected, collecting agencies, approximate northing UTM coordinates, and approximate easting UTM coordinates

Table A1.2. PCR multiplexes (Mplex) for 15 polymorphic microsatellite loci known to cross-amplify in M. dolomieu and M. punctulatus

Table A1.3. Observed heterozygosity $\left(H_{\mathrm{O}}\right)$, expected heterozygosity $\left(H_{\mathrm{E}}\right)$, rarefied allelic richness $\left(A_{\mathrm{R}}\right)$, number of non-rare alleles $\left(A_{95}\right)$, and private allele frequency $\left(A_{\mathrm{P}}\right)$ for 43 sampling sites of Neosho Smallmouth Bass, Northern Smallmouth Bass, and Spotted Bass 
Table A1.4. Pairwise $F_{\mathrm{ST}}$ values for all black bass populations following Table 3.1

Table A1.5. $K$, STRUCTURE replicates, replicates with major clusters, mean and standard deviation of posterior probability $(\operatorname{LnP}(K))$, and second order rate of change of log likelihood (Delta $K$ ) for 10 replicates in STRUCTURE using Default Parameters for (a) all black bass samples, (b) all samples from the Northern Smallmouth Bass range and all Spotted Bass, and (c) all samples from the Neosho Smallmouth Bass range

Table A1.6 $K$, STRUCTURE replicates, replicates representing major clusters, mean and standard deviation of posterior probability $(\operatorname{LnP}(K))$, and second order rate of change of log likelihood (Delta $K$ ) for 10 replicates in STRUCTURE using Wang Parameters for all black bass samples

Table A1.7. Table of Puechmaille (2016) estimators: median of medians (MedMedK), median of means $(\operatorname{MedMean} K)$, maximum of medians $(\operatorname{MaxMed} K)$, and maximum of means (MaxMeanK), based on STRUCTURE Puechmaille Metrics for all black bass samples

Table A1.8. Back-calculated grand mean of total length and ANCOVA coefficients calculated for log-transformed, adjusted means of standard length (SL), orbital length $(\mathrm{OL})$, head length (HL), and body depth for a) Neosho and Northern Smallmouth Bass assessed by taxonomic range and b) Neosho and Northern Smallmouth Bass assessed by genetic assignment

Table A1.9. Sample sizes and results from Discriminant Function Analysis (DFA) for total length (TL), standard length (SL), orbital length (OL), head length (HL), and body depth (BD) grouped by taxonomic range ("Range") or genetic assignment (“Assignment")

Table A2.1. References (with respect to Figure A2.2), ID codes, and descriptions of nine two-population diversification demographic models tested for admixed populations in $\delta a \delta i$

Table A2.2. Description of parameters estimated in $\delta a \delta i$

Table A2.3. Maximum likelihood, AIC, and BIC results for phylogenetic substitution models (General Time Reversible; GTR and TN93) and possible decorations (Dec) tested in PHYML

Table A2.4. Results of three-population tests for $p$-Admixed populations (UPPARK, ILLI, ELK, BAYOU). Combinations of parents (Source 1 and Source 2) with the most negative $f_{3}$ value are inferred as most likely parents of the corresponding admixed population (Admixed Pop) 
Table A2.5. Best-fitting models (highlighted in grey), log-likelihood, AIC, $\triangle$ AIC, and parameter estimates inferred in $\delta a \delta i$

Table A3.1. Sample sizes $(N)$ per $25 \mathrm{~mm}$ size bin $(200-400+\mathrm{mm})$ for females and males and for admixture status groups (Neosho, Northern, and Admixed) within Big Sugar Creek and the Elk River

Table A3.2. $K$, STRUCTURE replicates, mean and standard deviation of posterior probability $(\operatorname{LnP}(K))$, and second order rate of change of log likelihood (Delta $K)$ for 10 replicates in STRUCTURE

Table A3.3. Table of Puechmaille (2016) estimators: median of medians (MedMedK), median of means $(\operatorname{MedMean} K)$, maximum of medians $(\operatorname{MaxMed} K)$, and maximum of means (MaxMeanK), for 10 replicates in STRUCTURE

Table A3.4. Allelic richness $(A)$, observed heterozygosity $\left(H_{\mathrm{O}}\right)$, expected heterozygosity $\left(H_{\mathrm{E}}\right)$, and the inbreeding coefficient $\left(F_{\mathrm{IS}}\right)$ across 14 microsatellite loci for Smallmouth Bass samples assigned as Northern grouped within rivers in the Neosho Smallmouth Bass range (Big Sugar Creek and the Elk River) and the Northern Smallmouth Bass samples used to calculate ancestry in STRUCTURE

Table A3.5. Genetic diversity values including allelic richness $(A)$, observed heterozygosity $\left(H_{\mathrm{O}}\right)$, expected heterozygosity $\left(H_{\mathrm{E}}\right)$, and the inbreeding coefficient $\left(F_{\mathrm{IS}}\right)$ across 14 microsatellite loci for Smallmouth Bass samples assigned as Northern in Big Sugar Creek and the Elk River within the Neosho Smallmouth Bass range and in Tablerock Lake and tributaries of the White River (including White River and Crooked Creek) for the Northern Smallmouth Bass samples used to calculate ancestry in STRUCTURE

Table A3.6. Individual growth parameters from von Bertalanffy growth models for all individuals in (a) the global dataset, (b) rivers, (c) sexes, and (d) admixture status groups (Neosho, Northern, Admixed). $L_{\infty}$ is theoretical average maximum length $(\mathrm{mm}), K$ is the Brody growth coefficient (rate at which total length (TL) approaches $L_{\infty}$, and $t_{0}$ is theoretical age at which length is $0 \mathrm{~mm}$ 


\section{LIST OF FIGURES}

Figure 2.1. Conceptual framework for incorporating ecology and natural history into the study of Smallmouth Bass (Micropterus dolomieu) evolution

Figure 2.2. Native distributions of the two Smallmouth Bass subspecies, Northern Smallmouth Bass (M. d. dolomieu; light grey) and Neosho Smallmouth Bass (M. d. velox, dark grey), and the proposed native distribution of the Ouachita Smallmouth Bass (indicated with a black arrow)

Figure 3.1. Subspecies distributions and sampling sites in the Central Interior Highlands (CIH)

Figure 3.2. Geographic distribution of cluster assignments from STRUCTURE for Smallmouth Bass. Individual charts show average membership coefficients of 25 Smallmouth Bass populations to either (a) $K=3$ major clusters based on Default Parameters, or (b) $K=5$ major clusters based on Wang Parameters. Genoa Hatchery, Wisconsin (Population 18), is shown in the lower right of each panel

Figure 3.3. ANCOVA results for four morphometric traits: standard length (a and $b$ ), orbital length (c and d), head length (e and f), and body depth ( $g$ and h) evaluated by range of collection (left column) and by genetic assignment (right column)

Figure A1.1. Q-plots of major clusters from STRUCTURE. Within sources (upper horizontal), sites are presented north to south from left to right and correspond to Table 1, with the exception of Skiatook Lake, which lies outside both subspecies ranges. Species distinction is delineated by a bold black line; subspecies distinction is delineated by a dotted black line. Number of clusters $(K)$, parameters utilized, and $\Delta \mathrm{K}$ are listed to the right of each plot. Plots a-d show genotypic assignments based on Default Parameters to (a) 2 clusters; (b) 2 clusters for Northern Smallmouth Bass and Spotted Bass (SPB) only; (c) 2 clusters for Neosho Smallmouth Bass only; and (d) 3 clusters. Plots e and f show assignments based on Wang Parameters to (e) 3 clusters, and (f) 5 clusters. Plot (g) shows assignment based on Puechmaille Metrics

Figure A1.2. Geographic distribution of cluster assignments for Smallmouth Bass. Individual charts show average membership coefficients of 25 Smallmouth Bass populations to $K=9$ major clusters based on Puechmaille Metrics. Genoa Hatchery, Wisconsin (Population 18), is shown in the lower right

Figure A1.3. PCA of 14 microsatellites showing clustering at the a) taxonomic, (b) subspecies, (c) river system, and (d) population levels. Panel (a) includes Spotted Bass data. Panels $(b-d)$ include only Smallmouth Bass data and therefore depict groupings at or below subspecies level. Panel c shows groupings among river systems of the CIH. 
Panel d corresponds with population clusters shown in Figure $3.3 \mathrm{f}$ and Figure 3.4c; individuals were grouped according to highest membership coefficient

Figure A1.4. $q q$-plots showing adherence to a normal distribution for all log-transformed morphometric traits (top to bottom: total length, standard length, orbital length, head length, and body depth) across taxonomic ranges and genetic assignments (left to right: Neosho range samples, Northern range samples, Neosho non-admixed samples, Northern non-admixed samples)

Figure A1.5. Probability density distributions for all log-transformed morphometrics (right to left: total length, standard length, orbital length, head length, and body depth), colored by taxonomic range ("Range"; a-e) and genetic assignment ("Assignment"; f-g)

Figure A1.6. Logistic regression of soft dorsal fin ray count. Values of 0 represent samples possessing 14 soft dorsal rays, and values of 1 represent samples possessing 13 soft dorsal rays

Figure A2.1. Proportion of missing genotype data per sample across all SNPs $(127,428)$ before filtering

Figure A2.2. Two-population diversification demographic models tested in $\delta$ a $\delta$ i for each population pair (ELK and WHITE, BAYOU and WHITE, UPPARK and WHITE, and ILLI and SKIA), along with associated parameters. Models were fitted using 2D folded joint frequency spectra. Descriptions of all models are given in Table A2.1

Figure A2.3. Population structure results for $K=4$ generated in ADMIXTURE for all samples $(N=92)$ and all SNPs $(50,828)$ passing quality filters

Figure A2.4. 10-fold cross-validation error results for admixture screening analysis of all Smallmouth Bass samples

Figure A2.5. SNPs with outlier $F_{\mathrm{ST}}$ detected in BAYESCAN. (a) Outlier SNPs detected across Spotted Bass and Smallmouth Bass samples; (b) outlier SNPs detected across Smallmouth Bass only; (c) outlier SNPs detected across Neosho Smallmouth Bass only; and (d) outlier SNPs detected across Northern Smallmouth Bass only

Figure A2.6. Scree plots (left column) and PCA score plots (right column) from outlier $F_{\text {ST }}$ analysis in PCADAPT for all Spotted Bass and Smallmouth Bass samples combined (a and b), Smallmouth Bass samples only (c and d), Neosho Smallmouth Bass samples only (e and f) and Northern Smallmouth Bass samples only (g and h)

Figure A2.7. Optimization rounds for nine demographic models (a-i) run in $\delta a \delta i$ for the admixed Neosho Smallmouth Bass population in the Elk River (ELK) and its Northern Smallmouth Bass parent in the White River drainage (WHITE). Model codes are 
associated with the model descriptions in Table A2.1. Schematics for each model are given in Figure A2.2

Figure A2.8. Optimization rounds for nine demographic models (a-i) run in $\delta a \delta i$ for the admixed Neosho Smallmouth Bass population in the Illinois River system (ILLI) and its Northern Smallmouth Bass parent in the hatchery strain represented by Skiatook Lake (SKIA). Model codes are associated with the model descriptions in Table A2.1.

Schematics for each model are given in Figure A2.2

Figure A2.9. Optimization rounds for nine demographic models (a-i) run in $\delta a \delta i$ for the admixed Neosho Smallmouth Bass population in the Illinois Bayou River and Big Piney Creek, AR (BAYOU) and its Northern Smallmouth Bass parent in the White River drainage (WHITE). Model codes are associated with the model descriptions in Table A2.1. Schematics for each model are given in Figure A2.2

Figure A2.10. Optimization rounds for nine demographic models (a-i) run in $\delta a \delta i$ for the admixed Neosho Smallmouth Bass population in three streams of the upper Arkansas River Basin, including Buffalo Creek, Big Sugar Creek, and Spavinaw Creek (UPPARK) and its Northern Smallmouth Bass parent in the White River drainage (WHITE). Model codes are associated with the model descriptions in Table A2.1. Schematics for each model are given in Figure A2.2

Figure A2.11. Residuals of empirical data (first column) and distribution of residuals (second column) with respect to the best fitting two-population demographic model for (a) ELK and WHITE, (b) ILLI and SKIA, (c) BAYOU and WHITE, and (d) UPPARK and WHITE

Figure A2.12. Validation of 200 diagnostic SNPS generated with the validation set of samples from MIDARK and WHITE. Three replicates were run in each of three independent simulations: Simulation 1 (a-c), Simulation 2 (d-f), and Simulation 3 (g-i). Simulated hybrids from all replicates were assigned to hybrid categories with a posterior probability in NEWHYBRIDS

Figure A2.13. Validation of 200 diagnostic SNPS generated with the validation set of samples from MIDARK and WHITE. Three replicates were run in each of three independent simulations: Simulation 1 (a-c), Simulation 2 (d-f), and Simulation 3 (g-i)

Figure A2.14. Hybrid category assignments for empirical data on admixed populations in NEwHYBRIDS. Parent and admixed populations are labeled and color-coded along the upper horizontal 


\section{LIST OF ABBREVIATIONS}

$A_{95}$ : Frequency of non-rare alleles

ABI: Applied Biosystems, Inc.

AGFC: Arkansas Game and Fish Commission

AIC: Akaike Information Criterion

ALD: Admixture linkage disequilibrium

$A_{\text {P: }}$ Frequency of private alleles

AR: Arkansas, USA

$\boldsymbol{A}_{\mathrm{R}}$ : Rarefied allelic richness

ARB: Arkansas River Basin

ATU: Arkansas Tech University

BD: Body depth

BIC: Bayesian information criterion

CIH: Central Interior Highlands

DAPC: Discriminant analysis of principal components

ddRADseq: Double-digest restriction enzyme associated DNA sequencing

DFA: Deep Ford conservation access point

DNA: Deoxyribonucleic acid

$\boldsymbol{F}_{\text {IS: Inbreeding coefficient }}$

$\boldsymbol{F}_{\text {ST: }}$ Fixation index

gDNA: Genomic DNA

$\boldsymbol{H}_{\mathbf{E}}$ : Expected heterozygosity

HFC: Heterozygosity-fitness correlation

HL: Head length

$\boldsymbol{H}_{\mathbf{O}}$ : Observed heterozygosity

HWE: Hardy-Weinberg Equilibrium

JTH: Juvenile Transition Hypothesis

$\boldsymbol{K}$ : Brody growth coefficient 
$\boldsymbol{L}_{\infty}$ : Theoretical average maximum length

LGM: Last Glacial Maximum ( 22-18 thousand years ago)

$\boldsymbol{L}_{\boldsymbol{i}}$ : Individual length at increment $i$

MCMC: Markov Chain Monte Carlo

MDC: Missouri Department of Conservation

MO: Missouri, USA

MRT: Missouri River Tributaries

MSA: Mount Shira conservation access point

MU: University of Missouri

$N$ : Sample size

ODWC: Oklahoma Department of Wildlife Conservation

OK: Oklahoma, USA

OL: Orbital length

OSU: Oklahoma State University

PCA: Principal Component Analysis

PCR: Polymerase chain reaction

$\boldsymbol{p R}^{\mathbf{2}}$ : pseudo $R^{2}$

$\boldsymbol{S}_{\boldsymbol{c}}$ : Length of otolith radius

$S_{\mathrm{i}}$ : Length of otolith radius to increment $i$

SL: Standard length

SMB: Smallmouth Bass

SNP: Single nucleotide polymorphism

SPB: Spotted Bass

$\boldsymbol{T}$ : Observed age

$t_{0}$ : Theoretical age at length 0

TL: Total length

USA: United States of America

$\boldsymbol{W}$ : Mass

WRD: White River Drainage 


\begin{abstract}
The Smallmouth Bass (Micropterus dolomieu) is one of the most highly targeted sport fishes in the world. Anglers vie for the opportunity to catch Smallmouth Bass recreationally and competitively, spending billions of dollars every year on travel, equipment, and conservation permits. Along with their extreme popularity, they are of central importance in their native ecosystems throughout central and eastern North America. They are voracious apex predators, controlling top-down food web dynamics among fishes and invertebrates in both streams and natural lakes, and they act as obligate hosts in the life cycles of several freshwater mussels.

A great deal is known about the general ecology of Smallmouth Bass and their role in aquatic communities across their extensive native distribution. Much less is known about levels and distribution of diversity within the species. In 1940, Carl Hubbs and Reeve Bailey published descriptions of two distinct subspecies: the Northern Smallmouth Bass (M. d. dolomieu), inhabiting the central and eastern portion of the range, and the Neosho Smallmouth Bass (M. d. velox), which is range-restricted to the Arkansas River Basin in the Central Interior Highlands. While the subspecies classification was largely accepted among taxonomists, it was predicated on only a few subtle morphological traits, including differences in coloration, body size, and the presence of glossohyal teeth. Researchers began to investigate genetic divergence among Smallmouth Bass populations at the end of the twentieth century. Some genetic structure has been detected, but the overall diversity and the evolutionary forces generating contemporary patterns have been considered extremely complex and therefore
\end{abstract}


unresolved, especially where the Neosho and Northern subspecies ranges meet in the Central Interior Highlands.

To address the need for a robust understanding of the divergence and evolution history of Smallmouth Bass in the Central Interior Highlands, I addressed three broad areas concerning the phylogeography and conservation of the species using a combination of morphological, genetic, and genomic data: 1) patterns of genetic and morphological differentiation between the Neosho and Northern Smallmouth Bass subspecies, 2) lineage diversification and the extent and origins of admixture within the subspecies, and 3) effects of admixture on individual growth and fitness in two streams within the Neosho Smallmouth Bass native range.

Using neutral microsatellite markers and a combination of three independent Bayesian analysis methods, I detected complex and hierarchical population structure of Smallmouth Bass in the Central Interior Highlands. The broadest level of structure indicated two distinct genetic clusters corresponding to the Neosho and Northern subspecies, but with substantial and heterogenous patterns of admixture within some streams in the Neosho native range. At finer levels of structure, clusters corresponded to river drainages and to potentially distinct populations within drainages. The Northern and Neosho subspecies were morphologically distinct overall based on principal component analysis of five morphometric traits, but they significantly differed only in head length.

Based on genome-wide variation at over 50,000 single nucleotide polymorphisms, the Neosho and Northern subspecies represented two diverged, monophyletic clades, each comprising two additional monophyletic lineages. Populations in Big Piney Creek and the Illinois Bayou within the Neosho range also showed signatures of local 
adaptation based on outlier $F_{\mathrm{ST}}$ analysis. Admixture in the Illinois River system within the Neosho range originated from a hatchery strain of Northern Smallmouth Bass found in Skiatook Lake, Oklahoma, while admixture in the Elk River, upper Arkansas River tributaries, and the Illinois Bayou and Big Piney Creek system originated from the White River in the Northern range. Demographic analysis revealed that admixture in these streams has occurred on different time scales, in some cases likely due to historic migration, and in other cases likely due to secondary contact, possibly as a result of anthropogenic introductions.

In Big Sugar Creek and the Elk River, two Neosho Smallmouth Bass native streams known to be admixed with White River Northern Smallmouth Bass, individual growth did not differ between genetically pure Neosho, pure Northern, or admixed fish. However, in the Elk River alone, average length-at-infinity (maximum length) was lower for admixed fish than for either pure Neosho or pure Northern fish. We also found a significant negative relationship between multi-locus heterozygosity (based on fourteen microsatellite loci) and body condition, suggesting that increased intermixing may be causing outbreeding depression in these streams.

The Neosho and Northern Smallmouth Bass constitute highly differentiated, locally adapted, and independently evolving lineages in the Central Interior Highlands. Despite divergence, there are also complex and extensive patterns of admixture in the Neosho range which may be contributing to lower fitness in two Neosho Smallmouth Bass streams. It will be crucial to consider these patterns and their potential outcomes in the development of management protocols for the preservation of endemic diversity within this economically and ecologically vital sportfish. 


\section{CHAPTER 1}

\section{Using genetics and genomics to understand divergence, admixture, and fitness of Smallmouth Bass (Micropterus dolomieu) in the Central Interior Highlands}

Joe C. Gunn

Division of Biological Sciences, University of Missouri, 226 Tucker Hall, Columbia, MO 65211, USA, ORCID: 0000-0001-6916-8678

\section{Ecological Genetics, Genomics, and Admixture}

Genetic mutations, errors in the living cell's molecular machinery which create chance alterations to the DNA code, are the starting ingredients of evolution. Natural selection and random genetic drift mix and knead those ingredients in different directions and with varying degrees of pressure, eventually translating them into a rich diversity of traits that are well-adapted to the immediate environment. As populations become genetically and phenotypically diverged, one homogenous population splits into two distinct, independent lineages. The multi-generational progression continues - as summarized in Charles Darwin's Theory of Evolution-turning two lineages into four, four into eight, eight into sixteen, and with some persisting longer than others. Speciation, the emergence of new, distinct lineages, is the basis of biodiversity and the reason for the vast collage of forms and functions on Earth.

Molecular sequencing technologies are constantly becoming more accurate, computationally powerful, and affordable, giving researchers ever-increasing access to genome-wide information in wild, non-model organisms. Increased genomic resolution in natural, previously unstudied populations offers insights into speciation and how it links ecology with evolution. Using the tools of ecological genetics, we can infer the causative 
mechanisms of genetic structure in natural populations (Latta 2008): mutation, natural selection, genetic drift, and gene flow. We can then pair our genetic inferences with morphological and behavioral data to establish a broad picture of the patterns that emerge through evolution. We can ascertain the unique biogeographic processes that mediate those patterns. And we can start to realize the fitness-related consequences of those processes and of our own anthropogenic influence. As our understanding of patterns, processes, and consequences grows, we become more equipped to leverage genetics and genomics to conserve the wide range of adaptations within and among species.

Evolutionary biologists largely agree that allopatric speciation, or the divergence of lineages that are spatially disconnected, is the most common driver of genetic differentiation and the generation of new taxa (Mayr 1963; Coyne 1992; Rice and Hostert 1993; Coyne and Orr 2004). The model is conceptually intuitive in that it assumes complete geographic isolation between two populations. Physical barriers-e.g., mountain ranges, river drainages, canyons, even human-made structures like highwaysprevent interbreeding between individuals on one side of the barrier and those on the other, blocking the exchange of genetic information. The absence of gene flow eliminates the homogenizing effect of chromosomal recombination. In turn, separation allows each population to independently accumulate unique traits under the influence of multiple evolutionary forces. The rate of subsequent divergence will depend on demography and ecological pressures (Mayr 1942, 1963).

In large, closed populations, natural selection will act as the strongest force increasing the frequency of advantageous alleles. If conditions in the environment remain 
constant, and if certain alleles are consistently favored because of the high fitness value of their associated phenotype under these conditions, then these alleles will be passed on to subsequent generations and contribute to local adaptation. Smaller populations may also be subject to strong selection, but they may be more predominantly affected by genetic drift (Giddings et al. 1989), which, by chance alone, is likely to result in the fixation or elimination of random alleles. It is these smaller populations that are most threatened by human activities, as they are more likely to go extinct (Lynch and Lande 1992). In either case, different populations will take their own evolutionary paths. Determining which evolutionary force is responsible for divergence—natural selection or random genetic drift-is difficult, yet crucial, for understanding how best to manage the conservation of at-risk taxa (Latta 2008), as it informs research decisions on how best to manage populations and their habitat.

An important next step in conservation is to determine what actually constitutes a unique lineage. Ideally, evolutionarily independent units need to be considered species before they can receive the requisite funding, public backing, or legislation for conservation priority (Isaac et al. 2004; Beheregaray and Caccone 2007). Allopatric populations will diverge genetically and may attain different morphological, ecological, or behavioral characteristics. Regardless of the magnitude of these differences, geographic isolation alone is not sufficient to confirm the existence of unique species. There is no absolute threshold of genetic differentiation or morphological contrast that marks the arrival of a new taxon in the phylogeny of life. Instead, speciation progresses on a continuum, with different populations lying anywhere between uninhibited exchangeability, i.e., sympatric populations with the capacity to interbreed freely and 
encounter no consequences for survival or fecundity, and complete reproductive isolation, i.e., the inability to breed or, if breeding is still possible, the inability to produce fertile or viable offspring. No immutable definition of a species exists (Hey 2001). Instead, we have accrued a long list of "species concepts" (see Mayden 1997 for at least 22 of these concepts along with a proposed hierarchical classification of them) that highlight various types of dissimilarities among organisms. Each of them can be useful for organizing life and preserving diversity in specific situations.

The divergence between allopatric populations is best evaluated as the degree to which those populations would remain distinct in sympatry (Coyne and Orr 2004), perhaps if they were rejoined through secondary contact. Divergence should be a measure of the strength of reproductive isolating mechanisms when distinct populations are able to interact spatially and temporally. Isolating mechanisms, whether prezygotic or postzygotic, are not directly favored by natural selection, because they operate to deter reproduction. Instead, they are inevitable byproducts of evolution (Coyne and Orr 2004). Highly diverged populations are likely to be reinforced by postzygotic barriers, which act to reduce the individual viability — survival to sexual maturity — or the reproductive capacity of hybrid offspring once successful fertilization has occurred. These mechanisms are usually linked to underlying genetic incompatibilities. The BatesonDobzhansky-Muller (BDM; Bateson 1909; Dobzhansky 1934; Muller 1942) model demonstrates how the continuous process of nucleotide substitution will produce alleles that are unique to different allopatric populations. When these unique alleles meet for the first time in an unrelated genetic background after interspecific mating, they may not function properly. The BDM model is just one conceivable pathway to reproductive 
isolation, but, no matter what model we employ, genetic incompatibility can lead to multiple detrimental fitness outcomes, including hybrid sterility or inviability. As populations become more significantly diverged, more hybrid offspring exhibit reduced fertility across generations, more embryos fail to fully develop, and gene flow is increasingly limited. Furthermore, postzygotic barriers accumulate over time; greater genetic distance between populations is positively correlated with the absolute strength of reproductive isolation (Coyne and Orr 1997).

Likely the most powerful evolutionary force impeding the divergence of populations is hybridization and introgression through gene flow (resulting in genetic admixture), which can occur anywhere along the speciation continuum if reproductive barriers are permeable. Hybridization is common in nature (Reiseberg 2009), even for organisms that are normally allopatric. It can occur if a previously robust physical barrier disappears naturally, perhaps if separate river drainages become connected or mountainous regions erode over time.

Alternatively, hybridization may be an inadvertent outcome of human actions. If individuals of a distinct lineage are translocated from their native range into the range of another, they may invade and become introgressed with the indigenous population. As introgression becomes widespread, there may be complex and devastating consequences for biodiversity. The newly introduced taxon may itself incur reductions in genetic diversity through the founder effect (Dlugosch and Parker 2008). More likely, the native population may face hybrid breakdown with the dissolution of gene complexes evolved over millions of years and may eventually succumb to faster growth, greater reproductive success, greater competitive ability, or any number of other fitness-related traits of the 
introduced population. Natural or anthropogenic, hybridization is a strong force of evolution, a process which contributes as much to patterns of biological diversity and local adaptation as selection and drift (Barton 2001).

\section{Divergence and diversity in the Central Interior Highlands}

The Interior Highlands, a broad ecoregion of North America stretching from the Ouachita Mountains in central Arkansas to the northernmost edge of the Ozark Plateau in Missouri, has been well-studied (Duvernell et al. unpublished). This ecoregion has been shaped by a tumultuous history of glacial deposition, elevational changes and shifting river connections over more than 200 million years (Mayden 1988). Because of periodic geological disruptions, the Interior Highlands harbor complex patterns of population genetic structure across multiple taxa, from insects (Allen 1990), to the American Black Bear (Ursus americanus; Puckett et al. 2014, 2015), to pond-breeding Ambystomid salamanders (Burkhart et al. 2017, 2019), to trees (Hendrickson et al. 2018). The central portion of the Interior Highlands (the Central Interior Highlands) is therefore an interesting, even ideal ecoregion to investigate the role of biogeographic processes involved in local adaptation, allopatric speciation, and evolution.

Fish diversity is also of great interest in the Central Interior Highlands (McAllister et al. 1986; Matthews et al. 1996), and perhaps one of the most widely known species is the Smallmouth Bass (Micropterus dolomieu). Both of the recognized subspecies, the Neosho Smallmouth Bass (M. d. velox) and the Northern Smallmouth Bass (M. $d$. dolomieu) are found there. Following nearly 60 years after the initial classification of these two subspecies (Hubbs and Bailey 1940), recent studies have started to uncover 
more complex levels of genetic structure in the Smallmouth Bass in the Central Interior Highlands (Stark and Echelle 1998; Taylor et al. 2018; Gunn et al. 2020; Long et al. 2020) than expected. At least one additional, unique lineage, the Ouachita Smallmouth Bass, has been named in the last decade. The emerging signatures of genetic structure imply that there may be undetected diversity in need of conservation priority.

\section{Dissertation Outline}

The goal of this dissertation is to use the tools of conservation genetics and genomics to describe patterns of diversity, the process of evolution, and the fitness consequences of hybridization in a North American endemic freshwater fish, and one of the most popular sport fishes in the world, the Smallmouth Bass. I focus on the part of its native distribution that lies in the Central Interior Highlands, where the allopatric ranges of the two recognized subspecies, the Neosho Smallmouth Bass and Northern Smallmouth Bass, meet. I have chosen to focus on this species and this ecoregion for two reasons. First, the recognized native range of the Neosho Smallmouth Bass is narrowly restricted within small and mid-sized tributaries of the Arkansas River Basin, so the population is likely small and lacking in genetic diversity compared to the more broadly distributed Northern subspecies. Second, the Central Interior Highlands is a known hotbed of endemic fish diversity (Cross et al. 1986; McAllister et al. 1986; Lundberg et al. 2010), which gives precedence to identifying potentially unknown Smallmouth Bass lineages.

I ultimately hope to provide insight into the number of unique evolutionary lineages that exist in this ecoregion and to infer the ecological and evolutionary forces 
involved. With my findings, I hope to inform management and conservation policies so that this beloved sportfish and vital piece of the ecosystem will be preserved for generations to come.

In Chapter 2, I synthesize a collection of the historic and current literature on the natural history and ecology of Smallmouth Bass, including their taxonomic classification, distribution and habitat, movement and dispersal patterns, and spawning biology and sexual selection. I propose a framework by which these elements of Smallmouth Bass biology can and should be incorporated into the study of their evolution moving forward.

In Chapter 3, I assess contemporary patterns of genetic and morphological differentiation across multiple populations of the Neosho Smallmouth Bass and Northern Smallmouth Bass in the Central Interior Highlands.

In Chapter 4, I use reduced-representation genomic sequencing methods (double digest RAD sequencing) to resolve phylogenomic diversification between and within the Smallmouth Bass subspecies. I scan the genomic data for signatures of local adaptation and infer both the individual genomic regions and populations that have undergone diversifying selection. Finally, I employ a demographic model-testing framework to explore genomic admixture between the Neosho Smallmouth Bass and Northern Smallmouth Bass within the Neosho native range, quantifying levels of admixture in different stream populations, identifying the parental origins of each admixed population, and estimating relative timing of admixture events since subspecies divergence.

In Chapter 5, I assess the effects of admixture on growth and individual multilocus heterozygous as proxies for fitness in Smallmouth Bass in two known admixed populations within the Neosho Smallmouth Bass native range in the Arkansas River 
Basin: The Elk River and Big Sugar Creek, MO. I additionally compare genetic diversity between introduced Northern Smallmouth Bass in these two streams with Northern Smallmouth Bass populations in the nearby White River.

In Chapter 6, I summarize my research findings and discuss their application to the field of ecological genomics. I then offer possible avenues for future research that may be valuable in the conservation of Smallmouth Bass. 


\section{References}

Allen R (1990) Insect endemism in the Interior Highlands of North America. Florida Entomol 73:539-569.

Barton NH (2001) The role of hybridization in evolution. Mol Ecol 10:551-568.

Bateson W (1909) Heredity and variation in modern lights. In: Seward A (ed) Darwin and Modern Science. Cambridge University Press, Cambridge, UK, pp 85-101

Beheregaray LB, Caccone A (2007) Cryptic biodiversity in a changing world. J Biol 6:9.1-9.5.

Burkhart JJ, Peterman WE, Brocato ER, et al (2017) The influence of breeding phenology on the genetic structure of four pond-breeding salamanders. Ecol Evol $7: 4670-4681$.

Burkhart JJ, Puckett EE, Beringer CJ, et al (2019) Post-Pleistocene differentiation in a Central Interior Highlands endemic salamander. Ecol Evol 9:11171-11184.

Coyne J (1992) Genetics and speciation. Nature 355:511-515.

Coyne J, Orr H (2004) Speciation. Sinauer Associates, Inc., Sunderland, MA.

Coyne J, Orr H (1997) "Patterns of speciation in Drosophila" revisited. Evolution 51:295-303.

Cross FB, Mayden RL, Stewart JD (1986) Fishes in the western Mississippi drainage. In: Hocutt H, Wiley EO (eds) The zoogeography of North American freshwater fishes. John Wiley \& Sons, Ltd, New York, NY, pp 363-412.

Dobzhansky T (1934) Studies on hybrid sterility. I. Spermatogenesis in pure and hybrid Drosophila pseudoobscura. Zeitschrift fur Zellforsch und mikroskopische Anat 21:169-221.

Giddings L, Kaneshiro K, Anderson W (1989) Genetics, Speciation and the Founder Principle. Oxford University Press, New York, NY.

Gunn JC, Berkman LK, Koppelman J, et al (2020) Complex patterns of genetic and morphological differentiation in the Smallmouth Bass subspecies (Micropterus dolomieu dolomieu and $M . d$. velox) of the Central Interior Highlands. Conserv Genet 21:891-904.

Hendrickson B, Anderson M, Nelson C, et al (2018) Genetic diversity and population structure of Shortleaf Pine (Pinus echinata) in the Missouri Ozarks. Am Midl Nat $180: 37-51$ 
Hey J (2001) Genes, Categories, and Species. Oxford University Press, Oxford, UK.

Hubbs CL, Bailey RM (1940) A revision of the black basses (Micropterus and Huro) with descriptions of four new forms. Mich Univ, Mus Zool, Misc Pub 48:1-49.

Isaac NJB, Mallet J, Mace GM (2004) Taxonomic inflation: Its influence on macroecology and conservation. Trends Ecol Evol 19:464-469.

Latta RG (2008) Conservation genetics as applied evolution: from genetic pattern to evolutionary process. Evol Appl 1:84-94.

Long JM, Taylor AT, Buonaccorsi V (2020) A conservation-oriented SNP panel for Smallmouth Bass (Micropterus dolomieu), with emphasis on Interior Highlands lineages. Conserv Genet Resour 13:47-59.

Lundberg JG, Kottelat M, Smith GR, et al (2010) So many fishes, so little time: An overview of recent ichthyological discovery in continental waters. Ann Missouri Bot Gard 87:26-62.

Lynch M, Lande R (1992) Evolution and extinction in response to environmental change. In: Kareive P, Kingsolver J, Huey R (eds) Biotic Interactions and Global Change. Sinauer Associates, Inc., Sunderland, MA, pp 234-250.

Matthews WJ, Schorr MS, Meador MR (1996) Effects of experimentally enhanced flows on fishes of a small Texas (USA) stream: Assessing the impact of interbasin transfer. Freshw Biol 35:349-362.

Mayden R (1997) A hierarchy of species concepts: the denouement in the saga of the species problem. In: Claridge M, Dawah H, Wilson M (eds) Species: The Units of Biodiversity. Chapman and Hall, Tuscaloosa, AL, pp 381-424.

Mayden R (1988) Vicariance biogeography, parsimony, and evolution in North American freshwater fishes. Syst Zool 37:329-355.

Mayr E (1963) Animal Species and Evolution. Harvard University Press, Cambridge, MA

Mayr E (1942) Systematics and the Origin of Species. Columbia University Press, New York, NY.

McAllister DE, Platania SP, Schueler FW, et al (1986) Ichthyofaunal patterns on a geographic grid. In: Hocutt CH, Wiley EO (eds) The zoogeography of North American freshwater fishes. John Wiley \& Sons, Ltd, New York, NY, pp 17-51.

Muller H (1942) Isolating mechanisms, evolution, and temperature. Biol Symp 6:71-125 
Puckett EE, Etter PD, Johnson EA, Eggert LS (2015) Phylogeographic analyses of American black bears (Ursus americanus) suggest four glacial refugia and complex patterns of postglacial admixture. Mol Biol Evol 32:2338-2350.

Puckett EE, Kristensen T, Wilton C, et al (2014) Influence of drift and admixture on population structure of American black bears (Ursa americanus) in the Central Interior Highlands, USA, 50 years after translocation. Mol Ecol 23:2414-2427.

Rice W, Hostert E (1993) Laboratory experiments - what have we learned in 40 years. Evolution 47:1637-1653.

Stark WJ, Echelle AA (1998) Genetic structure and systematics of Smallmouth Bass, with emphasis on interior highlands populations. Trans Am Fish Soc 127:393416.

Taylor AT, Long JM, Schwemm MR, Brewer SK (2018) Hybridization and genetic structure of Neosho Smallmouth Bass in the Ozark Highlands. North Am J Fish Manag 38:1226-1240. 


\section{CHAPTER 2}

Integrating taxonomy, natural history and ecology into the study of evolution and local adaptation in the Smallmouth Bass (Micropterus dolomieu): A framework for advancing conservation and management of a popular sportfish

Joe C. Gunn

Division of Biological Sciences, University of Missouri, 226 Tucker Hall, Columbia, MO 65211, USA, ORCID: 0000-0001-6916-8678

\section{The Allure and Plight of the Smallmouth Bass}

The Smallmouth Bass (Micropterus dolomieu) may be the most thrilling freshwater game fish species, maybe even "the gamest fish that swims," to use the words of J.A. Henshall (1881). The Smallmouth Bass is no stranger to the angling enthusiasts of the world, or really to anyone who has stopped in or lived near a Bass Pro Shop, one of the largest private outfitters of sports and outdoors equipment in the United States and Canada. From family outings at local recreation areas to competitive angling tournaments, Smallmouth Bass contribute to a multi-billion-dollar industry (ASA 2015).

Smallmouth Bass can be big, they are usually fast, and they are always aggressive. Landing a big one is an exhilarating and memorable experience. Knowing how to land a big one, aside from the occasional "Beginner's Luck," requires years mastering and fine-tuning one's knowledge of when and where to look, which lures to use and where to use them, and the mechanics of the perfect hookset. Countless books have been written on the joys, challenges, and frustrations of Smallmouth angling. Entire organizations dubbed "Smallmouth Alliances" are devoted to this one species (e.g., Missouri Smallmouth Alliance, 1992; Illinois Smallmouth Alliance, 1994). 
Anglers and scientists share a great appreciation for the fundamental ecological roles of Smallmouth Bass in their diverse native habitats across central and northeastern North America. Perhaps most notable is the species' reputation as a voracious, often piscivorous, predator. In stream systems, they generally focus on larval fish (Pflieger 1966; Easton and Orth 1992) and crayfish (Rabeni 1992; Roell and Orth 1993), but do not shy away from much larger prey and are not easily satiated. I once caught a 12 -inch Smallmouth Bass on a live crayfish, and when I removed the bait, I discovered an as yet un-ingested, decent-sized snake still sticking halfway out of its throat! As apex predators (Scott and Crossman 1973), Smallmouth Bass largely control top-down food web dynamics in the ecosystem. They have other vital roles, acting as symbiotic hosts to the early life history stages of some mussels (Haag et al. 1999; Hoffman 1999). The species is also a known bioaccumulator of heavy metals and other anthropogenic water contaminants (Brewer and Orth 2015), so their physiology can be a reliable proxy of ecosystem health. Although many aspects of Smallmouth Bass biology have been well described (see Scott and Crossman 1973; Brewer and Long 2015; Brewer and Orth 2015), there are a number of outstanding questions about their morphological, behavioral, demographic, and evolutionary complexities.

Fascination with Smallmouth Bass, along with many of its similarly popular sister species, has spread across the globe. With greater interest, there is higher demand than ever for fishing opportunities, which, for eager anglers, is complicated by the species' restricted distribution in North America. To overcome this, for decades federal managers, and at times anglers themselves, have widely stocked hatchery-born Smallmouth Bass in 
streams and lakes both within and outside their native range (Robbins and MacCrimmon 1974; Stark and Echelle 1998; Brewer and Orth 2015).

Stocking is a common practice that serves two main purposes: 1) the restoration of fish populations imperiled by habitat fragmentation and climate change (Johnson and Jensen 1991; Shute et al. 2005; George et al. 2009); and 2) supplementation of sport fisheries for recreation. The former function of stocking is of paramount importance in the preservation of at-risk species, although the latter may be equally powerful in engaging the public with wildlife and natural resources, which may ultimately have a positive impact for conservation. By creating fishing opportunities, stocking sport fish stimulates local economies (see examples of revenue generated from fishing in Carey et al. 2011). Exposure to native fishes and to fishing in general also teaches people in the community about the importance of natural resources and their conservation, and that awareness can become integrated into the cultural fabric.

Smallmouth Bass introductions may generate tourist revenue and foster community, but, as with many other species, putting fish into an environment where they are not native may bring unintended ecological, genetic, and evolutionary consequences. If Smallmouth Bass are moved into an environment where they are not well adapted, the stocked population may not be viable for more than a few generations. Conversely, they may be exceptionally tolerant of new environmental conditions because of evolution over an extensive geographic range. In some cases, as with the Northern pikeminnow and Pacific salmon in parts of the Pacific Northwest, USA, and Atlantic salmon in southeastern Canada (O’Sullivan et al. 2020) invading Smallmouth Bass have outcompeted native fish or decimated other species through predation (Fritts and 
Pearsons 2004; Tabor et al. 2007; Carey et al. 2011), leading to population declines and ecosystem instability.

A lesser-known risk of stocking in Smallmouth Bass occurs at the molecular level, when geographically separated and genetically distinct lineages hybridize after secondary contact (Avise et al. 1997a). The resulting exchange of genetic material may destroy adaptive gene complexes that have enabled each lineage to survive for millions of years. Continued hybridization can homogenize the two lineages, reducing overall genetic diversity and hindering the ability of the admixed populations to adapt to a changing environment.

\section{Evolution in the Smallmouth Bass Lineages}

Recent studies suggest that the Smallmouth Bass is ecologically versatile and much more genetically diverse than previously thought (Brown 2009; Stark and Echelle 1998; Taylor et al. 2018; Gunn et al. 2020; This Dissertation, Chapter 4). Two distinct, geographically separated subspecies, the Neosho Smallmouth Bass (M. d. velox) in the Arkansas River Basin and the Northern Smallmouth Bass (M. d. dolomieu) across the rest of the species native range, have been unofficially recognized since the mid-1900s (Hubbs and Bailey 1940). However, in just the last thirty years, several more lineages have been proposed, all of them in the Central Interior Highlands of North America, a known hotspot of freshwater fish diversity (Lundberg et al. 2010). One of these lineages occurs in the Ouachita Mountains of eastern Oklahoma and central Arkansas, USA (Stark and Echelle 1998). Another inhabits the White River and Black River drainages and may represent an intergrade between the Neosho and Northern subspecies (Stark and Echelle 
1998) or may be considered genetically distinct (Gunn et al. 2020). Further, new evidence suggests there may be locally adapted populations at an even finer scale, within river drainages (This Dissertation, Chapter 4).

The presence of multiple Smallmouth Bass genetic units in the Interior Highlands ecoregion suggests that the evolution of this species has been influenced by complex processes. Random genetic drift may be sufficient to explain genetic differentiation between allopatric populations in disconnected river drainages, as in tributaries of the Missouri River, the Arkansas River, the White River, and the Ouachita River. However, the phenotypic differences among these lineages are likely the result of unique selective pressures associated with climate and habitat. Depending on how long these lineages have been geographically separated, a question which has yet to be answered, sufficient genetic and phenotypic differences may have accrued to facilitate reproductive isolation.

It is more challenging, and perhaps more interesting, to explain genetic differences between populations of Smallmouth Bass within these river drainages. Patterns of divergence in sympatry are likely to be driven by complex niche partitioning, dispersal and movement (or lack thereof), and sexual selection processes that limit gene flow between potentially connected individuals. More research is needed to address these questions.

We are progressing quickly in our study of Smallmouth Bass evolution, discovering that what was once thought to be a single species may, in reality, be a system of multiple distinct taxa. But we are also accumulating evidence of intermixing between distinct lineages, particularly within the Neosho Smallmouth Bass native range (Gunn et al. 2020). Signatures of admixture may be confounded by incomplete lineage sorting due 
to shallow divergence times. But, if intermixing is due to hybridization and introgression, it could counteract speciation, eroding the genetic integrity of each lineage and reducing the generation of biodiversity. In addition to the imminent threats of rising global temperatures, habitat loss, anthropogenic exposure to toxic contaminants, and overexploitation, it is becoming increasingly urgent to consider conservation measures to ensure the long-term persistence of the species.

\section{A Framework for Integrating Natural History and Ecology with Evolution}

To conserve extant populations and maximize the ability of Smallmouth Bass to deal with future environmental changes, we must consider both its taxonomy and natural history. Taxonomy incorporates the current hypotheses regarding among- and withinspecies relationships and helps to identify areas where resolution is lacking. Natural history helps us identify the biotic and abiotic forces acting on individuals and populations, either leading to the diversification of new lineages or the fusion of distinct ones. Knowledge of these forces then informs decisions about how best to manage populations with respect to their native habitat. For Smallmouth Bass, there is a rich body of literature in both taxonomy and natural history. Taxonomists have classified and reclassified forms within the Black Basses (genus Micropterus) and within the Smallmouth Bass species for two centuries, and researchers have documented astoundingly specific and remarkable details of the species' anatomy, physiology, behavior, and ecology (see Brown 2009 and Brewer and Orth 2015 for a review).

With the advent of high-resolution genetic techniques, including massively highthroughput genomic sequencing, researchers have begun to explore the Smallmouth Bass 
phylogenetic tree. Genomics can address many questions: How much diversity exists within and among Smallmouth Bass lineages? To what extent have evolutionarily distinct populations hybridized, and over what timeframe? Are there specific, functional loci across the genome that are under strong diversifying or balancing selection and thus indicative of locally adapted traits? Answers to these questions may or may not warrant reassessment of Smallmouth Bass taxonomy. But, in many ways, the newest literature is moving too quickly into the intricacies of molecular genetics, often ignoring explicit tests of the fundamental ecological characteristics that are crucial to the species' survival and reproduction in its native environment. Authors find fascinating differences and patterns among populations. They will then mention some ecological parameters-habitat, dispersal, geography, etc. - that might be contributing to their observations, but these inferences often seem like an afterthought rather than a confident explanation.

I therefore propose an eco-evolutionary framework by which we, as Smallmouth Bass biologists, should consider the evolutionary processes that drive the ecological patterns. My overall goal for this framework - to connect processes with patterns - is not new and is not unique to Smallmouth Bass. I believe it can and should be applied to all taxonomic groups. As with any species, in my view, we should begin with a thorough examination of the taxonomy of the Smallmouth Bass, as it reflects the most recent hypotheses for how the species has evolved. It gives us a basis on which to propose new hypotheses as we gather new data. Then, we should attempt to show connections between characteristics of the species' ecology to the evolutionary forces-genetic drift, selection, gene flow, and mutation - that they may influence. I propose that future studies focus on three main components of Smallmouth Bass ecology: distribution and habitat, which may 
result in random genetic drift and dictate natural selection patterns; dispersal and movement, which may influence gene flow through source-sink dynamics and create selection pressures across ecological gradients; and reproduction, which facilitates gene flow, whereby mutations in distinct populations may be introgressed and subsequently acted on by selection (Figure 2.1). It must be said that drawing direct connections between ecology and evolution is extremely difficult. It becomes especially arduous when we try to infer processes in deep time. However, by following this framework, we can best ensure that our growing knowledge of the Smallmouth Bass diversity is grounded in the natural characteristics that have facilitated its continued existence.

Here, I begin with an overview of the current Smallmouth Bass taxonomy, followed by a synthesis of literature sources that span three broad categories of the species' ecology: distribution and habitat, dispersal and movement, and spawning biology, parental care, and mating systems. Within each category, I begin with a brief explanation of how they may contribute to the forces of evolution. I then provide a thorough review of the historic and current literature in each category. I give some final remarks on the remaining gaps in our knowledge of each category and how new data could be effectively incorporated into future research on Smallmouth Bass evolution. I conclude with a discussion of why it is important for us to continue learning about and working toward the conservation of this economically and ecologically valuable fish.

\section{Smallmouth Bass Taxonomy}

The black bass genus (Micropterus) was originally described by Bernard Germaine de Lacépède in 1802 (Kassler et al. 2002), and it included an undocumented 
type specimen for the Smallmouth Bass (Brewer and Orth 2015). Lacépède's earliest taxonomic architecture comprised six different groups within the Black Basses, but his descriptions drew widespread criticism among fish naturalists for insufficient detail and numerous inconsistencies regarding morphological characters (Henshall 1881).

Dissatisfaction with the taxonomy led to a continuous series of revisions over the next few decades, periodically splitting and then re-lumping the groups.

Biologists have been refining the taxonomy of the black basses since the beginning of the nineteenth century. In the mid-1800s, leading naturalists agreed that the black basses were not a single genus, but instead formed a monophyletic clade consisting of eight genera and 20 species (Ramsey 1975). Not long after, Jordan and Evermann (1898) consolidated these groups again into a single genus and lumped many apparently distinct forms into two broad, distinct taxa: the Smallmouth Bass (M. dolomieu) and the Largemouth Bass (M. salmoides). Hubbs and Bailey (1940) re-divided the black basses into two separate genera: Huro, which housed the Largemouth Bass, and Micropterus, which included three distinct species and five subspecies. In a later revision, Huro was absorbed into Micropterus (Bailey and Hubbs 1949).

Although the notion of a single genus, Micropterus, seems to have stabilized, within the last 15 years, the number of recognized species within Micropterus has increased substantially. Acceleration in the discovery of previously undetected diversity is largely attributable to progress in molecular techniques, particularly genomic sequencing. In some cases, researchers have revealed cryptic genetic divergence that conforms to the phylogeographic patterns of other fishes (Bagley et al. 2011). The former subspecies Alabama Bass (M. henshalli) was determined to be evolutionarily distinct and 
elevated to species status in 2008 (Baker et al. 2008). Four more species, all of which previously classified as Redeye Bass (M. coosae), were named in 2013 (Baker et al. 2013). Micropterus taxonomy is still fraught with debate, but resolution is increasing rapidly.

Today, there are 17 described species (Taylor et al. 2019). Of these, the Smallmouth Bass is arguably the most enigmatic in an evolutionary sense and currently the least resolved taxonomically. Scientists are actively investigating the potential existence of three independent lineages within the Smallmouth Bass: the Northern Smallmouth Bass (currently the subspecies M. d. dolomieu), the Neosho Smallmouth Bass (currently the subspecies M. d. velox), and the Ouachita Smallmouth Bass (currently unrecognized; Taylor et al. 2019). Researchers have found even more genetically distinct forms nested within these already uncertain groups (Gunn et al. 2020).

\section{Distribution and Habitat}

The Smallmouth Bass has a broad distribution in east-central North America. Populations span thousands of miles, warm and cold temperatures, mountainous and lowland geologies, and diverse freshwater environments and communities. However, owing to their popularity in the angling world, non-native populations have colonized every corner of North America (Schade and Bonar 2005) and have been at least partially establish on nearly every continent (Iguchi et al. 2004a,b; Schade and Bonar 2005; Carey et al. 2011; Loppnow et al. 2013). Across their broad distribution, Smallmouth Bass inhabit disconnected river drainages and lakes, leading different populations to drift to fixation to distinct genetic loci. Within these allopatric environments, populations are 
then subjected to differential selective pressures and varying directionalities of gene flow. Standing genetic variation dictates how individuals will evolve under different biotic and abiotic variables in their environment (Figure 2.1) Ultimately, their response leads to complex patterns of habitat niche partitioning.

\section{Distribution}

As it is currently recognized, the native distribution of the Smallmouth Bass (Micropterus dolomieu) extends from the southern edge of the Arkansas River Basin to the Saint-Lawrence Great Lakes at the northern border of the USA (Brewer and Orth 2015; Figure 2.2). The Northern Smallmouth Bass (M. d. dolomieu), found north and east of the Mississippi River and its corresponding tributaries, is the most widely distributed subspecies and occupies most of the range. The Neosho Smallmouth Bass (M. d. velox) is restricted to the Arkansas River and its feeder tributaries in the lower Ozark Highlands ecoregion (Stark and Echelle 1998; Nigh and Schroeder 2002). A tentatively named but unofficial lineage, the Ouachita Smallmouth Bass, is restricted to tributaries of the Ouachita River in the Ouachita Mountains of central Arkansas and western Oklahoma, USA (Robbins and MacCrimmon 1974; Stark and Echelle 1998; Figure 2.2).

The Smallmouth Bass is known to inhabit lentic (lakes) and lotic (rivers and streams) systems throughout most of its range (Scott and Crossman 1973), although these broad ecological tolerances have only been extensively studied in the Northern Smallmouth Bass subspecies. In additional to natural environments, Northern Smallmouth Bass subsist in impoundments, sometimes growing even larger than in natural systems (Malloy et al. 2000). On the other hand, the Neosho Smallmouth Bass, 
having evolved in the Arkansas River Basin well south of the last glacial maximum, is not known to survive well in impoundments or reservoirs (Malloy et al. 2000; Taylor et al. 2018c) and therefore may not be accustomed to lentic environments. Parts of the Neosho native range, like river systems throughout the southeastern USA, have been fragmented in the last 100 years due to the formation of impoundments by dam construction (Taylor et al. 2019). For both subspecies, the long-term effects of habitat fragmentation on survival and reproduction are not known.

Increases in average water temperatures due to global climate change, is expected to expand the northern boundary of the Smallmouth Bass native range. By 2100, the species distribution may cover the entire North American arctic (Sharma et al. 2007). Coupled with non-native introductions, whether intentional or by natural connections between previously separated water bodies, these climate trends will likely make more areas suitable for Smallmouth Bass and may have detrimental impacts on native ichthyofauna (Dukes and Mooney 1999; Sharma et al. 2009).

\section{Habitat}

Smallmouth Bass habitat use varies considerably between lotic and lentic systems, seasons, different life stages, and subspecies (Cooke and Philipp 2009). Until very recently, studies have almost exclusively covered habitat associations within the larger Northern Smallmouth Bass native range. However, the body of literature on the Neosho subspecies and other lineages, as well as non-native, introduced populations, is growing, allowing us to make several generalizations about the whole species. 
In their review, Brewer and Orth (2015) noted that Smallmouth Bass share an affinity for clear water, rocky substrates (Paragamian 1981, 1984; Pflieger 1997; Brewer et al. 2007), and structure, such as woody debris (Hubert and Lackey 1980; Hubert 1981; Paragamian 1981; Lyons 1991; Orth and Newcomb 2002; Olson and Young 2003; Brewer et al. 2007; Fore et al. 2007; Brown and Bozek 2010). Several other variables, including water velocity and light, also affect occupancy (Sechnick et al. 1986). Smallmouth Bass are associated with cobble substrates and tend to avoid areas with heavy vegetation (George and Hadley 1979; Sechnick et al. 1986). Winemiller and Taylor (1987) suggest that the preference for cobble is a consequence of their ambush and biting predatory behavior, which gives them high feeding efficiency in the crevices between stones compared to the interstitial space between flimsy aquatic plants. Likewise, Putman et al. (1995) showed that adult Smallmouth Bass chose large, cobbly substrate to such a high degree that, in cobbly areas, individual growth rates were decreased through intraspecific competition for food.

In lentic systems, i.e., lakes and impoundments, Smallmouth Bass spend most of their lives in or near the littoral zone (shoreline) since it is often the most suitable for nest building (Hoff 1991). This behavior may vary seasonally, although adult Smallmouth Bass are known to be prevalent in the littoral zone during summer months in northern lakes (Brown et al. 2000). Within the littoral zone, individuals select for higher habitat complexity — more structural features in the environment - comprised of woody cover, large cobble, and gravel (Bozek et al. 2002). Water depth is also an important predictor of Smallmouth Bass presence or absence, although less is known about specific depth preferences in the context of reproduction and other behaviors (Bozek et al. 2002). 
In lotic systems, i.e., rivers and streams, Smallmouth Bass abundance is often highest in pools and runs (Probst et al. 1984; Todd and Rabeni 1989; Sowa and Rabeni 1995; Dauwalter and Fisher 2008), although fish will tolerate shallow riffles in small streams (Sowa and Rabeni 1995; Johnson et al. 2009c). Within pools, runs, and riffles, numerous biotic and abiotic factors, such as average water temperature, stream size, water quality, and management regulations, influence Smallmouth Bass occupancy at a microhabitat scale (Zorn et al. 2002; Jansen et al. 2008; Humston et al. 2010). One of the most consistent limiting variables is sediment size - the degree to which it is dispersed and suspended in the water column — and amount (Jansen et al. 2008). Paragamian (1991) found that greater concentrations of fine sediment led to lower Smallmouth Bass population densities in some Iowa streams. Aside from natural substrates, heavy metal contamination and variation in $\mathrm{pH}$ can also strongly dictate individual presence or absence (Rahel and Magnuson 1983; Shuter and Ihssen 1991).

Regardless of the type of ecosystem, selection of specific home ranges depends on life stage (Brown and Bozek 2010). In particular, adults are typically found in areas of streams and lake littoral zones that are most suitable for nesting. In lentic systems, these sites are largely chosen based on the amount of protection available for swim-up fry (Bozek et al. 2002). Coarse, gravelly substrate is considered important for fry survival (Bozek et al. 2002) by limiting fungus development and providing oxygenation (Eipper 1975). Large boulders and woody debris (Hoff 1991) are also selected, likely because they aid with concealment from predators. However, young-of-year fish tend to abandon complex, woody structure in favor of cobbly substrate after the swim-up stage (leaving the nest; Brown et al. 2000; Brown and Bozek 2010). 
Conditions are similar for nesting adults in streams; individuals usually build nests and remain in areas near the stream bank (Pflieger 1966) that have available cover (usually consisting of boulders and woody debris; Orth and Newcomb 2002). Several studies have shown that depth is more important in streams than in lakes, with individuals often nesting in a minimum of $20 \mathrm{~cm}$ (Orth and Newcomb 2002). Deeper areas in streams offer protection against avian predators and greater stability in instances of heavy stream velocity, as in flash floods (Reynolds and O’Bara 1991). Contrary to nesting adults, relatively little is known about habitat selection in young-of-year. However, several studies have shown that juvenile Smallmouth Bass begin to inhabit sites with higher and higher velocity after emerging from the nest (Sabo and Orth 1994), and they tend to decrease their association with woody cover in favor of large, rocky stones, presumably to escape congregations of predatory fish that forage in woody structures (Brown and Bozek 2010).

The distinct meso- and microhabitat features of the Neosho Smallmouth Bass subspecies and the Ouachita Smallmouth Bass lineage are not well characterized, but studies have begun to accumulate over the last few decades and the subject has been recently reviewed (Brewer and Long 2015a). Preference for cobble substrates, avoidance of macrophytes, tendency to nest near the stream bank, and affinity for pools and runs are all largely shared among lineages (Brewer and Long 2015a). The Neosho subspecies' and Ouachita lineage's restricted native ranges occur over landscapes dominated by soluble limestone and defined by a mixture of smooth and rugged, woody plains. The combination of geology and geographic location most often subject them to slow-moving 
streams (Fore et al. 2007; Dauwalter and Fisher 2008) which carry limited sediment loads and have variable discharge as a function of seasonal precipitation.

Having evolved and remained in refugia south of the last glacial maximum, Neosho and Ouachita Smallmouth Bass are accustomed to warmer temperatures than their Northern counterpart. At the same time, the thermal and hydrological environments within the Neosho and Ouachita native range can be more variable - relative to their geographic extent - than in the Northern native range. In some stream areas, average water temperatures can rise above 30 C (Hafs et al. 2010), approaching the upper limits of known Smallmouth Bass heat tolerance. Some of the Neosho range is characterized by continuous stream flow (Robison and Buchanan 1984) out of natural springs, but, in the Boston Mountains of northern Arkansas, streams may dry almost completely during the summer months due to high evapotranspiration and decreased precipitation (Hines 1975), leaving only deep, isolated pools for fish refuge (Hafs et al. 2010). Long stretches of low precipitation may be interrupted by flash flooding (Leasure et al. 2016). These periodic stream flow disturbances likely result in the higher abundances of Neosho Smallmouth Bass observed in perennial pools (Fajen 1962).

Very little is known about habitat characteristics associated with spawning and nesting in the Neosho and Ouachita Smallmouth lineages. Broadly, both conform to the same general features as the Northern Smallmouth Bass in terms of adult nest-building sites and juvenile habitat transitions (Dauwalter and Fisher 2007; Brewer and Long 2015a), except that nesting tends to take place in warmer, wider, and slower-moving stream reaches (Miller and Brewer 2021). Nesting sites may also be more tightly clustered at the beginning of the breeding season in Ozark streams, due both to relatively 
limited nesting habitat and the flashy nature of flow regimes in this ecoregion (Miller and Brewer 2021). Interestingly, Ouachita Smallmouth Bass populations may be extremely limited in their nesting habitat due to a lack of preferred substrates (B. Brown, Oklahoma Department of Wildlife Conservation, unpublished data). More data are needed to differentiate the specific habitat needs of the Ouachita lineage compared to the more widely distributed groups.

\section{Dispersal and Movement}

Over the last century, researchers have contributed a wealth of knowledge on the unique spatial dynamics of Smallmouth Bass. Most studies agree that movement is a means of thermoregulation (Ettinger-Dietzel et al. 2016; Westhoff et al. 2016); as water temperature fluctuates at both coarse and fine scales in streams and lakes, Smallmouth Bass will migrate to thermal refuges (Torgerson et al. 1999) with better conditions. In Ozark streams, for example, Neosho Smallmouth Bass are known to move from their natal tributaries to spring-fed groundwater systems (Dauwalter and Fisher 2008). Movement into more suitable habitat is crucial for foraging and home range establishment. Greater mobility may translate to greater fitness, acting as a strong mechanism of natural selection and diversification.

Perhaps more directly, movement affects gene flow, making it a contributor to the geographic (Larimore 1952) and genetic (Euclide et al. 2020) structuring of populations (Figure 2.1) and perhaps driving sexual selection dynamics by affecting the availability of mates. We therefore need a concise, yet robust synthesis of movement patterns in 
Smallmouth Bass over the course of their life history and across their distribution to understand their evolutionary potential.

\section{Juvenile and Adult Movements}

Amid the vast literature are many documented inconsistencies in movement patterns between Smallmouth Bass populations, life stages, and times of the year, making it challenging to characterize the general features of their ecology (Humston et al. 2017). Some Smallmouth Bass populations are sedentary, while others undergo long-distance migrations (Lyons and Kanehl 2002) that involve significant transitions in habitat or resource use (Forney 1961; Langhurst and Schoenike 1990). The tendency to move or not move varies seasonally, and also between and within lentic and lotic systems (it is important to note that sedentary behavior and high motility are not discretely associated with streams and lakes, respectively). Funk (1955), following a hypothesis of Gowan et al. (1994) with regard to stream-dwelling salmonid species, determined that, in the summer months, seven different river systems in Missouri contained populations of both sedentary and migratory Smallmouth Bass. Later fall movement behavior is similarly mutable, with longer-distance migrations - reaching over $100 \mathrm{~km}$ - being more common in far northern systems with harsh winters, such as the Wapsipinicon River in northeastern Iowa, USA (Siegwarth 1996, 1997), the Little Platte River in southwestern Wisconsin, USA (Lyons and Kanehl 1993), and the Embarrass and Wolf Rivers in northeastern Wisconsin, USA. (Langhurst and Schoenike 1990). Of all seasons, winter movements are the most limited and least variable, with stream fish usually remaining 
quiescent in deep pools (Coble 1975) and lake fish traveling short distances to sites away from the shoreline until the spring (Langhurst and Schoenike 1990).

The spring season is associated with substantial Smallmouth Bass movement in lakes and streams, as adults will move long distances to locate suitable nesting habitat for spawning (Lyons and Kanehl 2002). There is considerable variation among systems, with some showing little to no evidence of movement (Munther 1970; Todd and Rabeni 1989; Beam 1990) and others showing movements up to $75 \mathrm{~km}$ (Langhurst and Schoenike 1990). In migratory populations of both lakes and mainstem rivers, males will travel upstream into warm feeder tributaries for spawning, often followed by homing behavior (Fajen 1962) in which they will return to their original home range. Observational (Ridgway et al. 1991, 2002) and genetic (Gross et al. 1994) studies, primarily in lake systems, have also found that Smallmouth Bass are philopatric, returning to the same spawning locations year after year.

Movement patterns in Smallmouth Bass are further complicated by variation at finer temporal scales. Gerber and Haynes (1988) found that Smallmouth Bass movement was highly variable within the day, with movement being common during daylight hours and almost non-existent at night. Different levels of activity between day and night may be related to individual light requirements for site-feeding.

Juvenile Smallmouth Bass movement is initially constrained by their vulnerability to predation and starvation, so they usually stay on or around their natal nest for the first two or three weeks (Scott and Crossman 1973; Ridgway 1988). Dispersal is then dictated by the ability of maturing fish to partition themselves spatially, a process dubbed the “juvenile transition hypothesis" (JTH; Ridgway et al. 2002). The JTH has been proposed 
as an explanation for the observation that male nest building and reproductive success is negative density-dependent. A greater number of mature males leads to fewer males that are reproductively successful, and this trend is typically not dictated by limited availability of favorable nesting sites (Ridgway et al. 2002). The JTH suggests that as young-of-year (age-0) fry become ready to leave the nest, they remain in the vicinity of the spawning area to increase their ability to forage. As individuals age, they gradually disperse farther away from the nest, and adults tend to segregate themselves from juveniles. At this point, they begin to establish extensive home ranges (200-400 hectares), which a behavior that may have evolved as a way to optimize energy allocation at different life stages. The JTH is thus considered to be extremely important for recruitment to the breeding population and overall survival.

During the juvenile transition period, Smallmouth Bass are highly susceptible to downstream flow, especially during periods of high water or flooding (Larimore and Duever 1968). Movement from natal tributaries into mainstem rivers has been confirmed in at least one study using otolith microchemistry analysis (Humston et al. 2010). In this case, movement was found to be almost entirely asymmetrical, with fry flowing into the mainstem but not returning to their natal tributary. Movement exclusively from tributaries to mainstem rivers may allow for gene flow in the downstream direction, but may also contribute to isolation, and therefore genetic drift, in small stream populations.

\section{Introductions}

Smallmouth Bass have moved into streams and lakes that would have been unreachable if not for anthropogenic stocking, usually of hatchery-raised fish. Hatcheries 
have been perfecting the science of Smallmouth Bass propagation for over a century (Langlois 1935; Sparrow and Barkoh 2002). During that period, the species' reputation as a gamefish has spread across the globe. Whether intentionally by fisheries managers and biologists, or illegally by private entities and citizens (Jackson 2002), they have been introduced all over the world to encourage fishing and to bring in millions of dollars in yearly angler revenue (U.S. Fish and Wildlife Service 1996, 2001, 2006). Their range expansion into non-native systems is expected to continue as increasing global temperatures open up previously unsuitable habitat (Sharma and Jackson 2008). Once Smallmouth Bass are established in a non-native system, they may dominate and become extremely difficult to remove (Brown et al. 2009).

Although the native, endemic range of the Smallmouth Bass lies in central-eastern North America between the Ozark Highlands and the Laurentian Great Lakes (Nigh and Schroeder 2002), its realized distribution now extends to at least 20 different countries (Iguchi et al. 2004a; Woodford et al. 2005; Carey et al. 2011; Loppnow et al. 2013). In North America, Smallmouth Bass have been widely stocked both within and outside their native range (Schade and Bonar 2005; Miller et al. 2006; Brewer and Orth 2015). They are now also established throughout Canada and Mexico, and, outside of North America, they are present in parts of South America, central Asia, central and southern Africa, and most of Europe (Jackson 2002).

Introductions of Smallmouth Bass are problematic for ecosystem function, because they can acclimate to a broad range of biotic and abiotic conditions and can quickly invade habitats outside their native range. High tolerance for varying water temperatures and prey sources allows them to outcompete other large, piscivorous game 
species (Vander Zanden et al. 1999; Jackson 2002; Morbey et al. 2007; O'Sullivan et al. 2020) but also allows them to decimate lower trophic species through predation (Power et al. 1985; Harvey et al. 1988; Jackson et al. 1992, 2001). Smallmouth Bass may even alter available habitat by disrupting predator-prey and competition dynamics between native species. These effects can actuate a trophic cascade, leading to the local extinction of multiple species and lower diversity (Chapleau et al. 1997; Whittier et al. 1997) both of fishes and of prey species. Jackson (2002) conducted multiple population surveys throughout streams and lakes in lower Ontario and, in each case, found that the presence of non-native Smallmouth Bass (and Largemouth Bass, a sister species) reduced the number of species of small Cyprinid minnow species. He proposed that this was due both to competitive exclusion from shared littoral zone habitat and from added predation. In the Cape Floristic Region of South Africa, Woodford et al. (2005) found that invasive Smallmouth Bass in the Olifants-Doring River system—stocked there in 1937 to increase angling opportunities (Harrison 1952) — have had a drastic, negative impact on overall species richness and the abundance of important indigenous fishes. The effect of Smallmouth Bass in South Africa is nothing new; they have extirpated several endemic species since the 1940s (Gaigher 1973; De Moor and Bruton 1988). Many other ecosystems have experienced these kinds of ecological disasters where Smallmouth Bass have become invasive.

Smallmouth Bass may also hybridize, either with other populations of Smallmouth Bass or with other species with which they are reproductively compatible, when they are translocated to non-native habitat. They are known to interbreed readily with several other Black Bass species, perhaps most notably Spotted Bass ( $M$. 
punctulatus; Koppelman 1994; Avise et al. 1997). The effects of interspecific hybridization may look similar to those of ecosystem disruption. Smallmouth Bass alleles may introgress into the genomes of other species, swamping out genetic variation and dissolving adaptive gene complexes, which can eliminate biodiversity in the same fashion as competition or predation. New evidence (Gunn et al. 2020) of introductions in the Central Interior Highlands, specifically from the White River drainage in the Northern Smallmouth Bass native range to the Arkansas River Basin in the Neosho native range, may be causing admixture between different lineages within the species. We know relatively little about the adaptive consequences of admixture, both for the invader and for the invaded native species. However, the process may counter the natural process of incipient speciation, making it an urgent issue in conservation.

\section{Spawning Biology, Parental Care, and Mating Systems}

The spawning biology of the Smallmouth Bass has been described in detail, from underwater snorkel surveys (perhaps the earliest account is by Schneider (1971)), observations in laboratory aquaria (James 1930), and in hatcheries (Reighard 1906; Beeman 1924). Nest construction, courtship, spawning, and parental care have thus been well-characterized, although current knowledge of these characteristics is heavily biased to the more common Northern Smallmouth Bass subspecies. We know much less about the idiosyncrasies in reproduction associated with the Neosho subspecies or other distinct lineages. Within the past few decades, researchers have delved more intensely into the selection pressures that have shaped reproduction. Reproduction causes gene flow and generates novel genotypes in individuals by transferring unique mutations among 
populations, creating the substrate on which sexual and natural selection can act (Figure 2.1). Our understanding of the process must therefore be integrated into our knowledge of distribution, habitat, dispersal and movement to know how best to conserve this species.

\section{Spawning Biology}

As a result of the recent influx of research on Smallmouth Bass as a whole species as well as their distinct subspecies and lineages (see Brewer and Long 2015; Brewer and Orth 2015), it is possible to make generalizations about their spawning biology. In addition, the Northern, Neosho, and Ouachita Smallmouth native distributions are geographically oriented on a broad north-south axis; given the known effects of latitudinal temperature gradients on ectotherms (Wieser 1973) and the importance of temperature in regulating reproductive activity, we can draw strong inferences about patterns specific to these diverse populations.

As external fertilizers, males initiate the reproductive sequence by excavating a bowl-shaped divot in the available substrate - usually cobblestone, fine gravel, or sandusing steady sweeping motions of the caudal fin (Cooke and Philipp 2009). This divot becomes the nest, at which the male will stay and continuously pivot for up to two weeks (Pflieger 1966; Wrenn 1984; Ridgway et al. 1991) to stave off potential rivals or to locate mates (Beeman 1924; Pflieger 1966; Winemiller and Taylor 1982). When a male detects a potentially suitable female, he will coax her toward the nest using jabbing motions with the lower mandible (Ridgway et al. 1989). Courtship is signaled as the male's eyes turn bright red and the female develops dark, vertical bands along her side (Breder and Rosen 1966). The mating pair engages in an intricate, spiraling dance as they descend to the rim 
of the nest, where the female then tilts to one side and begins ovipositing eggs in approximately 30 second bouts. This sequence repeats after each egg-laying bout and can last more than 2 hours, resulting in around 5000 eggs (Cooke and Philipp 2009). Males then release an opaque white fluid called milt, which contains sperm, to fertilize the eggs (Ridgway 1988) and immediately drives the female away from the nest (Reighard 1906; Schneider 1971).

Spawning typically occurs between mid-spring and mid-summer once individuals have reached sexual maturity, which varies between males (maturing between two and five years) and females (maturing between three and seven years; Carlander 1977; Jackson et al. 2008). Males will often nest each year, and often re-establish a nest in the same year if it is lost or abandoned due to flooding or other destructive forces (Lukas and Orth 1995; Larimore 2002; Orth and Newcomb 2002b). Timing of reproduction, along with the success of egg incubation and hatching, is highly dependent on water temperature (Armour 1993). Temperature is likely equally important in lotic and lentic systems, but in streams, water flow rates and subsequent changes to the hydrologic environment can impact nest-building success (Surber 1943; Reynolds 1965; Graham and Orth 1986). Changes of just $2^{\circ} \mathrm{C}$, or more severe decreases in temperature after flooding events, can lead to nest desertion by males or high mortality of offspring (Rawson 1945; Henderson and Foster 1957). Temperatures that are amenable to spawning vary between $15^{\circ} \mathrm{C}$ and approximately $26^{\circ} \mathrm{C}$ depending on the geography of the population (Pflieger 1966; Vogele 1981; Wrenn 1984; Cooke et al. 2003); Northern Smallmouth Bass populations at far northern latitudes tend to spawn in the middle of summer, while 
Neosho and Ouachita populations further south can begin much earlier (Pflieger 1966; Vogele 1981; Wrenn 1984; Graham and Orth 1986).

Other than temperature, male body size is one of the most significant predictors of breeding age and timing. Wiegmann et al. $(1997,2004)$ found that body size was important in dictating the timing of sexual maturity, with larger males maturing faster than smaller males. Additionally, Ridgway et al. (1991) showed compelling evidence that, in Lake Opeongo, the timing of reproduction was correlated with size in both males and females. Larger male and female Smallmouth Bass consistently nested, mated, and spawned before smaller ones. Surprisingly, they found that the size-dependence of reproduction could not be explained by the ability of larger males to claim greater amounts of territory or to drive off smaller males (Ridgway et al. 1991). Instead, they hypothesized that this relationship is mediated by metabolic demands in the fish as they emerge from the overwintering period, in which they have limited access to food sources and experience energy deficits in the following spring (Keast 1968, 1970). Metabolic rates in poikilothermic organisms, like Smallmouth Bass, decrease with body weight (Robinson et al. 1983), so larger fish encounter less energy loss after the winter months and should therefore have greater stored energy for earlier reproduction (Shuter and Post 1990; Ridgway et al. 1991).

Spawning biology seems to be consistent throughout the Smallmouth Bass species range based on limited published data. The trend of larger males breeding before smaller males, for example, has been corroborated in Baron Fork Creek, a tributary of the Arkansas River Basin within the Neosho Smallmouth Bass distribution (Dauwalter and Fisher 2007). As in the Northern subspecies range, temperature is the most significant 
factor influencing reproductive timing and nest success. However, populations in the southern subspecies are subjected to much higher average temperatures and harsher hydrologic conditions, so reproduction is more variable. Neosho Smallmouth Bass spawn in early- to mid-April, near the beginning of the species known reproductive season, when temperatures reach at least $15^{\circ} \mathrm{C}$ (Graham and Orth 1986; Dauwalter and Fisher 2007; Martin 2017). Nesting may occur in even higher average temperatures, between $17^{\circ} \mathrm{C}$ and $25^{\circ} \mathrm{C}$ (Martin 2017). Perhaps the most notable distinction in the Neosho range is the restricted breeding chronology. In one stream, the timeframe for nesting has been observed to be as short as 17 days (Martin 2017), which is much shorter than the several months possible at more northern latitudes. Such a limited span may be explained by discontinuous stream flow and high flooding probability in the Ozark plateau.

Compared to the Northern and Neosho Smallmouth lineages, little is known about Ouachita Smallmouth Bass reproduction. Fish in the Ouachita Mountain range are subjected to many of the same geographic, climatic, and geological features as those in the Arkansas River Basin, which generate higher average water temperatures and variable stream flow regimes. Research on the life history of the Ouachita lineage is ongoing.

\section{Parental Behavior}

One of the most well-defined characteristics of Smallmouth Bass reproduction, and likely one of the most important for offspring survival, is aggressive nest-guarding by males (Pflieger 1966; Vogele 1981; Ridgway and Friesen 1992; Cooke et al. 2002, 2006). In an interesting departure from the biparental care of the Largemouth Bass $(M$. salmoides) and other Micropterus species, female Smallmouth Bass provide no care and 
leave the nest once fertilization of eggs has occurred. Nesting males are sole providers of parental care (Cooke et al. 2003). Sole male parental care is not uncommon in nature, but it is not necessarily indicative of sex role reversal (Vincent et al. 1992; Barlow 2005). Instead, it must be evolved to maximize reproductive output given both environmental and mating limitations. Not surprisingly, however, the evolutionary origins of this sole paternal care are not clear in this species. Smallmouth Bass paternal care has several functions, including aeration of the ova by caudal fin sweeping, but its main purpose is defense against potential predators (Hinch and Collins 1991). Unlike many mammal and bird species, Smallmouth do not provide additional nutrition to their fry once they have hatched. Males spend 24 hours per day for up to 7 weeks guarding the nest (Pflieger 1966; Vogele 1981; Hinch and Collins 1991; Ridgway and Friesen 1992; Scott et al. 1997; Cooke et al. 2002, 2006). In that time, they will frequently pivot in circles, surveilling the area immediately in the nest vicinity (Brewer and Orth 2015). Guarding behavior occurs very close to the nest in the early stages of egg development, but males begin to distance themselves later in fry ontogeny (Scott et al. 1997).

Allocation of time and energy to parental care is largely dictated by intrinsic biotic characteristics of males. Males must constantly guard their nests after breeding, which requires substantial energy expenditure and prevents feeding. For that reason, nest success varies based on the males' ability to obtain food in the overwinter period (Hinch and Collins 1991; Gillooly and Baylis 1999; Cooke et al. 2002). Shifts in average water temperature between seasons has a confounding effect on energy allocation; since Smallmouth Bass are ectothermic, water temperature directly influences metabolic rates. 
Abiotic factors can be equally important in constraining male nesting behavior. Studies in Jones Bay of Lake Opeongo, Ontario, a high-density breeding area for Smallmouth Bass, have shown that nest sites are clustered heterogeneously in the littoral zone based on flow rates and thermal dynamics (Rejwan et al. 1997, 1999; Finlay et al. 2001; Kaevats et al. 2005). Periodic disturbance in the form of extreme weather-i.e., prolonged drought, flash flooding, or high wind (Kaevats et al. 2005)—strongly impact year-to-year nesting by causing nest abandonment or high mortality in offspring (Brewer and Orth 2015).

\section{Mating Systems}

Smallmouth Bass have historically been characterized as socially monogamous (Wiegmann et al. 1992) even though this mating system is rare in nature (Jennions and Petrie 2000), particularly in externally fertilizing freshwater fishes that have great potential to exploit polygamy or parasitic mating (Wiegmann et al. 1992; DeWoody et al. 2000; DeWoody and Avise 2001). Pairs typically exhibit size assortment, where larger and smaller males breed with larger and smaller females, respectively (Wiegmann et al. 1992; Knotek and Orth 1998); this apparent mate choice is likely a result of staggered breeding times depending on body size. Using microsatellite genetic markers on adult Smallmouth Bass in Lake Opeongo, Ontario, Canada, Franckowiak et al. (2017) found that Smallmouth Bass were genetically monogamous, but that they do not necessarily maintain single pairings throughout adulthood. Some individuals in this lake showed genetic signatures of polygynandry, meaning that both males and females had multiple 
mates. Those adults that only mated once in a particular year nearly always displayed iteroparous monogamy, with no mate fidelity between seasons (Franckowiak et al. 2017).

Researchers have struggled to explain the evolution of iteroparous monogamy and the potential for polygynandry in the context of sexual selection. In Smallmouth Bass, the sexes are not morphologically distinct and have not yet been shown to possess sexspecific genomic markers (Nelson 2018). The predominance of monogamy is probably responsible for the lack of strong intrasexual competition in this species and thus the lack of sexual dimorphism or alternative reproductive tactics (see below; Gross 1984, 1991; Dewoody et al. 1998). Furthermore, infrequent multiple mating has been shown to be constrained by both male and female body size (Vogele 1981; Wiegmann et al. 1992), so it is unlikely to result in significant variation in reproductive success among individuals.

While the effects of Smallmouth Bass life history characteristics on mating systems are clear, it is difficult to trace the evolutionary origins of these systems. Smallmouth Bass have not been able to capitalize on the environmental heterogeneity inherent in lake and stream systems, which should lead to polygamy (Emlen and Oring 1977). One leading hypothesis for the evolution of monogamy in this species begins with intense nest-guarding behavior in spawning males (see a fuller description of nestguarding parental care in the above section on parental behavior; Franckowiak et al. 2017). This behavior, in conjunction with elaborate and prolonged courtship behavior during mating (Ridgway et al. 1989), means that males are unreceptive to multiple females for long spans of time. Operational sex ratios may therefore be heavily female biased in Smallmouth Bass populations. As a result of this lack of male availability, it would be difficult for females to find multiple mates. Additionally, their success is 
contingent on males' willingness to provide care for multiple egg clutches (Emlen and Oring 1977; Franckowiak et al. 2017). The optimal mating system in this scenario would be monogamy, in which males can provide uniparental care, benefiting themselves by ensuring paternity.

Although sexual selection is thought to be weak in Smallmouth Bass populations, variation in reproductive success seems to be influenced in part by female choice (Wiegmann et al. 1992, 2004; Franckowiak et al. 2017). Selection of a suitable male is most likely associated with direct benefits, such as the ability of the male to protect eggs from predators and to care for them through tail fanning. There may be additional, indirect benefits by good genes; regardless, neither direct nor indirect fitness are well understood in this species. Females generally do not engage in multiple mating, but they may do so in order to maximize genetic diversity (Franckowiak et al. 2017). Despite the predominance of monogamy, polygynandry may also raise heterozygosity in offspring, ultimately increasing survival. More research is needed to quantify patterns of female choice in Smallmouth Bass to understand its implications for sexual selection and fitness.

Smallmouth Bass are relatively rare among the Centrarchid fishes in their lack of alternative behavioral reproductive strategies (Ridgway et al. 1989). While males of other species exhibit both aggressive "bourgeois" and parasitic "sneaker" morphs as evolutionarily stable reproductive tactics, Smallmouth Bass males are exclusive, solitary nest-guarders (Vogele 1981). A study by Gross et al. (1994) provides conclusive evidence that Smallmouth Bass do not share paternity, as 100 percent of offspring from 15 different broods in Lake Opeongo, Ontario, were sired by a single male. Likewise, Wiegmann et al. (1992) observed that nearly all (87 out of 89) Smallmouth Bass broods 
sampled in Lake Nebish, Wisconsin, USA contained eggs at a single developmental stage, suggesting that all offspring were fertilized at the same time by a single male. Ridgway et al. (1989) also directly observed single-pair spawnings in their study, resulting in a lack of multiple paternity.

In place of alternative reproductive strategies, in some populations, as in Nebish Lake, Wisconsin, USA, Smallmouth Bass have adopted a nuanced set of alternating reproductive tactics that are derived from ontogenetic patterns rather than morphology or behavior (Raffetto et al. 1990; Wiegmann et al. 1992; Baylis et al. 1993), which presumably allow different-sized males to maximize their reproductive contribution to the next generation. The alternating life history dynamic in Smallmouth Bass proceeds if there is variation in size among sexually mature and breeding males. Importantly, large variation in size among adult Smallmouth Bass males can be driven by just a few days difference in the timing of their dispersal from the nest as fry. Such variation is mediated primarily by the environment rather than genetic polymorphism; however, more research is needed to determine the genetic contribution to growth. As illustrated in Baylis et al. (1993) and Wiegmann et al. (2004), offspring that hatch early in the breeding season will have more time to grow, and offspring that hatch late will have less time to grow. Those that hatched earlier will then mature faster and will be able to breed at a younger age than the later dispersers. However, because these earlier dispersers mature more quickly, they will compete with larger, older males in the same season. As a result of size-mediated mate competition (Baylis et al. 1993) and differential energetic costs incurred over the winter months (Keast 1968, 1970), these faster-growing males will thus tend to mate later in the breeding season. This mechanism staggers the size cohorts such that older, larger 
males breed first, and younger, smaller males breed second. Within a season, the male Smallmouth Bass who were themselves rapidly maturing will spawn offspring later in the season; those offspring will be slow growers, breeding at an older age but earlier in their respective breeding season. The cycle creates alternating generations: large males produce smaller males, and smaller males produce larger males.

Mating systems in Smallmouth Bass appear to be consistent between lentic and lotic ecosystems and among genetically distinct lineages. Sexual selection may not be as strong in Smallmouth Bass as in other fishes in the Centrarchid family or black bass genus. However, there is still considerable differentiation in fecundity and survival among individuals due to the plasticity of reproductive strategies (Dunlop et al. 2005), which arise as a result of varying environmental conditions (Ridgway and Friesen 1992; Baylis et al. 1993; Gross et al. 1994; Wiegmann et al. 1997). As with all other aspects of Smallmouth Bass evolution and ecology, more research is needed to identify unique aspects of reproductive life history, spawning biology and behavior, sexual selection, and reproductive fitness in different subspecies and populations.

\section{Concluding Remarks}

We already know a great deal about Smallmouth Bass biology, and even though we can describe many intricate details about their ecology, behavior, and reproduction, interest continues to grow. Each of these areas, specifically their distribution and habitat, dispersal and movement patterns, and spawning biology and sexual selection, are contributing to the evolution of this popular sportfish. 
However, we still have much to learn about Smallmouth Bass ecology. We are only beginning to resolve the biodiversity of the Smallmouth Bass within the far southwestern portion of its range. We are confident that there are at least two distinct subspecies in the Central Interior Highlands, the Northern Smallmouth Bass and the Neosho Smallmouth Bass, but there may be several other distinct, allopatric lineages throughout the complex river networks of the ecoregion. Data on the movement and dispersal ecology of the Smallmouth Bass also remain highly variable, with some studies revealing patterns of sedentary behavior and others showing substantial migrations depending on the time of year. Our understanding of sexual selection pressures continues to expand as well, but we have yet to assess the relative strengths and interactions of intersexual choice and intrasexual competition in the formation of Smallmouth Bass mating systems.

We will likely continue uncovering important aspects of Smallmouth Bass ecology and diversity well into the future, especially with the progression of genetic, genomic, and analytical tools that are revolutionizing our ability to assess within-species variation. New discoveries will spark greater interest in this already extremely popular sportfish and will give us a richer view of endemic freshwater diversity in North America. But we need to start connecting this knowledge with the mechanisms that generate it. This will become increasingly urgent as we strive to conserve new taxa as we discover them. People care deeply about Smallmouth Bass, but the excitement of fishing is not enough to ensure the long-term persistence of the species.

The imperative is clear. Extensive research is needed to understand the forces driving historic and contemporary ecological patterns in the Smallmouth Bass species so 
that we can be better equipped to conserve existing biodiversity, particularly where it is concentrated in the Central Interior Highlands. We need to delimit distinct populations which may be locally adapted and play crucial roles in the ecosystem, and we need to identify the traits under selection. We need to find the sources of intermixing if they are present in these populations, especially within the native range of the potentially threatened Neosho Smallmouth Bass subspecies, and we need to understand the genetic consequences. We then need to assess the capacity for independent taxa to adapt in the face of our own deliberate actions and the impacts of global climate change.

\section{Acknowledgments}

I would like to thank J. Goyes Vallejos, C. Perez, and S. Michael for the initial inspiration to write a full review of my study species. I also thank L. Eggert, L. Berkman, and K. Budd for their insightful comments and suggestions that have greatly improved the text and flow of the manuscript. Finally, thank you to the University of Missouri for providing the resources necessary to complete this work. 


\section{References}

Armour C (1993) Evaluating temperature regimes for protection of Smallmouth Bass. US Dep Inter Fish Wildl Serv Resour Publ 191:1-32.

American Sportfishing Association (2015) Economic contributions of recreational fishing: U.S. congressional districts. Southwick Associates: 1-32.

Avise J, Pierce P, Van Den Avyle M, et al (1997) Cytonuclear introgressive swamping and species turnover of bass after an introduction. J Hered 88:14-20.

Bagley JC, Mayden RL, Roe KJ, et al (2011) Congeneric phylogeographical sampling reveals polyphyly and novel biodiversity within black basses (Centrarchidae: Micropterus). Biol J Linn Soc 104:346-363.

Bailey R, Hubbs C (1949) The black basses (Micropterus) of Florida, with description of a new species. Univ Michigan, Museum Zool Occas Pap 516:1-40.

Baker W, Blanton R, Johnston C (2013) Diversity within the Redeye Bass, Micropterus coosae (Perciformes: Centrarchidae) species group, with descriptions of four new species. Zootaxa 3635:379-401.

Baker W, Johnston C, Folkerts G (2008) The Alabama Bass, Micropterus henshalli (Teleostei: Centrarchidae), from the Mobile River basin. Zootaxa 1861:57-67.

Barlow GW (2005) How do we decide that a species is sex-role reversed? Q Rev Biol $80: 28-35$.

Baylis J, Wiegmann D, Hoff M (1993) Alternating life histories of Smallmouth Bass. Trans Am Fish Soc 122:500-510.

Beam J (1990) Daily and seasonal movement, as related to habitat use, of Smallmouth Bass in the Huron River, Michigan. University of Michigan.

Beeman H (1924) Habits and propagation of the Small-mouthed black bass. Trans Am Fish Soc 54:92-107.

Bozek MA, Short PH, Edwards CJ, et al (2002) Habitat selection of nesting Smallmouth Bass Micropterus dolomieu in two north temperate lakes. Am Fish Soc Symp 2002:135-148.

Breder C, Rosen D (1966) Modes of reproduction in fishes. TFH Publications, Neptune City, NJ. 
Brewer S, Long J (2015) Biology and ecology of the Neosho Smallmouth Bass and the genetically distinct Ouachita lineage. In: Tringali, MD; Long, JM; Birdsong, TW; Allen M (ed) Black Bass Diversity: Multidisciplinary Science for Conservation. American Fisheries Society, Bethesda, MD, pp 281-296.

Brewer S, Orth D (2015) Smallmouth Bass Micropterus dolomieu Lacepede, 1802. In: Tringali, MD; Long, JM; Birdsong, TW; Allen M (ed) Black Bass Diversity: Multidisciplinary Science for Conservation. Bethesda, pp 9-26.

Brewer SK, Rabeni CF, Sowa SP, Annis G (2007) Natural landscape and stream segment attributes influencing the distribution and relative abundance of riverine Smallmouth Bass in Missouri. North Am J Fish Manag 27:326-341.

Brown PJ, Bozek MA (2010) Habitat selection and abundance of young-of-year Smallmouth Bass in north temperate lakes. Trans Am Fish Soc 139:1247-1260.

Brown PJ, Josephson DC, Krueger CC (2000) Summer habitat use by introduced Smallmouth Bass in an oligotrophic adirondack lake. J Freshw Ecol 15:135-144.

Brown TG, Runciman B, Pollard S, et al (2009) Biological synopsis of Smallmouth Bass (Micropterus dolomieu). Can Manuscr Rep Fish Aquat Sci 2887:1-50.

Carey MP, Sanderson BL, Friesen TA, et al (2011) Smallmouth Bass in the Pacific Northwest: A threat to native species; a benefit for anglers. Rev Fish Sci 19:305315.

Carlander KD (1977) Handbook of Freshwater Fish Biology. Ames, IA.

Chapleau F, Findlay S, Szenasy E (1997) Impact of piscivorous fish introductions on fish species richness of small lakes in Gatineau Park, Quebec. Ecoscience 4:259-268.

Coble D (1975) Smallmouth Bass. In: Stroud R, Clepper H (eds) Black bass biology and management. Sport Fishing Institute, Washington, D.C., pp 21-33.

Cooke S, Philipp D (2009) Micropterus dolomieu (Lacepede). In: Cooke S, Philipp D (eds) Centrarchid Fishes: Diversity, Biology, and Conservation. John Wiley \& Sons, Ltd, West Sussex, UK, pp 439-442.

Cooke S, Philipp D, Wahl D, Weatherhead P (2006) Energetics of parental care in six syntopic centrarchid fishes. Oecologia 148:235-249.

Cooke SJ, Schreer J, Wahl D, Philipp D (2002) Physiological impacts of catch-andrelease angling practices on Largemouth Bass and Smallmouth Bass. In: Philipp D, Ridgway M (eds) Black Bass Diversity: Multidisciplinary Science for Conservation. American Fisheries Society, Bethesda, MD, pp 489-512. 
Cooke SJ, Schreer JF, Philipp DP, Weatherhead PJ (2003) Nesting activity, parental care behavior, and reproductive success of smallmouth bass, Micropterus dolomieu, in an unstable thermal environment. J Therm Biol 28:445-456.

Dauwalter DC, Fisher WL (2008) Spatial and temporal patterns in stream habitat and Smallmouth Bass populations in eastern Oklahoma. Trans Am Fish Soc 137:1072-1088.

Dauwalter DC, Fisher WL (2007) Spawning chronology, nest site selection and nest success of Smallmouth Bass during benign streamflow conditions. Am Midl Nat 158:60-78.

De Moor I, Bruton M (1988) Atlas of alien and translocated indigenous aquatic animals of southern Africa. South African Natl Sci Program Rep 144:78-133.

DeWoody JA, Avise JC (2001) Genetic perspectives on the natural history of fish mating systems. J Hered 92:167-172.

Dewoody JA, Dean I, Wilkins SD, Avise JC (1998) Molecular genetic dissection of spawning, parentage, and reproductive tactics in a population of Redbreast Sunfish, Lepomis auritus. Evolution 52:1802-1810.

DeWoody JA, Fletcher DE, Wilkins SD, et al (2000) Genetic monogamy and biparental care in an externally fertilizing fish, the Largemouth Bass (Micropterus salmoides). Proc R Soc B Biol Sci 267:2431-2437.

Dukes JS, Mooney HA (1999) Does global change increase success of biological Invaders? 14:135-139.

Dunlop ES, Orendorff JA, Shuter BJ, et al (2005) Diet and divergence of introduced Smallmouth Bass (Micropterus dolomieu) populations. Can J Fish Aquat Sci 62:1720-1732.

Easton R, Orth D (1992) Ontogenetic diet shifts of age-0 Smallmouth Bass (Micropterus dolomieu Lacepede) in the New River, West Virginia, USA. Ecol Freshw Fish 1:86-98.

Eipper A (1975) Environmental influences on the mortality of bass embryos and larvae. In: Clepper H, Stroud R (eds) Black Bass: Biology and Management. Washington, D.C., pp 295-305.

Emlen ST, Oring LW (1977) Ecology, sexual selection, and the evolution of mating systems. Science (80- ) 197:215-223. 
Ettinger-dietzel SA, Dodd HR, Westhoff JT, Michael J (2016) Movement and habitat selection patterns of Smallmouth Bass Micropterus dolomieu in an Ozark river. J Freshw Ecol 31:61-75.

Euclide PT, Ruzich J, Hansen SP, et al (2020) Genetic structure of Smallmouth Bass in the Lake Michigan and Upper Mississippi River drainages relates to habitat, distance, and drainage boundaries. Trans Am Fish Soc 149:383-397.

Fajen O (1962) The influence of stream stability on homing behavior of two Smallmouth Bass populations. Trans Am Fish Soc 91:346-349.

Finlay KP, Cyr H, Shuter BJ (2001) Spatial and temporal variability in water temperatures in the littoral zone of a multibasin lake. Can J Fish Aquat Sci 58:609-619.

Fore JD, Dauwalter DC, Fisher WL (2007) Microhabitat use by Smallmouth Bass in an ozark stream. J Freshw Ecol 22:189-199.

Forney J (1961) Growth, movements and survival of Smallmouth Bass (Micropterus dolomieu) in Oneida Lake, New York. New York Fish Game J 8:88-105.

Franckowiak RP, Ridgway MS, Wilson CC (2017) Genetic mating system and mate selection in Smallmouth Bass. Ecol Evol 8864-8875.

Fritts AL, Pearsons TN (2004) Smallmouth Bass predation on hatchery and wild salmonids in the Yakima River, Washington. Trans Am Fish Soc 133:880-895.

Funk J (1955) Movement of stream fishes in Missouri. Trans Am Fish Soc 85:39-57.

Gaigher C (1973) The Clanwillam River: It is not yet too late? Piscator 88:75-78.

George A, Kuhajda B, Williams D, et al (2009) Guidelines for propagation and translocation for freshwater fish conservation. Fisheries 34:529-545.

George E, Hadley W (1979) Food and habitat partitioning between Rock Bass (Ambloplites rupestris) and Smallmouth Bass (Micropterus dolomieu) young of year. Trans Am Fish Soc 108:253-261.

Gerber G, Haynes J (1988) Movements and behavior of Smallmouth Bass, Micropterus dolomieu, and Rock Bass, Ambloplites rupestris, in southcentral Lake Ontario and two tributaries. J Freshw Ecol 4:425-440.

Gillooly JF, Baylis JR (1999) Reproductive success and the energetic cost of parental care in male Smallmouth Bass. J Fish Biol 54:573-584. 
Gowan C, Young M, Fausch K, Riley S (1994) Restricted movement in resident stream salmonids: A paradigm lost? Can J Fish Aquat Sci 51:2626-2637.

Graham RJ, Orth DJ (1986) Effects of temperature and streamflow on time and duration of spawning by Smallmouth Bass. Trans Am Fish Soc 115:693-702.

Gross M (1984) Sunfish, salmon, and the evolution of alternative reproductive strategies and tactics in fishes. In: Wootton R, Potts G (eds) Fish Reproduction: Strategies and Tactics. Academic Press, London, UK, pp 55-75.

Gross M, Kapuscinski A, Faras A (1994) Nest-specific DNA fingerprints of Smallmouth Bass in Lake Opeongo, Ontario. Trans Am Fish Soc 123:449-459.

Gross MR (1991) Evolution of alternative reproductive strategies: Frequency-dependent sexual selection in male bluegill sunfish. Philos Trans - R Soc London, B 332:5966.

Gunn JC, Berkman LK, Koppelman J, et al (2020) Complex patterns of genetic and morphological differentiation in the Smallmouth Bass subspecies (Micropterus dolomieu dolomieu and $M . d$. velox) of the Central Interior Highlands. Conserv Genet 21:891-904.

Haag WR, Warren ML, Shillingsford M (1999) Host fishes and host-attracting behavior of Lampsilis altilis and Villosa vibex (Bivalvia: Unionidae). Am Midl Nat 141:149-157.

Hafs AW, Gagen CJ, Whalen JK (2010) Smallmouth Bass summer habitat use, movement, and survival in response to low flow in the Illinois Bayou, Arkansas. North Am J Fish Manag 30:604-612.

Harrison A (1952) Introduction of exotic fishes to the Cape Province, section three: Black basses and Bluegills. Piscator 22:57-64.

Harvey B, Cashner R, Matthews W (1988) Differential effects of Largemouth and Smallmouth Bass on habitat use by Stoneroller minnows in stream pools. J Fish Biol 33:481-487.

Henderson C, Foster R (1957) Studies of the Smallmouth black bass (Micropterus dolomieui) in the Columbia River near Richland, Washington. Trans Am Fish Soc $86: 112-127$.

Henshall J (1881) Book of the Black Bass. Comprising its Complete Scientific and Life History Together with a Practical Treatise on Angling and Fly Fishing and a Full Description of Tools, Tackle, and Implements. Cincinnati, $\mathrm{OH}$. 
Hinch S, Collins N (1991) Importance of diurnal and nocturnal nest defense in the energy budget of male Smallmouth Bass: Insights from direct video observations. Trans Am Fish Soc 120:657-663.

Hines M (1975) Flow duration and low-frequency determinations of selected Arkansas streams. Little Rock, AR.

Hoff M (1991) Effects of increased nesting cover on nesting and reproduction of Smallmouth Bass in northern Wisconsin lakes. In: First International Smallmouth Bass Symposium. American Fisheries Society, Southern Division, Bethesda, MD, pp 96-103.

Hoffman G (1999) Parasites of North American Freshwater Fishes, 2nd edn. Cornell University Press, Ithica, NY.

Hubbs CL, Bailey RM (1940) A revision of the black basses (Micropterus and Huro) with descriptions of four new forms. Mich Univ, Mus Zool, Misc Pub 48:1-49.

Hubert W (1981) Spring movements of Smallmouth Bass in the Wilson Dam tailwater, Alabama. J Tennessee Acad Sci 56:105-106.

Hubert W, Lackey R (1980) Habitat of adult Smallmouth Bass in a Tennessee River reservoir. Trans Am Fish Soc 109:364-370.

Humston R, Doss SS, Wass C, et al (2017) Isotope geochemistry reveals ontogeny of dispersal and exchange between main-river and tributary habitats in Smallmouth Bass Micropterus dolomieu. J Fish Biol 90:528-548.

Humston R, Priest BM, Hamilton WC, Bugas PE (2010) Dispersal between tributary and main-stem rivers by juvenile Smallmouth Bass evaluated using otolith microchemistry. Trans Am Fish Soc 139:171-184.

Iguchi K, Matsuura K, McNyset K, et al (2004a) Predicting invasions of North American basses in Japan using native range data and a genetic algorithm. Trans Am Fish Soc 133:845-854.

Iguchi K, Yodo T, Matsubara N (2004b) Spawning and brood defense of smallmouth bass under the process of invasion into a novel habitat. Environ Biol Fishes 70:219-225.

Jackson D, Peres-Neto P, Olden J (2001) What controls who is where in freshwater fish communities-the roles of biotic, abiotic, and spatial factors? Can J Fish Aquat Sci 58:157-170.

Jackson D, Somers K, Harvey H (1992) Null models and fish communities: Evidence of nonrandom patterns. Am Nat 139:930-951. 
Jackson DA (2002) Ecological effects of Micropterus introductions: The dark side of black bass. Am Fish Soc Symp 2002:221-232.

Jackson ZJ, Quist MC, Larscheid JG (2008) Growth standards for nine North American fish species. Fish Manag Ecol 15:107-118.

James M (1930) Spawning reactions of Small-mouthed Bass. Trans Am Fish Soc 60:6263.

Jansen AC, Quist MC, Kopaska J (2008) Assessment of Smallmouth Bass Populations in Iowa Interior Rivers. J Iowa Acad Sci 115:17-23.

Jennions MD, Petrie M (2000) Why do females mate multiply? A review of the genetic benefits. Biol Rev 75:21-64.

Johnson J, Jensen B (1991) Hatcheries for endangered freshwater fishes. In: Minckley W, Deacon J (eds) Battle Against Extinction: Native Fish Management in the American West. University of Arizona Press, Tuscon, AZ, pp 199-217.

Johnson RL, Christian AD, Henry SD, Barkley SW (2009) Distribution, population characteristics, and physical habitat associations of black bass (Micropterus) in the lower Eleven Point River, Arkansas. Southeast Nat 8:653-670.

Jordan D, Evermann B (1898) The fishes of North and Middle America: A descriptive catalogue of the species of fish-like vertebrates found in the waters of North America, north of the Isthmus of Panama. Washington, D.C.

Kaevats L, Sprules W, Shuter B (2005) Effects of wind-induced spatial variation in water temperature and zooplankton concentration on the growth of young-of-the-year Smallmouth Bass. Environ Biol Fishes 74:273-281.

Kassler T, Koppelman J, Near T, et al (2002) Molecular and morphological analyses of the black basses: Implications for taxonomy and conservation. Am Fish Soc Symp 31:291-322.

Keast A (1968) Feeding of some Great Lakes fishes at low temperatures. J Fish Res Board Canada 25:1199-1218.

Keast A (1970) Food specializations and bioenergetic interrelations in the fish faunas of some small Ontario waterways. In: Steele J (ed) Marine Food Chains. Oliver \& Boyd, Edinburgh, pp 377-411.

Knotek L, Orth DJ (1998) Survival for specific life intervals of smallmouth bass, Micropterus dolomieu, during parental care. Environ Biol Fishes 51:285-296. 
Koppelman J (1994) Hybridization between Smallmouth Bass, Micropterus Dolomieu, and Spotted Bass, M. punctulatus, in the Missouri River System, Missouri. Copeia 1994:204-210.

Langhurst R, Schoenike D (1990) Seasonal migration of Smallmouth Bass in the Embarrass and Wolf rivers, Wisconsin. North Am J Fish Manag 10:224-227.

Langlois T (1935) The production of Smallmouth Bass under controlled conditions. Progress Fish Cult 7:1-7.

Larimore R (1952) Home pools and homing behavior of Smallmouth black bass in Jordan Creek. Urbana, IL.

Larimore R (2002) Temperature acclimation and survival of Smallmouth Bass fry in flooded warmwater streams. In: Philipp D, Ridgeway M (eds) Black Bass: Ecology, Conservation, and Management. American Fisheries Society, Bethesda, MD, pp 115-122.

Larimore R, Duever M (1968) Effects of temperature and acclimation on the swimming ability of Smallmouth Bass fry. Trans Am Fish Soc 97:175-185.

Leasure DR, Magoulick DD, Longing SD (2016) Natural flow regimes of the OzarkOuachita Interior Highlands region. River Res Appl 32:18-35.

Loppnow GL, Vascotto K, Venturelli PA (2013) Invasive Smallmouth Bass (Micropterus dolomieu): History, impacts, and control. Manag Biol Invasions 4:191-206.

Lukas J, Orth D (1995) Factors affecting nesting success of Smallmouth Bass in a regulated Virginia stream. Trans Am Fish Soc 124:726-735.

Lundberg JG, Kottelat M, Smith GR, et al (2010) So many fishes, so little time: An overview of recent ichthyological discovery in continental waters. Ann Missouri Bot Gard 87:26-62.

Lyons J (1991) Predicting Smallmouth Bass presence/absence and abundance in Wisconsin streams using physical habitat characteristics. In: Jackson D (ed) The first international Smallmouth Bass symposium. Mississippi State University, Starkville, MS, pp 96-103.

Lyons J, Kanehl P (2002) Seasonal movements of Smallmouth Bass in streams. In: Philipp D, Ridgway M (eds) Black Bass: Ecology, Conservation, and Management. American Fisheries Society, Bethesda, MD, pp 149-160.

Lyons J, Kanehl P (1993) A comparison of four electroshocking procedures for assessing the abundance of Smallmouth Bass in Wisconsin streams. St. Paul, MN. 
Malloy T, Van Den Bussche R, Coughlin W, Echelle A (2000) Isolation and characterization of microsatellite loci in smallmouth bass, Micropterus dolomieu (Teleostei: Centrarchidae), and cross-species amplification in Spotted Bass, $M$. punctulatus. Mol Ecol 9:1946-1948.

Martin JH (2017) Neosho Smallmouth Bass movement, spawning, and associated environmental conditions in a seasonally discontinuous stream: The Illinois Bayou, Arkansas.

Miller AD, Brewer SK (2021) Riverscape nesting dynamics of Neosho Smallmouth Bass: To cluster or not to cluster? Divers Distrib 1-14.

Miller R, Minckley W, Norris S (2006) Freshwater fishes of Mexico. University of Chicago Press, Chicago.

Morbey Y, Vascotto K, Shuter B (2007) Dynamics of piscivory by lake trout following a Smallmouth Bass invasion: A historical reconstruction. Trans Am Fish Soc $136: 477-483$

Munther G (1970) Movement and distribution of Smallmouth Bass in the middle Snake River. Trans Am Fish Soc 99:44-53.

Nelson E (2018) Sex determination and population genetics of Smallmouth Bass (Micropterus dolomieu) in eastern Lake Ontario. Queens University, Kingston, Ontario

Nigh TA, Schroeder WA (2002) Atlas of Missouri ecoregions. Jefferson City, MO.

O’Sullivan AM, Samways KM, Perreault A, et al (2020) Space invaders: Searching for invasive Smallmouth Bass (Micropterus dolomieu) in a renowned Atlantic Salmon (Salmo salar) river. Ecol Evol 10:2588-2596.

Olson M, Young B (2003) Patterns of diet and growth in co-occurring populations of Largemouth Bass and Smallmouth Bass. Trans Am Fish Soc 132:1207-1213.

Orth DJ, Newcomb TJ (2002) Certainties and uncertainties in defining essential habitats for riverine Smallmouth Bass. Am Fish Soc Symp 2002:251-264.

Paragamian V (1984) Population characteristics of Smallmouth Bass in five Iowa streams and management recommendations. North Am J Fish Manag 4:497-506.

Paragamian V (1981) Some habitat characteristics that affect abundance and winter survival of Smallmouth Bass in the Maquoketa River, Iowa. In: Krumholtz L (ed) Warmwater stream symposium. American Fisheries Society, Southern Division, Bethesda, MD, pp 45-53. 
Paragamian V (1991) Stream sedimentation and abundance of Smallmouth Bass. In: Jackson D (ed) The first international Smallmouth Bass symposium. Mississippi State University, Starkville, MS, pp 55-60.

Pflieger W (1966) Reproduction of the Smallmouth Bass (Micropterus dolomieui) in a small Ozark stream A. Am Midl Nat 76:410-418.

Pflieger W (1997) Fishes of Missouri. Missouri Department of Conservation, Jefferson City, MO

Power M, Matthews W, Stewart A (1985) Grazing minnow, piscivorous bass, and stream algae: dynamics of a strong interaction. Ecology 66:1488-1456.

Probst W, Rabeni C, Covington W, Marteney R (1984) Resource use by stream-dwelling Rock Bass and Smallmouth Bass. Trans Am Fish Soc 113:283-294.

Putman JH, Pierce CL, Day DM (1995) Relationships between environmental variables and size-specific growth rates of Illinois stream fishes. Trans Am Fish Soc 124:252-261.

Rabeni C (1992) Trophic linkages between stream centrarchids and their crayfish prey. Can J Fish Aquat Sci 49:1714-1721.

Raffetto N, Baylis J, Serns S (1990) Complete estimates of repreductive success in a closed population of Smallmouth Bass (Micropterus dolomieui). Ecology 71:1523-1535.

Rahel F, Magnuson J (1983) Low pH and the absence of fish species in naturally acidic Wisconsin lakes: Inferences for cultural acidification. Can J Fish Aquat Sci 40:39.

Ramsey J (1975) Taxonomic history and systematic relationships among species of Micropterus. Sport Fishing Institute, Washington, D.C.

Rawson D (1945) The experimental introduction of Smallmouth black bass into lakes of the prince Albert National Park, Saskatchewan. Trans Am Fish Soc 73:19-31.

Reighard J (1906) The breeding habits, development and propagation of the black bass (Micropterus dolomieu Lacepede and Micropterus salmoides Lacepede). Bull Michigan Fish Comm 7:1-70.

Rejwan C, Collins NC, Brunner LJ, et al (1999) Tree regression analysis on the nesting habitat of Smallmouth Bass. Ecology 80:341. 
Rejwan C, Shuter BJ, Ridgway MS, Collins NC (1997) Spatial and temporal distributions of Smallmouth Bass (Micropterus dolomieu) nests in Lake Opeongo, Ontario. Can J Fish Aquat Sci 54:2007-2013.

Reynolds C, O’Bara C (1991) Reproductive ecology and spawning habitat of Smallmouth Bass in two small streams of the Tennessee River system. In: Jackson D (ed) The first international Smallmouth Bass symposium. Mississippi State University, Nashville, TN, pp 61-65.

Reynolds J (1965) Life history of Smallmouth Bass, Micropterus dolomieui Lacepede, in the Des Moines River, Boone County, Iowa. Iowa State J Sci 3:417-436.

Ridgway M (1988) Developmental stage of offspring and brood defense in Smallmouth Bass (Micropterus dolomieui). Can J Zool 66:1722-1728.

Ridgway M, Friesen T (1992) Annual variation in parental care in Smallmouth Bass (Micropterus dolomieu). Environ Biol Fishes 35:243-255.

Ridgway M, Goff G, Keenleyside M (1989) Courtship and spawning behavior in Smallmouth Bass (Micropterus dolomieui). Am Midl Nat 122:209-213.

Ridgway M, Shuter B, Post E (1991) The relative influence of body size and territorial behavior on nesting asynchrony in male Smallmouth Bass, Micropterus dolomieui (Pisces : Centrarchidae). J Anim Ecol 60:665-681.

Ridgway MS, Shuter BJ, Middel TA, Gross ML (2002) Spatial ecology and densitydependent processes in Smallmouth Bass: The juvenile transition hypothesis. Am Fish Soc Symp 2002:47-60.

Robbins WH, MacCrimmon HR (1974) The Black Bass in America and Overseas. Biomanagement and Research Enterprises, Sault Ste. Marie, Ontario, Canada.

Robinson W, Peters R, Zimmerman J (1983) The effects of body size and temperature on metabolic rate of organisms. Can J Zool 61:281-288.

Robison H, Buchanan T (1984) Fishes of Arkansas. University of Arkansas Press, Fayetteville, AR.

Roell M, Orth D (1993) Trophic basis of production of stream-dwelling Smallmouth Bass, Rock Bass, and Flathead Catfish in relation to invertebrate bait harvest. Trans Am Fish Soc 122:46-62.

Sabo M, Orth D (1994) Temporal variation in microhabitat use by age-0 Smallmouth Bass in the North Anna River, Virginia. Trans Am Fish Soc 123:733-746. 
Schade CB, Bonar SA (2005) Distribution and abundance of nonnative fishes in streams of the western United States. North Am J Fish Manag 25:1386-1394.

Schneider C (1971) SCUBA observations of spawning Smallmouth Bass. New York Fish Game J 18:112-116.

Scott R, Ridgway M, Noakes D (1997) The nest range of Smallmouth Bass (Micropterus dolomieu): Parental care after swim-up. Can J Zool 75:2058-2062.

Scott WB, Crossman EJ (1973) Freshwater fishes of Canada. Fisheries Research Board of Canada, Ottawa, Canada.

Sechnick C, Carline R, Stein R, Rankin E (1986) Habitat selection by Smallmouth Bass in response to physical characteristics in a natural stream. Trans Am Fish Soc 115:322-334.

Sharma S, Jackson D (2008) Predicting Smallmouth Bass (Micropterus dolomieu) occurrence across North America under climate change: A comparison of statistical approaches. Can J Fish Aquat Sci 65:471-481.

Sharma S, Jackson DA, Minns CK (2009) Quantifying the potential effects of climate change and the invasion of Smallmouth Bass on native lake trout populations across Canadian lakes. Ecography 32:517-525.

Sharma S, Jackson DA, Minns CK, Shuter BJ (2007) Will northern fish populations be in hot water because of climate change? Glob Chang Biol 13:2052-2064.

Shute J, Rakes P, Shute P (2005) Reintroduction of four imperiled fishes in Abrams Creek, Tennessee. Southeast Nat 4:93-110.

Shuter B, Ihssen P (1991) Chemical and biological factors affecting acid tolerance of Smallmouth Bass. Trans Am Fish Soc 120:23-33.

Shuter B, Post J (1990) Climate, population viability, and the zoogeography of temperate fishes. Trans Am Fish Soc 119:314-336.

Siegwarth G (1996) Evaluation of the use and importance of available interior river habitat by gamefish species. Des Moines, IA.

Siegwarth G (1997) Evaluation of the use and importance of available interior river habitat by gamefish species. Des Moines, IA.

Sowa S, Rabeni C (1995) Regional evaluation of the relation of habitat to distribution and abundance of Smallmouth Bass and Largemouth Bass in Missouri streams. Trans Am Fish Soc 124:240-251. 
Sparrow R, Barkoh A (2002) Intensive production of Smallmouth Bass fry. N Am J Aquac 64:205-209.

Stark WJ, Echelle AA (1998) Genetic structure and systematics of Smallmouth Bass, with emphasis on interior highlands populations. Trans Am Fish Soc 127:393416.

Surber E (1943) Observations on the natural and artificial propagation of the Smallmouth black bass, Micropterus dolomieui. Trans Am Fish Soc 72:233-245.

Tabor RA, Footen BA, Fresh KL, et al (2007) Smallmouth Bass and Largemouth Bass predation on juvenile Chinook Salmon and other salmonids in the Lake Washington basin. North Am J Fish Manag 27:1174-1188.

Taylor AT, Long JM, Schwemm MR, Brewer SK (2018) Hybridization and genetic structure of Neosho Smallmouth Bass in the Ozark Highlands. North Am J Fish Manag 1-15.

Taylor AT, Long JM, Tringali MD, Barthel BL (2019) Conservation of Black Bass Diversity: An Emerging Management Paradigm. Fisheries 44:20-36.

Todd B, Rabeni C (1989) Movement and habitat use by stream-dwelling Smallmouth Bass. Trans Am Fish Soc 118:229-242.

Torgerson C, Price D, Li H, McIntosh B (1999) Multiscale thermal refugia and stream habitat associations of Chinook Salmon in northeastern Oregon. Ecol Appl 9:301319.

Vander Zanden M, Casselman J, Rasmussen J (1999) Stable isotope evidence for the food web consequences of species invasions in lakes. Nature 401:464-467.

Vincent A, Ahnesjo I, Berglund A, Rosenqvist G (1992) Pipefishes and seahorses: Are they all sex role reversed? Trends Ecol Evol 7:237-241.

Vogele L (1981) Reproduction of Smallmouth Bass, Micropterus dolomieui, in Bull Shoals Lake, Arkansas. United States Fish Wildl Serv Tech Pap 106:1-15.

Westhoff JT, Paukert C, Ettinger-dietzel S, et al (2016) Behavioral thermoregulation and bioenergetics of riverine Smallmouth Bass associated with ambient cold-period thermal refuge. $72-85$.

Whittier T, Halliwell D, Paulsen S (1997) Cyprinid distributions in Northeast USA lakes: Evidence of regional-scale minnow biodiversity losses. Can J Fish Aquat Sci 54:1593-1607. 
Wiegmann D, Baylis J, Hoff M (1997) Male fitness, body size and timing of reproduction in Smallmouth Bass, Micropterus dolomieui. Ecology 78:111-128.

Wiegmann DD, Angeloni LM, Baylis JR, Newman SP (2004) Negative maternal or paternal effects on tactic inheritance under a conditional strategy. Evolution 58:1530-1535.

Wiegmann DD, Baylis JR, Hoff MH (1992) Sexual selection and fitness variation in a population of Smallmouth Bass, Micropterus dolomieui (Pisces: Centrarchidae). Evolution 46:1740-1753.

Wieser W (1973) Temperature relations of ectotherms: A speculative review. In: Wieser W (ed) Effects of Temperature on Ectothermic Organisms. Springer Berlin Heidelberg, Berlin, Germany, pp 1-23.

Winemiller KO, Taylor DH (1987) Predatory behavior and competition among laboratory-housed largemouth and Smallmouth Bass. Am Midl Nat 117:148-166.

Winemiller KO, Taylor DH (1982) Smallmouth Bass nesting behavior and nest site selection in a small Ohio stream. Ohio Acad Sci 82:266-273.

Woodford DJ, Impson ND, Day JA, Bills IR (2005) The predatory impact of invasive alien Smallmouth Bass, Micropterus dolomieu (Teleostei: Centrarchidae), on indigenous fishes in a Cape Floristic Region mountain stream. African J Aquat Sci 30:167-173.

Wrenn W (1984) Smallmouth Bass reproduction at elevated temperature regimes at the species' native southern limit. Trans Am Fish Soc 113:295-303.

Zorn TG, Seelbach PW, Wiley MJ (2002) Distributions of stream fishes and their relationship to stream size and hydrology in Michigan's Lower Peninsula. Trans Am Fish Soc 131:70-85. 


\section{Figures}

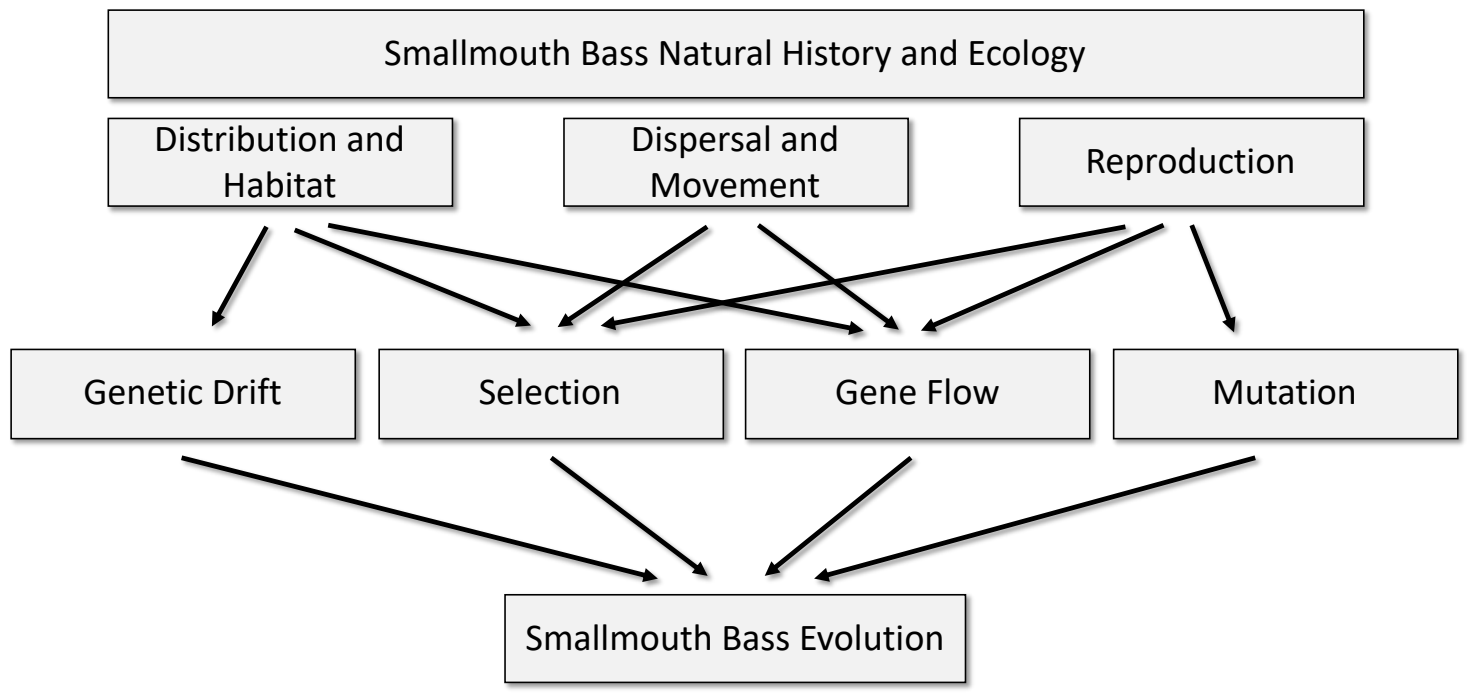

Figure 2.1. Conceptual framework for the study of Smallmouth Bass evolution.

Researchers of Smallmouth Bass evolution should directly integrate three primary aspects of Smallmouth Bass ecology, namely distribution and habitat, dispersal and movement, and reproduction, with the specific evolutionary processes (genetic drift, selection, gene flow, mutation) they may influence. 


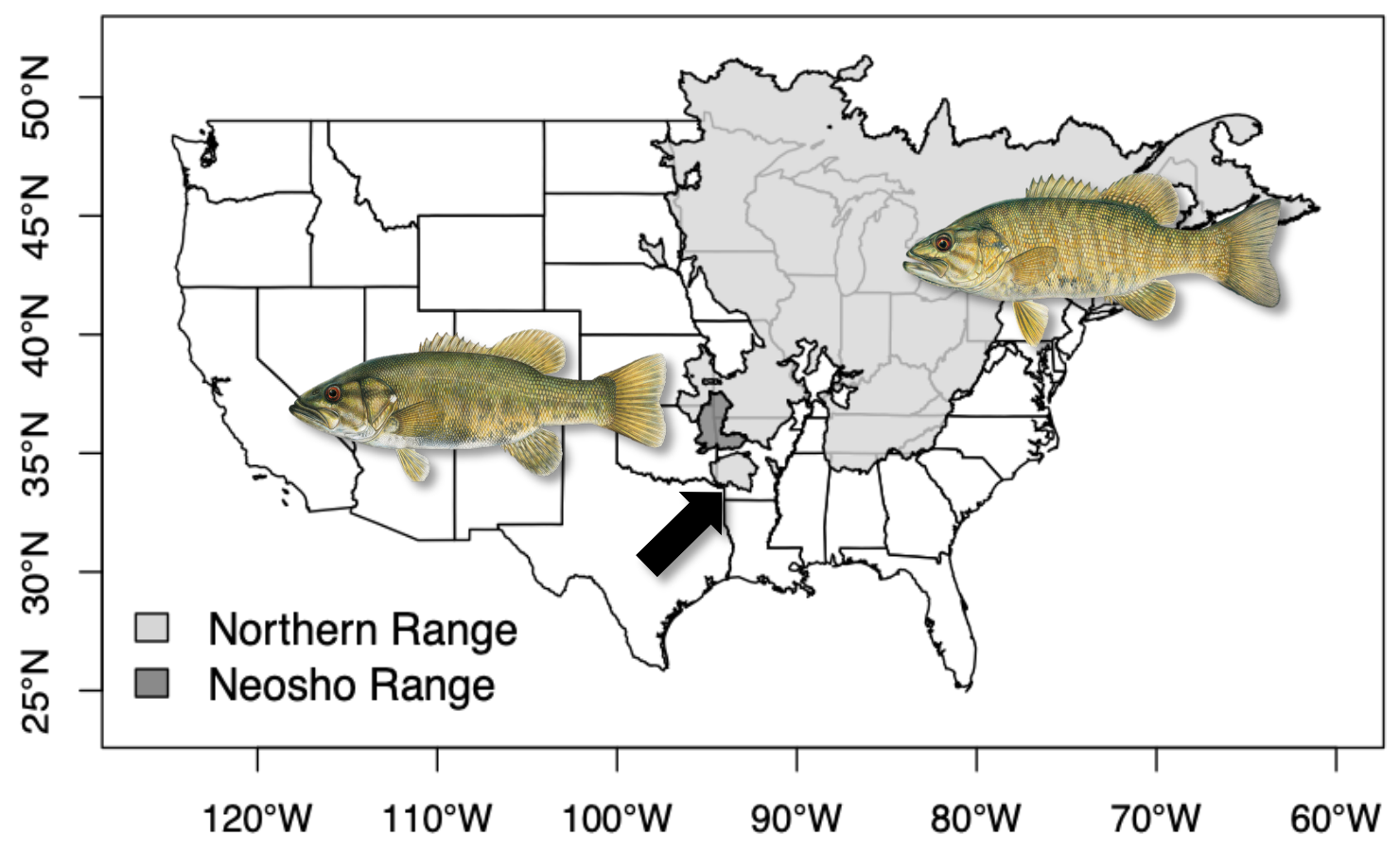

Figure 2.2. Native distributions of the two Smallmouth Bass subspecies: Northern Smallmouth Bass (M. d. dolomieu; light grey) and Neosho Smallmouth Bass (M. d. velox, dark grey). The proposed native distribution of the Ouachita Smallmouth Bass is indicated with a black arrow. Illustrations of the subspecies are shown at the top right (Northern) and at center left (Neosho). 


\section{CHAPTER 3}

\section{Complex patterns of genetic and morphological differentiation in the Smallmouth Bass subspecies (Micropterus dolomieu dolomieu and M. d. velox) of the Central Interior Highlands}

Joe C. Gunn ${ }^{1}$, Leah K. Berkman², Jeff Koppelman², Andrew T. Taylor ${ }^{3}$, Shannon Brewer $^{4}$, James M. Long ${ }^{4}$, Lori S. Eggert ${ }^{1}$

${ }^{I}$ Division of Biological Sciences, University of Missouri, 226 Tucker Hall, Columbia, MO 65211, USA, ORCID: 0000-0001-6916-8678

${ }^{2}$ Missouri Department of Conservation, 3500 E. Gans Rd. Columbia, MO 65201, USA

${ }^{3}$ Department of Natural Resource Ecology and Management, Oklahoma State University, Stillwater, Oklahoma 74078, USA

${ }^{4}$ U.S. Geological Survey, Oklahoma Cooperative Fish and Wildlife Research Unit, Department of Natural Resource Ecology and Management, Oklahoma State University, Stillwater, Oklahoma 74078, USA

\footnotetext{
Abstract

Due to geologic processes and recent anthropogenic introductions, patterns of genetic and morphological diversity within the Smallmouth Bass (Micropterus dolomieu), which are endemic to the central and eastern United States (USA), are poorly understood. We assessed genetic and morphological differentiation between the widespread Northern Smallmouth Bass (M. d. dolomieu) and the more restricted Neosho Smallmouth Bass $(M . d$. velox) where their ranges meet in the Central Interior Highlands ecoregion $(\mathrm{CIH})$. Data from 14 microsatellite loci were used to conduct STRUCTURE and principal components analyses to evaluate diversity across populations and screen for hybridization with sympatric Spotted Bass (M. punctulatus). We also tested for morphological differences using five morphometric traits and one meristic trait. We
} 
found support for three genetic clusters corresponding to previously described taxonomic variation; five clusters largely corresponding to river systems; and nine clusters representing hierarchical population structure within both ranges. We found evidence of a unique genetic cluster in tributaries of the White River within the Northern Smallmouth Bass range and admixture between the subspecies throughout the Neosho range. We also found evidence of morphological differentiation between subspecies; Neosho Smallmouth Bass exhibited larger head length than Northern Smallmouth Bass relative to total length, and there was a significant interaction of subspecies and orbital length, possibly indicating differential growth patterns between subspecies. Our results reveal multiple levels of divergence, suggesting the $\mathrm{CIH}$ harbors greater and more complex Smallmouth Bass diversity than previously thought.

\section{Introduction}

Preserving genetic integrity is important for all locally adapted taxa, from crops (Hails and Morley 2005) to wild animals (Rhymer and Simberloff 1996). The evolutionary capacity of species in changing environmental conditions depends on rangewide genetic diversity (Frankel 1974; Hedrick 2001). Freshwater ecosystems are particularly diverse, containing $40 \%$ of described fish species (Dudgeon et al. 2006). Often, these systems are small and geographically isolated (Herdegen et al. 2014), which can produce highly structured, genetically divergent populations (Ward et al. 1994; Puebla 2009).

Genetic isolating mechanisms operating over geologic time have produced similar phylogeographic patterns across many freshwater fish species in the eastern United States 
(USA), suggesting that vicariance before and during the Pleistocene has shaped diversity (Mayden 1988). Receding glacial boundaries after the last glacial maximum, followed by instances of stream capture (Smith 1956; Branson 1963; Matthews and Robison 1988), allowed colonization and co-occurrence of species (Bernatchez and Wilson 1998). On contemporary time scales, secondary contact has been facilitated anthropogenically; freshwater fish have often been subjected to non-native introductions (i.e., "stocking") for a variety of reasons, including to create angling opportunities (Addison and Spencer 1971; Jennings et al. 2005; Pregler et al. 2018).

The black basses (genus Micropterus) have been broadly influenced by natural and anthropogenic processes, making them an ideal group for studying complex phylogeographic patterns in fishes. The genus is highly diverse, comprising up to 17 species (Taylor et al. 2019) whose evolutionary history has been molded through Pleistocene habitat fragmentation (Bermingham et al. 1992) and contemporary anglinginspired introductions (Snow 1975; Long et al. 2015; Taylor et al. 2019). Black basses exhibit weak reproductive isolation (Bolnick and Near 2005), so hybridization has occurred frequently between congeners (Whitt et al. 1971; Koppelman 2015; Taylor et al. 2018).

Of the black basses, Smallmouth Bass are among the most sought-after by anglers and are critical to ecosystem function as apex predators (Scott and Crossman 1973). Consequently, Smallmouth Bass have been widely released within and outside their native range since the early 1900s (Robbins and MacCrimmon 1974; Stark and Echelle 1998; Brewer and Orth 2015; Long et al. 2015). Introductions may substantially alter the genetic composition of populations. More notably, introductions may be maladaptive 
(Barton 2001), decreasing overall diversity if distinct populations are genetically homogenized through introgressive hybridization (Koppelman 2015). Avise et al. (1997), for example, detected near-complete genetic swamping of Smallmouth Bass alleles by introduced Spotted Bass (M. punctulatus; Pflieger and Fajen 1975; Koppelman 1994; Pierce and Van Den Avyle 1997) in Lake Chatuge, Georgia, USA Preserving distinct black bass forms and preventing loss of traits valued by humans (Thorpe et al. 1981) requires that releases of congeners be accomplished with a full understanding of the phylogeography of native populations and the potential for swamping by introduced forms.

The Smallmouth Bass comprises two described subspecies (Hubbs and Bailey 1940): Northern Smallmouth Bass (M. d. dolomieu), whose distribution extends from tributaries of the White River to the northeastern coast of the USA and Canada, and Neosho Smallmouth Bass $(M . d$. velox), which is restricted to the lower Ozark Highlands (Stark and Echelle 1998; Nigh and Schroeder 2002). The subspecies designation is largely predicated on soft dorsal fin ray number; the Northern subspecies usually has 14, while the Neosho usually has 13 . Other body size characteristics may also be involved (Hubbs and Bailey 1940). Because of subtlety in phenotypic differences, legitimacy of the subspecies has long been debated (Bailey 1956; Gilbert 1998). However, increasing evidence of divergence has given precedence to quantifying genetic, morphological, and ecological differences between the subspecies (Stark and Echelle 1998; Taylor et al. 2019).

The Neosho and Northern subspecies are native to separate river systems in the Central Interior Highlands (CIH), a well-studied ecoregion contained within the Ozark 
Plateau in the central USA that is known for substantial fish diversity (Lundberg et al. 2000; Figure 3.1). The Neosho Smallmouth Bass inhabits southeast-flowing streams in the Arkansas River Basin, while the Northern Smallmouth Bass inhabits both northflowing tributaries of the Missouri River and east- and southeast-flowing tributaries of the White River. All three river systems eventually drain into the mainstem of the Mississippi River further southeast. Regardless of their Mississippi River connection, the subspecies are not known to move between systems and have been presumed to be allopatric. However, several studies (Hubbs and Bailey 1940; Stark and Echelle 1998) have proposed an intergrade zone in the $\mathrm{CIH}$ encompassing the White and Black Rivers (Figure 3.1). Taylor et al. (2018) used seven microsatellites to assess introgression in the Neosho range resulting from introductions of Northern Smallmouth Bass (the "Tennessee lake-strain"). They showed that native Neosho Smallmouth Bass were genetically differentiated from non-native, lake-strain Northern Smallmouth Bass and that substantial introgression could occur in stream populations near stocked impoundments. Despite uncovering population structure, recent studies lack sample coverage in drainages neighboring the Neosho range, leaving both the extent of geographic divergence and the presence of an intergrade zone unexplored. Understanding the phylogeography of this species is of interest to evolutionary biologists, ecologists, and sport-fishery managers ( $\mathrm{Li}$ et al. 2015), as it is vital for maintaining genetic integrity.

We assessed phylogeographic and morphological relationships across the entire Neosho Smallmouth Bass native range and the adjacent portion of the Northern Smallmouth Bass range in the $\mathrm{CIH}$, expanding the work of Taylor et al. (Taylor et al. 2018). We evaluated genetic differentiation, population structure, admixture, and 
morphological differentiation between Northern and Neosho Smallmouth Bass. We included congeneric Spotted Bass to assess intraspecific variation relative to interspecific variation.

\section{Materials and Methods}

\section{Sample Collection}

We collected 838 black bass tissue samples from 43 sites between May 2014 and November 2017 (Table 3.1; Table A1.1), encompassing the entire Neosho Smallmouth Bass subspecies distribution and adjacent parts of the Northern Smallmouth Bass subspecies distribution within the Central Interior Highlands (CIH). We also sampled one hatchery within the Northern range (Genoa Hatchery, Wisconsin, USA) and one hatchery-stocked impoundment outside both ranges (Skiatook Lake, Oklahoma, USA, the

"Tennessee lake-strain" of the Northern subspecies) to assess genetic differentiation in non-wild populations. We collected Spotted Bass samples from the northern edge of their native distribution (Figure 3.1).

Sampling was uneven across collection sites (sample size range: $3-51$ ) due to the opportunistic nature of our effort (Table 3.1). Small sample sizes are known to affect allele frequency and heterozygosity calculations (Hale et al. 2012) by failing to detect rare alleles. We therefore acknowledge that genetic diversity analyses may be biased. Fish were captured through tow-barge or boat electrofishing and hook-and-line angling and visually identified as Smallmouth Bass or Spotted Bass. For all sampled individuals, we removed a $\sim 1 \mathrm{~cm} 2$ section of upper caudal fin tissue. Fin clips were stored in 
Longmire Buffer (Longmire et al. 1997), RNAlater, or 95\% ethanol on ice before being transferred to long-term storage at $-20^{\circ} \mathrm{C}$.

We assessed six morphological traits - total length, standard length, orbital length, head length, body depth (Gharaei 2012; Rehman et al. 2015) and the number of soft dorsal fin rays — on a subset of adult Smallmouth Bass samples (Table 3.1). Some samples were acquired from a previous study (Taylor et al. 2018), supplied with the authors' permission; due to sampling differences, not all morphological traits were collected for all fish. We recorded measurements on adult fish exceeding $200 \mathrm{~mm}$ in total length (Carlander 1977; Jackson et al. 2008). No morphological traits were obtained for Spotted Bass. Fish were measured without anesthesia and released immediately afterward.

\section{Microsatellite Genotyping and Genotyping Error}

We isolated DNA from fin clips using the DNeasy Blood and Tissue Kit (QIAGEN, Germantown, Maryland, USA) and arranged samples in 96-well plates, with one positive control and one no-DNA (negative) control. Fifteen polymorphic microsatellite loci (Colbourne et al. 1996; Malloy JR et al. 2000; Seyoum et al. 2013; Table A1.2) were amplified in four multiplex reactions (Table A1.2). We performed PCR in $8 \mu \mathrm{L}$ reactions with $1 \mathrm{X}$ Platinum Multiplex PCR Master Mix (Applied Biosystems Inc, Foster City, California, USA), $2 \mu \mathrm{M}$ primer multiplex mix, $0.9 \mu \mathrm{L} 1 \mathrm{X}$ GC enhancer (Applied Biosystems), 0.8mM BSA, and 20-100ng template DNA. PCR was run with the following profile: $95^{\circ} \mathrm{C}$ for 15 minutes; 35 cycles denaturation at $94^{\circ} \mathrm{C}$ for 30 
seconds, primer annealing at optimal annealing temperature for 90 seconds, primer extension at $72^{\circ} \mathrm{C}$ for 1 minute; and 1 cycle at $60^{\circ} \mathrm{C}$ for 30 minutes.

PCR products were analyzed on an ABI 3730xl DNA analyzer (Applied Biosystems) with a GS600 size standard at the MU DNA Core Facility. We called alleles using Genemarker v.1.97 (Softgenetics, State College, Pennsylvania, USA). Samples failing to amplify at $>60 \%$ of loci were omitted from further analyses. We estimated genotyping error and null allele frequencies by repeating PCR and allele-calling for 190 DNA samples at all microsatellite loci; error rates were assessed using GIMLET v.1.3.2 (Valière 2002).

Hardy-Weinberg Equilibrium, and Linkage Disequilibrium

We assessed genetic composition within sites $(N=43)$. We tested for deviations from Hardy-Weinberg equilibrium (HWE) expectations and linkage disequilibrium across genotypes using GENEPOP (Raymond and Rousset 1995; Rousset 2008), applying a Bonferroni correction $(\alpha=0.001)$.

Analysis of Genetic Diversity and Differentiation

Observed heterozygosity $(H O)$, expected heterozygosity $(H E)$, and frequency of non-rare alleles (A95) were calculated for each site in gstudio v.1.5.0 (Dyer 2016); rarefied allelic richness $(A R)$ and frequency of private alleles $(A P)$ were each calculated and corrected for population size assuming eight "genes" per locus using HP-RARE (Kalinowski 2005). Differences in genetic diversity metrics were tested using one-way 
ANOVA and by assessing overlap of 95\% confidence intervals in RStudio v.3.5.2 (R Core Team 2018).

We calculated pairwise fixation indices $\left(F_{\mathrm{ST}}\right)$ among sites using GENODIVE v.2.0b23 (Meirmans and Van Tienderen 2004). When no two sites within the same river were found to differ significantly based on $F_{\mathrm{ST}}$, we combined those data into a single population. We recalculated pairwise $F_{\mathrm{ST}}$ for these putative populations and conducted all subsequent analyses at the population level.

\section{Analysis of Population Structure}

To comprehensively assess population structure of Smallmouth Bass in the CIH and capture genetic clusters that may be undetectable due to uneven sampling, we used three sets of parameters to analyze our data in STRUCTURE v.2.3.4 (Pritchard et al. 2000). We initially ran STRUCTURE on all samples with the admixture model for $K=1-28$ with 500,000 burn-in steps, 1,000,000 MCMC iterations, 10 replicates per $K$, and no prior for location, to scan for unique genetic clusters corresponding to each putative population. There was no population structure among populations beyond $K=15$. To reduce computation time, all subsequent analyses were run using the same settings for $K=1-15$. For the first set of parameters (Default Parameters), we used default parameters in STRUCTURE. We tested for substructure within the major divisions, setting $K=1-5$ possible clusters and $K=1-10$ possible clusters for each substructure analysis (Janes et al. 2017). For the second set (Wang Parameters), we used alternative parameters in STRUCTURE as suggested by Wang (2017) to account for non-uniformity in allelic contribution from each population to each individual's genotypic assignment. For these 
two sets, we calculated the most probable number of population clusters using the $\Delta K$ metric (Evanno et al. 2005) in Structure Selector (Li and Liu 2018). For the third set (Puechmaille Metrics), we used default STRUCTURE parameters but inferred genetic clusters using the approach outlined in Puechmaille (2016) that is expected to be more robust to uneven sampling. For these estimators, we used mean and median individual membership thresholds of 0.50 .

For each parameter set, we produced a consensus assignment for individuals across all STRUCTURE replicates using CLUMPAK (Kopelman et al. 2015). To account for spurious multimodality, we only considered replicates representing major clusters inferred in CLUMPAK, omitting minor clusters from further analyses. Average assignment to major clusters was calculated across populations using the LargeKGreedy parameter and 10,000 repeats in CLUMPP v.1.1.2 (Jakobsson and Rosenberg 2007). Assignment values were visualized graphically in $R$ using the package pophelper v.2.2.9 (Francis 2017). Genetic clusters were similarly visualized at the species, subspecies, river system, and population levels using principal component analysis (PCA) of all microsatellite loci in $R$ using the package gstudio.

\section{Analysis of Morphological Differentiation}

Morphometric data were log-transformed to reduce variance due to measurement scale (Hansen and Houle 2008; Berner 2011) and labeled in two ways: 1) by the taxonomic range from which they were collected (Neosho or Northern) and 2) if applicable, by the cluster to which $>90 \%$ of their genotype was assigned in STRUCTURE (non-admixed). Within ranges and genetic assignments, we evaluated adherence of each 
log-transformed morphometric trait to normality using the Shapiro-Wilk test and $q q$-plots in the $R$ package ggpubr v.0.2.1 (Kassambara 2019). Additionally, we compared probability density distributions of each trait for taxonomic range and genetic assignment. We assessed whether individual morphometric traits differed between 1) Neosho and Northern subspecies ranges, and 2) admixed and non-admixed individuals by performing univariate mixed-effect ANCOVA in $R$ using the package nlme v.3.1-137 (Pinheiro et al. 2018; R Core Team 2018). ANCOVA was run on log-transformed standard length, orbital length, head length, and body depth, retaining total length as a covariate in each model. Population was included as a random effect to account for riverlevel variation. Each trait was initially assessed with the inclusion of an interaction for the covariate and group (taxonomic range or genetic assignment). If interactions were insignificant, traits were assessed additively.

We back-calculated means of each length-adjusted trait using unique slope and intercept coefficients obtained from ANCOVA and the overall grand mean of total length for Neosho (Equation 1) and Northern Smallmouth Bass (Equation 2):

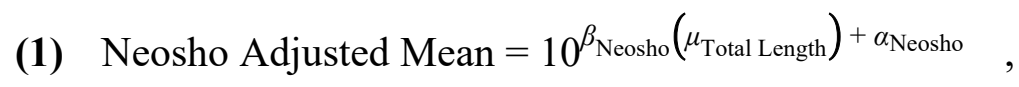

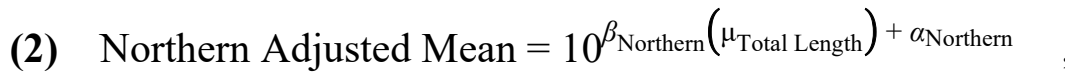

where $\beta$ is the slope derived from ANCOVA, $\mu$ is the grand mean of pooled total length, and $\alpha$ is the intercept derived from ANCOVA.

We also assessed subspecies differences through a multivariate framework using Discriminant Function Analysis (DFA; Sneath and Sokal 1973) with leave-one-out cross 
validation in the R package MASS ed.4 (Venables and Ripley 2002). We calculated mean probability of correctly identifying a Neosho or Northern Smallmouth Bass based on taxonomic range and genetic assignment and determined the most predictive traits for each group. Number of soft dorsal fin rays was excluded from DFA; it is recommended that morphometric and meristic traits not be combined in multivariate analysis (Ihssen et al. 1981; Turan 1999).

We assessed the association between number of soft dorsal fin rays and subspecies by conducting logistic regression on soft dorsal fin ray count with respect to genetic assignment. Data were regressed on the proportion of the genotype assigned to the Neosho cluster in STRUCTURE. We calculated pseudo $R^{2}\left(p R^{2}\right.$; McFadden 1973) to assess logistic regression model fit using the $R$ package DescTools v. 0.99.28 (Signorell et al. 2019).

\section{Results}

Sample Collection and Genotyping Error

Of our 838 black bass samples, $72(8.60 \%)$ failed to amplify at $>60 \%$ of loci. We attributed poor DNA quality to inadequate tissue preservation and excluded these samples from analyses. We therefore used a total of 766 individuals including juveniles (66-200mm total length, $N=32)$ and adults $(200-466 \mathrm{~mm}$ total length, $N=734)$ for genetic analysis. Juvenile samples were distributed relatively randomly among sites. Of our samples, 616 were obtained from the Arkansas River Basin within the putative Neosho range; 117 were obtained from Missouri River tributaries and White River tributaries 
within the southwestern edge of the putative Northern range; and 33 were identified as Spotted Bass and obtained from tributaries within the putative Neosho range (Table 3.1).

\section{Hardy-Weinberg Equilibrium and Linkage Disequilibrium}

Microsatellite locus mdo8 significantly deviated from HWE in 14 of 43 sites and was removed from further analyses. No other locus deviated from HWE in more than 6 sites. We found no evidence of linkage disequilibrium for any pair of loci. In the final data set, error rates were low, with a $3.3 \%$ false allele rate (percent of samples with a PCR artefact resembling an allele) across loci, a 2.7\% false allele rate across samples, a $4.7 \%$ allelic dropout rate across loci, and a $2.8 \%$ allelic dropout rate across samples.

\section{Genetic Diversity and Differentiation}

We found $H O(F=20.66 ; \mathrm{p}<0.001), H E(F=7.75 ; \mathrm{p}=0.008), A 95(F=2.286$; $p=0.028)$, and $A P(F=22.33 ; p<0.001)$ were significantly higher in Northern Smallmouth Bass sites compared to Neosho based on one-way ANOVA and 95\% confidence intervals (Table A1.3). $A R$ was not significantly different between subspecies $(F=3.537 ; p=0.068$; Table A1.3).

We collapsed 43 sampling sites into 28 putative populations. Pairwise $F_{\text {ST }}$ values were significant between most populations within subspecies, between subspecies, and between species. We found a mean pairwise $F_{\mathrm{ST}}$ among Neosho populations of 0.09 $(0.00-0.27)$, a mean pairwise $F_{\mathrm{ST}}$ among Northern populations of $0.13(0.01-0.26)$, and a mean $F_{\mathrm{ST}}$ among Spotted Bass populations of $0.04(-0.02-0.08)$. The mean pairwise $F_{\mathrm{ST}}$ between Neosho and Northern Smallmouth Bass was $0.21(0.02-0.40)$; the mean pairwise 
$F_{\mathrm{ST}}$ between Neosho and Spotted Bass was $0.34(0.21-0.50)$; and the mean pairwise $F_{\mathrm{ST}}$ between Northern and Spotted Bass groups was 0.30 (0.21-0.4; Table A1.4).

\section{Population Structure}

Based on Default Parameters, we initially found support for $K=2$ major genetic clusters, generally grouping Northern Smallmouth Bass populations with Spotted Bass (Table A1.5a; Figure A1.1a) and showing substantial admixture within Neosho Smallmouth Bass populations. Substructure analysis for Northern Smallmouth Bass and Spotted Bass showed very strong support for $K=2$ major genetic clusters representing the two species (Table A1.5b; Figure A1.1b). Tests for substructure within the Neosho Smallmouth Bass samples also found support for $K=2$ and represented admixture between the Northern and Neosho subspecies (Table A1.5c; Figure A1.1c). We therefore inferred population structure from Default Parameters at $K=3$ (Figure 3.2a). We detected only traces of admixture with Spotted Bass within Neosho and Northern populations at $K=3$ (Figure 3.2a). Among all Smallmouth Bass samples, the average membership coefficient to the Spotted Bass genetic cluster was 0.06. Of those, five Smallmouth Bass samples (4 Neosho, 1 Northern) were identified as putative Spotted Bass hybrids, with Spotted Bass cluster membership coefficients ranging from 0.50 to 0.59 . Another 17 Smallmouth Bass samples (11 Neosho, 6 Northern) were identified as putative Smallmouth backcrosses, with Spotted Bass cluster membership coefficients ranging from 0.25 to 0.46 .

Using Wang Parameters, we found support for $K=3$ and $K=5$ major clusters (Table A1.6). Clusters for $K=3$ were similar to those identified by Default Parameters 
(Figure A1.1e). Clusters for $K=5$ largely grouped by species and by river systems, with one cluster representing Spotted Bass, a second representing Genoa Hatchery and Missouri River tributaries, a third representing White River tributaries, a fourth representing Populations 14 (Lee Creek), 16 (Big Piney Creek, AR), and 17 (Illinois Bayou), and a fifth representing the rest of the Neosho range (Figure A1.1f; Figure 3.2b). Based on Puechmaille Metrics, each estimator gave $K=9$ major clusters (Table A1.7; Figure A1.1g), with one cluster representing Spotted Bass; three clusters within the Northern range (Missouri River tributaries/Genoa Hatchery, Skiatook Lake, White River tributaries) and five clusters within the Neosho range. Clusters were distributed geographically (Figure A1.2).

All STRUCTURE analyses showed non-uniform levels of admixture between the Northern and Neosho Smallmouth Bass within the Arkansas River Basin (Figure 3.2). This admixture was derived from Northern Smallmouth Bass populations (Figure 3.2a), either from the White River tributaries (Figure 3.2b; Figure A1.2) or from the Skiatook “Tennessee lake-strain” population (Figure A1.2).

PCA showed genetic clustering at species, subspecies, river system, and population levels (Figure A1.3). Northern and Neosho Smallmouth Bass exhibited divergence with some overlap along the first principal component both with (Figure A1.3a) and without Spotted Bass (Figure A1.3b). PCA also showed differential grouping at the river system level; the Arkansas River Basin overlapped almost entirely with Illinois Bayou and Lee Creek, but both clustered separately from the White River tributaries and the Missouri River tributaries and Hatchery samples with some overlap on the first principal component (Figure A1.3c). Within the Neosho Smallmouth Bass 
samples, we observed similar clustering of subspecies, and we observed little differential clustering among populations (Figure A1.3d).

\section{Morphological Differentiation}

We collected five morphometrics and one meristic trait (total length, standard length, orbital length, head length, body depth, and number of soft dorsal rays) for 249 Smallmouth Bass ( $N=65$ Northern Range, $N=184$ Neosho Range; size range: 200 466mm). All but three traits (Neosho Range orbital length, Northern Range head length, and Northern Genetic Assignment head length) conformed to a normal distribution after log-transformation (Figure A1.4). Given the robustness of ANOVA to non-normal distributions (Blanca et al. 2017) and the low frequency of deviations, we performed all analyses with no additional data transformation.

Grouping these data by genetic assignment, based on results for $K=3$ using Default Parameters, eliminated 161 admixed samples and resulted in 88 non-admixed samples ( $N=71$ Northern Cluster, $N=17$ Neosho Cluster; size range: $203-400 \mathrm{~mm})$. Probability density distributions were similar between ranges and genetic assignments for all unadjusted trait values (Figure A1.5a-j), suggesting no differences in traits before size correction.

Based on univariate ANCOVA of length-adjusted morphometric traits, standard length showed no interaction and was not different between Neosho and Northern Smallmouth Bass, either when assessed by taxonomic range (Table 3.2a; Figure 3.3a) or genetic assignment (Table 3.2b; Figure 3.3b). Orbital length showed a significant interaction with total length when assessed by taxonomic range $\left(F_{\text {int }}=30.628 ; p_{\text {int }}<0.001\right.$; 
Table 3.2a; Figure 3.3c) but no interaction when assessed by genetic assignment (Table 3.2b; Figure 3.3d), and neither comparison revealed any differences between subspecies. Head length was different between subspecies when assessed by taxonomic range $\left(F_{\text {cat }}=14.070 ; p_{\text {cat }}=0.001\right.$; Table $3.2 \mathrm{a}$; Figure $\left.3.3 \mathrm{e}\right)$, but there were no interactions for either taxonomic range (Table 3.2a; Figure 3.3e) or genetic assignment (Table 3.2b; Figure 3.3f). Body depth showed no interaction and was not different between subspecies for either taxonomic range (Table 3.2a; Figure 3.3g) or genetic assignment (Table 3.2b; Figure 3.3h). Grand mean of total length and ANCOVA coefficients for all morphometrics assessed by taxonomic range and genetic assignment are provided in Table A1.8.

Discriminant Function Analysis (DFA) indicated significant classification to subspecies by taxonomic range and genetic assignment, with mean accuracy values of $79.92 \%\left(X^{2}=43.75 ; p<0.001\right)$ and $81.81 \%\left(X^{2}=6.981 ; p=0.008\right)$, respectively. For taxonomic range, standard length (35.529) and head length (-21.645) returned the highest DFA coefficients by absolute value and were the most predictive. Standard length (38.414) and total length (-11.588) were the most predictive for genetic assignment (Table A1.9).

Logistic regression showed a strong association between number of soft dorsal rays and genetic assignment $(p<0.001)$. Samples with a higher genetic proportion assigned to the Neosho cluster were more likely to possess 13 soft dorsal rays, whereas samples with a higher proportion assigned to the Northern cluster were more likely to possess 14. Despite the significant relationship, we calculated a low pseud $R^{2}$ value $\left(p R^{2}=0.115\right)$ for the model (Figure A1.6). 


\section{Discussion}

Our results support previous studies showing genetic and morphological differentiation between Neosho and Northern Smallmouth Bass in the Central Interior Highlands (CIH; Hubbs and Bailey 1940; Stark and Echelle 1998; Taylor et al. 2018). However, we revealed more complex levels of genetic structure than previously reported. Analyses in STRUCTURE with different parameter sets showed strong divergence between subspecies (Default Parameters), among river systems (Wang Parameters), and among populations within subspecies (Puechmaille Metrics). Regardless of parameters, all analyses showed heterogeneous admixture between subspecies and among populations. Each of the parameter sets we utilized makes different assumptions about population allele frequencies, sample sizes, and cluster membership (Pritchard et al. 2000; Puechmaille 2016; Wang 2017). However, when considered holistically, they reveal multiple, complex levels of population structure that may otherwise be undetectable under a single Bayesian model.

The White River tributaries genetic cluster fell within the previously hypothesized intergrade zone (Hubbs and Bailey 1940). Although PCA showed that the White River tributaries samples overlapped clusters representing the Arkansas River Basin and Missouri River tributaries, all STRUCTURE parameters showed the White River tributaries mostly as a unique cluster with little admixture. Our data therefore do not fully support the hypothesis of an intergrade zone. Instead, we provide novel evidence of genetically distinct Northern Smallmouth Bass in this part the range, suggesting the White River tributaries may represent an Interior Highlands population that diverged before or during glacial maxima and remained distinct from the Northern Smallmouth Bass that 
recolonized the Great Lakes and major river systems after glaciers receded (Mayden 1988; Borden and Krebs 2009; Stepien et al. 2017).

We detected admixture at all examined taxonomic levels. Admixture between Smallmouth Bass and Spotted Bass was not extensive but consistent with previous studies (Koppelman 1994). In areas of sympatry, low levels of interspecific hybridization may be maintained by ecological or behavioral factors, including niche partitioning or sexual selection (Rundle and Nosil 2005). Genetic incompatibility, although unlikely given the relative lack of reproductive isolation among Centrarchid fishes (Bolnick and Near 2005), may also restrict gene flow between Smallmouth Bass and Spotted Bass. Admixture between Neosho and Northern Smallmouth Bass was widespread but not uniform; a disproportionately higher amount was observed in tributaries near the northern and eastern edges of the Arkansas River Basin than in other parts of the Neosho range. This signature could be attributed to human-driven hybridization via introductions and subsequent introgression. If Northern Smallmouth Bass have been introduced within the Neosho range, introgression may have occurred. However, few introductions have been documented. We know of one recent introduction of "Tennessee lake-strain" Northern Smallmouth Bass in the early 1990s (Boxrucker et al. 2003). Although surveys have shown introgression of non-native alleles since introduction (Malloy JR et al. 2000; Boxrucker et al. 2003; Taylor et al. 2018), it is unlikely that the amount of admixture across the Neosho range would result from a single introduction. Unauthorized, illegal, or inadvertent stocking of Smallmouth Bass is thought to have occurred numerous times throughout North America (Rahel 2004; Johnson et al. 2009). Hoyt (1973) suggested that several rivers in the Arkansas River Basin were stocked with fish from the Northern 
subspecies' range in the early 1960s. Although he offers a convincing explanation for admixture in the Neosho range, it should be noted with caution, because he was unable to identify stocking origins.

Human-mediated translocations may not fully explain the admixture we observed. Incomplete lineage sorting, introgression, and polyphyly are common among black basses (Bagley et al. 2011), so allele-sharing among the Smallmouth Bass subspecies could be attributed to their recent evolutionary divergence. Alternatively, historic and repeated secondary contact among lineages may have been facilitated by natural processes. Some studies have posited an historic stream capture (Bishop 1995; Bonnet 2009) event between streams in the Arkansas River Basin and the White River drainage. These reports cite multiple shared taxa, including hellbenders (Cryptobranchus alleganiensis; Smith 1956), gastropods (Branson 1963), and stonerollers (Campostoma oligolepis; Matthews and Robison 1988), as evidence for faunal exchange. Such a drastic river diversion would likely have been caused by geological shifts (Heim and Howe 1963), perhaps encompassing an even broader area, including multiple rivers (Branson 1967). Admixture of White River populations with southwestern Missouri and northwestern Arkansas populations, as seen in our study, is consistent with this hypothesis. Wide variation in the amount and distribution of admixture within the Neosho Smallmouth Bass range, with some populations being assigned almost purely to one cluster and others showing substantial mixing, could also be explained by recent divergence and periodic stream capture.

We found morphological differentiation between the Neosho and Northern Smallmouth Bass, including differences in head length and a significant interaction 
between orbital length and subspecies native range. Although we found a significant association between subspecies and the number of soft dorsal fin rays, this trait was not diagnostic. Different growth patterns in head length and orbital length may be influenced by unique ecological pressures related to adaptive fitness. To understand whether the Smallmouth Bass subspecies are locally adapted, associations between environmental and genetic differentiation would need to be explored in future studies.

\section{Conclusions}

We increased our understanding of Smallmouth Bass population structure in the $\mathrm{CIH}$ and found more complex signatures of differentiation and admixture than previously reported (Stark and Echelle 1998). We expanded the findings of Taylor et al. (2018), whose analysis primarily focused on Neosho range rivers in southwestern Missouri and hatchery-stocked Northern Smallmouth Bass. We corroborated findings in Taylor et al. (Taylor et al. 2018) showing admixture of "Tennessee lake-strain" alleles in the Illinois River, explained by upstream invasion and subsequent introgressive hybridization following recent introduction of lake-strain fish into Lake Tenkiller. Our results did not support an intergrade zone in the White River system. Instead, we detected a unique genetic signature in the White River tributaries as well as previously undetected admixture between the White River and Neosho range.

More extensive phylogeographic investigation is needed to fully understand the diversity of Smallmouth Bass in the CIH. To attribute genetic structure patterns to contemporary hybridization via stocking or to natural secondary contact (i.e., stream capture) would require establishing timing and origin of intermixing in the Neosho range. 
The processes contributing to the complex population structure we detected in this study could be overshadowing historic levels of divergence between the Neosho and Northern Smallmouth Bass and therefore counteracting incipient speciation. Biologists and managers will require genome-level evolutionary analysis to further investigate divergence between these subspecies.

\section{Acknowledgments}

We thank the students, faculty, and staff at the University of Missouri, Arkansas Game and Fish Commission, Missouri Department of Conservation, and Arkansas Tech University who helped with sample collection. In particular, R. Horton of the Missouri Department of Conservation, J. Quinn of the Arkansas Game and Fish Commission, and C. Gagen at Arkansas Tech University, were essential for support, organization and sample collection. We thank K. Budd, J.J. Burkhart, M. Harris, K. Storey, and C. Titus for their assistance with data interpretation. Undergraduate researcher K. Sulkowski provided invaluable help with sample collection and DNA extraction. The Oklahoma Cooperative Fish and Wildlife Research Unit is a joint collaboration among U.S. Geological Survey, Oklahoma State University, the Oklahoma Department of Wildlife Conservation, the Wildlife Management Institute, and the U.S. Fish and Wildlife Service. Any use of trade, firm, or product names is for descriptive purposes only and does not imply endorsement by the U.S. Government. This project was supported financially by the Missouri Department of Conservation and conducted under the University of Missouri Animal Care and Use Permit \#8826. 


\section{References}

Addison J, Spencer S (1971) Preliminary evaluation of three strains of Largemouth Bass, Micropterus salmoides (Lacepede), stocked in ponds in south Alabama. Proc Annu Conf Southeast Assoc Game Fish Comm 25:366-374.

Avise JC, Pierce PC, Van Den Avyle MJ, Smith MH, Nelson WS, Asmussen MA (1997) Cytonuclear introgressive swamping and species turnover of bass after an introduction. J Hered 88:14-20.

Bagley JC, Mayden RL, Roe KJ, Holznagel W, Harris PM (2011) Congeneric phylogeographical sampling reveals polyphyly and novel biodiversity within the black basses (Centrarchidae: Micropterus). Biol J Linn Soc 104:346-363.

Bailey RM (1956) A revised list of the fishes of Iowa, with keys for identification. In: Harlan JR, Speaker EB (eds) Iowa fish and fishing. Des Moines, IA, pp 327-377

Barton NH (2001) The role of hybridization in evolution. Mol Ecol 10:551-568.

Bermingham E, Rohwer S, Freeman S, Wood C (1992) Vicariance biogeography in the Pleistocene and speciation in North American wood warblers: A test of Mengel's model. Proc Natl Acad Sci 89:6624-6628.

Bernatchez L, Wilson CC (1998) Comparative phylogeography of Nearctic and Palearctic fishes. Mol Ecol 7:431-452.

Berner D (2011) Size correction in biology: How reliable are approaches based on (common) principal component analysis? Oecologia 166:961-971.

Bishop P (1995) Drainage rearrangement by river capture, beheading and diversion. Prog Phys Geog 19:449-473.

Blanca MJ, Alarcón R, Arnau J, Bono R, Bendayan R (2017) Non-normal data: Is ANOVA still a valid option? Psicothema 29:552-557.

Bolnick DI, Near TJ (2005) Tempo of hybrid inviability in Centrarchid fishes (Teleostei: Centrarchidae). Evolution 59:1754 - 1767.

Bonnet S (2009) Shrinking and splitting of drainage basins in orogenic landscapes from the migration of the main drainage divide. Nat Geosci 2:766-771.

Borden WC, Krebs RA (2009) Phylogeography and postglacial dispersal of Smallmouth Bass (Micropterus dolomieu) into the Great Lakes. Can J Fish Aquat Sci:21422156. 
Boxrucker J, Echelle AA, Van Den Bussche RA (2003) Determining the degree of hybridization in the Smallmouth Bass population of Broken Bow Reservoir and the Mountain Fork River. In: Oklahoma Department of Wildlife Conservation, Oklahoma City, OK

Branson BA (1963) New mollusks from Oklahoma and their zoogeographical significance. Trans Kans Acad Sci 66:501-512.

Branson BA (1967) Fishes of the Neosho River system in Oklahoma. Am Midl Nat $78: 126-154$.

Brewer SK, Long JM (2015) Biology and ecology of Neosho Smallmouth Bass and the genetically distinct Ouachita lineage. In: Tringali MD, Long JM, Birdson TW, Allen MS (eds) Black bass diversity: Multidisciplinary science for conservation. Bethesda, MD, pp 281-295

Brewer SK, Orth DJ (2015) Smallmouth Bass Micropterus dolomieu Lacepede, 1802. In: Tringali MD, Long JM, Birdsong TW, Allen MS (eds) Black bass diversity: Multidisciplinary science for conservation. Bethesda, MD, pp 9-26

Carlander KD (1977) Handbook of freshwater fish biology, Volume 2. Ames, IA.

Colbourne JK, Neff BD, Wright JM, Gross MR (1996) DNA fingerprinting of Bluegill sunfish (Lepomis macrochirus) using (GT)n microsatellites and its potential for assessment of mating success. Can J Fish Aquat Sci 53:342-349.

Dudgeon D, Arthington AH, Gessner MO, Kawabata ZI, Knowler DJ, Lévêque C, Naiman RJ et al (2006) Freshwater biodiversity: Importance, threats, status and conservation challenges. Biol Rev 81:163-182.

Dyer RJ (2016) gstudio: tools related to the spatial analysis of genetic marker data. R package version 1.5.0.

Evanno G, Regnaut S, Goudet J (2005) Detecting the number of clusters of individuals using the software STRUCTURE: A simulation study. Mol Ecol 14:2611-2620.

Francis RM (2017) pophelper: an R package and web app to analyze and visualize population structure. Mol Ecol Resour 17:27-32.

Frankel GH (1974) Genetic conservation: Our evolutionary responsibility. Genetics 78:53-65.

Gharaei A (2012) Morphometric and meristic studies of snow trout Schizothorax zarudnyi (Nikolskii, 1897) as a threatened endemic fish. World J Fish Mar Sci 4:426-429. 
Gilbert CR (1998) Type catalogue of recent and fossil North American freshwater fishes: Families Cyprinidae, Catostomidae, Ictaluridae, Centrarchidae, and Elassomatidae. F1 Mus Nat Hist Spec Pub 1:1-284.

Hails RS, Morely K (2005) Genes invading new populations: A risk assessment perspective. Trends Ecol Evol 20:245-252.

Hale ML, Burg TM, Stevens TE (2012) Sampling for microsatellite-based population genetic studies: 25 to 30 individuals per population is enough to accurately estimate

allele frequencies. PLoS ONE 7: e45170.

Hansen TF, Houle D (2008) Measuring and comparing evolvability and constraint in multivariate characters. J Evol Biol 21:1201-1219.

Heim GE, Howe WB (1963) Pleistocene drainage and depositional history in northwestern Missouri. Trans Kans Acad Sci 66:378-392.

Hedrick PW (2001) Conservation genetics: Where are we now? Trends Ecol Evol 16:629-636.

Herdegen M, Alexander HJ, Babik W, Mavárez J, Breden F, Radwan J (2014) Population structure of guppies in north-eastern Venezuela, the area of putative incipient speciation. BMC Evol Biol 14:1-14.

Hoyt RD (1974) The effect of stocking on the meristic complement of the Neosho Smallmouth Bass. Proc Annu Conf Southeast Assoc Game Fish Comm 27:643652.

Hubbs CL, Bailey RM (1940) A revision of the black basses (Micropterus and Huro) with descriptions of four new forms. Mich Univ, Mus Zool, Misc Pub 48:1-49.

Ihssen PE, Brooke HE, Casselman JM, McGlade JM, Payne NR, Utter FM (1981) Stock identification: Materials and methods. Can J Fish Aquat Sci 38:1838-1855.

Jackson ZJ, Quist MC (2008) Growth standards for nine North American fish species. Fish Manag Ecol 15:107-118.

Jakobsson M, Rosenberg NA (2007) CLUMPP: A cluster matching and permutation program for dealing with label switching and multimodality in analysis of population structure. Bioinform 23:1801-1806. https://doi.org/10.1093/bioinformatics/btm233 
Janes JK, Miller JM, Dupuis JR, Malenfant RM, Gorrell JC, Cullingham CI, Andrew RL (2017) The $K=2$ conundrum. Mol Ecol 26:3594-3602.

Jennings MJ, Kampa JM, Hatzenbeler GR, Emmons EE (2005) Evaluation of supplemental walleye stocking in northern Wisconsin lakes. N Am J Fish Manage 25:1171-1178.

Johnson BM, Arlinghaus R, Martinez PJ (2009) Introduced species - are we doing all we can to stem the tide of illegal fish stocking? Fisheries 34:389-394.

Kalinowski ST (2005) HP-Rare: A computer program for performing rarefaction on measures of allelic diversity. Mol Ecol Notes 5:187-189.

Kassambara, A. (2019). ggpubr: ggplot2 based publication ready plots. R Package Version 0.2.1.

Kopelman NM, Mayzel J, Jakobsson M, Rosenberg NA, Mayrose I (2015) CLUMPAK: A program for identifying clustering models and packaging population structure inferences across K. Mol Ecol Resour 15:1179-1191.

Koppelman JB (1994) Hybridization between Smallmouth Bass, Micropterus dolomieu, and Spotted Bass, M. punctulatus, in the Missouri River System, Missouri. Copeia 1994:204-210.

Koppelman JB (2015) Black bass hybrids: A natural phenomenon in an unnatural world. In: Tringali MD, Long JM, Birdsong TW, Allen MS (eds) Black bass diversity: Multidisciplinary science for conservation. Bethesda, MD, pp 467-479

Li C, Gowan S, Anil A, Beck BH, Thongda W, Kucuktas H et al (2015) Discovery and validation of gene-linked diagnostic SNP markers for assessing hybridization between Largemouth Bass (Micropterus salmoides) and Florida Bass ( $M$. floridanus). Mol Ecol Resour 15:395-404.

Li YL, Liu JX (2018) StructureSelector: A web-based software to select and visualize the optimal number of clusters using multiple methods. Mol Ecol Resour 18:176-177.

Long JM, Allen MS, Porak WF, Suski CD (2015) A historical perspective of black bass management in the United States. In: Tringali MD, Long JM, Birdsong TW, Allen MS (eds) Black bass diversity: Multidisciplinary science for conservation. Bethesda, MD, pp 99-122

Longmire JL, Maltbie M, Baker RJ (1997) Use of "lysis buffer" in DNA isolation and its implications for museum collections. Occas pap Mus Tex Tech Univ 163:1-3. 
Lundberg JG, Kottelat M, Smith GR, Stiassny MLJ, Gill AC (2000) So many fishes, so little time: An overview of recent ichthyological discovery in continental waters. Ann Missouri Bot Gard 87:26-62.

Malloy TP, Van Den Bussche RA, Coughlin WD, Echelle AA (2000) Isolation and characterization of microsatellite loci in Smallmouth Bass Micropterus dolomieu (Teleostei: Centrarchidae), and cross-species amplification in Spotted Bass, $M$. punctulatus. Mol Ecol 9:1919-1952.

Matthews WJ, Robison HW (1988) The distribution of the fishes of Arkansas: A multivariate analysis. Copeia 2:358-374. https://doi.org/10.2307/1445876

Mayden RL (1988) Vicariance biogeography, parsimony, and evolution in North American freshwater fishes. Syst Biol 37:329-355.

McFadden D (1973) Conditional logit analysis of qualitative choice behavior. In: Zarembka P (ed) Frontiers in econometrics. New York, NY, pp 105-142

Meirmans PG, Van Tienderen PH (2004) GENOTYPE and GENODIVE: Two programs for the analysis of genetic diversity of sexual organisms. Mol Ecol Notes 4:792794.

Nigh TA, Schroeder WA (2002) Atlas of Missouri ecoregions. Missouri Department of Conservation: Jefferson City, MO

Pflieger WL, Fajen OF (1975) Natural hybridization between the Smallmouth Bass and Spotted Bass. In: Final report, Missouri Department of Conservation, federal aid in fish restoration, Project F-1-R-24, Study S-7. Jefferson City, MO

Pierce PC, Van Den Ayyle MJ (1997) Hybridization between introduced Spotted Bass and Smallmouth Bass in reservoirs. Trans Am Fish Soc 126:939-947.

Pinheiro J, Bates D, DebRoy S, Sarkar D, R Core Team (2018) nlme: Linear and nonlinear mixed effects models. R package version 3.1-137.

Pregler KC, Kanno Y, Rankin D, Coombs JA, Whiteley AR (2018) Characterizing genetic integrity of rear-edge trout populations in the southern Appalachians. Conserv Genet 19:1487-1503.

Pritchard JK, Stephens M, Donnelly P (2000) Inference of population structure using multilocus genotype data. Genetics 155:945-959.

Puebla O (2009) Ecological speciation in marine v. freshwater fishes. J Fish Biol 75:960996. 
Puechmaille SJ (2016) The program STRUCTURE does not reliably recover the correct population structure when sampling is uneven: Subsampling and new estimators alleviate the problem. Mol Ecol Resour 16:608-627.

R Core Team (2018) R: A language and environment for statistical computing. R

Foundation for Statistical Computing, Vienna, Austria.

Rahel FJ (2004) Unauthorized fish introductions: Fisheries management of the people, for the people, or by the people? In: Nickum MJ, Mazik PM, Nickum JG, MacKinlay DD (eds) Propagated fishes in resource management. Bethesda, MD, pp 431-444.

Raymond M, Rousset F (1995) GENEPOP (version 1.2): Population genetics software for exact tests and ecumenicism. J Hered 86:248-249.

Rehman FU, Rehman HU, Aman S, Aziz S, Shabir H, Majid A et al (2015) Morphometric and meristic analysis of Silver Carp (Hypophthalmichthys molitrix) from Tanda Dam, Distric Kohat, Pakistan. Glob Vet 15:82-92.

Rhymer JM, Simberloff D (1996) Extinction by hybridization and introgression. Ann Rev Ecol Evol Syst 27:83-109.

Robbins WH, MacCrimmon HR (1974) The black bass. In: Robbins WH, MacCrimmon HR (eds) America and overseas Sault St. Marie, Ontario, Canada, p 196.

Rousset F (2008) Genepop'007: A complete reimplementation of the Genepop software for Windows and Linux. Mol Ecol Resour 8:103-106.

Rundle HD, Nosil P (2005) Ecological speciation. Ecol Lett 8:336-352.

Scott WB, Crossman EJ (1973). Freshwater fishes of Canada. Ottawa, Canada. Retrieved from

Seyoum S, Barthel BL, Tringali MD, Davis MC, Schmitt SL, Bellotti PS, Porak WF (2013) Isolation and characterization of eighteen microsatellite loci for the Largemouth Bass, Micropterus salmoides, and cross amplification in congeneric species. Conserv Genet Resour 5:697-701.

Signorell A, Aho K, Alfons A, Anderegg N, Aragon T, Arppe A et al (2019) DescTools: Tools for descriptive statistics. R Package Version 0.99.28.

Smith HM (1956) Handbook of amphibians and reptiles of Kansas. Misc Pub Univ of Kans Mus of Nat Hist 9:1-356. 
Sneath PHA, Sokal RR (1973) In: Kennedy D, Park RB (eds) Numerical taxonomy: The principles and practice of numerical classification. San Francisco, CA, pp 1-573.

Snow JR (1975) Hatchery propagation of the black basses. In: Clepper H (ed) Black bass: Biology and management. Washington, D.C., pp 344-356.

Stahl G (1987) Genetic population structure of Atlantic Salmon. In: Ryman N, Utter FM (eds) Population genetics and fishery management. Seattle, WA, pp 121-135.

Stark WJ, Echelle AA (1998) Genetic structure and systematics of Smallmouth Bass, with emphasis on Interior Highlands populations. Trans Am Fish Soc 127:393416.

Stepien CA, Karsiotis SI, Sullivan TJ, Klymus KE (2017) Population genetic structure and comparative diversity of smallmouth bass Micropterus dolomieu: Congruent patterns from two genomes. J Fish Biol 90:2125-2147.

Taylor AT, Long JM, Schwemm MR, Brewer SK (2018) Hybridization and genetic structure of Neosho Smallmouth Bass in the Ozark Highlands. N Am J Fish Manage 38:1226-1240.

Taylor AT, Tringali MD, O'Rouke PM, Long JM (2018) Shoal Bass hybridization in the Chattahoochee River basin near Atlanta, Georgia. J Southeast Assoc Fish Wild Agcys 5:1-9.

Taylor AT, Long JM, Tringali MD, Barthel BL (2019) Conservation of black bass diversity: An emerging management paradigm. Fisheries 44:20-36.

Thorpe JE, Koonce JF (1981) Assessing and managing man's impact on fish genetic resources. Can J Fish Aquat Scis 38:1899-1907.

Turan C (1999) A note on the examination of morphometric differentiation among fish populations: The Truss system. Turk J Zool 23:259-263.

Valiere N (2002) GIMLET: A computer program for analyzing genetic individual identification data. Mol Ecol Notes 2:377-379.

Venables WN, Ripley BD (2002) Modern applied statistics with S. Fourth Edition. New York, NY. ISBN 0-387-95457-0.

Wang J (2017) The computer program Structure for assigning individuals to populations: Easy to use but easier to misuse. Mol Ecol Resour 17:981-990.

Ward RD, Woodwark M Skibinski DOF (1994) A comparison of genetic diversity levels in marine, freshwater, and anadromous fishes. J Fish Biol 44:213-232. 
Whitt GS, Childers WF, Wheat TE (1971) The inheritance of tissue specific lactate dehydrogenase isozymes in interspecific bass (Micropterus) hybrids. Biochem Genet 5:257-273. 


\section{Tables and Figures}

Table 3.1. Sampling sites for 838 Smallmouth and Spotted Bass. Tavern Creek is marked with "X"; we retained no samples from this site, and it is not mapped in Figure 3.1.

\begin{tabular}{|c|c|c|c|c|c|c|}
\hline Pop ID & Source & Site & River System & Noriginal & $N_{\text {Genetics }}$ & $N_{\text {Morphology }}$ \\
\hline \multicolumn{7}{|c|}{ Range: Neosho Smallmouth Bass } \\
\hline 1 & Center Creek & 1 & Arkansas Basin & 6 & 5 & 6 \\
\hline \multirow[t]{3}{*}{2} & Shoal Creek & 1 & Arkansas Basin & 8 & 3 & 6 \\
\hline & & 2 & & 9 & 8 & 9 \\
\hline & & 3 & & 24 & 20 & 15 \\
\hline 3 & Sycamore Creek & 1 & Arkansas Basin & 37 & 37 & -- \\
\hline 4 & Buffalo Creek & 1 & Arkansas Basin & 51 & 51 & -- \\
\hline \multirow[t]{2}{*}{5} & Indian Creek & 1 & Arkansas Basin & 26 & 21 & 26 \\
\hline & & 2 & & 9 & 9 & 8 \\
\hline \multirow[t]{3}{*}{6} & Big Sugar Creek & 1 & Arkansas Basin & 21 & 12 & 21 \\
\hline & & 2 & & 10 & 8 & 9 \\
\hline & & 3 & & 15 & 11 & -- \\
\hline 7 & Little Sugar Creek & 1 & Arkansas Basin & 26 & 14 & 26 \\
\hline \multirow[t]{3}{*}{8} & Elk River & 1 & Arkansas Basin & 24 & 19 & 19 \\
\hline & & 2 & & 23 & 14 & 21 \\
\hline & & 3 & & 49 & 49 & -- \\
\hline 9 & Honey Creek & 1 & Arkansas Basin & 44 & 44 & -- \\
\hline 10 & Spavinaw Creek & 1 & Arkansas Basin & 19 & 19 & -- \\
\hline \multirow[t]{4}{*}{11} & Illinois River & 1 & Arkansas Basin & 9 & 7 & 1 \\
\hline & & 2 & & 20 & 20 & -- \\
\hline & & 3 & & 6 & 6 & -- \\
\hline & & 4 & & 34 & 34 & -- \\
\hline \multirow[t]{2}{*}{12} & Baron Fork & 1 & Arkansas Basin & 18 & 18 & -- \\
\hline & & 2 & & 29 & 29 & -- \\
\hline \multirow[t]{3}{*}{13} & Caney Creek & 1 & Arkansas Basin & 22 & 22 & -- \\
\hline & & 2 & & 23 & 23 & -- \\
\hline & & 3 & & 33 & 33 & -- \\
\hline 14 & Lee Creek & 1 & Arkansas Basin & 20 & 20 & -- \\
\hline 15 & Mulberry River & 1 & Arkansas Basin & 8 & 8 & 8 \\
\hline 16 & Big Piney Creek, AR & 1 & Arkansas Basin & 17 & 17 & 7 \\
\hline \multirow[t]{3}{*}{17} & Illinois Bayou & 1 & Arkansas Basin & 30 & 30 & -- \\
\hline & & 2 & & 5 & 5 & 2 \\
\hline & & & Total Neosho & 675 & 616 & 184 \\
\hline \multicolumn{7}{|c|}{ Range: Northern Smallmouth Bass } \\
\hline 18 & Genoa Hatchery & 1 & Hatchery & 20 & 20 & -- \\
\hline 19 & Meramec River & 1 & Missouri River & 13 & 8 & 13 \\
\hline 20 & Stockton Lake & 1 & Missouri River & 10 & 10 & 10 \\
\hline \multirow[t]{2}{*}{21} & Big Piney River, MO & 1 & Missouri River & 5 & 4 & 5 \\
\hline & & 2 & Missouri River & 21 & 20 & 16 \\
\hline$N A^{\mathrm{X}}$ & Tavern Creek $^{\mathbf{X}}$ & $N A^{\mathbf{x}}$ & Missouri River $\mathbf{x}$ & 5 & -- & 5 \\
\hline 22 & Tablerock Lake & 1 & White River & 20 & 19 & 16 \\
\hline 23 & Crooked Creek & 1 & White River & 13 & 13 & -- \\
\hline 24 & White River & 1 & White River & 3 & 3 & -- \\
\hline \multirow[t]{2}{*}{25} & Skiatook Lake & 1 & Hatchery & 20 & 20 & -- \\
\hline & & & Total Northern & 130 & 117 & 65 \\
\hline 26 & Spotted Bass & 1 & Arkansas Basin & 17 & 17 & -- \\
\hline 27 & Spotted Bass & 1 & Arkansas Basin & 4 & 4 & -- \\
\hline \multirow[t]{3}{*}{28} & Spotted Bass & 1 & Arkansas Basin & 12 & 12 & -- \\
\hline & & & Total Spotted & 33 & 33 & -- \\
\hline & & & Total Overall & 838 & 766 & 249 \\
\hline
\end{tabular}


Table 3.2. Raw and adjusted trait means of standard length (SL), orbital length (OL), head length (HL), and body depth (BD) for Neosho and Northern Smallmouth Bass samples assessed by a) taxonomic range, and b) genetic assignment. Trait means were back-transformed to provide values in millimeters. ANCOVA results are based on coefficients calculated from log-transformed trait values and include $F$-statistics and $p$ values for interactions (int) and categories (cat; taxonomic range or genetic assignment)

\begin{tabular}{|c|c|c|c|c|c|c|c|c|}
\hline \multirow[b]{2}{*}{ Trait } & \multicolumn{2}{|c|}{ Raw Mean (mm) } & \multicolumn{2}{|c|}{ Adjusted Mean (mm) } & \multicolumn{4}{|c|}{ ANCOVA Results } \\
\hline & Neosho & Northern & Neosho & Northern & $F_{\text {int }}$ & $F_{\text {cat }}$ & $p_{\text {int }}$ & $p_{\text {cat }}$ \\
\hline \multicolumn{9}{|c|}{ a. Taxonomic Range } \\
\hline SL & 234.864 & 246.726 & 232.274 & 238.232 & 1.200 & 2.100 & 0.271 & 0.166 \\
\hline $\mathrm{OL}$ & 14.135 & 14.474 & 14.060 & 14.322 & 30.628 & 0.110 & $<0.001$ & 0.744 \\
\hline $\mathrm{HL}$ & 79.966 & 76.463 & 79.616 & 73.282 & 0.220 & 14.070 & 0.636 & 0.001 \\
\hline $\mathrm{BD}$ & 66.803 & 68.340 & 65.766 & 65.013 & 1.130 & 0.160 & 0.289 & 0.696 \\
\hline \multicolumn{9}{|c|}{ b. Genetic Assignment } \\
\hline SL & 206.588 & 244.809 & 232.809 & 234.963 & 1.800 & 0.300 & 0.181 & 0.620 \\
\hline $\mathrm{OL}$ & 13.925 & 14.721 & 14.521 & 14.488 & 2.041 & 0.100 & 0.158 & 0.756 \\
\hline $\mathrm{HL}$ & 71.921 & 78.259 & 79.433 & 74.645 & 0.120 & 3.140 & 0.728 & 0.097 \\
\hline $\mathrm{BD}$ & 58.026 & 68.065 & 66.834 & 63.973 & 0.160 & 0.180 & 0.693 & 0.681 \\
\hline
\end{tabular}




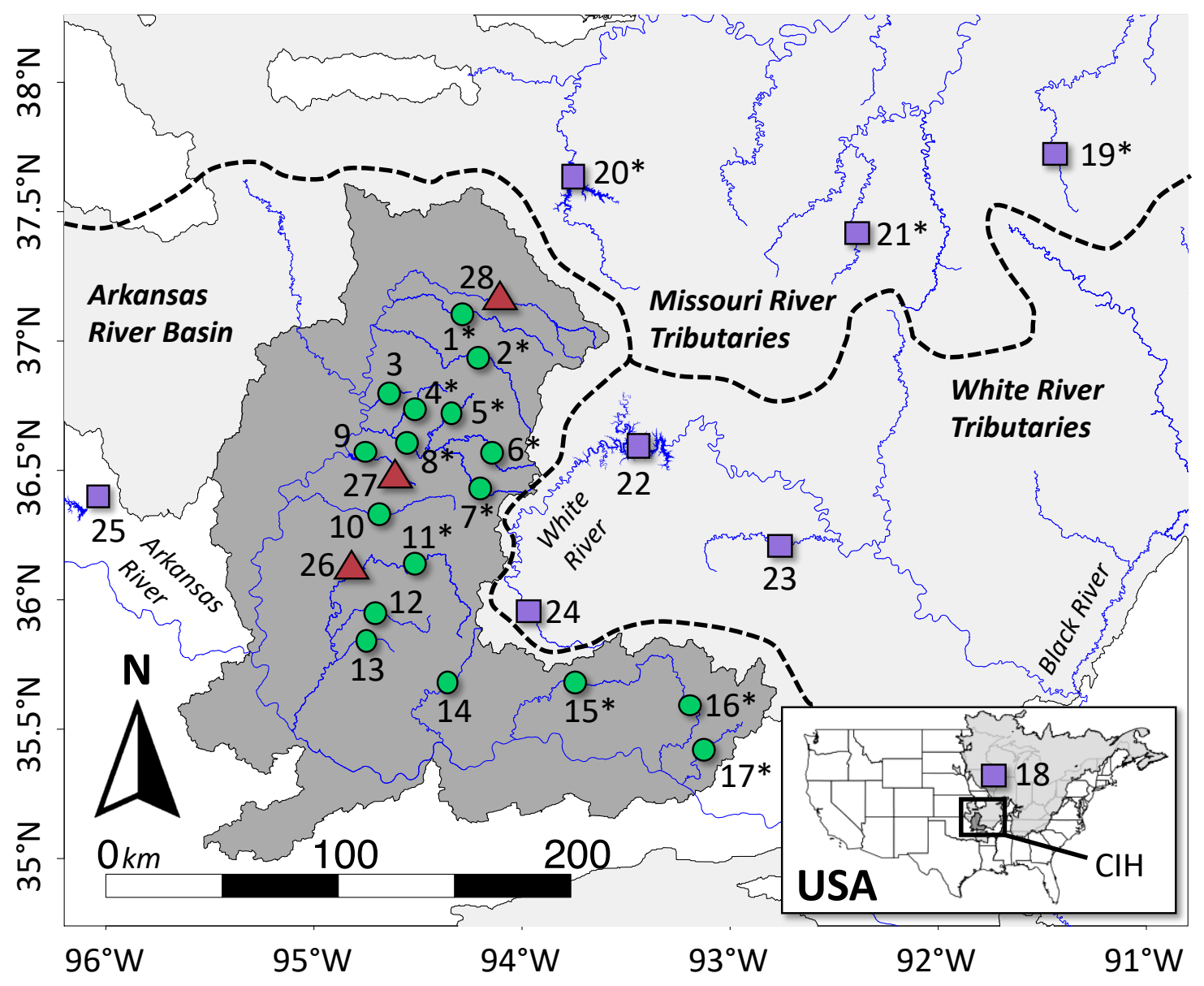

Figure 3.1. Subspecies distributions and sampling sites within the Central Interior Highlands $(\mathrm{CIH})$. Neosho Smallmouth Bass distribution is shaded in dark grey with populations as green circles; Northern Smallmouth Bass distribution is shaded in light grey with populations as purple squares; Spotted Bass populations are shown as red triangles. Population numbering follows "POP ID" in Table 3.1. Populations denoted with "*" indicate populations from which we collected morphological data. Dotted black lines delineate three major river systems represented in the $\mathrm{CIH}$, which are labeled in bold. The lower right inset shows the full distribution of Northern Smallmouth Bass (light grey) and Neosho Smallmouth Bass (dark grey) in the USA and outlines the CIH. 


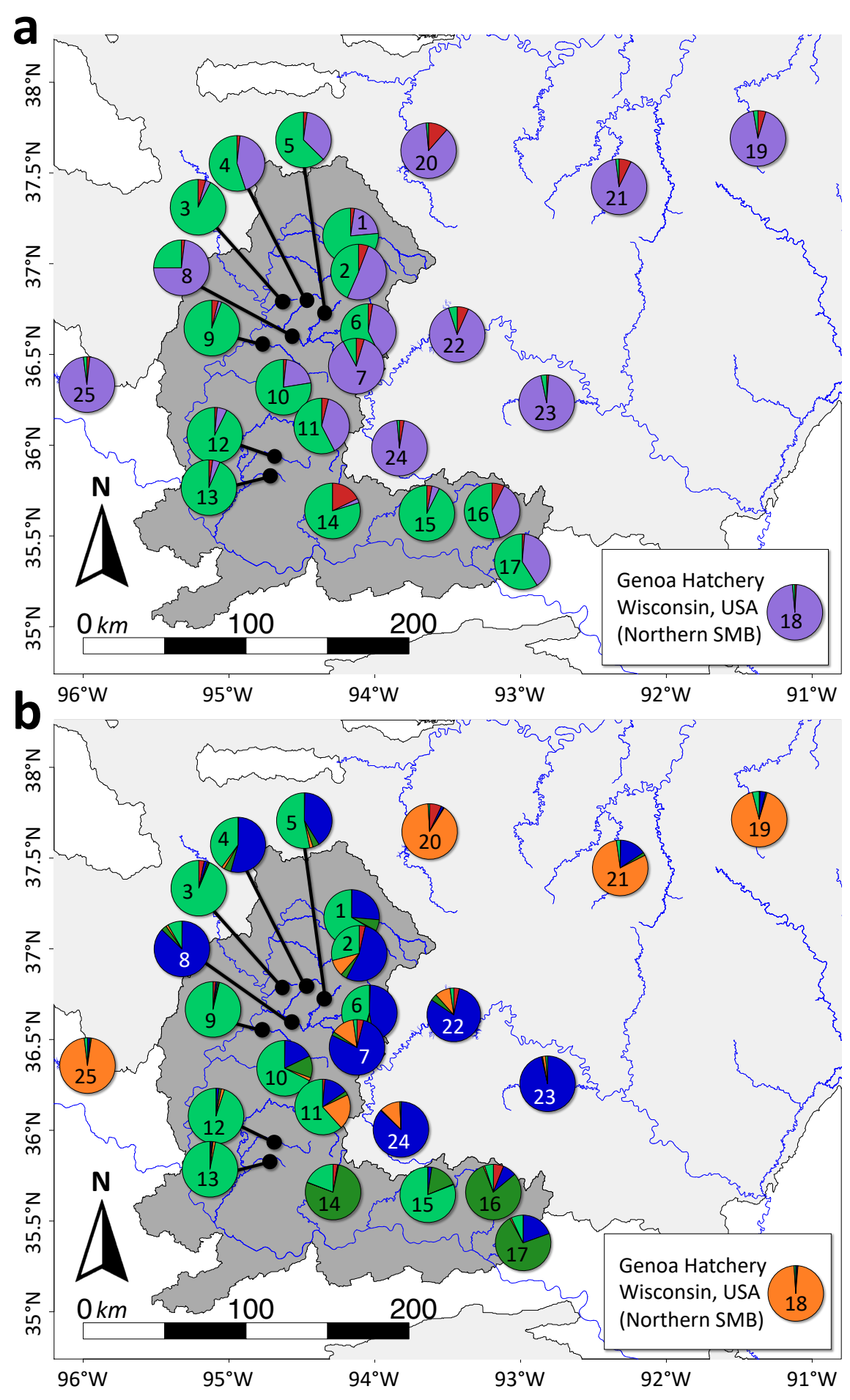

Figure 3.2. Geographic distribution of cluster assignments for Smallmouth Bass. Individual charts show average membership coefficients of 25 Smallmouth Bass populations to either (a) $K=3$ major clusters based on Default Parameters, or (b) $K=5$ major clusters based on Wang Parameters. Genoa Hatchery, Wisconsin (Population 18), is shown in the lower right of each panel. 

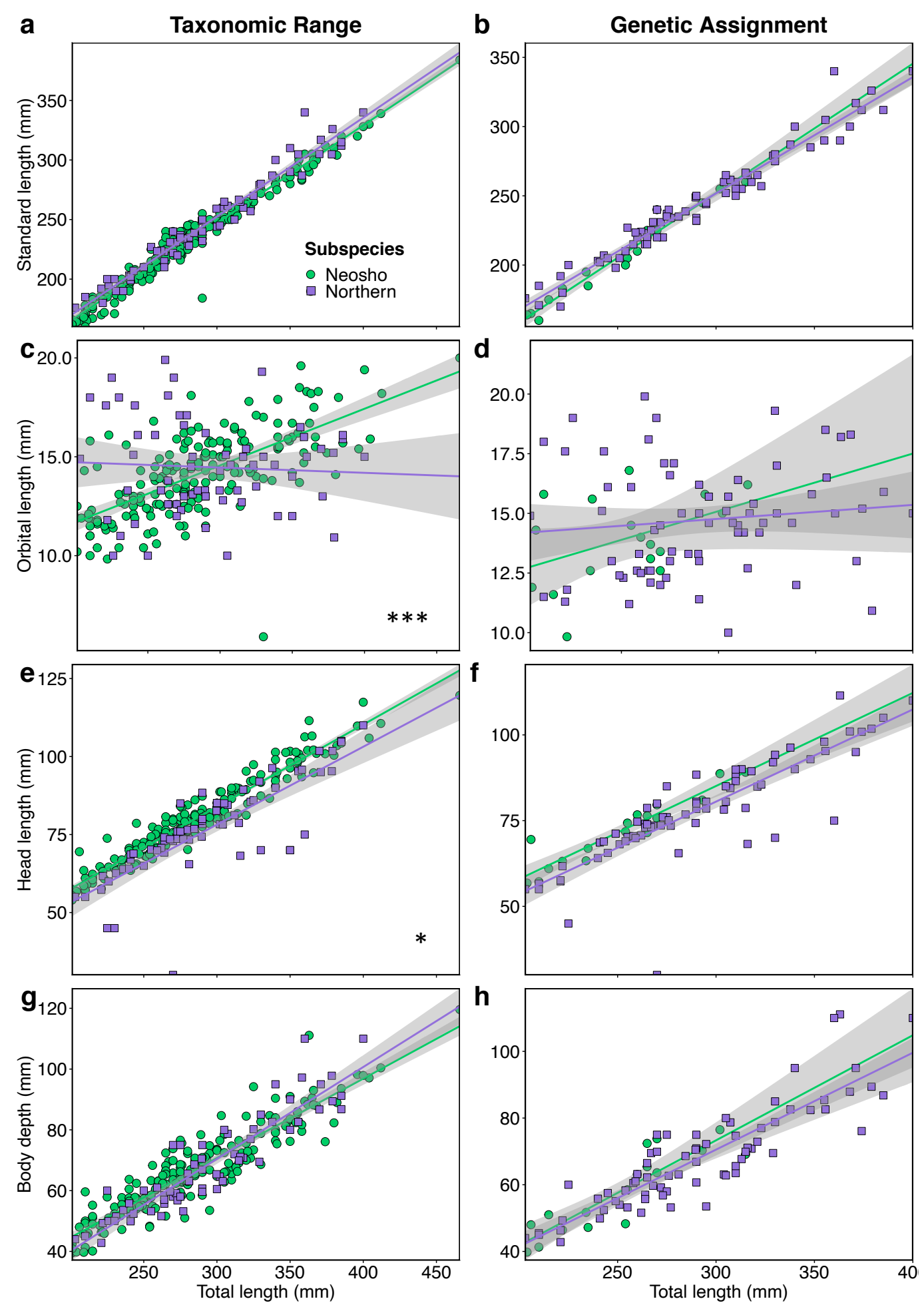

Figure 3.3. ANCOVA for four morphometric traits: standard length (a and b), orbital length (c and d), head length (e and f), and body depth ( $g$ and $h$ ) evaluated by range of collection (left column) and by genetic assignment (right column). Comparisons resulting in a significant interaction between category and trait or a significant difference between subspecies' adjusted trait means are marked with $* * *(p<0.001)$ or $*(p<0.05)$. 


\title{
CHAPTER 4
}

\section{Lineage diversification, local adaptation, and historic and anthropogenic secondary contact have shaped Smallmouth Bass (Micropterus dolomieu) diversity in the Central Interior Highlands}

Joe C. Gunn ${ }^{1}$, Leah K. Berkman², Jeff Koppelman², Andrew T. Taylor ${ }^{3}$, Shannon Brewer $^{4}$, James M. Long ${ }^{4}$, Lori S. Eggert ${ }^{1}$

${ }^{1}$ Division of Biological Sciences, University of Missouri, 226 Tucker Hall, Columbia, MO 65211, USA, ORCID: 0000-0001-6916-8678

${ }^{2}$ Missouri Department of Conservation, 3500 E. Gans Rd. Columbia, MO 65201, USA

${ }^{3}$ Department of Natural Resource Ecology and Management, Oklahoma State University, Stillwater, Oklahoma 74078, USA

${ }^{4}$ U.S. Geological Survey, Oklahoma Cooperative Fish and Wildlife Research Unit, Department of Natural Resource Ecology and Management, Oklahoma State University, Stillwater, Oklahoma 74078, USA

\begin{abstract}
Genomic technologies allow us to investigate eco-evolutionary patterns and their causative mechanisms in rare, non-model taxa at risk of local extinction. The Neosho Smallmouth Bass (Micropterus dolomieu velox) is a genetically and morphologically distinct subspecies along with the more widely distributed Northern Smallmouth Bass (M. d. dolomieu). Previous studies have detected heterogenous admixture among these subspecies, which may erode diversity, undermine adaptive genome complexes, and decrease fitness. Thus, it is critical to quantify diversification and local adaptation to identify units of high conservation value. We sought to assess: 1) divergence, 2) local adaptation, and 3) the extent and origins of admixture, whether biogeographic or anthropogenic, among Smallmouth Bass populations in the Central Interior Highlands of the USA. We conducted population genomic analyses across the Neosho and Northern
\end{abstract}


subspecies' ranges with 50,828 SNPs obtained through ddRADseq. The subspecies formed two monophyletic groups with 100\% bootstrap support; we identified four lineages and nine distinct populations within subspecies. We discovered 29 SNPs under diversifying selection in the Neosho range, suggesting some populations are locally adapted to environmental conditions. The Illinois River system and the Illinois Bayou and Big Piney Creek, AR streams were admixed via recent asymmetric secondary contact, consistent with the hypothesis of anthropogenic introduction. The Elk River and tributaries of the upper Arkansas River Basin were likely admixed via more complex combinations of ancient processes (e.g., stream capture) and recent asymmetric secondary contact. We demonstrate these subspecies are independently evolving lineages with a complex history of natural and anthropogenic admixture, information that will be vital in updating conservation and management practices to preserve diversity in the Smallmouth Bass.

\section{Introduction}

Global rates of species die-off, largely due to human activity and climate change, continue to climb on a scale that warrants the declaration of Earth's sixth mass extinction (Ceballos et al. 2017; Kuipers et al. 2019). The potential ecosystem-level consequences of these prevailing trends are dire; ecosystem stability and function depend on the interconnected ecological roles-e.g., predation, competition, mutualisms, nutrient cycling _ of native, locally adapted lineages (Pimm and Raven 2000; Rovito et al. 2009;

De Meester et al. 2016). Intensive efforts to quantify biodiversity are necessary to understand the resiliency of species to disturbance. Even more diligence is required to 
characterize the stochastic and anthropogenic forces contributing to population changes in these species so they can be managed for conservation.

The first step to conserving at-risk taxa is to identify them, which is challenging if they cannot be distinguished morphologically, perhaps due to crypsis or convergence under some shared selection pressures in their respective habitats (Culver et al. 1995; Schluter 1996; Culver and Pipan 2009). Species thought to occupy large geographic ranges may actually be made up of small, diverging populations with locally high fitness under unique conditions (Bickford et al. 2007; Funk et al. 2012; Niemiller et al. 2012). Even when evolutionarily unique groups may exist, genetic variation at the scale of the whole species distribution spans multiple hierarchical levels, from major lineages, to metapopulations, to populations, to pedigrees, to individuals (Lawson 2013). Classifying any of these groups as worthy of protection is difficult, often politically motivated, and controversial.

Once distinct taxa are recognized, it becomes imperative to understand both the processes driving divergence and the homogenizing forces that may lead to admixture or complete lineage fusion (Jansson and Dynesius 2002; Garrick et al. 2019). Random genetic drift and natural selection under varying environmental constraints, leading to locally adapted phenotypes, will diversify allopatric populations (Lande 1976). However, if distinct populations become connected and mating is not restricted by reproductive barriers, they will be vulnerable to genomic homogenization through gene flow (Allendorf et al. 2010). Such "genome collisions" (Springer and Gompert 2020) occur naturally as the climate and physical landscape shift and species distributions ebb and flow in response, sometimes creating dynamic hybrid zones where individuals may 
acquire novel, adaptive allele combinations (reviewed in Arnold and Martin 2010). In these cases, hybridization and subsequent introgression is an important contributor to the evolutionary process, either by promoting speciation through reinforcement or generating an entirely new homoploid species (Servedio and Noor 2003; Mavárez and Linares 2008). However, continuous hybridization over multiple generations can also reduce diversity through destruction of adaptive linkage disequilibria (Moyle et al. 1986; Altukhov and Salmenkova 1987), genetic swamping (Rhymer and Simberloff 1996; Hasselman et al. 2014), or, potentially, extinction of entire lineages (Todesco et al. 2016). Range-wide genetic diversity of the Smallmouth Bass (Micropterus dolomieu), a North American endemic freshwater fish in the family Centrarchidae, reflects patterns of hierarchical population structure despite some interconnectivity within drainages. This apex predator (Scott and Crossman 1973) is one of the most economically valuable sport fish worldwide, so understanding the evolutionary processes that have generated these patterns have been prioritized by conservationists (Stark and Echelle 1998; Stepien et al. 2007, 2017; Taylor et al. 2018, 2019; Euclide et al. 2020; Gunn et al. 2020). In particular, the populations in the southwestern edge of the species distribution in the Central Interior Highlands (CIH) remain understudied. Currently, two subspecies are recognized in the ecoregion: the Neosho Smallmouth Bass (M. d. velox), which is restricted to tributaries of the Arkansas River Basin, and the Northern Smallmouth Bass (M. d. dolomieu), which occupies the adjacent Missouri River and White River watersheds. However, as many as five distinct genetic clusters have been found across both subspecies, with one in the Arkansas River Basin (the Neosho Smallmouth Bass), one in each of the Missouri and White River drainages (the Northern Smallmouth Bass; Gunn et al. 2020), and potentially 
two other allopatric lineages in the Ouachita River and Red River Basins (the unnamed “Ouachita Smallmouth Bass;” Stark and Echelle 1998; Long et al. 2020).

It is not surprising that Smallmouth Bass exhibit more genetic structure in the CIH, a known endemism hotspot (Soltis et al. 2006) for freshwater fishes (Cross et al. 1986; McAllister et al. 1986; Robison 1986; Lundberg et al. 2010), than other parts of their range. Many researchers agree that vicariant divergence and subsequent allopatric speciation are responsible for lineage diversification of fishes in the ecoregion, including Smallmouth Bass (Mayden 1985). Further, different ecological conditions within the geographic ranges of the diverged lineages, perhaps involving prey availability, temperature, and hydrological parameters, may have led to specific adaptations.

To further confound the phylogeography of the region, some streams within the native range of the Neosho Smallmouth Bass contain fish that show signatures of substantial admixture either with the White River Northern Smallmouth Bass cluster or with a distinct hatchery lineage (Gunn et al. 2020). This admixture may be incomplete lineage sorting or may be indicative of an ancient migration event facilitated by previously connected stream systems (Branson 1963). Alternatively, it may be driven by hybridization as a consequence of recent introductions. Smallmouth Bass face the contemporary risk of anthropogenic stocking. As a prized game fish, Smallmouth Bass are frequently stocked outside their native range to fuel the angling industry (Robbins and MacCrimmon 1974; Stark and Echelle 1998; Brewer and Orth 2015). They may also be moved among rivers illegally by private citizens.

Because of stocking, admixture is becoming increasingly common where it would otherwise be geographically impossible (Allendorf et al. 2010), in some cases bringing 
long-isolated lineages into secondary contact and facilitating intermixing. Multiple studies (Eldridge and Naish 2007; Hansen et al. 2009; Miller et al. 2012; Valiquette et al. 2014) have documented instances of high admixture and introgression in fish populations after human-mediated introductions. In a few cases, the genetic integrity of the native population has been completely undermined (e.g., Hansen and Mensberg 2009; Perrier et al. 2011). Decreased fitness after non-native species introductions is now one of the leading reasons for global biodiversity loss (Seehausen et al. 2008). This is especially problematic in black bass species. The deleterious effects of non-native black bass introductions into the relatively small native ranges of congeners are known (Koppelman 2015), but there has been a relatively lax management response to date (Jackson 2002).

Emerging genomic sequencing technologies have given us unprecedented insights into previously undetected diversity and its mediating forces, i.e., natural selection and gene flow. Genomic methods are superior to microsatellites and other genetic markers in computing population-level metrics (Väli et al. 2008; Thrasher et al. 2018; Lemopoulos et al. 2019), because they provide a much higher volume of data encompassing variation across the whole genome. They can help to make inferences about diversification, local adaptation, and intermixing and by revealing specific molecular signatures across the genome (e.g., Portik et al. 2017; Ebersbach et al. 2020). Reduced-representation methods, such as Restriction Enzyme Associated DNA sequencing (RADseq; Baird et al. 2008) and ddRADseq (Peterson et al. 2012), open the door for studying non-model organisms (Davey and Blaxter 2010; Ellegren 2014) by targeting random but homologous restriction sites throughout the genome (Andrews et al. 2016). We can now use thousands to 
millions of DNA markers, paired with known information on distribution and behavior, to answer questions about evolutionary history and lineage diversification in wild species.

Growing evidence of admixture within endemic Smallmouth Bass has given urgency to understanding the forces shaping its evolution in the CIH. With genomic tools, we have the statistical power to resolve the relationship between the Smallmouth Bass subspecies and to glean valuable information about their demographic history to understand whether population genomic patterns have been driven by natural or anthropogenic forces over both evolutionary and ecological timeframes. We harnessed genomic data to address multiple aspects of Smallmouth Bass evolutionary history, incorporating a demographic model-testing framework to assess alternative scenarios of lineage divergence, local adaptation, and admixture. We sequenced individuals of both the Neosho and Northern Smallmouth Bass subspecies from streams throughout the $\mathrm{CIH}$ using ddRADseq to 1) resolve the diversification of lineages in the species with population structure and phylogenetic methods; 2) to investigate the role, if any, of genomic variation in local adaptation; and 3) to infer the origins, extent, and timing of admixture between and within the subspecies using a demographic model-testing framework.

\section{Materials and Methods}

\section{Sample Collection and Genomic DNA Preparation}

We obtained 91 Smallmouth Bass (Micropterus dolomieu) samples, representing the Neosho Smallmouth Bass (M. d. velox; $N=66)$ and Northern Smallmouth Bass (M. $d$. dolomieu; $N=20$ ), from multiple sites throughout the Arkansas River Basin (ARB), White 
River drainage (WRD), and tributaries of the Missouri River (MRT), to encompass the putative native ranges of the two subspecies in Central Interior Highlands $(\mathrm{CIH}$; Figure 4.1a; Table 4.1; Gunn et al. 2020). We additionally included samples from Skiatook Lake (M. d. dolomieu; $N=5$; LAKE), an impoundment in northeastern Oklahoma situated outside the native range of Smallmouth Bass that was stocked with a hatchery-reared strain of Northern Smallmouth Bass colloquially known as "Tennessee lake-strain" sourced from the Cumberland River drainage. We used four Spotted Bass ( $M$. punctulatus) from the ARB as an outgroup for phylogenomic comparison (Table 4.1).

We extracted genomic DNA ( $g$ DNA) from fin clips using the Animal Tissue protocol of the DNeasy Blood and Tissue kit (QIAGEN, Germantown, MD), including addition of $4 \mu \mathrm{L}$ RNase-A per sample. We verified non-degraded, high molecular weight DNA on a $1.2 \%$ agarose gel. Samples were diluted to $\sim 20 \mathrm{ng} / \mu \mathrm{L}$ with $\mathrm{ddH}_{2} \mathrm{O}$, arranged on a 96-well plate in $50 \mu \mathrm{L}(\sim 100 \mu \mathrm{g}$ gDNA $)$ aliquots and stored at $-20^{\circ} \mathrm{C}$ before library preparation. We included a single, no-DNA negative control sample.

\section{Library Preparation and Sequencing}

Library preparation, sequencing, and initial bioinformatic processing for double digest RAD-seq were completed at Floragenex, Inc. (Eugene, OR) according to a modified version of the Sequence-based Genotyping protocol for lettuce outlined in Truong et al. (2012) For the modified protocol, approximately 500ng genomic DNA was digested with $P s t I$ and $M s e I$ at $65^{\circ} \mathrm{C}$ for 1 hour, followed by ligation of paired-end P5 Pst I and AFLP $M s e \mathrm{I}$ adaptors at $37^{\circ} \mathrm{C}$ for 3 hours. Unique, 5-base pair (bp) barcodes were included in the P5 PstI adaptor for individual sample identification. PCR was 
performed using the parameters listed in Truong et al. (2012), but in deviation from this protocol, all samples were pooled and sequenced with 1X95bp chemistry on a single lane of the Illumina HiSeq 4000.

\section{Bioinformatic Processing}

Sequenced reads (total 1.07 billion, mean-per-sample 11.21 million) were prefiltered before clustering to 1) remove reads containing adaptor sequences and 2) remove reads with missing or incorrect nucleotides in the $5 \mathrm{bp}$ barcodes. Resulting reads were demultiplexed and clustered in SEED (Bao et al. 2011). At the time of sequence processing, we did not know of a high quality, publicly available reference genome for a species closely related to the Smallmouth Bass. Thus, clusters from one sample with a high number of reads passing quality filters (“AR21," Neosho Smallmouth Bass, Sampling ID 17, Mulberry River; Table 4.1; Figure 4.1), were used to assemble a de novo reference sequence with de Bruijn graphs in VELVET v.1.2.10 (Zerbino and Birney 2008). Clusters were aligned to the de novo reference using BOWTIE v.1.1.1 (Langmead et al. 2009) and BwA v.0.6.1 (Li and Durbin 2009). The final assembly contained $\sim 12.86$ million reads clustered into 240,085 RAD kmers, with an average of $59.2 \%$ of kmers aligning to the de novo reference.

\section{SNP Discovery and Filtering}

Results from clustering alignment were processed into RAD kmers (95bp sequences) in SAMTOOLS v.0.1.16 ( $\mathrm{Li}$ et al. 2009), and single nucleotide polymorphisms (SNPs) were called using the Unified Genotyper within the Genome Analysis Tool Kit 
workflow (GATK; Depristo et al. 2011). The resulting dataset (127,429 SNPs) was converted to variant call format (VCF). Subsequent data filtering and sub-setting were conducted in VCFTOOLS v.0.1.16 (Danecek et al. 2011) to prepare for population genomic analyses.

Variants were initially filtered based on individual read depth such that only sequences with a minimum of $15 \mathrm{X}$ coverage were kept for downstream analyses. We removed individual samples $(N=3)$ from the dataset that had greater than $20 \%$ missing genotype calls across SNPs (Figure A2.1). We then removed SNPs with a phred quality score less than 20 and those with greater than $20 \%$ missing genotype calls across samples. To reduce the likelihood of linkage between nearby variants, we thinned RAD kmers to retain a single, randomly selected SNP. At this point, the full, non-thinned dataset (127,023 SNPs) was set aside for downstream analyses requiring multiple SNPs per RAD kmer to increase computation power.

After thinning, we removed any remaining SNPs with a minor allele count of two or less (equivalent to a minor allele frequency of $\sim 0.011$ ). We used the VariantsToTable function within the GATK software package to create a SNP table, with which we computed genotype frequencies across samples and SNPs in $R$ v.4.0.2 (R Core Team 2018). To reduce bias due to gene duplication, which is known to have occurred on the fish phylogeny (McKinney et al. 2017), we eliminated potential paralogs by omitting SNPs that were heterozygous in greater than $45 \%$ of samples. The final dataset $(N=92)$ contained 50,828 SNPs for population genomic analysis. 


\section{Lineage Divergence}

After filtering, we screened the full dataset for individuals of putative admixed ancestry, i.e., those of interspecific (Smallmouth Bass X Spotted Bass) or intraspecific (Neosho X Northern Smallmouth Bass) hybrid origin. This step was taken to limit potential allele-sharing bias in our downstream assessment of lineage diversification, which has been shown to be important in phylogenomic resolution (Kim et al. 2021). Our full VCF file was converted to browser extensible data (BED) format in a high-contig build of PLINK v.1.90 (Chang et al. 2015). We estimated ancestry proportions $(q)$ for individual fish in the program ADMIXTURE v.1.3.0 (Alexander et al. 2009). We inferred population structure by testing $K=1-20$ possible clusters (the number of stream sites represented in our study plus one additional cluster for the Spotted Bass outgroup). We determined the optimal number of clusters by running a 10-fold cross-validation procedure and choosing the value with the lowest resulting cross-validation error. We used very stringent criteria to determine pure or admixed origin: individuals were considered putatively pure if $q \geq 0.95$ for any one inferred cluster at the optimal $K$. Among fish of putative admixed origin, one was found to be a likely hybrid with Spotted Bass and was removed from further analyses. The full dataset was separated into two subsets, one with individuals meeting our $q$ value criteria for putative pure genomic origin (" $p$-Pure") and one with putative admixed fish (" $p$-Admixed").

We used the $p$-Pure dataset to investigate the phylogenomic relationship between Spotted Bass and Smallmouth Bass and to detect lineage divergence within the Smallmouth Bass. We assessed population structure using the program ADMIXTURE, testing $K=1-20$ possible clusters and running a 10 -fold cross-validation procedure to 
obtain the optimal number of $K$. We then constructed a phylogenomic tree for all samples using maximum likelihood methods in the SNPHYLO (Lee et al. 2014) pipeline, which combines filtering steps to account for linkage disequilibrium and minor allele frequency thresholds (Zheng et al. 2012), multiple sequence alignment of concatenated SNPs (Edgar 2004), maximum likelihood-based inference (Felsenstein 1989), and bootstrapping (Schliep 2011). We ran 10,000 bootstrap replicates (-b) using Spotted Bass as an outgroup (-o) and setting a linkage disequilibrium threshold $(-l)$ of 0.1 .

As suggested in Lee et al. (2014), we complemented SNPHYLO with a parallel bootstrap analysis in PHYML v.3.0 (Guindon et al. 2010). PHYML provides the added function of AIC and BIC model comparison (Burnham and Anderson 2002) to identify the best-fitting substitution model for the data. We carried out 1000 bootstrap replicates for five candidate models: 1) the General Time Reversible (GTR), 2) GTR + Discrete Gamma distribution $(G), 3)$ GTR + Invariable Sites (I), 4) GTR $+I+G$, and 5) TN93. The model with the lowest AIC and BIC estimates was selected for tree building. Consensus trees for both SNPHYLO and PHYML were generated and compared in FigTREE v.1.4.2 (Rambaut 2010). Major evolutionary lineages were defined based on the presence of distinct population clusters and phylogenomic monophyly.

\section{Population Discovery}

To delimit populations in the $p$-Pure and $p$-Admixed groups, relationships among Smallmouth Bass individuals in both groups were examined at a finer resolution in FINERADSTRUCTURE v 0.3.2 (Malinsky et al. 2018), a derivation of FINESTRUCTURE (Lawson et al. 2012). We utilized our full, non-thinned SNP dataset and concatenated 
SNPs on the same RAD kmer to form haplotypes using the hapsFromVCF function in the RADPAINTER package (Malinsky et al. 2018). We calculated co-ancestry matrices for the p-Pure and $p$-Admixed groups using a Markov Chain Monte Carlo (MCMC) clustering algorithm with 100,000 burn-in steps $(-x), 100,000$ MCMC iterations (-y), and thinning ($z$ ) every 1,000 iterations. We used a full hill-climbing tree-building method to construct trees, running 10,000 iterations $(-x)$, providing no value for the initialization parameter ($T)$. Results for co-ancestry matrices and best trees were generated using the $R$ scripts FinestructureLibrary.R and findRADstructurePlot.R (Malinsky et al. 2018). Individuals were collapsed into populations if they formed blocks of high co-ancestry along the diagonal of the co-ancestry matrix and which were confirmed to be monophyletic at deeper nodes in the tree.

\section{Local Adaptation}

We tested for genomic signatures of local adaptation in inferred Smallmouth Bass populations by scanning our SNP dataset for outlier SNPs with high (diversifying selection) or low (balancing selection) $F_{\mathrm{STS}}$. SNPs under significant diversifying selection may fall on or near functional genes in the genome and may contribute to phenotypic adaptation to certain environmental conditions. Outlier $F_{\mathrm{ST}}$ methods are used frequently in population genomic studies (Flanagan and Jones 2017) but may be prone to false positives, particularly when populations are highly structured (Nei and Maruyama 1975; Robertson 1975; Jost 2008; Excoffier et al. 2009; Jakobsson et al. 2013). We ameliorated the potential for spurious results by using multiple programs that have different underlying statistical models and consolidated outliers that were shared across analyses. 
We employed two programs, BAYESCAN (Foll and Gaggiotti 2008) and PCADAPT (Luu et al. 2017), to search for SNPs with outlier $F_{\mathrm{ST}}$. The former program uses a Bayesian model-based framework to assign posterior probabilities to candidate SNPs, whereas the latter uses a multivariate frequentist approach. Additionally, we conducted genome scans hierarchically to assess local adaptation at the species, subspecies, and population levels, as it is important to test for the potential for selection at multiple spatial scales (Chen et al. 2016). We therefore used our full, thinned SNP dataset and divided individuals into four groups: 1) All black bass samples, including Smallmouth Bass and Spotted Bass, 2) All Smallmouth Bass samples, including Neosho and Northern Smallmouth Bass populations, 3) Neosho Smallmouth Bass populations only, and 4) Northern Smallmouth Bass populations only.

For each hierarchical analysis, we used default MCMC parameters in BAYESCAN, retaining only SNPs with a log posterior probability greater than 1.5 , which is deemed "very strong" support for selection (Foll and Gaggiotti 2008). We ran the principal component analysis method in PCADAPT in $R$, testing up to $K=20$ principal components (PCs). To determine the optimal number of PCs to use for analysis, we assessed Scree plots and selected the number of PCs at which the accounted-for variation began to plateau. We then generated $p$-values for all SNPs, applying a Bonferroni correction for multiple tests. Only significant SNPs after Bonferroni correction were retained. The final set of outlier SNPs for each hierarchical analysis was created by merging candidate outliers from BAYESCAN and PCADAPT. To assess neutral differentiation, we also created datasets with only shared neutral SNPs (non-outliers) for each hierarchical analysis. 
We plotted samples at only outlier and neutral SNPs for all hierarchical analyses using DAPC (Jombart et al. 2010) in the $R$ package adegenet v.2.3.1 (Jombart 2008; Jombart and Ahmed 2011), for which we retained 3 PCs and 2 discriminant functions. Local adaptation was inferred if populations were non-overlapping with other populations based on only outlier SNPs. Genetic drift was inferred the same way but based solely on neutral SNPs.

\section{Admixture Mapping}

Signatures of intermixing within populations inferred to be potentially admixed ( $p$-Admixed) in population structure analysis could be due to previous and/or ongoing gene flow or to incomplete lineage sorting. We tested for evidence of either of these processes using MIXMAPPER v.2.0 (Lipson et al. 2013, 2014), which uses squared allele frequency differentiation ( $f_{2}$ statistics) between pairs of populations to compute momentbased statistics, through which we could identify populations of admixed origin using $f_{3}$ statistics (Reich et al. 2009; Patterson et al. 2012) and map them onto an un-admixed "scaffold" phylogeny. Populations exhibiting incomplete lineage sorting should be inferred as non-admixed, while those with a history of interbreeding due to secondary contact should be inferred as admixed.

We used the full dataset with all nine populations and created our input files for MixmapPer in EIgENSOFT v.7.2.1(Patterson et al. 2006; Price et al. 2006). MixMAPPER requires linkage information - physical and genetic distance between SNPs — to calculate genetic drift after admixture. Since our data were not mapped to a reference genome, we were unable to provide true linkage information and therefore did not infer divergence 
times using the drift units generated. Thus, to identify significantly admixed populations and fit them to a scaffold tree, we generated pseudo-positional data by arbitrarily labeling all SNPs to the same chromosome and generating physical and genetic distance values for each SNP according to the custom formula:

$$
d=\frac{100 x-y}{100}
$$

where $d=$ physical $/$ genetic distance, $x=$ the nucleotide coordinate on the SNP, and $y=$ an integer representing the numerical label of the $\operatorname{RAD} \operatorname{kmer}(1,2, \ldots)$. Moment statistics were calculated using 100 bootstrap replicates over 50 blocks, and the scaffold tree was constructed using 10,000 data subsets. For populations inferred to be significantly admixed based on $f_{3}$ statistics, we tested fit of two-way admixtures between all possible pairs of un-admixed parents (sources), running 100 bootstrap replicates for each test. Admixed populations were plotted on the scaffold tree, with position on each branch and subsequent time since admixture in drift units. All four $p$-Admixed populations were found to be significantly admixed, rather than indicative of incomplete lineage sorting, and were subsequently used in demographic analyses (see following paragraph):

\section{Demographic History}

For populations found to be admixed based on moment statistics, we explored the biogeographic processes driving admixture patterns, testing nine diversification demographic models developed by Portik et al. (2017) in $\delta a \delta i$ (Diffusion Approximation of Demographic Inference; Gutenkunst et al. 2009; Figure A2.2a-i; Table A2.1). We 
tested only two-population models in $\delta a \delta i$ to reflect migration between the Neosho Smallmouth Bass and Northern Smallmouth Bass native ranges. Candidate scenarios differed in timing of migration, i.e., either ancient or due to recent secondary contact, and directionality of migration, i.e., symmetric or asymmetric. Descriptions of parameters estimated in $\delta a \delta i$ are given in Table A2.2.

Demographic inference in $\delta a \delta i$ assumes SNPs are unlinked and neutral (Gutenkunst et al. 2009). Thus, we used VCF files containing only neutral SNPs ascertained from local adaptation analysis, converting SNP data for each population pair into folded 2D joint site frequency spectra (2D-JSFS). Sample sizes were projected down to account for missing genotypes, and three sequentially finer extrapolation grid sizes were set for each population pair based on the number of alleles per site per population $(2 N)$. Parameter estimates for each model were determined through a four-round perturbed optimization procedure. In the first optimization round, parameter values were initially chosen at random and likelihood values were calculated over a maximum of 3 iterations per 10 replicates. Parameters for the best-scoring replicate were then used to initiate the next optimization round, in which likelihood was calculated over a maximum of 5 rounds per 20 replicates in round 2, 10 iterations per 30 replicates in round 3, and 15 iterations per 40 replicates in round 4 . We checked for convergence of likelihood estimates across rounds for all models. Best-scoring replicates in round 4 were used to calculate AIC scores for each model within each admixed-parent pair, and $\triangle \mathrm{AIC}$ was then used for model comparison.

It is also theoretically feasible to convert parameter estimates calculated in $\delta a \delta i$ to biologically meaningful measures of migration rates, divergence times, and populations 
sizes. However, there is a possibility that none of our candidate models are representative of the true demographic history of these populations. Additionally, parameter conversion should ideally be conducted along with a bootstrapping procedure to quantify uncertainty (Gutenkunst et al. 2009; Portik et al. 2017). For this reason, we did not interpret parameter estimates directly and instead use them for model selection and comparison only.

\section{Detection of Recent Hybrids}

We complemented admixture mapping and demographic model analysis by testing for the presence of very recent hybridization (early-generation $F_{1}, F_{2}$, or backcross) following the hybrid detective workflow (Wringe et al. 2017) in $R$. We created four VCF files corresponding to each admixed population along with parent population inferred in MIXMAPPER. We converted VCF files to GENEPOP format using PGDSPIDER v.2.1.1.5 (Lischer and Excoffier 2012).

For each dataset, we performed two procedures. For the first, we used half of the parent samples as a training set to select 200 diagnostic SNPs. Then, we simulated individuals from six hybrid categories (Parent 1, Parent 2, $F_{1}, F_{2}$, Backcross to Parent 1, Backcross to Parent 2) with the remaining samples as a validation set, running the simulation three times with three replicates using the freqbasedsim_AlleleSample() function. Simulated hybrids were then analyzed in NEWHYBRIDS (Anderson and Thompson 2002), which uses a Bayesian algorithm to classify individuals to the six hybrid categories of interest, to verify that they could be accurately assigned to expected categories using the chosen 200 diagnostic SNPs. NEWHYBRIDS was run with 100,000 
burn-in steps and 500,000 sweeps. We checked for model convergence using the nh_preCheckR() function.

For the second procedure, we used the 200 validated diagnostic SNPs to simulate 100 hybrids from each of the six hybrid categories for the four sets of parents. We then created new GENEPOP files for our four empirical datasets, including admixed populations, for the 200 diagnostic SNPs. We plotted simulated hybrids using DAPC, choosing the number of principal components to retain based on amount of variance explained. We retained two discriminant functions for each set of populations. We overlaid our empirical data for both parents and admixed individuals onto the DAPC plots to compare them in genotype space. We supplemented DAPC results by running NEwHYBRIDS on the empirical data.

\section{Results}

\section{Lineage Divergence}

Population structure analysis for all samples in ADMIXTURE revealed that $45 \%$ of all individuals $(N=41)$ were admixed while $55 \%(N=51)$ were putatively of pure origin at $K=4$ (Figure A2.3). No $p$-Admixed individuals were found among the Spotted Bass or Northern Smallmouth Bass samples. One individual was identified as a likely interspecific hybrid (BFC10) and was removed from downstream analyses. At least one $p$-Admixed individual was identified in all but three Neosho Smallmouth Bass sample sites (Site 8, Sycamore Creek; Site 11, Honey Creek; Site 17, Mulberry River). In six of the Neosho sampling sites (Site 7, Buffalo Creek; Site 9, Big Sugar Creek; Site 10, Elk River; Site 12, Spavinaw Creek; Site 18, Big Piney Creek, AR; Site 19, Illinois Bayou), 
all individuals were putatively admixed (Figure A2.3). Population structure results were supported for $K=4$ by 10 -fold cross validation $\left(C V_{\text {error }}=0.253\right.$; Figure A2.4).

Subsequent population structure analysis on only the $p$-Pure group revealed the optimum number of clusters to be $K=3$ (Figure 4.1b), with all Spotted Bass (SPB), Northern Smallmouth Bass, and Neosho Smallmouth Bass assigning 95-100\% to their own distinct genomic clusters. These three major divisions were supported by the maximum likelihood phylogeny produced in SNPHYLO, which showed an initial split between the Spotted Bass and Smallmouth Bass species with 100\% bootstrap support, followed by a later split, again at 100\% bootstrap support, into two monophyletic groups representing the Neosho and Northern Smallmouth Bass subspecies (Figure 4.1b). The combination of population structure and phylogenomic inference suggested the presence of distinct lineages within Smallmouth Bass subspecies. At $K=4$ in ADMIXTURE, two monophyletic lineages, Lineage 1 (deep pink) and Lineage 2 (navy blue) emerged within the Northern Smallmouth Bass (Figure 4.1b). At $K=5$, an additional lineage was detected in the Neosho Smallmouth Bass, forming Lineage 3 (sky blue) and Lineage 4 (dark green; Figure 4.1b). The emergent lineage in the Neosho subspecies did not form a monophyletic group; however, cross-validation error results for $K=4\left(C V_{\text {error }}=0.276\right)$ and $K=5\left(C V_{\text {error }}=0.283\right)$ were within $8 / 1000$ of the optimal $K=3\left(C V_{\text {error }}=0.275\right.$; Figure $\left.4.1 \mathrm{c}\right)$, so we considered this to be evidence of four evolutionary lineages within Smallmouth Bass.

Parallel phylogenomic analysis in PHYML agreed with SNPHYLO at all major nodes on the tree. The best fitting substitution model for the data based on AIC and BIC model comparison was the General Time Reversible plus Discrete Gamma Distribution 
model (GTR + G; Table A2.3). Some inferences of nearest-neighbor individuals within the major clades varied between PHYML and SNPHYLO, but no substantial lineage or population-level differences were detected.

Distinct genomic lineages of Smallmouth Bass were shown to be clustered geographically, primarily along watershed boundaries (Figure 4.1d). In the Northern subspecies, Lineage 1 consisted of three sampling sites restricted to the tributaries of the WRD, while Lineage 2 spanned the MRT and the LAKE site. In the Neosho subspecies, Lineage 3 consisted of four sites throughout the middle portion of the ARB, and Lineage 4 was comprised of two sites confined to southward-flowing streams in the Boston Mountains of northern Arkansas, USA in the ARB (Figure 4.1d). Sites with either all or mostly admixed individuals (shown as white circles; Figure 4.1d) were distributed throughout the ARB.

\section{Population Discovery}

Using FINERADSTRUCTURE, we collapsed individuals into nine populations within the Smallmouth Bass, five of which were found in the $p$-Pure group (Figure 4.2a) and four of which were found in the $p$-Admixed group (Figure 4.2b), based on the formation of high-co-ancestry blocks along the diagonal of the co-ancestry matrices and corresponding monophyly at deeper nodes in the phylogeny. Of the five $p$-Pure populations, three were detected in the Northern Smallmouth Bass: one coincided exactly with Lineage 1 in the WRT (WHITE), and two were nested in Lineage 2: the LAKE site (SKIA) and the MRT (MISS). The remaining two $p$-Pure populations belonged to the Neosho Smallmouth Bass and corresponded exactly to Lineage 3 within the middle ARB 
(MIDARK) and Lineage 4 encompassing Lee Creek and Mulberry River (LMULB; Figure 4.2a).

The four $p$-Admixed populations each formed a monophyletic group adhering geographically to stream sites: the Elk River (ELK), the Illinois River system (ILLI), tributaries of the upper ARB (UPPARK), and the Illinois Bayou River and Big Piney Creek, AR (BAYOU; Figure 4.2b). All nodes in the phylogenetic tree for $p$-Pure and $p$ Admixed were confirmed at 100\% bootstrap support (Figure 4.2).

\section{Local Adaptation}

Scanning our SNPs with BAYESCAN across all Spotted Bass and Smallmouth Bass revealed three candidate SNPs under very strong balancing selection (low $F_{\mathrm{ST}}$ ) and 50,825 neutral SNPs (Figure A2.5a). Among Smallmouth Bass samples only, we found 703 candidate SNPs under diversifying selection, 118 of which were considered to be decisively outliers, and 50,125 neutral SNPs (Figures A2.5b). Among Neosho Smallmouth Bass only, we found 32 candidate diversifying SNPs, two of which were considered decisive, and 50,796 neutral SNPs (Figure A2.5c). Among Northern Smallmouth Bass only, only six candidate SNPs were found to be under substantial selection, none of which were decisive, and we found 50,822 neutral SNPs (Figure A2.5d).

For our scan of outlier SNPs using the multivariate model in PCADAPT, we retained two PCs for analysis with all Spotted Bass and Smallmouth Bass samples (Figure A2.6a-b), two PCs for analysis with Smallmouth Bass samples only (Figure A2.6c-d), four PCs for analysis with Neosho Smallmouth Bass only (Figure A2.6e-f), and 
three PCs for analysis with Northern Smallmouth Bass only (Figure A2.6g-h) according to the underlying population structure. Outlier SNPs were called based on their loading on retained $\mathrm{PCs}$, with those contributing to most of the variation on a given $\mathrm{PC}$ being classified as significant.

In PCAdapt, we detected 16,358 candidate outlier SNPs and 34,466 neutral SNPs for all Spotted Bass and Smallmouth Bass samples. Among Smallmouth Bass samples only, we detected 1,006 candidate diversifying SNPs and 41,871 neutral SNPs. Among Neosho Smallmouth Bass only, we detected 1,304 candidate diversifying SNPs and 35,041 neutral SNPs. Among Northern Smallmouth Bass only, we detected 1,518 diversifying SNPs and 25,662 neutral SNPs. In each analysis, some SNPs were removed before p-value calculation because they did not meet the minor allele frequency threshold of 0.01 for that group of samples.

There were no shared outlier SNPs between BAYESCAN and PCADAPT for either all Spotted Bass and Smallmouth Bass or the Northern Smallmouth Bass only samples, so we could not reliably consider any SNPs to be contributing to local adaption. However, among Smallmouth Bass samples only, we found 156 SNPs with outlier $F_{\text {ST }}$ values shared between the two models, which drove tight clustering of Northern Smallmouth Bass separately from Neosho Smallmouth Bass (Figure 4.3a). We also found 41,324 shared neutral SNPs, which indicated differentiation between the two subspecies and strong drift at the drainage level within the Northern Smallmouth Bass (Figure 4.3b). Among Neosho Smallmouth Bass, we detected 29 shared diversifying SNPs which drove strong divergence between the two populations in the Boston Mountains (LMULB, dark green; BAYOU, light green) and between the Boston Mountains and all other Neosho 
populations (Figure 4.3c). We detected 35,038 neutral SNPs, which were indicative of strong genetic drift among populations (Figure 4.3d).

\section{Admixture Mapping}

All $p$-Pure populations (WHITE, MISS, SKIA, MIDARK, LMULB) were found to be un-admixed and formed the branch tips of the tree for admixture mapping (Figure 4.4). Furthermore, all $p$-Admixed populations (ELK, ILLI, UPPARK, BAYOU) were significantly admixed based on $f_{3}$ statistics (Table A2.4). All admixed populations were inferred to be parented by the MIDARK population within the Neosho Smallmouth Bass lineage. The ELK, BAYOU, and UPPARK populations were all admixed with the WHITE population within the Northern Smallmouth Bass lineage (Table 4.2; Figure 4.4). The ILLI population was admixed with the SKIA population (Table 4.2; Figure 4.4). In each case, sources were inferred with 100\% bootstrap support (Table 4.2).

\section{Demographic History}

For each significantly admixed population (ELK, ILLI, BAYOU, and UPPARK), which were all within the Neosho Smallmouth Bass native range, we tested nine twopopulation demographic scenarios, one population being admixed and the other being the Northern Smallmouth Bass parent inferred in MiXMAPPER. All nine models were successfully optimized, such that the standard error around the maximum likelihood value was minimized, for the ELK and WHITE (Figure A2.7a-i), ILLI and SKIA (Figure A2.8a-i), BAYOU and WHITE (Figure A2.9a-i), and UPPARK and WHITE (Figure A2.10a-i) analyses. The best fitting model (the one with the lowest AIC value and for 
which $\triangle \mathrm{AIC}=0$ ) for ELK and WHITE was AM, indicating continuous asymmetric migration after subspecies divergence (Table 4.3; Figure 4.5a). Migration rate from WHITE to ELK $\left(m_{12}=4.903\right)$ was substantially higher than in the opposite direction (ELK to WHITE; $m_{21}=0.026$; Table 4.3).

The best fitting model for ILLI and SKIA was SCAM, indicating divergence, followed immediately by isolation with subsequent secondary contact (Table 4.3; Figure 4.5b). Migration rate from SKIA to ILLI $\left(m_{12}=3.434\right)$ was higher than in the opposite direction (ILLI to SKIA; $m_{21}=0.276$ ). The estimate for the period of isolation following divergence $\left(T_{1}=1.143\right)$ was substantially greater than the time since secondary contact $\left(T_{2}\right.$ $=0.091 ;$ Table 4.3) .

The most suitable model for BAYOU and WHITE was SCAM, indicating divergence, followed immediately by isolation with subsequent secondary contact (Table 4.3; Figure 4.5c). Migration rate from WHITE to BAYOU $\left(m_{12}=19.782\right)$ was much higher than in the opposite direction (BAYOU to WHITE; $m_{21}=0.775$ ). The estimate for the period of isolation following divergence $\left(T_{1}=0.750\right)$ was substantially greater than the time since secondary contact $\left(T_{2}=0.019\right.$; Table 4.3$)$. Residual estimates and distributions for all best-fitting models are given in Figure A2.11.

The AM2E model was the most suitable for UPPARK and WHITE, indicating divergence, followed by varying rates of asymmetric migration over two distinct “epochs" of time (Table 4.3; Table A2.5; Figure 4.5d). In both the first and second epochs, migration rate from WHITE to UPPARK $\left(m_{12 \mathrm{a}}=1.656\right.$ and $m_{12 \mathrm{~b}}=1.413$, respectively) was greater than the opposite direction $\left(m_{21 \mathrm{a}}=0.096\right.$ and $m_{21 \mathrm{~b}}=0.011$; Table 4.3). Timing of each epoch with respect to subspecies divergence was variable, 
although the second epoch $\left(T_{2}=16.128\right)$ was estimated to last longer than the first $\left(T_{1}\right.$ $=3.076$; Table 4.3).

\section{Detection of Recent Hybrids}

Comparison of empirical data with simulated early-generation hybrids through the hybrid detective workflow complemented our demographic analyses by evaluating the possibility of very recent hybridization and introgression in our admixed populations. For each admixed population, we verified that the 200 selected diagnostic SNPs were able to accurately assign simulated hybrids to the correct hybrid category (Parent 1 , Parent $2, F_{1}$, $F_{2}$, Backcross to Parent 1, Backcross to Parent 2) using our validation sets from the parent populations (MIDARK and WHITE; MIDARK and SKIA). For MIDARK and WHITE, the diagnostic SNP set performed consistently across independent replicates within Simulation 1 (Figure A2.12a-c), Simulation 2 (Figure A2.12d-f) and Simulation 3 (Figure A2.12g-i), as all samples were correctly assigned with nearly $100 \%$ posterior probability. The same was true for MIDARK and SKIA, where nearly all samples were

correctly assigned across Simulation 1 (Figure A2.13a-c), Simulation 2 (Figure A2.13d-f) and Simulation 3 (Figure A2.13g-i).

For the empirical data, both sets of parents, MIDARK and WHITE and MIDARK and SKIA, were assigned with nearly $100 \%$ posterior probability to the parent categories (Figure A2.14a-b). Admixed individuals were assigned either to the backcross or $F_{2}$ categories (Figure A2.14a-b), except for one individual from the ILLI population, which was inferred as a pure MIDARK sample (Figure A2.14b). 
DAPC for admixed populations from MIDARK and WHITE revealed that the UPPARK (light pink) and ELK populations (light brown) likely harbor some earlygeneration hybrids; some UPPARK individuals were overlaid on simulated MIDARK backcrosses, and one ELK individual was overlaid on the $F_{2}$ cluster (Figure 4.6a). Most ELK and all BAYOU samples did not map onto the simulated hybrid clusters, indicating that they are probably later-generation hybrids or introgressed over deeper time. Conversely, DAPC for ILLI, admixed between MIDARK and SKIA, showed that nearly all samples were either MIDARK backcrosses or $F_{2} / F_{1}$ hybrids. There was a single outlier sample, BFORK30, which appeared to be a later-generation hybrid (Figure 4.6b).

\section{Discussion}

Recent phylogenomic and fossil analyses of the black bass genus (Micropterus) date the divergence of Smallmouth Bass from its sister clade at between four and six million years ago (Near and Kim 2021). However, these estimates are not concordant among different types of genetic data (Near and Kim 2021). Earlier studies proposed that the Smallmouth Bass, as with congeneric species and many other fishes, emerged substantially later during a radiation of allopatric speciation events during the Pleistocene (2.6 million - 12,000 years ago) owing to frequent habitat fragmentation and climate oscillations (Miller 1965; Bermingham et al. 1992; Zink and Slowinski 1995; Near et al. 2003; Puckett et al. 2015). Pleistocene glacial movements would have promoted vicariant diversification (Mayden 1985) of fish lineages by carving out new, ecologically diverse riverine habitats (Near and Keck 2005). Advancement of the glaciers to the last glacial maximum (LGM, 22-18 thousand years ago) would have pushed species into southern 
refugial habitat, with later recession allowing colonization and expansion northward, as has been hypothesized for freshwater fishes in North America (Near et al. 2001; Ray et al. 2006; Berendzen et al. 2008; Puckett et al. 2015).

The allopatric native distributions of the Smallmouth Bass subspecies converge on the Ozark Plateau in the Central Interior Highlands $(\mathrm{CIH})$, which lies at the projected boundary of the LGM. The Neosho Smallmouth Bass is confined to the Arkansas River Basin in this ecoregion, while the Northern Smallmouth Bass has a much more extensive range that encompasses tributaries of the White River and Missouri drainages (Brewer and Long 2015; Brewer and Orth 2015). Given the tumultuous geological and ecological history of the CIH (Mayden 1985; Wiley and Mayden 1985), today's range boundaries for the two subspecies may be a result of complex processes leading to their divergence. We do not have direct evidence that the contemporary Neosho Smallmouth Bass native range served as a glacial refugium for ancestral Smallmouth Bass during the LGM. However, the phylogeographic patterns of the two extant subspecies may suggest a postPleistocene northward expansion of a single lineage followed by a natural disconnect between the Arkansas River Basin and river networks further north. More research combining genomics and niche distribution modeling is needed to determine whether the Arkansas River Basin harbored a compression of genetic diversity (Austerlitz et al. 1997; Hewitt 1999) consistent with these hypotheses.

Hubbs and Bailey (1940) inferred via study of meristics that Smallmouth Bass in the White River and nearby drainages represented an intergrade between the Neosho and Northern subspecies, which was also supported based on a limited number of allozyme loci (Stark and Echelle 1998). Our results do not support this long-standing hypothesis. 
Phylogenomic and population genomic analyses reveal that the Neosho and Northern Smallmouth Bass subspecies are highly diverged, forming two monophyletic clades in the portions of their range in the $\mathrm{CIH}$. Within the Northern subspecies, genomic analyses found two distinct, monophyletic lineages, with one encompassing the previously assumed intergrade in the White River drainage, supporting a recent microsatellite-based study (Gunn et al. 2020). This finding is surprising but makes sense given that endemism in the White River has been observed in other fishes (Roe et al. 2008; Blanton et al. 2013; Bossu et al. 2013). Echelle et al. (2014) recently uncovered a highly distinct, cryptic species of cyprinid (Nocomis c.f. biggutatus) in this drainage. A second lineage within the Northern Smallmouth Bass inhabits tributaries of the Missouri River along with a Tennessee lake-strain population in Skiatook Lake, Oklahoma, USA Although Skiatook Lake is known to have been stocked with the Tennessee lake-strain (Taylor et al. 2018), our data confirm that it constitutes a population of Northern Smallmouth Bass origin.

Within the Neosho native range, we found a distinct, un-admixed, monophyletic lineage consisting of tributaries throughout the middle of the Arkansas River Basin within the $\mathrm{CIH}$, including Honey Creek, Sycamore Creek, Caney Creek, and Baron Fork. We found an additional genetically divergent lineage in the southward-flowing streams of northern Arkansas, USA in the Boston Mountain ecoregion, including the Mulberry River and Lee Creek. These lineages may represent segments of an ancestral Neosho Smallmouth Bass population and could therefore constitute units of conservation value for the subspecies.

Concordant with their independent evolutionary trajectories, the Smallmouth Bass subspecies are highly differentiated at multiple, outlier markers across the genome 
(SNPs), suggesting that they harbor adaptive variation in their respective ranges. While previously described morphological differences between the Smallmouth Bass subspecies, including head length and the number of soft dorsal fin rays (Hubbs and Bailey 1940; Gunn et al. 2020), have suggested differential adaptive variation, this is the first genomic evidence for local adaptation between subspecies. In addition, two populations in the Neosho subspecies range, one in the Illinois Bayou River and Big Piney Creek and the other in Lee Creek and the Mulberry River, were diverged from one another and from the rest of the Neosho Smallmouth Bass populations. These data reveal local adaptation at the lineage and population levels within the Neosho subspecies, possibly indicating that environmental conditions in different parts of the Neosho distribution are influencing diversifying selection.

Phenotypic differentiation may occur along an ecological cline (Conover et al. 2009; Savolainen et al. 2013), perhaps of temperature, precipitation, or water depth, suggesting the presence of specialization and variation that are necessary for adaptation in the face of climate change and other environmental stressors (Davis and Shaw 2001; Aitken et al. 2008; Franks and Hoffmann 2012). Many ecological variables could contribute to ecological specialization in the Smallmouth Bass subspecies. Both the Illinois Bayou River and Big Piney Creek flow through the Boston Mountains of northern Arkansas, USA southward until they empty into the Arkansas River. Ecologically, this part of the $\mathrm{CIH}$ is relatively warm and characterized by steep gradients; water temperatures may exceed $30^{\circ} \mathrm{C}$ (Hafs et al. 2010) in the summer months, approaching the known average heat tolerance of Smallmouth Bass. Similarly, while some streams in the Neosho range flow continuously (Robison and Buchanan 1984), the Boston Mountains 
streams are not spring-fed and may partially dry out due to evapotranspiration and decreased precipitation (Hines 1975), leaving only deep, isolated pools for fish refuge (Hafs et al. 2010). Neosho Smallmouth Bass in the Boston Mountains may therefore be well-adapted to extreme temperature and flow regimes, warranting further investigation and conservation actions given climate projection for warmer temperatures and increased drought intensity for the region (Sharma and Jackson 2008).

Our results demonstrate that the Smallmouth Bass subspecies and lineages and populations within the Neosho range are diverged at several SNPs in the genome. We can also pinpoint the nucleotide position of these SNPs on their respective RAD kmers. Although this provides evidence of local adaptation at multiple hierarchical levels, it does not offer information as to the loci that may be under selection, nor does it say whether these loci fall on or near functional genes. The degree to which any of our discovered diversifying SNPs are being selected under specific environmental variables will need to be rigorously tested by linking the SNPs to functional traits, which may be possible in the future with a full, annotated Smallmouth Bass genome. Researchers have very recently published a chromosome-level genome of the Largemouth Bass (Micropterus salmoides; Sun et al. 2021), which will be an invaluable resource in future studies of phylogenomics, hybridization, and speciation in the black bass genus. Regardless, development of a genome resource specifically for Smallmouth Bass is necessary to understand fine-scale patterns and processes of genetic diversity.

We identified a substantial number of SNPs that were selectively neutral among Smallmouth Bass at both the subspecies and population levels. These markers showed strong divergence that is likely due to genetic drift. Behaviorally, Smallmouth Bass have 
been shown in some stream environments to be sedentary (Funk, 1957) and philopatric with respect to nest site (Ridgeway et al. 1991), which likely contributes to genetic differentiation between populations through isolation. Dispersal, when it occurs, typically occurs seasonally (Funk 1955; Gowan et al. 1994; Lyons and Kanehl 2002) and unidirectionally, most often from tributaries to the mainstem river and rarely in the opposite direction (Humston et al. 2010). Alternatively, movement is likely limited by dams (Taylor et al. 2019). Dams may close off populations in the Neosho range, driving periodic demographic bottlenecks, making fish especially susceptible to drift.

Movement restriction due to nest-site fidelity, sedentation, and dam construction cannot fully explain neutral patterns of divergence, though, because some Smallmouth Bass populations are known to migrate long distances (Langhurst and Shoenike 1990) and not all streams have been unnaturally obstructed. Isolation between streams may have occurred physically over evolutionary time due to paleodrainage reconfiguration (Near and Kim 2021), causing vicariance through the formation of the Arkansas River (Thornbury 1965; Mayden 1985). The Interior Highlands ecoregion was once a continuous upland plain, bridging both the Ozark and Ouachita highlands, consisting of numerous northeast-flowing streams with cool-water adapted fluvial fishes (Cross et al. 1986; Taylor et al. 2004; Bonett and Chippindale 2004). It was subsequently bisected via downcutting by the Arkansas River. This process would have changed stream directionality and the gradient of water flow, perhaps significantly altering geological and biotic components of the ecosystem. The Arkansas River may then have lacked favorable habitat, preventing ravel between feeder tributaries. 
We show that the evolutionary history of the Smallmouth Bass has been strongly influenced by asymmetric gene flow from the Northern subspecies range into the Neosho range. Four of our populations, including seven sampling sites, were significantly admixed. The Elk River, the Illinois Bayou River, Big Piney Creek, and tributaries of the upper Arkansas River Basin including Buffalo Creek, Spavinaw Creek, and Big Sugar Creek, all had signatures of allele-sharing with the White River drainage genomic cluster even though they all shared an origin with the middle Arkansas River Basin tributaries (Honey Creek, Sycamore Creek, Caney Creek, and Baron Fork Creek).

We found that admixture patterns in the Elk River were best explained by a demographic model of divergence followed by continuous migration from the White River lineage. This result suggests that the Elk River has been subjected to periodic, asymmetric migration events over evolutionary time despite lack of obvious stream connections between the Arkansas River Basin and White River drainage. Gene flow in this part of the range could be facilitated from natural, transient reconnections between the Elk River and the White River system, perhaps owing to the karst topography. Several studies (Branson, 1963, 1967) have found evidence of stream capture events in the $\mathrm{CIH}$ that may have occurred post-Pleistocene, a timeframe that could qualify as secondary contact with respect to the timing of subspecies divergence. Intermittent periods of high water (flooding) may have also brought temporary stretches of connectivity.

Admixture in the upper Arkansas River Basin tributaries was best modeled by differential rates of asymmetric migration over two distinct epochs of time. While this demographic scenario is defined by a distinct joint site frequency spectrum with respect 
to the continuous asymmetric model (Portik et al. 2017) for the Elk River, we presume that the two populations have undergone similar biogeographic processes given their geographic proximity. It is important to note that both populations have likely been subjected to anthropogenic introductions of Northern Smallmouth Bass, perhaps inadvertently or deliberately to promote angling (Rahel 2004; Johnson et al. 2009). Upper Arkansas tributaries may have been stocked more recently than the Elk River. This is consistent with the results from our early-generation hybrid analysis, showing the presence of several potential middle Arkansas backcrosses in the upper Arkansas population. The Elk River, in contrast, showed no early-generation hybrids, except for one potential $F_{2}$ individual. Varied timing and differential volumes of introduced fish in these two river systems could explain our unique demographic inferences.

In contrast to the upper Arkansas River Basin tributaries and the Elk River, admixture in both the Illinois River system and the Illinois Bayou and Big Piney Creek population was best explained by divergence with later secondary contact, strongly implicating recent, anthropogenic introductions. We expected to find that the Illinois River system has been subjected to secondary contact, because we know that it is admixed with the Skiatook Lake genomic cluster due to stocking of Lake Tenkiller with the same hatchery strain in the 1990s (Taylor et al. 2018). The presence of recent hybrids in the Illinois River system was corroborated by early-generation hybrid analysis, showing that all but one fish was either an $F_{2}$ or a middle Arkansas backcross. We were surprised to obtain the same demographic history for the Illinois Bayou and Big Piney Creek population, because we inferred a greater amount of genetic drift following admixture in this part of the range from our admixture mapping results. However, our 
hybrid simulations provided no strong evidence of recent hybrids here, showing that secondary contact has occurred in these populations on different timeframes. Because we cannot determine the exact timing of secondary contact using the time parameters derived in our demographic analysis, caution is needed when interpreting our conclusions regarding recent introductions. Analysis of a full Smallmouth Bass genome and associated linkage map is needed to ascertain precise estimates of admixture timing.

\section{Conclusions}

The Neosho and Northern Smallmouth Bass constitute phylogenetically diverged, locally adapted lineages in the $\mathrm{CIH}$. We have identified at least six streams in the Arkansas River Basin—Honey Creek, Sycamore Creek, Caney Creek, Baron Fork, Lee Creek, and the Mulberry River - which are of pure genomic origin and may represent descendant populations of ancestral Neosho Smallmouth Bass. These populations may therefore be evolutionarily distinct units that harbor genomic diversity that is valuable both for the Smallmouth subspecies and the greater ecosystem in the Ozark highlands.

Our findings clarify the lingering questions left by Taylor et al. (2018) and Gunn et al. (2020) that show substantial, heterogenous admixture interspersed with some unadmixed populations throughout the Neosho Smallmouth Bass native range. This admixture is asymmetric; individuals have only moved from the Northern range into some Neosho streams. We assert that these patterns of admixture are temporally complex. Some migration has likely occurred naturally in the past, while there have been more recent introductions of Northern Smallmouth Bass from both hatchery (i.e., Tennessee lake-strain) and wild (i.e., White River drainage) sources. 
Continued, human-mediated admixture is affecting the genomic integrity of populations of the range-restricted Neosho Smallmouth Bass. If left unchecked, it will continue to erode native genetic diversity that may be vital to the capacity of this endemic subspecies to respond to changing environmental conditions. It is now imperative that managers consider the potential threats of admixture on diversity within the Smallmouth Bass lineage, which may require the consideration of the Neosho Smallmouth Bass as an evolutionary significant unit — a genetically distinct, independently evolving lineage (Ryder 1986) _ or as a distinct species of black bass. We now have evidence from neutral microsatellite loci (Taylor et al. 2018; Gunn et al. 2020), morphology (Hubbs and Bailey 1940; Gunn et al. 2020), and genomics (Long et al. 2020; this study) indicating the presence of remaining pure Neosho Smallmouth Bass populations. This level of evidence could be used to justify elevation of the Neosho Smallmouth Bass to species status, giving it increased conservation priority. In any case, we must continue to reach a fuller understanding of the processes, both natural and anthropogenic, contributing to population change in this economically and ecologically important taxon.

\section{Acknowledgments}

This project would not have been possible without the funding, resources, and guidance of the Missouri Department of Conservation. We would like to thank M. Thomas, J. Chilton, and Z. Morris for assistance with sample collection. We thank the staff at Floragenex, Inc., especially J. Walsh and J. Boone, for processing the genomic data analyzed in this study. We thank C. Chang, M. Malinski, M. Lipson, J. Ebersbach, E. Nielsen, and D. Portik for assisting with data analysis from afar. We would like to 
thank K. Budd, J. Burkhart, E. Puckett, R. Munds, C. Titus, T. Rowan, H. Durbin, B. Schnabel, J. Decker and all other members and friends of the Eggert Lab and faculty at the University of Missouri, past and present, who helped with data analysis and interpretation of results. We would like to say a special thank you to M. Mabry, P. Blischak, and P. Petrowski, who devoted numerous hours of support for coding and bioinformatic troubleshooting. 


\section{References}

Aitken SN, Yeaman S, Holliday JA, et al (2008) Adaptation, migration or extirpation: Climate change outcomes for tree populations. Evol Appl 1:95-111.

Alexander DH, Novembre J, Lange K (2009) Fast model-based estimation of ancestry in unrelated individuals. Genome Res 19:1655-1664.

Allendorf FW, Hohenlohe PA, Luikart G (2010) Genomics and the future of conservation genetics. Nat Rev Genet 11:697-709.

Altukhov Y, Salmenkova E (1987) Stock transfer relative to natural organization, management, and conservation of fish populations. In: Ryman N, Utter F (eds) Population Genetics and Fishery Management. Seattle, WA, pp 333-344.

Anderson EC, Thompson EA (2002) A model-based method for identifying species hybrids using multilocus genetic data. Genetics 160:1217-1229.

Andrews KR, Good JM, Miller MR, et al (2016) Harnessing the power of RADseq for ecological and evolutionary genomics. Nat Rev Genet 17:81-92.

Arnold ML, Martin NH (2010) Hybrid fitness across time and habitats. Trends Ecol Evol 25:530-536.

Austerlitz FD, Jung-muller B, Godelle B, Gouyon P (1997) Evolution of coalescence times, genetic diversity and structure during colonization. Theor Popul Biol 51:148164.

Baird NA, Etter PD, Atwood TS, et al (2008) Rapid SNP discovery and genetic mapping using sequenced RAD markers. PLoS One 3:1-7.

Bao E, Jiang T, Kaloshian I, Girke T (2011) SEED: Efficient clustering of nextgeneration sequences. Bioinformatics 27:2502-2509.

Berendzen PB, Simons AM, Wood RM, et al (2008). Recovering cryptic diversity and ancient drainage patterns in eastern North America: historical biogeography of the Notropis rubellus species group (Teleostei: Cypriniformes). Mol Phylogenet Evol 46:721-737.

Bermingham E, Rohwer S, Freeman S, Wood C (1992) Vicariance biogeography in the Pleistocene and speciation in North American wood warblers: A test of Mengel's model. Proc Natl Acad Sci 89:6624-6628.

Bickford D, Lohman DJ, Sodhi NS, et al (2007) Cryptic species as a window on diversity and conservation. Trends Ecol Evol 22:148-155. 
Blanton RE, Page LM, Hilber SA (2013) Timing of clade divergence and discordant estimates of genetic and morphological diversity in the Slender Madtom, Noturus exilis (Ictaluridae). Mol Phylo Evol 66: 679-693.

Bonett RM, Chippindale PT (2004) Speciation, phylogeography and evolution of life history and morphology in plethodontid salamanders of the Eurycea multiplicata complex. In: Molecular Ecology, Blackwell Publishing Limited, pp 1189-1203.

Bossu CM, Beaulieu JM, Ceas PA, Near TJ (2013) Explicit tests of palaeodrainage connections of southeastern North America and the historical biogeography of Orangethroat Darters (Percidae: Etheostoma: Ceasia). Mol Ecol 22:5397-5417.

Branson BA (1963) New mollusk records from Oklahoma and their zoogeographical significance. Am Midl Nat 66:501-512.

Branson BA (1967) Fishes of the Neosho River system in Oklahoma. Am Midl Nat $78: 126-154$.

Brewer SK, Long JM (2015) Biology and ecology of Neosho Smallmouth Bass and the genetically distinct Ouachita lineage. In: Tringali MD, Long JM, Birdsong TW, Allen MS (eds) Black Bass Diversity: Multidisciplinary Science for Conservation. Transactions of the American Fisheries Society, Bethesda, MD, pp 281-295.

Brewer SK, Orth DJ (2015) Smallmouth Bass Micropterus dolomieu Lacepede, 1802. In: Tringali MD, Long JM, Birdsong TW, Allen MS (eds) Black Bass Diversity: Multidisciplinary Science for Conservation. Transactions of the American Fisheries Society, Bethesda, MD, pp 9-26.

Burnham K, Anderson D (2002) Model selection and multimodel inference: A practical information-theoretic approach, 1st edn. Springer-Verlag, New York Inc., New York, NY.

Ceballos G, Ehrlich PR, Dirzo R (2017) Biological annihilation via the ongoing sixth mass extinction signaled by vertebrate population losses and declines. Proc Natl Acad Sci 114:E6089-E6096.

Chang CC, Chow CC, Tellier LCAM, et al (2015) Second-generation PLINK: Rising to the challenge of larger and richer datasets. Gigascience 4:1-16.

Chen J, Kallman T, Xiao-Fei M, Zaina G, Morgante M, Lascoux M (2016) Identifying genetic signatures of natural selection using pooled population sequencing in Picea abies. G3-Genes Genom Genet 6:1979-1989.

Conover DO, Duffy TA, Hice LA (2009) The covariance between genetic and environmental influences across ecological gradients: Reassessing the evolutionary 
significance of countergradient and cogradient variation. Ann Acad Sci 1168:100129.

Cross FB, Mayden RL, Stewart JD (1986) Fishes in the western Mississippi drainage. In: Hocutt H, Wiley EO (eds) The zoogeography of North American freshwater fishes. John Wiley \& Sons, Ltd, New York, NY, pp 363-412.

Culver DC, Kane TC, Fong DW (1995) Adaptation and nautral selection in caves: The evolution of Gammarus minus. Harvard University Press, London, UK.

Culver DC, Pipan T (2009) The biology of caves and other subterranean habitats. Oxford University Press, Oxford, UK.

Danecek P, Auton A, Abecasis G, et al (2011) The variant call format and VCFtools. Bioinformatics 27:2156-2158.

Davey JL, Blaxter MW (2010) RADseq: Next-generation population genetics. Brief Funct Genomics 9:416-423.

Davis MB, Shaw RG (2001) Range shifts and adaptive responses to quaternary climate change. Science 292:673-679.

De Meester N, Gingold R, Rigaux A, et al (2016) Cryptic diversity and ecosystem functioning: A complex tale of differential effects on decomposition. Oecologia 182:559-571.

Depristo MA, Banks E, Poplin R, et al (2011) A framework for variation discovery and genotyping using next-generation DNA sequencing data. Nat Genet 43:491-501.

Ebersbach J, Posso-Terranova A, Bogdanowicz S, et al (2020) Complex patterns of differentiation and gene flow underly the divergence of aposematic phenotypes in Oophaga poison frogs. Mol Ecol 29: 1944-1956.

Echelle AA, Schwemm MR, Lang NJ, et al (2014) Molecular systematics and historical biogeography of the Nocomis biguttatus species group (Teleostei: Cyprinidae): Nuclear and mitochondrial introgression and a cryptic Ozark species. Mol Phylogenet Evol 81:109-119.

Edgar RC (2004) MUSCLE: Multiple sequence alignment with high accuracy and high throughput. Nucleic Acids Res 32:1792-1797.

Eldridge WH, Naish KA (2007) Long-term effects of translocation and release numbers on fine-scale population structure among Coho Salmon (Oncorhynchus kisutch). Mol Ecol 16:2407-2421. 
Ellegren H (2014) Genome sequencing and population genomics in non-model organisms. Trends Ecol Evol 29:51-63.

Euclide PT, Ruzich J, Hansen SP, et al (2020) Genetic structure of Smallmouth Bass in the Lake Michigan and upper Mississippi River drainages relates to habitat, distance, and drainage boundaries. Trans Am Fish Soc 149:383-397.

Excoffier L, Hofer T, Foll M (2009) Detecting loci under selection in a hierarchically structured population. Heredity 103:285-298.

Felsenstein J (1989) PHYLIP-Phylogeny inference package (version 3.2). Cladistics 5:164-166

Flanagan SP, Jones AG (2017) Constraints on the F ST -Heterozygosity Outlier Approach. J Hered 108:561-573.

Foll M, Gaggiotti O (2008) A genome-scan method to identify selected loci appropriate for both dominant and codominant markers: A Bayesian perspective. Genetics 180:977-993.

Franks SJ, Hoffmann AA (2012) Genetics of climate change adaptation. Annu Rev Genet 46:185-208.

Funk CW, Caminer M, Ron SR (2012) High levels of cryptic species diversity uncovered in Amazonian frogs. Proc R Soc B Biol Sci 279:1806-1814.

Funk J (1955) Movement of stream fishes in Missouri. Trans Am Fish Soc 85:39-57.

Funk J (1957) Movement of stream fishes in Missouri. Trans Am Fish Soc 85:39-57.

Garrick RC, Banusiewicz JD, Burgess S, et al (2019) Extending phylogeography to account for lineage fusion. J Biogeogr 46:268-278.

Gowan C, Young M, Fausch K, Riley S (1994) Restricted movement in resident stream salmonids: A paradigm lost? Can J Fish Aquat Sci 51:2626-2637.

Guindon S, Dufayard JF, Lefort V, et al (2010) New algorithms and methods to estimate maximum-likelihood phylogenies: Assessing the performance of PhyML 3.0. Syst Biol 59:307-321.

Gunn JC, Berkman LK, Koppelman J, et al (2020) Complex patterns of genetic and morphological differentiation in the Smallmouth Bass subspecies (Micropterus dolomieu dolomieu and M. d. velox) of the Central Interior Highlands. Conserv Genet 21:891-904.

Gutenkunst RN, Hernandez RD, Williamson SH, Bustamante CD (2009) Inferring the 
joint demographic history of multiple populations from multidimensional SNP frequency data. PLoS Genet 5:e1000695.

Hafs AW, Gagen CJ, Whalen JK (2010) Smallmouth Bass summer habitat use, movement, and survival in response to low flow in the Illinois Bayou, Arkansas. North Am J Fish Manag 30:604-612.

Hansen MM, Fraser DJ, Meier K, Mensberg KLD (2009) Sixty years of anthropogenic pressure: A spatio-temporal genetic analysis of brown trout populations subject to stocking and population declines. Mol Ecol 18:2549-2562.

Hansen MM, Mensberg KLD (2009) Admixture analysis of stocked brown trout populations using mapped microsatellite DNA markers: Indigenous trout persist in introgressed populations. Biol Lett 5:656-659.

Hasselman DJ, Argo EE, McBride MC, et al (2014) Human disturbance causes the formation of a hybrid swarm between two naturally sympatric fish species. Mol Ecol 23:1137-1152.

Hewitt GM (1999) Post-glacial re-colonization of European biota. Biol J Linn Soc 68:87112.

Hines M (1975) Flow duration and low-frequency determinations of selected Arkansas streams. Little Rock, AR.

Hubbs CL, Bailey RM (1940) A revision of the black basses (Micropterus and Huro) with descriptions of four new forms. Mich Univ, Mus Zool, Misc Pub 48:1-49.

Humston R, Priest BM, Hamilton WC, Bugas PE (2010) Dispersal between tributary and main-stem rivers by juvenile Smallmouth Bass evaluated using otolith microchemistry. Trans Am Fish Soc 139:171-184.

Jackson DA (2002) Ecological effects of Micropterus introductions: The dark side of black bass. In: Philipp DP, Ridgway MS (eds) Black Bass: Ecology, Conservation, and Management. American Fisheries Society, Bethesda, MD, pp 221-232.

Jakobsson M, Edge M, Rosenberg N (2013) The relationship between FST and the frequency of the most frequent allele. Genetics 195:515-528.

Jansson R, Dynesius M (2002) The fate of clades in a world of recurrent climatic change: Milankovitch oscillations and evolution. Annu Rev Ecol Syst 33:741-777.

Johnson B, Arlinghaus R, Martinez PJ (2009) Introduced species: Are we doing all we can to stem the tide of illegal fish stocking? Fisheries 34:389-394. 
Jombart T (2008) adegenet: A R package for the multivariate analysis of genetic markers. Bioinformatics 24:1403-1405.

Jombart T, Ahmed I (2011) adegenet 1.3-1: new tools for the analysis of genome-wide SNP data

Jombart T, Devillard S, Balloux F (2010) Discriminant analysis of principal components: A new method for the analysis of genetically structured populations. BMC Genet 11:94.

Jost L (2008) GST and its relatives do not measure differentiation. Mol Ecol 17:40154026.

Kim D, Bauer BH, Near TJ (2021) Introgression and species delimitation in the Longear Sunfish Lepomis megalotis (Teleostei: Percomorpha: Centrarchidae). Syst Biol 2021:syab029.

Koppelman J (2015) Black bass hybrids: a natural phenomenon in an unnatural world. In: Tringali MD, Long JM, Birdson TW, Allen MS (eds) Black Bass Diversity: Multidisciplinary Science for Conservation. American Fisheries Society, Bethesda, MD, pp 467-479.

Kuipers KJJ, Hellweg S, Verones F (2019) Potential consequences of regional species loss for global species richness: A quantitative approach for estimating global extinction probabilities. Environ Sci Technol 53:4728-4738.

Lande R (1976) Natural selection and random genetic drift in phenotypic evolution. Evolution 30:314-334.

Langhurst R, Schoenike D (1990) Seasonal migration of Smallmouth Bass in the Embarrass and Wolf rivers, Wisconsin. North Am J Fish Manag 10:224-227.

Langmead B, Trapnell C, Pop M, Salzberg SL (2009) Ultrafast and memory-efficient alignment of short DNA sequences to the human genome. Genome Biol 10:1-10.

Lawson D (2013) Populations in statistical genetic modelling and inference. arXiv 1306.0701 .

Lawson DJ, Hellenthal G, Myers S, Falush D (2012) Inference of population structure using dense haplotype data. PLoS Genet 8:11-17.

Lee TH, Guo H, Wang X, et al (2014) SNPhylo: A pipeline to construct a phylogenetic tree from huge SNP data. BMC Genomics 15:1-6.

Lemopoulos A, Prokkola JM, Uusi-Heikkilä S, et al (2019) Comparing RADseq and 
microsatellites for estimating genetic diversity and relatedness - Implications for brown trout conservation. Ecol Evol 9:2106-2120.

Li H, Durbin R (2009) Fast and accurate short read alignment with Burrows-Wheeler transform. Bioinformatics 25:1754-1760.

Li H, Handsaker B, Wysoker A, et al (2009) The sequence alignment/map format and SAMtools. Bioinformatics 25:2078-2079.

Lipson M, Loh PR, Levin A, et al (2013) Efficient moment-based inference of admixture parameters and sources of gene flow. Mol Biol Evol 30:1788-1802.

Lipson M, Loh PR, Patterson N, et al (2014) Reconstructing Austronesian population history in Island Southeast Asia. Nat Commun 5:1-7.

Lischer HEL, Excoffier L (2012) PGDSpider: An automated data conversion tool for connecting population genetics and genomics programs. Bioinformatics 28:298299.

Long JM, Taylor AT, Buonaccorsi V (2020) A conservation-oriented SNP panel for Smallmouth Bass (Micropterus dolomieu), with emphasis on Interior Highlands lineages. Conserv Genet Resour 13:47-59.

Lundberg JG, Kottelat M, Smith GR, et al (2010) So many fishes, so little time: An overview of recent ichthyological discovery in continental waters. Ann Missouri Bot Gard 87:26-62.

Luu K, Bazin E, Blum MGB (2017) pcadapt: An R package to perform genome scans for selection based on principal component analysis. Mol Ecol Resour 17:67-77.

Lyons J, Kanehl P (2002) Seasonal movements of Smallmouth Bass in streams. In: Philipp D, Ridgway M (eds) Black Bass: Ecology, Conservation, and Management. American Fisheries Society, Bethesda, MD, pp 149-160.

Malinsky M, Trucchi E, Lawson DJ, Falush D (2018) RADpainter and fineRADstructure: Population Inference from RADseq Data. Mol Biol Evol 35:1284-1290.

Mavárez J, Linares M (2008) Homoploid hybrid speciation in animals. Mol Ecol $17: 4181-4185$.

Mayden RL (1985) Biogeography of Ouachita Highland fishes. Southwest Nat 30:195211.

McAllister DE, Platania SP, Schueler FW, et al (1986) Ichthyofaunal patterns on a geographic grid. In: Hocutt CH, Wiley EO (eds) The Zoogeography of North 
American Freshwater Fishes. John Wiley \& Sons, Ltd, New York, NY, pp 17-51.

McKinney GJ, Waples RK, Seeb LW, Seeb JE (2017) Paralogs are revealed by proportion of heterozygotes and deviations in read ratios in genotyping-bysequencing data from natural populations. Mol Ecol Resour 17:656-669.

Miller LM, Mero SW, Younk JA (2012) The impact of stocking on the current ancestry in twenty native and introduced muskellunge populations in Minnesota. Trans Am Fish Soc 141:1411-1423.

Miller R (1965) Quaternary freshwater fishes of North America. In: Wright J, Frey D (eds) The Quaternary of the United States. Princeton University Press, Princeton, NJ, pp 569-581.

Moyle PB, Li HW, Barton BA (1986) The Frankenstein effect: Impact of introduced fishes on native fishes in North America. In: Stroud R (ed) Fish culture in fisheries management. Bethesda, MD, pp 415-426.

Near TJ, Page LM, Mayden RL (2001) Intraspecific phylogeography of Percina evides (Percidae: Etheostomatinae): an additional test of the Central Highlands prePleistocene vicariance hypothesis. Mol Ecol 10:2235-2240.

Near TJ, Kassler TW, Koppelman JB, et al (2003) Speciation in North American black basses, Micropterus (Actinopterygii: Centrarchidae). Evolution 57:1610-1621.

Near TJ, Keck BP (2005) Dispersal, vicariance, and timing of diversification in Nothonotus darters. Mol Ecol 14:3485-3496.

Near TJ, Kim D (2021) Phylogeny and time scale of diversification in the fossil-rich sunfishes and black basses (Teleostei: Percomorpha: Centrarchidae). Mol Phylogenet Evol 161:107-156.

Nei M, Maruyama T (1975) Lewontin-Krakauer test for neutral genes. Genetics 80:395395.

Niemiller ML, Near TJ, Fitzpatrick BM (2012) Delimiting species using multilocus data: Diagnosing cryptic diversity in the southern cavefish, Typhlichthys subterraneus (Teleostei: Amblyopsidae). Evolution 66:846-866.

Patterson N, Moorjani P, Luo Y, et al (2012) Ancient admixture in human history. Genetics 192:1065-1093.

Patterson N, Price AL, Reich D (2006) Population structure and eigenanalysis. PLoS Genet 2:2074-2093. 
Perrier C, Guyomard R, Bagliniere JL, Evanno G (2011) Determinants of hierarchical genetic structure in Atlantic salmon populations: Environmental factors vs. anthropogenic influences. Mol Ecol 20:4231-4245.

Peterson BK, Weber JN, Kay EH, et al (2012) Double digest RADseq: An inexpensive method for de novo SNP discovery and genotyping in model and non-model species. PLoS One 7:e37135.

Pimm SL, Raven P (2000) Biodiversity - extinction by numbers. Nature 403:843-845.

Portik DM, Leaché AD, Rivera D, et al (2017) Evaluating mechanisms of diversification in a Guineo-Congolian tropical forest frog using demographic model selection. Mol Ecol 26:5245-5263.

Price AL, Patterson NJ, Plenge RM, et al (2006) Principal components analysis corrects for stratification in genome-wide association studies. Nat Genet 38:904-909.

Puckett EE, Etter PD, Johnson EA, Eggert LS (2015) Phylogeographic analyses of American black bears (Ursus americanus) suggest four glacial refugia and complex patterns of postglacial admixture. Mol Biol Evol 32:2338-2350.

Rahel FJ (2004) Unauthorized fish introductions: Fisheries management of the people, for the people, or by the people? In: Nickum, M.J., Mazik, P.M., Nickum, J.G., MacKinlay DD (ed) Propagated Fishes in Resource Management. Bethesda, MD, pp 431-444.

Rambaut A (2010) FigTree v.1.3.1.

Ray JM, Wood RM, Simons AM (2006) Phylogeography and post-glacial colonization patterns of the rainbow darter, Etheostoma caeruleum (Teleostei: Percidae). J Biogeogr 33:1550-1558.

Reich D, Thangaraj K, Patterson N, et al (2009) Reconstructing Indian population history. Nature 461:489-494.

Rhymer JM, Simberloff D (1996) Extinction by hybridization and introgression. Annu Rev Ecol Syst 27:83-109.

Ridgeway M, MacLean J, MacLeod J (1991) Nest-site fidelity in a centrarchid fish, the smallmouth Bass (Micropterus dolomieu). Can J Zool 69:3103-3105.

Robbins WH, MacCrimmon HR (1974) The black bass in America and overseas. Biomanagement and Research Enterprises, Sault Ste. Marie, Ontario, Canada

Robertson A (1975) Remarks on the Lewontin-Krakauer test. Genetics 80:396-396. 
Robison H, Buchanan T (1984) Fishes of Arkansas. University of Arkansas Press, Fayetteville, AR.

Robison HW (1986) Zoogeographic implications of the Mississippi River Basin. In: Hocutt H, Wiley EO (eds) The zoogeography of North American freshwater fishes. John Wiley \& Sons, Ltd, New York, NY, pp 267-285.

Roe KJ, Mayden RL, Harris PM (2008) Systematics and zoogeography of the rock basses (Centrarchidae: Ambloplites). Copeia 2008: 858-867.

Rovito SM, Parra-Olea G, Vásquez-Almazán CR, et al (2009) Dramatic declines in neotropical salamander populations are an important part of the global amphibian crisis. Proc Natl Acad Sci 106:3231-3236.

Ryder OA (1986) Species conservation and systematics: The dilemma of the subspecies. Trends Ecol Evol 1:9-10.

Savolainen O, Lascoux M, Merilä J (2013) Ecological genomics of local adaptation. Nat Rev Genet 14:807-820.

Schliep KP (2011) phangorn: Phylogenetic analysis in R. Bioinformatics 27:592-593.

Schluter D (1996) Ecological speciation in postglacial fishes. Philos Trans R Soc B Biol Sci 351:807-814.

Scott WB, Crossman EJ (1973) Freshwater fishes of Canada. Fisheries Research Board of Canada, Ottawa, Canada.

Seehausen O, Takimoto G, Roy D, Jokela J (2008) Speciation reversal and biodiversity dynamics with hybridization in changing environments. Mol Ecol 17:30-44.

Servedio MR, Noor MAF (2003) The role of reinforcement in speciation: Theory and data. Annu Rev Ecol Evol Syst 34:339-364.

Sharma S, Jackson DA (2008) Predicting Smallmouth Bass (Micropterus dolomieu) occurrence across North America under climate change: A comparison of statistical approaches. Can J Fish Aquat Sci 65:471-481.

Soltis DE, Morris AB, McLachlan JS, et al (2006) Comparative phylogeography of unglaciated eastern North America. Mol Ecol 15:4261-4293.

Springer A, Gompert Z (2020) Species collisions, admixture, and the genesis of biodiversity in poison frogs. Mol Ecol 1937-1940.

Stark WJ, Echelle AA (1998a) Genetic structure and systematics of Smallmouth Bass, with emphasis on interior highlands populations. Trans Am Fish Soc 127:393-416. 
Stepien CA, Karsiotis SI, Sullivan TJ, Klymus KE (2017) Population genetic structure and comparative diversity of smallmouth bass Micropterus dolomieu: Congruent patterns from two genomes. J Fish Biol 90:2125-2147.

Stepien CA, Murphy DJ, Strange RM (2007) Broad- to fine-scale population genetic patterning in the smallmouth bass Micropterus dolomieu across the Laurentian Great Lakes and beyond: An interplay of behaviour and geography. Mol Ecol 16:16051624.

Taylor AT, Long JM, Schwemm MR, Brewer SK (2018) Hybridization and genetic structure of Neosho Smallmouth Bass in the Ozark Highlands. North Am J Fish Manag 38:1226-1240.

Taylor AT, Long JM, Tringali MD, Barthel BL (2019) Conservation of Black Bass Diversity: An Emerging Management Paradigm. Fisheries 44:20-36.

Taylor CA, Jones SN, Bergey EA (2004) Crayfishes of Oklahoma revisited: New state records and checklist of species. Southwest Nat 49:250-255.

Thornbury WD (1965) Regional geomorphology of the United States. John Wiley and Sons, New York.

Thrasher DJ, Butcher BG, Campagna L, et al (2018) Double-digest RAD sequencing outperforms microsatellite loci at assigning paternity and estimating relatedness: A proof of concept in a highly promiscuous bird. Mol Ecol Resour 18:953-965.

Todesco M, Pascual MA, Owens GL, et al (2016) Hybridization and extinction. Evol Appl 9:892-908.

Truong HT, Ramos AM, Yalcin F, et al (2012) Sequence-based genotyping for marker discovery and co-dominant scoring in germplasm and populations. PLoS One $7: 37565$.

Väli Ü, Einarsson A, Waits L, Ellegren H (2008) To what extent do microsatellite markers reflect genome-wide genetic diversity in natural populations? Mol Ecol 17:3808-3817.

Valiquette E, Perrier C, Thibault I, Bernatchez L (2014) Loss of genetic integrity in wild lake trout populations following stocking: Insights from an exhaustive study of 72 lakes from Québec, Canada. Evol Appl 7:625-644.

Wiley EO, Mayden RL (1985) Species and speciation in phylogenetic systematics, with examples from the North American fish fauna. Ann Missouri Bot Gard 72:596-635.

Wringe BF, Stanley RRE, Jeffery NW, et al (2017) hybriddetective: A workflow and 
package to facilitate the detection of hybridization using genomic data in R. Mol Ecol Resour 17:275-284.

Zerbino DR, Birney E (2008) Velvet: Algorithms for de novo short read assembly using de Bruijn graphs. Genome Res 18:821-829.

Zheng X, Levine D, Shen J, et al (2012) A high-performance computing toolset for relatedness and principal component analysis of SNP data. Bioinformatics 28:33263328.

Zink RM, Slowinski JB (1995) Evidence from molecular systematics for decreased avian diversification in the Pleistocene Epoch. Proc Natl Acad Sci 92:5832-5835. 


\section{Tables and Figures}

Table 4.1. Sampling sites and associated sample sizes for 91 Smallmouth Bass and 4 Spotted Bass from three river drainages (Missouri River tributaries (MRT), White River drainage (WRD), and Arkansas River Basin (ARB)), and one Tennessee Lake-strainstocked lake population (LAKE).

\begin{tabular}{lllll}
\hline Site ID & Site Name & Taxon & Drainage & N \\
\hline 1 & Stockton Lake & Northern & MRT & 4 \\
2 & Big Piney River, MO & Northern & MRT & 5 \\
3 & Tablerock Lake & Northern & WRD & 4 \\
4 & Crooked Creek & Northern & WRD & 4 \\
5 & White River & Northern & WRD & 3 \\
6 & Skiatook Lake & Northern & LAKE & 5 \\
& & & Total Northern & $\mathbf{2 5}$ \\
7 & Buffalo Creek & Neosho & ARB & 6 \\
8 & Sycamore Creek & Neosho & ARB & 2 \\
9 & Big Sugar Creek & Neosho & ARB & 6 \\
10 & Elk River & Neosho & ARB & 7 \\
11 & Honey Creek & Neosho & ARB & 6 \\
12 & Spavinaw Creek & Neosho & ARB & 6 \\
13 & Illinois River & Neosho & ARB & 7 \\
14 & Baron Fork & Neosho & ARB & 6 \\
15 & Caney Creek & Neosho & ARB & 5 \\
16 & Lee Creek & Neosho & ARB & 4 \\
17 & Mulberry River & Neosho & ARB & 4 \\
18 & Big Piney Creek, AR & Neosho & ARB & 2 \\
19 & Illinois Bayou River & Neosho & ARB & 5 \\
& & & Total Neosho & $\mathbf{6 6}$ \\
SPB & Honey Creek, Illinois & Spotted Bass & ARB & 4 \\
& River, Elk River & & & $\mathbf{4}$ Total SPB \\
\hline
\end{tabular}


Table 4.2. Admixed populations (Adm. Pop), their inferred parent populations, and parameters inferred from two-population tests in MIXMAPPER. BS gives the number of bootstrap replicates supporting the given pair of parents; resnorm gives the residual error for each test; alpha gives the 95\% confidence intervals for the proportion of ancestry from Parent 1; Branch 1 Loc and Branch 2 Loc give the positions on branch 1 and branch 2, respectively, of the admixed population; Mixed Drift gives the drift time since admixture occurred.

\begin{tabular}{lllllllll}
\hline Adm. Pop & Parent 1 & Parent 2 & BS & resnorm & alpha & Branch 1 Loc & Branch 2 Loc & Mixed Drift \\
\hline ELK & MIDARK WHITE & 100 & $1.19 \mathrm{E}-06$ & $0.509-0.519$ & $0.011-0.011 / 0.011$ & $0.005-0.006 / 0.009$ & $0.001-0.001$ \\
ILLI & MIDARK SKIA & 100 & $1.23 \mathrm{E}-06$ & $0.786-0.793$ & $0.011-0.011 / 0.011$ & $0.015-0.015 / 0.015$ & $0.000-0.001$ \\
BAYOU & MIDARK WHITE & 100 & $9.12 \mathrm{E}-07$ & $0.705-0.720$ & $0.001-0.002 / 0.011$ & $0.003-0.004 / 0.009$ & $0.005-0.005$ \\
UPPARK & MIDARK WHITE & 100 & $6.56 \mathrm{E}-07$ & $0.785-0.792$ & $0.011-0.011 / 0.011$ & $0.006-0.007 / 0.009$ & $0.001-0.001$
\end{tabular}


Table 4.3. Best-fitting $(\triangle \mathrm{AIC}=0)$ two-population demographic models, likelihood, AIC, and parameters output from $\delta a \delta i$. Descriptions of all models are given in Table A2.1, and definitions of model parameters are given in Table A2.2.

\begin{tabular}{|c|c|c|c|c|c|c|c|c|c|c|c|c|c|}
\hline \multirow{2}{*}{ Pop 1} & \multirow{2}{*}{ Pop 2} & \multirow{2}{*}{ Model } & \multicolumn{11}{|c|}{ Parameter Estimates } \\
\hline & & & $\theta$ & $n u_{1}$ & $n u_{2}$ & $m_{12}$ & $m_{21}$ & $m_{12 a}$ & $m_{21 a}$ & $m_{12 b}$ & $m_{21 b}$ & $T_{1}$ & $T_{2}$ \\
\hline ELK & WHITE & $\mathrm{AM}$ & 6367.420 & 0.362 & 0.690 & 4.903 & 0.026 & -- & -- & -- & -- & 0.878 & -- \\
\hline ILLI & SKIA & SCAM & 2854.340 & 0.962 & 0.957 & 3.434 & 0.276 & -- & -- & -- & -- & 1.143 & 0.091 \\
\hline UPPARK & WHITE & AM2E & 3135.310 & 0.637 & 1.508 & -- & -- & 1.656 & 0.096 & 1.413 & 0.011 & 3.076 & 16.128 \\
\hline BAYOU & WHITE & SCAM & 4965.440 & 0.437 & 0.867 & 19.782 & 0.775 & -- & -- & -- & -- & 0.750 & 0.019 \\
\hline
\end{tabular}



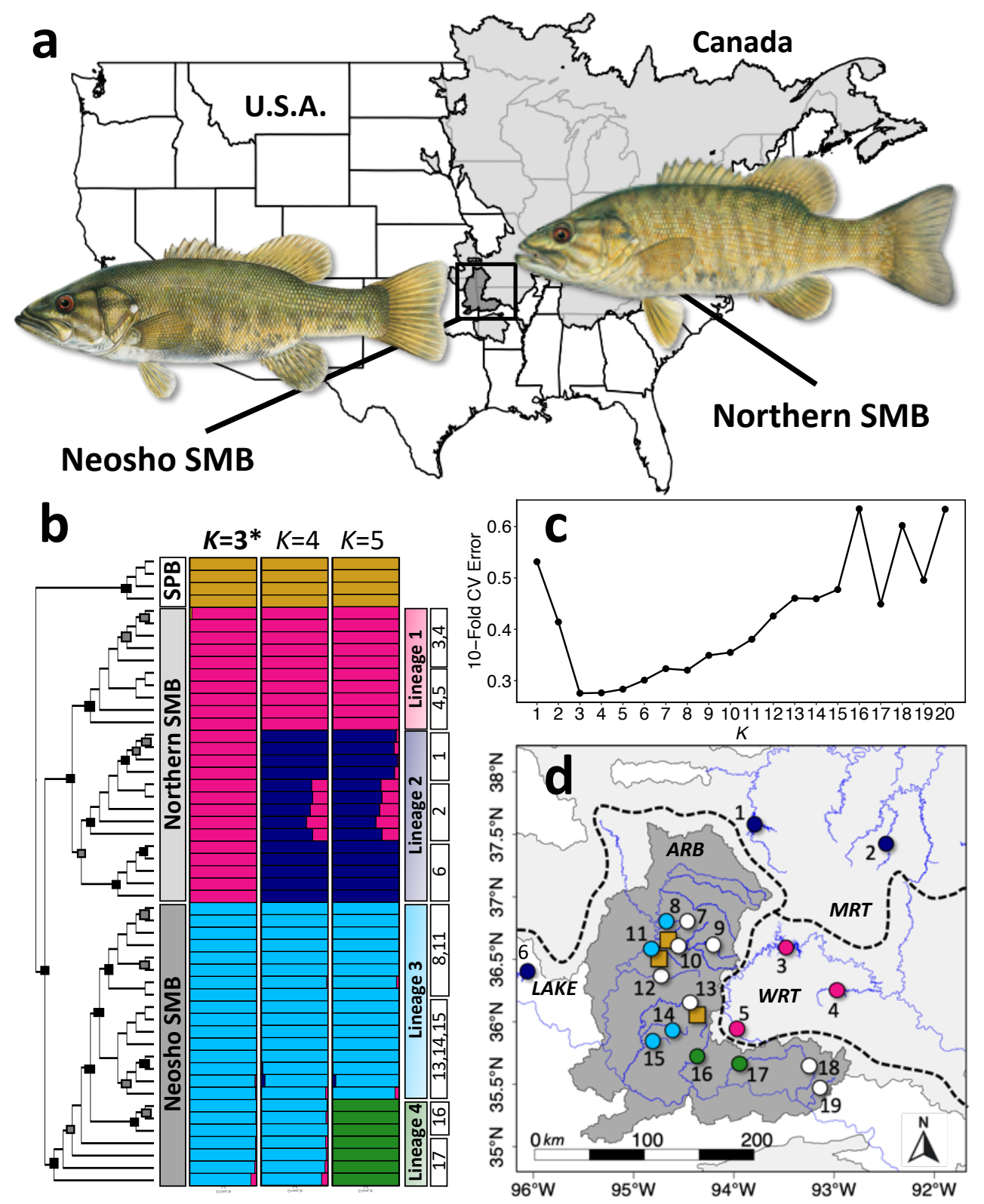

Figure 4.1. Subspecies geographic ranges, sampling sites, and distinct evolutionary lineages within the Smallmouth Bass. (a) Native ranges of the Neosho Smallmouth Bass (Neosho SMB; dark grey) and Northern Smallmouth Bass (Northern SMB; light grey), with representative illustrations. (b) Maximum likelihood phylogeny for putatively pure ( $p$-Pure) Smallmouth and Spotted Bass, with black and grey boxes at nodes indicating $100 \%$ and $>90 \%$ bootstrap support, respectively, and population structure results for $K=3$, $K=4$, and $K=5$, with major lineages and sample sites labeled corresponding to individual samples. (c) 10-fold cross-validation error results for admixture analysis. (d) Sampling sites (numbered as in Table 4.1) for Smallmouth (circles) and Spotted Bass (yellow squares), with Smallmouth Bass sites colored by distinct evolutionary lineages. White circles indicate sites where all or nearly all individuals were of putative admixed origin ( $p$-Admixed) based on preliminary analysis. *One individual in Site 13 was found to be $p$-Pure, and thus site 13 is listed under Lineage 3. Fish illustrations by Joseph Tomelleri. 

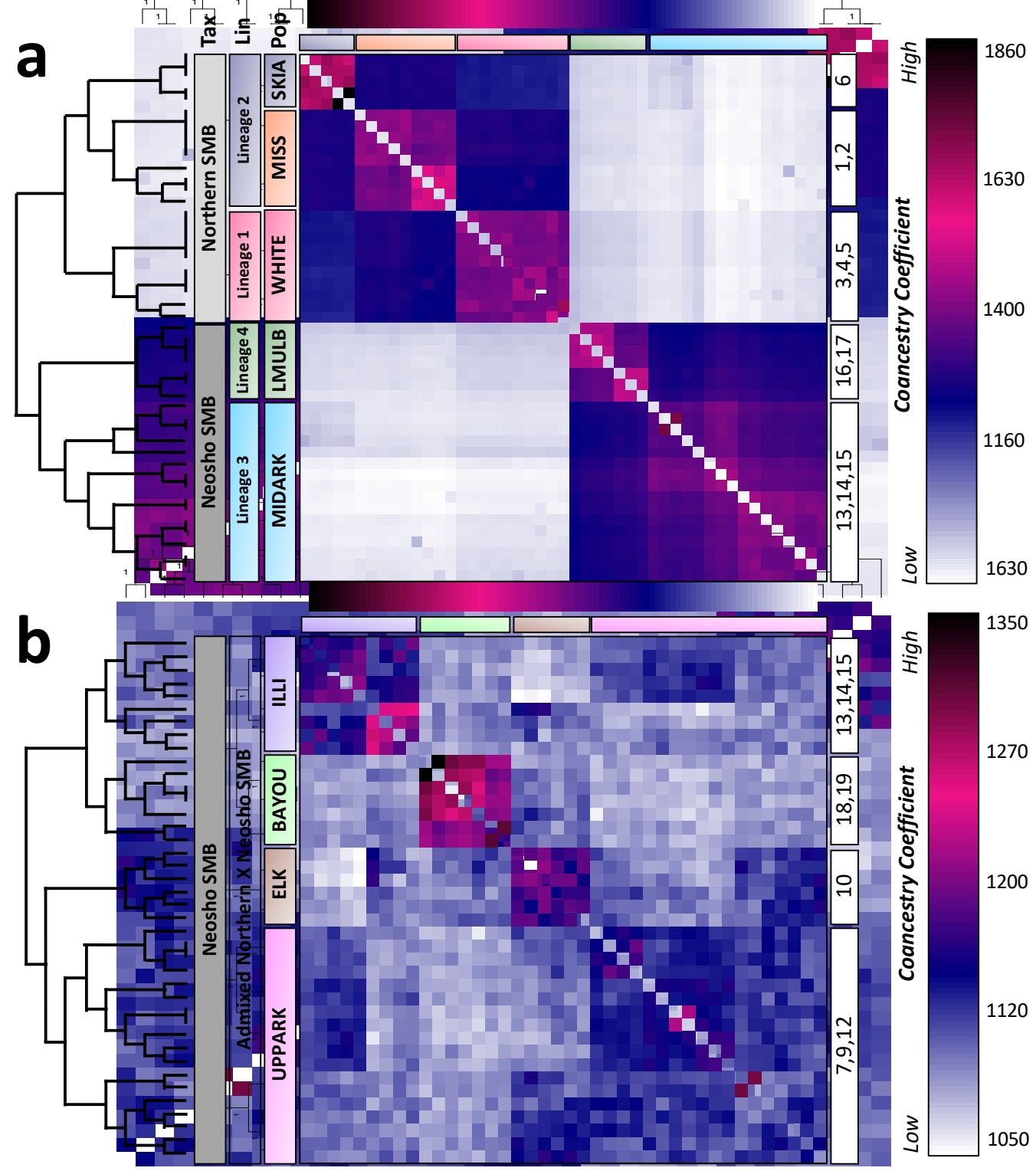

Figure 4.2. Co-ancestry and phylogenetic results from FINERADSTRUCTURE for (a) $p$ Pure samples, and (b) $p$-Admixed samples. We used the full non-thinned SNP dataset $(98,659)$ to generate SNP haplotypes for co-ancestry and phylogenetic assessment. Colors within the co-ancestry matrices reflect the extent of co-ancestry between adjacent samples, with white and blue representing low co-ancestry, and pink and black representing high co-ancestry. Inferred populations are colored on the vertical at left and along the top horizontal for reference, including the hatchery-stocked LAKE site (SKIA, navy blue), sites within the MRT (MISS, orange), sites within the WRT (WHITE, deep pink), Lee Creek and the Mulberry River (LMULB, dark green), tributaries of the middle ARB (MIDARK, sky blue), the Illinois River system (ILLI, light purple), Illinois Bayou River and Big Piney Creek, AR (BAYOU, light green), the Elk River (ELK, light brown), and tributaries of the upper ARB (UPPARK, light pink). All branches on the phylogenies at left are supported with $100 \%$ of bootstrap replicates. 

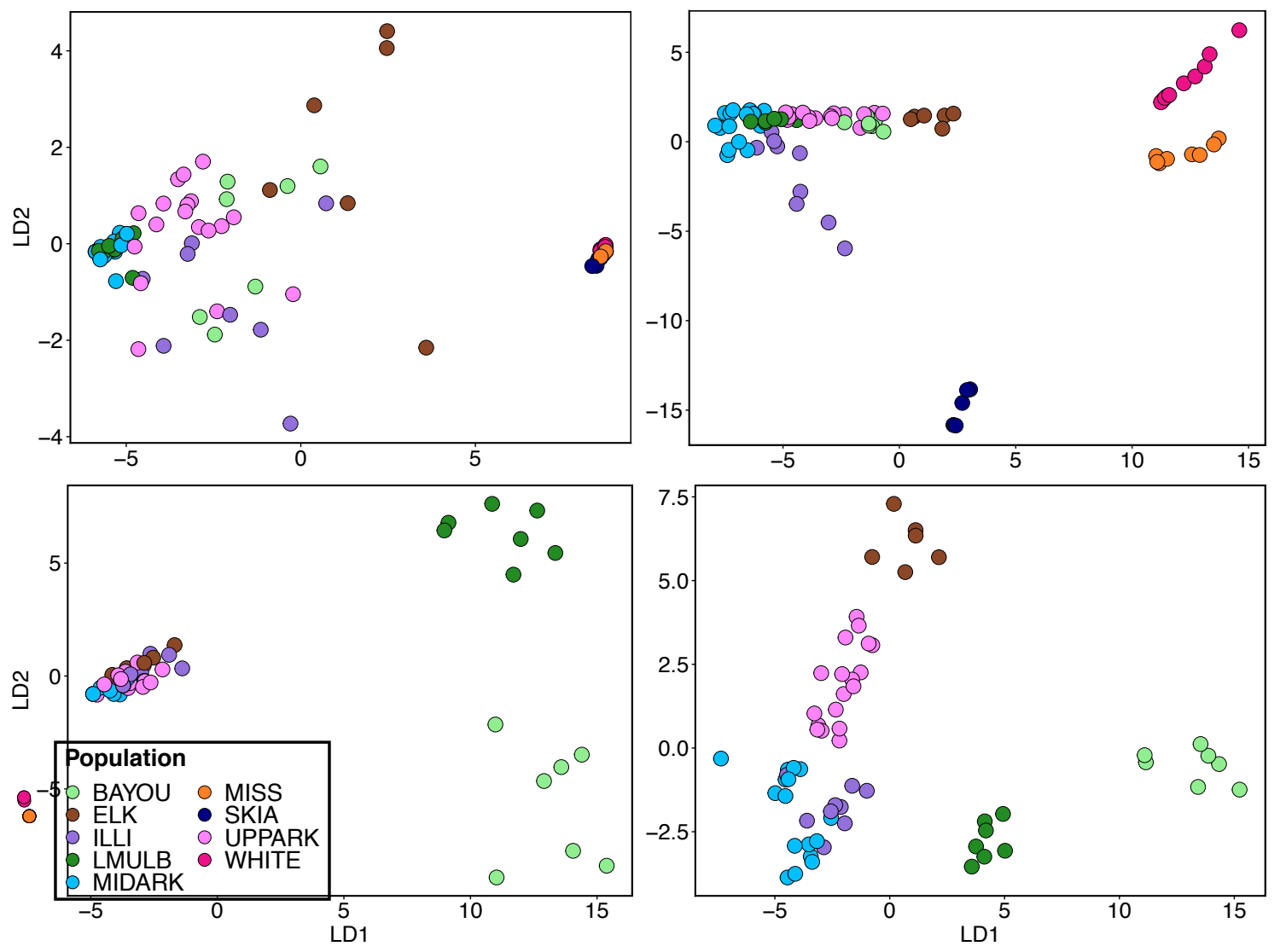

Figure 4.3. DAPC results for (a) outlier (156) and (b) neutral (41,324) SNPs shared by BAYESCAN and PCADAPT for all Smallmouth Bass samples; (c) outlier (29) and (d) neutral $(35,038)$ SNPs shared by BAYESCAN and PCADAPT for Neosho Smallmouth Bass only. 


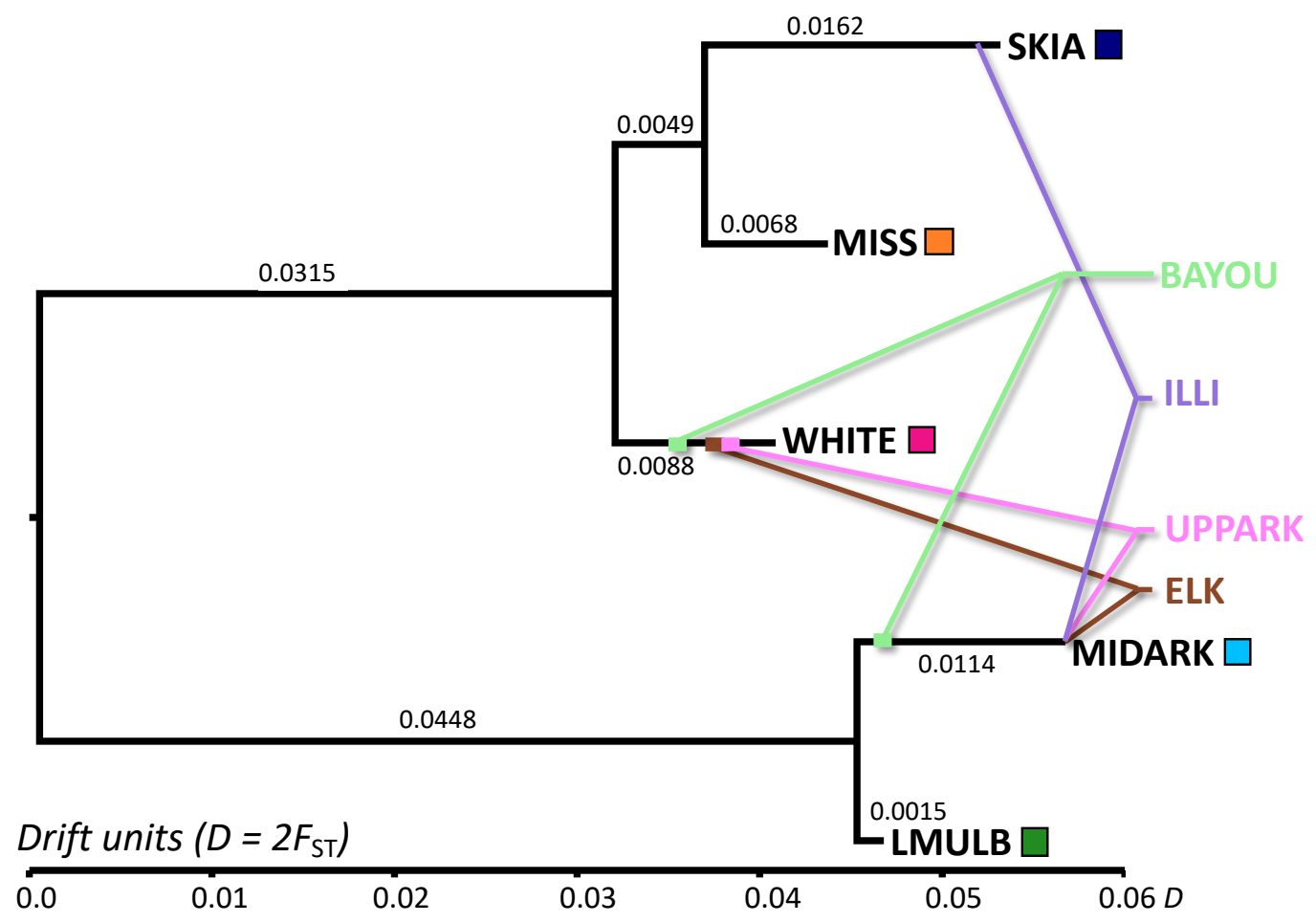

Figure 4.4. Admixture drift tree inferred in MIXMAPPER. Black labels plotted on the tips of the scaffold tree with corresponding-colored squares represent pure, unadmixed populations (as determined by a two-way $f_{3}$ test). Colored and shadowed branches and labels mapped onto the scaffold tree represent significantly admixed populations originating from their respective parents. The scale for branch lengths is in drift units $(D)$ in which $D$ is roughly equal to $2 F_{\mathrm{ST}}$. 

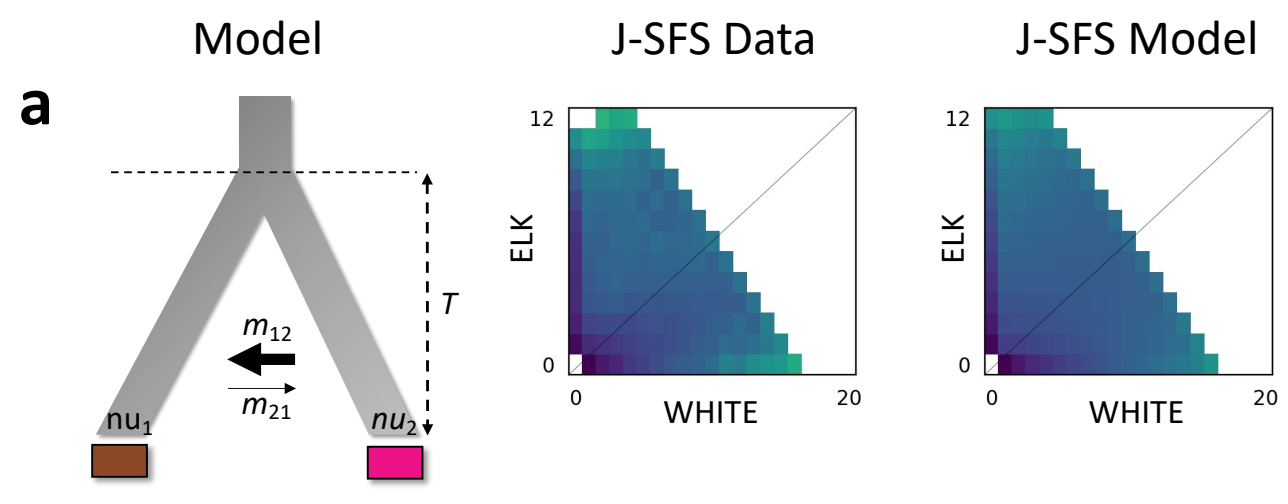

b
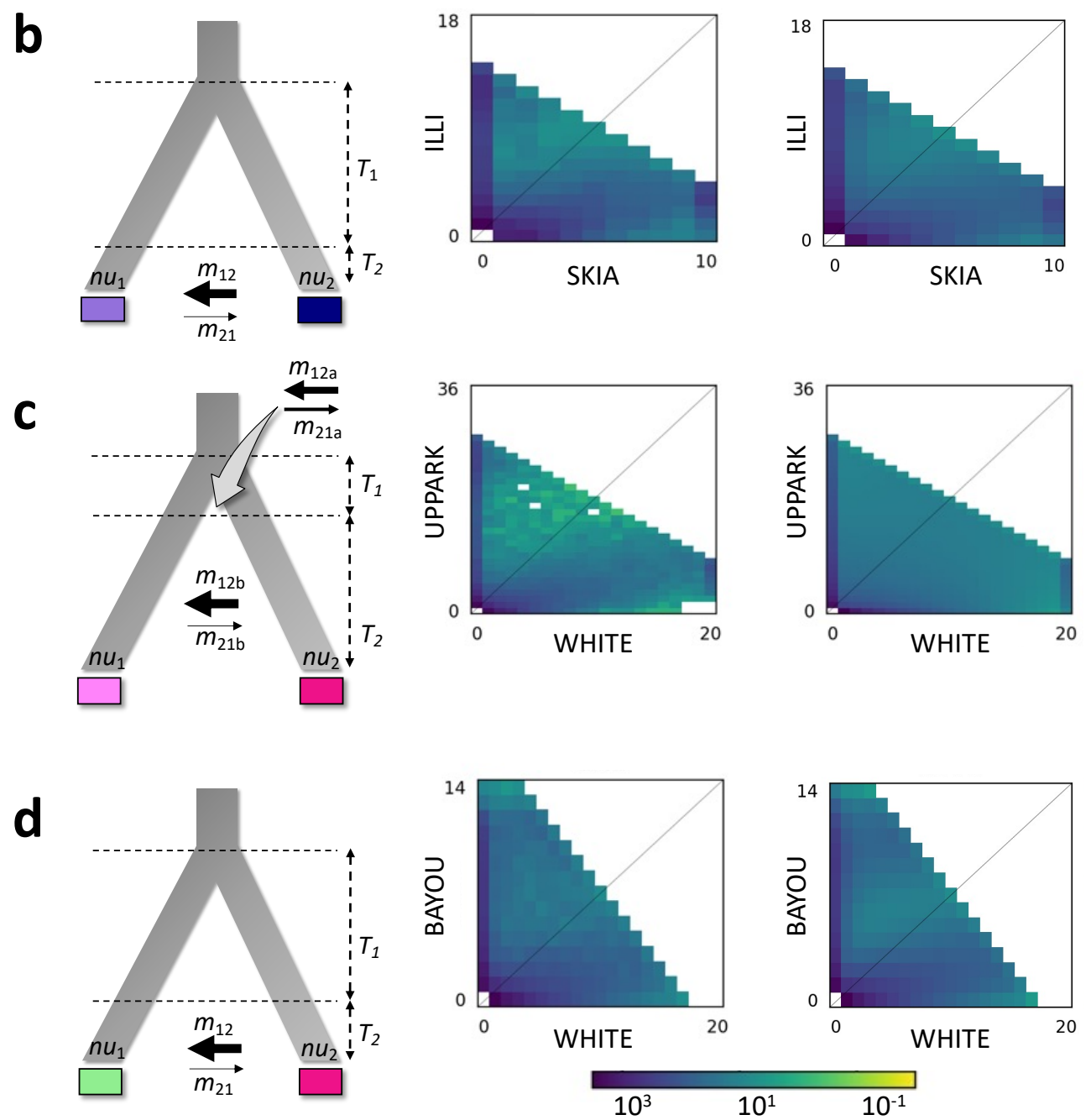

Figure 4.5. Schematics (first column), 2D joint site frequency spectrum of the empirical data (middle column), and 2D joint site frequency spectrum of the model (last column) of the best fitting two-population demographic models for (a) ELK and WHITE, (b) ILLI and SKIA, (c) UPPARK and WHITE, and (d) BAYOU and WHITE generated in $\delta a \delta i$. Lengths of arrows in the model schematics correspond roughly to the length of time (for $T$ parameters) or the rate of migration (for $m$ parameters) inferred in $\delta a \delta i$. 

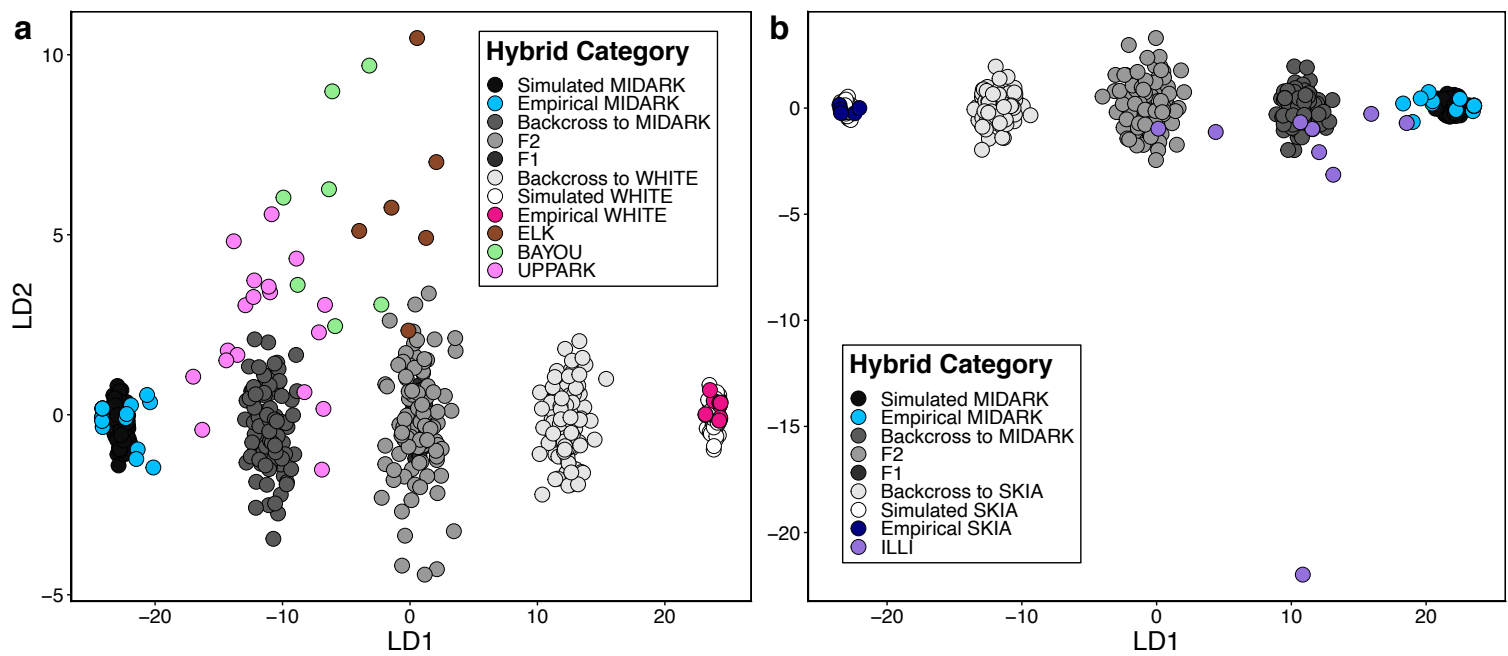

Figure 4.6. DAPC plot of simulated hybrid individuals in six hybrid categories (Parent 1 , Parent 2, $F_{1}$ hybrid, $F_{2}$ Hybrid, Backcross to Parent 1) based on 200 diagnostic SNPs selected from (a) MIDARK and WHITE parent populations, and (b) MIDARK and SKIA parent populations. Empirical data (colorful circles) are overlayed on simulated hybrid categories (grey-scaled circles) to determine similarity in genotypic space. 


\title{
CHAPTER 5
}

Admixture affects individual growth and body condition of the Neosho Smallmouth Bass (Micropterus dolomieu velox) in two Ozark rivers

Joe C. Gunn ${ }^{1}$, Edward M. Sterling ${ }^{2}$, Michael M. Moore ${ }^{3}$, Taylor Volkers ${ }^{1}$, Lori S. Eggert ${ }^{1}$

${ }^{1}$ Department of Biological Sciences, University of Missouri, 226 Tucker Hall, Columbia, MO 65211, USA

${ }^{2}$ U.S. Fish and Wildlife Service, 101 Park Deville Drive, Columbia, MO 65203, USA

${ }^{3}$ Missouri Cooperative Fish and Wildlife Research Unit, School of Natural Resources, University of Missouri, Columbia, MO 65211, USA

\begin{abstract}
Admixture between distinct lineages may facilitate introgressive hybridization, either inducing heterosis by masking deleterious alleles or, alternatively, driving species to extinction through outbreeding depression. It is critically important to understand the effects of introgression on wild populations, especially as human-mediated introductions occur more frequently. We sought to determine the effects of admixture on fitness in two rivers within the Neosho Smallmouth Bass (Micropterus dolomieu velox) range which are both known to be admixed with introduced Northern Smallmouth Bass (M. d. dolomieu). We genotyped 115 fish from Big Sugar Creek $(N=46)$ and the Elk River $(N=69)$ at 14 microsatellites and measured length and estimated age by counting annuli from sagittal otoliths. Combining genetic and age data, we mapped admixture geographically across rivers; modeled growth of Neosho, Northern, and Admixed Smallmouth Bass; assessed founder effects in the introduced Northern subspecies; and quantified heterozygosityfitness correlations (HFC) with body condition as a proxy for fitness. There was no
\end{abstract}


relationship between the proportion of Northern ancestry and geographic distance, and we found no evidence of founder effects. Smallmouth Bass grew more quickly and reached a higher maximum age in Big Sugar Creek than in the Elk River. There was no difference in growth or average length-at-infinity between Neosho, Northern, and Admixed fish in Big Sugar Creek, but Admixed fish reached a lower length-at-infinity than both Neosho and Northern Smallmouth Bass in the Elk River. We detected a significant HFC for body condition across both rivers, although there was no significant relationship within rivers. While hybridization may not be swamping out the Neosho subspecies, our results suggest that admixture negatively affects fitness in both rivers, which may have critical implications for the long-term persistence of the range-restricted Neosho Smallmouth Bass.

\section{Introduction}

Introgressive hybridization - the process by which unique, fixed alleles may move between distinct populations through repeated backcrossing — is a mechanism of interand intraspecific interbreeding (admixture) that may have significant implications for the preservation of species richness (Ellstrand and Schierenbeck 2006; Verhoeven et al. 2011; Bock et al. 2015). There are extensive bodies of literature regarding the influence of introgression on biodiversity (Seehausen et al. 2008), including scenarios in which it may induce speciation (Arnold 2006), and, conversely, scenarios in which it may cause extinction through genetic and phenotypic homogenization (Rhymer and Simberloff 1996; Allendorf et al. 2001). Conservationists have begun to pay greater attention to the 
topic in recent years, because admixture is now a common downstream result of humanmediated introductions (Estoup and Guillemaud 2010; Crispo et al. 2011).

Introgression following introduction may strongly benefit the non-native species by masking unfavorable genetic variants (Xiao et al. 1995) and simultaneously forming recombined genotypes that are favorable in its new environment (Verhoeven et al. 2011), resulting in heterosis (Keller and Taylor 2010; Shi et al. 2018). Numerous cases across animal and plant clades have been documented in which an introduced species has interbred with a closely related congener or subspecies, as with mallard ducks (Anas platyrhynchos; Lavretsky et al. 2019), feral housecats (Felis catus; Hubbard et al. 1992), rainbow and cutthroat trout (Oncorhynchus mykiss and O. clarki; Allendorf and Leary 1988; Dowling and Childs 1992), California tiger salamanders (Ambystoma californiense; Fitzpatrick and Shaffer 2007), Cuban anoles (Anolis sagrei; Kolbe et al. 2004), green crabs (Carnicus maenas; Vermeij 1982) and weedy sunflowers (Helianthus annuus; Rogers et al. 1982). In each of these cases, the non-native species has benefitted ecologically, or even become biologically invasive, after interbreeding as a result of increased hybrid fitness.

While admixture may be advantageous to the introduced species, it may have the reverse effect on native species. Susceptible native populations are often small, isolated, genetically depauperate (Brown 1989; Case 1990), and prone to high disturbance magnitudes (Suarez et al. 1998). Inhabiting such restricted ranges, they are likely to be highly specialized to a few narrowly defined ecological parameters. Over multiple generations, admixture with introduced species may lead to lack of hybrid fitness by creating epistatic incompatibilities among alleles (Bateson 1909; Dobzhansky 1934; 
Muller 1942) or may destroy linkage disequilibria among genes that have emerged in response to those parameters, eliminating local adaptation (Burton et al. 2013). The end result may be the complete replacement of the native species (Rhymer and Simberloff 1996). Predicting fitness outcomes after introduction is not trivial, so it is important to assess the effects of admixture on both populations directly where gene flow is likely ongoing.

Researchers have often turned to heterozygosity-fitness correlation (HFC; Chapman et al. 2009; Coltman and Slate 2009; Keller and Taylor 2010; Szulkin et al. 2010; Keller et al. 2014; Miller and Coltman 2014) as a tool for assessing the link between the degree of mixed ancestry and individual fitness in populations (David 1998). HFCs are traditionally used for detecting inbreeding depression (Santure et al. 2010; Townsend and Jamieson 2013; Botero-Delgadillo et al. 2020), in which higher heterozygosity in functional genes is expected to prevent expression of deleterious alleles through overdominance (Mitton 1997; David 1998). Inversely, in cases where HFCs are negative, they may reliably uncover cases of outbreeding depression, whereby greater admixture-induced heterozygosity breaks down adaptive gene complexes that function through epistasis between specific alleles (Allendorf et al. 2001; Chapman et al. 2009; Szulkin and David 2011). It is possible to test for outbreeding depression in an admixed population by assessing neutral genetic loci (i.e., microsatellites); if variance in heterozygosity is correlated among loci, it is assumed that heterozygosity extends across the whole genome and may therefore be affecting selection at functional loci (David et al. 1995; Lynch and Walsh 1998; Hansson et al. 2004). 
The Smallmouth Bass (Micropterus dolomieu), native to central and eastern North America (Nigh and Schroeder 2002; Brewer and Orth 2015) is an ecologically important freshwater fish species whose reputation as a popular sportfish has opened the door for widespread introductions outside its native range. Millions of Smallmouth Bass have been stocked — moved into bodies of water, usually after being propagated in a hatchery — to fuel the angling industry around the world (Iguchi et al. 2004; Aday et al. 2009). Although introductions are often lucrative for local tourist economies (USFW 2016; Carey et al. 2011), they have facilitated invasions in the Pacific Northwest (Carey et al. 2011), eastern Canada (O'Sullivan et al. 2020), and in at least nine other countries (Iguchi et al. 2004; Loppnow et al. 2013). In each of these cases, they have either outcompeted native fishes, decimated populations through predation, or introgressed with congeners (Avise et al. 1997). The high frequency of successful introductions of Smallmouth Bass may be related to broad ecological tolerances throughout its range, including high thermal tolerance (Brown et al. 2009).

A likely additional introduction of Smallmouth Bass has occurred at the range boundary of the two described subspecies in the Central Interior Highlands $(\mathrm{CIH})$ in the United States (USA). The Northern Smallmouth Bass (M. d. dolomieu) is native to regions between the eastern portion of the Ozark Plateau in the $\mathrm{CIH}$ and southeastern Canada (Hubbs and Bailey 1940; Brewer and Long 2015; Brewer and Orth 2015), but it has almost certainly been stocked within the narrowly-defined native range of the Neosho Smallmouth Bass (M. d. velox) in the Arkansas River Basin (This Dissertation, Chapter 4; Taylor et al. 2018). The Northern and Neosho Smallmouth Bass have been found to be divergent morphologically (Hubbs and Bailey 1940; Gunn et al. 2020) and genetically 
based on microsatellites (Gunn et al. 2020) and single nucleotide polymorphisms (SNPs, This Dissertation, Chapter 4), with multiple lineages evolving independently in each subspecies. Some Neosho populations have also been shown to be locally adapted based on the presence of multiple SNPs under strong diversifying selection pressure (This Dissertation, Chapter 4). Despite their differentiation, there are also strong signatures of recent, asymmetric admixture with the Northern Smallmouth Bass in several Arkansas River Basin streams within the Neosho range, suggesting the occurrence of previous stocking.

Two of the most substantially admixed populations in the Neosho range are in Big Sugar Creek and the Elk River, both of which flow into the mainstem of the Arkansas River (Gunn et al. 2020). The Elk River population has exhibited much higher average longevity than in surrounding streams. Longevity may be inconsistent among Smallmouth Bass populations (Ahlert et al. 1995; Brewer and Long 2015) as the relationship between age and size is largely dependent on water temperature (Serns 1982; King et al. 1999; Dunlop and Shuter 2006; Whitledge et al. 2006; Brewer 2013), flow rate (Paragamian and Wiley 1987) and type of prey resources available (Steinhart and Marschall 2004). But, fish in the Elk River have been observed to have much higher average longevity than in surrounding streams, surviving up to 10 years (Meneau 2010) as compared to other fish in the $\mathrm{CIH}$ which have been reported to reach a maximum of 6 years (Brewer and Long 2015).

The proximate reason for increased Smallmouth Bass survival in the Elk River system is unknown, although researchers have cited low angler exploitation and highquality habitat as possible contributing factors (Brewer and Long 2015). Each of these 
studies utilized fish scales to determine age for growth and longevity calculation. Sagittal otolith data, which is increasingly more common in fisheries research, is known to give more precise estimates of age in Smallmouth Bass than other previously used methods, including scales or dorsal spine (Long and Fisher 2001). Regardless, greater longevity, which may be indicative of higher survival rates in general, is coincident with the highest observed levels of genomic admixture between the Smallmouth Bass subspecies in the $\mathrm{CIH}$ and may therefore indicate heterosis, which has significant consequences for the evolutionary trajectory of these populations, the viability of the Neosho subspecies, and diversity of Smallmouth Bass overall.

Here, we sought to assess the effects of admixture on fitness in the Northern and Neosho Smallmouth Bass subspecies in two stream systems that are known to be highly admixed. We used estimates of individual age based on sagittal otoliths along with genetic information from 14 microsatellite loci to address three aims: 1) test for possible founder effects on introduced Northern Smallmouth Bass, 2) compare individual growth among Neosho, Northern, and admixed Smallmouth Bass in the Elk River and Big Sugar Creek, and 3) test the effect of admixture on fitness by identifying heterozygosity-fitness correlations for individual body condition. We hypothesized that the Northern Smallmouth Bass detected within the Elk River and Big Sugar Creek would have lower population-level genetic diversity than Northern Smallmouth Bass within the Northern native range, consistent with founder effects. We also hypothesized that admixture would have a positive effect on growth, with admixed individuals reaching higher maximum age than both Neosho and Northern Smallmouth Bass. Finally, we hypothesized that higher heterozygosity would be positively correlated with body condition. 


\section{Materials and Methods}

\section{Study Site Selection}

We sampled Smallmouth Bass (Micropterus dolomieu) from two rivers within the Neosho Smallmouth Bass (M. d. velox) native range: Big Sugar Creek and the Elk River. Big Sugar Creek is a mid-sized stream with headwaters $6.4 \mathrm{~km}$ west of the White River, which lies within the White River drainage and is part of the Northern Smallmouth Bass (M. d. dolomieu) native range. Big Sugar Creek flows $76 \mathrm{~km}$ west until it converges with Little Sugar Creek to form the headwaters of the Elk River near Pineville, MO (36.5871314, -94.3883997). The Elk River is a shorter but slightly faster-moving stream, flowing $57 \mathrm{~km}$ west until it feeds into the Neosho River at Grand Lake, OK (36.5460872, -95.036027; Figure 5.1a-c). Both streams have been shown in previous studies of population structure using microsatellite markers (Gunn et al. 2020) and genome-wide SNPs (Gunn et al. in prep) to contain substantial yet heterogeneous levels of admixture between the Smallmouth Bass subspecies, suggesting the presence of individuals of highly differential ancestry ranging from mostly pure Neosho to mostly pure Northern Smallmouth Bass. Varying ancestry proportions in these two streams allows us to directly compare growth rates of genetically Neosho, Northern, and admixed fish in a natural system.

\section{Sample Collection and Processing}

We collected Smallmouth Bass by angling from sites along the lower stretches of Big Sugar Creek and the upper Elk River, between Deep Ford (DFA; 36.6160668,94.3560097) and Mount Shira (MSA; 36.5766538, -94.463884) conservation access 
points, in Fall 2020 (Table 5.1; Figure 5.1a-c). We sampled only individuals that were a minimum of $200 \mathrm{~mm}$ in total length (TL). We aimed to collect 75 fish from each stream with approximately 10 individuals per $25 \mathrm{~mm}$ TL interval following the methods described in Sterling et al. (2019). Since our collections were conducted entirely by angling and thus highly opportunistic, sample sizes varied between Big Sugar Creek and the Elk River.

Upon capture, we immediately measured TL while fish were alive and placed them in individual plastic bags on ice. Whole fish were stored in a $-20^{\circ} \mathrm{C}$ freezer until processing. When processing began, we allowed fish to thaw completely, after which we recorded mass (g) and standard length (SL; mm) according to the methods of Gunn et al. (2020). We removed $\sim 25 \mathrm{mg}$ portions of tissue from the upper caudal fin of each fish and stored them in individual $1.5 \mu \mathrm{L}$ tubes with RNAlater buffer solution at $-20^{\circ} \mathrm{C}$ for later genetic analyses. Sex was determined by internal gonadal examination. Sagittal otoliths, which have been shown to be the preferred structure for precise and accurate assessment of Smallmouth Bass age (Long and Fisher 2001), were removed with fine tweezers to prevent cracking and stored whole in labeled vials at room temperature for later age estimation.

\section{Genetic Analyses}

We extracted genomic DNA ( $g$ DNA) from fin clips collected from Big Sugar Creek and the Elk River following the manufacturer's instructions in the DNeasy Blood and Tissue Kit (QIAGEN, Germantown, Maryland, USA), modifying the protocol slightly to elute DNA in $100 \mu \mathrm{L}$ AE buffer solution. To accurately assess ancestry 
proportions for fish in downstream analyses, we additionally re-extracted $g$ DNA from 20 fin clips from tributaries of the White River (Tablerock Lake (Table 5.1; Figure 5.1a, site 1), Crooked Creek (site 2), and the White River (site 3)) within the Northern Smallmouth Bass native range) which had been previously collected between Fall 2015 and Fall 2017 (Gunn et al. 2020). Additionally, we included genotypes from 503 fin clips previously collected from 15 stream populations, excluding the Elk River and Big Sugar Creek, throughout the Neosho Smallmouth Bass range and 99 fin clips previously collected from six stream populations in the Northern Smallmouth Bass range (Gunn et al. 2020) to serve as a Neosho reference and a Northern reference, respectively, to compare genetic diversity metrics (Gunn et al. 2020).

We amplified all samples at 14 microsatellite loci, which were arranged in four PCR multiplexes, following the methods of Gunn et al. (2020). In all PCRs, we included one positive control to standardize allele scoring and one negative (no-DNA) control to detect contamination of reagents.

We visualized amplified products on a $2 \%$ agarose gel and performed fragment analysis in an ABI 3730xl DNA analyzer (Applied Biosystems) with a GS600 size standard at the MU DNA Core Facility. We scored genotypes in GENEMARKER v.1.97 (Softgenetics, State College, Pennsylvania, USA) and tested for deviations from HardyWeinberg Equilibrium expectations and for linkage disequilibrium with GENEPOP (Raymond and Rousset 1995; Rousset 2008). We then tested for genotyping error, including false alleles, null alleles, and allelic dropout, by re-amplifying and rescoring a subset ( 18\%) of our samples at all 14 loci and comparing genotyping results in GIMLET v.1.3.2 (Valière 2002). 


\section{Individual Ancestry and Admixture Discovery}

To identify individuals as pure Northern Smallmouth Bass, pure Neosho Smallmouth Bass, or admixed, we conducted population structure analysis in STRUCTURE (Pritchard et al. 2000), which employs a Bayesian model-based clustering algorithm to calculate ancestry proportions $(q)$ of each individual from an a posteriori determined number of genetic clusters $(K)$. We included samples from Big Sugar Creek and the Elk River along with our Northern reference samples, for a total of three "populations" in the analysis. We did not include the Neosho reference population to avoid underestimating Neosho ancestry due to hierarchical structure within the Neosho range (Taylor et al. 2018; Gunn et al. 2020).

We used the admixture model with no prior for location and ran the model for $K=1-5$ with 500,000 burn-in steps, 1,000,000 MCMC iterations, and 10 replicates for each $K$. We inferred the most likely number of $K$ using the $\Delta K$ metric (Evanno et al. 2005) in StRUCTURE HARVESTER (Earl and vonHoldt 2012) and Puechmaille metrics (Puechmaille 2016) in StRUCTURE SELECTOR (Li and Liu 2018). We generated consensus assignments based on the best $K$ value in CLUMPAK (Kopelman et al. 2015). Average assignments to each genetic cluster across replicates were then calculated for each individual using the LARGEKGREEDY parameter and 10,000 repeats in CLUMPP v.1.1.2 (Jakobsson and Rosenberg 2007). Within our known pure Northern Smallmouth Bass population (tributaries of the White River), the lowest assignment to the Northern genetic cluster for any one individual was $q=0.729$. Thus, individuals with ancestry assignments greater than 0.729 to either Smallmouth Bass subspecies were assigned an admixture 
status of pure "Neosho" or "Northern," and individuals assigning $0.271<q<0.729$ were assigned an admixture status of "Admixed."

Age Estimation using Sagittal Otoliths

Otoliths are small, calcerous structures located near the posterior end of the cranial cavity in most fishes (Popper et al. 2005) and are thought to be involved in hearing and balance (Popper and Lu 2000). They grow through alternating depositions of protein and calcium carbonate; uniquely, these depositions (annuli) continue over the individual's lifespan despite potential cessations in somatic development caused by environmental factors, such as limited prey availability (Campana and Thorrold 2001). Of the three otolith types - lapilli, asterisci, and sagittae — the sagittae are the largest and thus most preferable to use for aging of teleost fishes, which include the Smallmouth Bass. Accretion of opaque protein-rich material and translucent calcium carbonate occur annually and can be distinguished visually through light microscopy (Figure A3.1). Because of the distinguishable layers that are formed uninterrupted on an annual basis, otoliths are currently the most commonly used structure (Maceina et al. 2007) for estimating individual age. Smallmouth Bass sagittal otoliths have been shown to reliably form annual ring depositions (Heidinger and Clodfelter 1987; DeVries and Frie 1996) that provide precise age estimates (Long and Fisher 2001).

Whole sagittal otoliths were dried and visualized under a dissecting microscope. To improve clarity, otoliths were submerged in glycerol and illuminated from the side with a fiber optic light source (Buckmeier and Howells 2003). Any otoliths that appeared to have annuli crowded at the margins or were unclear were fractured on the transverse 
plane, mounted in clay, submerged in glycerol, and viewed using illumination from a fiber optic light (Buckmeier and Howells 2003). We captured images of individual otoliths at low magnification using a Nikon SMZ25 dissecting microscope with a camera using NIS Elements software.

Due to sampling restrictions, only Smallmouth Bass greater than 200mm TL were collected for aging. Linear back-calculation of otoliths was used on a subset of high-age fish $(N=21)$ to provide estimates of length-at-age for missing age classes (Weisberg 1986) within inferred admixture status groups based on the Dahl-Lee formula:

$$
L_{\mathrm{i}}=L_{\mathrm{c}}\left(\frac{S_{\mathrm{i}}}{S_{\mathrm{c}}}\right)
$$

Where $L_{i}$ is the back-calculated length (mm) of the fish at the $i^{\text {th }}$ growth annulus, $L_{c}$ is the true measured length of the fish (mm), $S_{i}$ is the otolith radius at the $i^{\text {th }}$ annulus (microns), and $S_{c}$ is the radius of the whole otolith (microns, Francis 1990). Back-calculated lengthat-age of other centrarchid species using sagittal otoliths has been shown to be reliable (Frie 1982; Taubert and Tranquilli 1982; Hales and Belk 1991; Wahl et al. 2009). All back-calculations were conducted using previously captured photographs in the software program TPSDIG2 (Rohlf 2004).

Otolith images were assessed by three independent readers, each of whom counted the number of opaque ring depositions, beginning at the nucleus and radiating outward (Figure A3.1). When there were discrepancies in age between readers, otoliths were reassessed and discussed until consensus was reached (Maceina and Sammons 2006). 


\section{Geographic Distribution of Admixture}

We considered our sampled rivers, Big Sugar Creek and the Elk River, to be two independent replicates to account for potential ecological differences between them. We mapped the geographic distribution of admixture as inferred in STRUCTURE for each river by grouping samples approximately every 1,000 linear river meters (increasing the distance as necessary to maximize sample size per group) and calculating 1) the average proportion of ancestry assigning to inferred clusters for each individual (Figure 5.1b) and

2) the absolute proportion of individuals assigning to one of three categories: Neosho (pure Neosho Smallmouth Bass), Northern (pure Northern Smallmouth Bass), or Admixed (admixed Smallmouth Bass; Figure 5.1c).

To test for patterns of introduced Northern Smallmouth Bass cluster membership moving downstream between DFA on Big Sugar Creek and MSA on the Elk River, we tested for a linear relationship between the distance from DFA and percent of Northern ancestry globally (across both streams) and within each river using linear mixed effect models, setting sex as a random effect. Within Big Sugar Creek, we assessed this relationship between DFA and the Elk River headwaters; within the Elk River, we assessed this relationship between the headwaters and MSA. Additionally, we tested for a difference in overall proportion of Northern ancestry between Big Sugar Creek and the Elk River using a mixed effect ANOVA, again setting sex as a random effect.

We also tested for a relationship between distance from DFA and the proportion of individuals assigned as pure, introduced Northern Smallmouth Bass, again interrogating the global dataset and both replicate rivers individually, using linear models 
in $R$. We did not include sex as a mixed effect in this case, as proportion of Northern individuals was ascertained from multiple samples.

\section{Founder Effects}

We tested for evidence of founder effects (the presence of low genetic diversity as a result of population expansion after colonization by only a few individuals) in pure, introduced Northern Smallmouth Bass within Big Sugar Creek and the Elk River by comparing four metrics of genetic diversity between our replicate rivers and our Northern reference population: allelic richness $(A)$, observed heterozygosity $\left(H_{\mathrm{O}}\right)$, expected heterozygosity $\left(H_{\mathrm{E}}\right)$, and the inbreeding coefficient $\left(F_{\mathrm{IS}}\right)$. We computed diversity metrics across samples for each microsatellite locus independently, and we compared averages across loci both globally (between all Big Sugar Creek and Elk River samples and Northern Reference samples) and among rivers within populations using linear models. All metrics were calculated using the gstudio package (Dyer 2016) in $R$ v.4.0.2 (R Core Team 2018).

Individual Growth Analysis

We estimated individual growth for Smallmouth Bass samples by fitting TL, including back-calculations, and consensus age data from sagittal otoliths to the Von Bertalanffy growth model (Von Bertalanffy 1938) as parameterized by Beverton and Holt (1957):

$$
L=L_{\infty}\left[1-e^{-K\left(T-t_{0}\right)}\right],
$$


where $L$ is total length (mm), $L_{\infty}$ is theoretical maximum length, $T$ is age, $K$ is the Brody growth coefficient (the rate at which mean length approaches $L_{\infty}$ ), and $t_{0}$ is theoretical age at which fish length is zero. We used the built-in equation in the $R$ package $F S A$ v.0.8.32 (Ogle et al. 2021) for model parameterization, and we used the bootstrapping function in

the $R$ package car (Fox and Weisberg 2019) to compute 95\% confidence intervals for 999 bootstrap replicates across samples. Differences in parameter estimates among groups were inferred by non-overlapping confidence intervals.

We modeled individual growth for each admixture status (Neosho, Northern, or Admixed) both globally (combining samples from Big Sugar Creek and the Elk River) and within each replicate river. We additionally modeled growth for males and females globally and within rivers to control for differences between sexes in downstream analyses.

\section{Heterozygosity-Fitness Correlation}

We tested for a heterozygosity-fitness correlation (HFC) in Smallmouth Bass samples across the global dataset and within both Big Sugar Creek and the Elk River. We used body condition as a proxy for individual fitness, as this trait accounts for length and weight and is therefore considered to be a reliable indicator of fish health (see Bolger and Connolly 1989 for a review of body condition indices). To calculate body condition, we employed the Fulton's Condition Factor, defined by the equation:

$$
K=\frac{W}{L^{3}},
$$


where $K$ is the condition index, $W$ is mass $(\mathrm{g})$, and $L$ is total length $(\mathrm{cm})$. The Fulton Condition Index requires that fish grow isometrically; we ensured that fish in the global and individual river datasets conformed to this assumption by assessing whether the relationship between TL and mass was linear using linear models in $R$. We additionally tested whether body condition was correlated with age to determine whether we would need to control for this variable, and we tested whether body condition deviated from a normal distribution using the Shapiro-Wilk method in $R$.

For each analysis, we computed standardized multi-locus heterozygosity, calculated by dividing the proportion of heterozygous markers by the population average heterozygosity (e.g., Bensch et al. 2006), across microsatellite loci for each individual using the $R$ package inbreed $R$ v.0.3.2 (Stoffel et al. 2016). To determine our statistical power for detecting a significant, general-effect HFC given the correlation in heterozygosity between pairs of loci (Weir and Cockerham 1973), we calculated the $g_{2}$ statistic, a measure of identity disequilibrium (Szulkin et al. 2010), running 1000 permutations with 1000 bootstrap replicates each to estimate $95 \%$ confidence intervals.

We ran linear models with standardized heterozygosity as a predictor and body condition as a response variable to test for HFCs on all datasets. For each dataset, we additionally ran univariate mixed effect ANCOVA models to test for differences in slope between admixture status groups, retaining heterozygosity as a covariate and sex as a random effect. Finally, we complemented these analyses by determining 1) the extent to which multi-locus heterozygosity differed between our study populations (Elk River and Big Sugar Creek) and both the Neosho and Northern references, and 2) the extent to which multi-locus heterozygosity differed between all admixture status groups (Neosho, 
Northern, and Admixed) within Big Sugar Creek and the Elk River. Significant

differences between all pairs of groups were determined by post hoc Tukey tests in $R$.

\section{Results}

\section{Sample Collection}

We obtained 115 Smallmouth Bass samples from Big Sugar Creek $(N=46)$ and the Elk River ( $N=69)$ ranging from 200-419mm total length (TL; Table 5.1b; Table A3.1). All samples were successfully amplified in at least 12 of 14 microsatellite loci and so were retained for analysis. Within Big Sugar Creek, we obtained a greater number of females $(N=27)$ than males $(N=19)$, but in the Elk River, number of females $(N=32)$ and males $(N=37)$ were relatively even. In Big Sugar Creek, we inferred differing numbers of pure Neosho fish $(N=22)$, pure Northern fish $(N=7)$ and admixed fish $(N=17)$ from STRUCTURE analysis. Similarly, in the Elk River, we inferred differing numbers of pure Neosho fish $(N=26)$, pure Northern fish $(N=12)$ and admixed fish $(N=31)$ from STRUCTURE analysis (Table A3.1).

\section{Hardy-Weinberg Equilibrium and Genotyping Error}

No microsatellite locus deviated from expectations of Hardy-Weinberg Equilibrium in more than one of three populations after Bonferroni correction. Two loci, mdo6 and $m d o 2$, were found to be in linkage disequilibrium after Bonferroni correction in Big Sugar Creek and the Elk River. However, these loci were not linked in either the Northern or Neosho reference populations; thus, we attributed this signature to admixture linkage disequilibrium (ALD; Pfaff et al. 2001) and retained both loci in downstream 
analyses. We detected low genotyping error rates across loci $(2.7 \%$ allelic dropout rate, $0 \%$ false allele rate, and 1.2\% Type I error rate) and across samples (3.5\% allelic dropout rate, $0 \%$ false allele rate, and $0.07 \%$ Type I error rate).

\section{Individual Ancestry}

We found highest support for $K=2$ genetic clusters in STRUCTURE based on the $\Delta K$ metric ( $\Delta K=27.609$; Table A3.2) and Puechmaille metrics (Table A3.3; Figure A3.2). All Northern reference samples assigning to a single "Northern" cluster with $q$-values between 0.729-0.945, and samples within Big Sugar Creek and the Elk River assigning differentially to either of two clusters with varying ancestry proportions $(0.068-0.914$ to the "Northern" cluster and 0.086-0.932 to the "Neosho" cluster; Figure A3.2).

\section{Geographic Distribution of Admixture}

Within Big Sugar Creek and the Elk River, there were no clear patterns of genetic structure across the 10 sampling sites (sites 4-13; Figure 5.1b,c) moving downstream from DFA to MSA. Average cluster membership to either the Northern or Neosho genetic clusters were distributed evenly across all sampling sites, although the average proportion assigned to the Neosho cluster (light blue) was slightly higher in all but one site (site 12; Figure 5.1b). Furthermore, there was no significant relationship between the proportion of Northern cluster membership (Northern ancestry) and linear stream distance for the global dataset (between DFA and MSA, $p=0.262, R^{2}=0.011$, Figure A3.3a), within Big Sugar Creek (DFA to the Elk River headwaters, $p=0.361, R^{2}=0.019$, Figure A3.3b), or within the Elk River (Elk River headwaters to MSA, $p=0.442$, 
$R^{2}=0.008$, Figure A3.3c). There was no difference between overall proportion of Northern ancestry between Big Sugar Creek and the Elk River ( $p=0.526$, Figure A3.3d).

The proportion of individuals assigned to one of three admixture statuses (Neosho, Northern, or Admixed) also did not vary geographically moving downstream across 10 sampling sites (Figure 5.1c). Although the proportion of individuals assigned as Northern tended to increase moving downstream (Figure A3.4a-c), there was no significant relationship with geographic distance for the global dataset (between DFA and MSA, $p=0.174, R^{2}=0.120$, Figure A3.4a), within Big Sugar Creek (DFA to the Elk River headwaters, $p=0.084, R^{2}=0.76$, Figure A3.4b), or within the Elk River (Elk River headwaters to MSA, $p=0.149, R^{2}=0.306$, Figure A3.4c).

\section{Founder Effects}

We found no significant differences in any genetic diversity metrics between individuals assigned as Northern and the Northern reference population either in the global dataset (Table A3.4) or across rivers (Table A3.5). Among individuals assigned as Northern within the Neosho range, neither $A$ ( $p=0.942), H_{\mathrm{O}}(p=0.857), H_{\mathrm{E}}(p=0.796)$, nor $F_{\text {IS }}(p=0.641)$ were significantly different. Similarly, between rivers, neither $A(p=0.344)$, $H_{\mathrm{O}}(p=0.754), H_{\mathrm{E}}(p=0.899)$, nor $F_{\text {IS }}(p=0.631)$ were significantly different.

\section{Individual Growth Analysis}

Individual growth was variable across samples depending on river, sex, and admixture status. Theoretical average maximum length $\left(L_{\infty}\right)$ for all samples across the global dataset was $416.41 \mathrm{~mm}$ and was estimated with relatively narrow $95 \%$ confidence 
intervals (394.96-447.61; Table A3.6a; Figure A3.5a). Growth was different in Big Sugar Creek and the Elk River; $L_{\infty}$ was higher in Big Sugar Creek at $476.84 \mathrm{~mm}$ (433.41547.02) than in the Elk River at 391.04 (366.87-419.29), although the Brody growth coefficient $(K)$ showed the opposite trend, at $0.25(0.18-0.33)$ in Big Sugar Creek and $0.44(0.34-0.55)$ in the Elk River (Table A3.6b; Figure A3.5b). Males and females were not different in either $L_{\infty}$ or $K$ (Table A3.6c; Figure A3.5c). Similarly, $L_{\infty}$ and $K$ were not different among admixture statuses based on overlapping confidence intervals; however, Admixed fish did exhibit a lower overall $L_{\infty}$ at $393.58 \mathrm{~mm}$ (362.53-434-59) compared to both Neosho at $431.07 \mathrm{~mm}(392.13-504.83)$ and Northern at $446.26 \mathrm{~mm}(374.76-566.75$; Table A3.6d; Figure A3.5d).

Within Big Sugar Creek, males and females were not different in maximum length or growth rate based on overlapping confidence intervals, but $L_{\infty}$ for males at $448.35 \mathrm{~mm}(408.36-534.31)$ was lower overall than $L_{\infty}$ of females at $512.55 \mathrm{~mm}(435.42-$ 763.16; Table 5.2a; Figure 5.2a). Males and females were similarly not different in maximum length or growth rate in the Elk River; however, we detected the opposite trend as in Big Sugar Creek, such that the $L_{\infty}$ for males at $418.42 \mathrm{~mm}(375.65-481.30)$ was greater than $L_{\infty}$ for females at 385.99 (359.86-429.17; Table 5.2a; Figure 5.2b).

The Neosho and Admixed admixture status groups in Big Sugar Creek did not differ (Table 5.2b; Figure 5.2c). While the Northern admixture status group also did not differ significantly from either Neosho or Admixed, this was due to very wide $95 \%$ confidence intervals. The $L_{\infty}$ of Northern fish at $347.20 \mathrm{~mm}$ (272.48-938.38) fell well below the confidence intervals for both Neosho at $466.32 \mathrm{~mm}(410.01-558.37)$ and Admixed at 474.54mm (428.10-575.47) in this river (Table 5.2b; Figure 5.2c). Within 
the Elk River, Neosho and Northern fish did not differ in $L_{\infty}$ or $K$ (Table 5.2b; Figure 5.2d). However, Admixed fish at 353.19mm (322.12-384.12) differed significantly from both Neosho and Northern at 406.15mm (353.78-616.30) and 438.20mm (399.51531.83), respectively (Table 5.2b; Figure 5.2d). $K$ also differed between Northern at 0.33 (0.19-0.46) and Admixed at 0.57 (0.41-0.80; Table 5.2b; Figure 5.2d).

\section{Heterozygosity-Fitness Correlation}

Due to low sample size in larger, older fish, we omitted all samples that were estimated to be older than 5 years $\left(N=10 ; N_{\text {Big Sugar Creek }}=5, N_{\text {Elk River }}=5\right)$ for heterozygosityfitness correlation (HFC) analysis. Samples $(N=105)$ ranged in standardized multi-locus heterozygosity between 0.465 (low) and 1.395 (high). For the global dataset, we estimated a $g_{2}$ statistic of $0.10(-0.001-0.024)$, indicating significant correlation of heterozygosity among loci and high power for detecting general-effect HFC ( $p=0.040$, S.E. $=0.006)$. Within Big Sugar Creek, we estimated a $g_{2}$ of $0.002(-0.014-0.024)$, indicating insufficient power to detect general-effect HFC ( $p=0.377$, S.E. $=0.009)$. Within the Elk River, we estimated a $g_{2}$ of $0.015(0.001-0.030)$, indicating significant power $(p=0.025$, S.E. $=0.008)$.

Body condition $\left(\mathrm{g} / \mathrm{cm}^{2}\right)$ ranged among samples from $0.006-0.015$. To verify that the Fulton's Condition Factor could be used for analysis, we verified that mass (g) and TL were related linearly in the global dataset $\left(p<0.001, R^{2}=0.937\right.$; Figure A3.6a), in Big Sugar Creek $\left(p<0.001, R^{2}=0.936\right.$; Figure A3.6b), and in the Elk River $(p<0.001$, $R^{2}=0.934$; Figure A3.6c). We also verified that condition was not correlated with age in the global dataset ( $p=0.346, R^{2}=0.009$; Figure A3.6d), within Big Sugar Creek ( $p=0.147$, 
$R^{2}=0.050$; Figure A3.6e), and within the Elk River ( $p=0.781, R^{2}=0.001$; Figure A3.6f).

Finally, we found that condition was normally distributed in the global dataset $(W=0.969$, $p=0.430$; Figure A3.6g), in Big Sugar Creek ( $W=0.955, p=0.117$; Figure A3.6h), and in the Elk River ( $W=0.973, p=0.181$; Figure 3.6i).

We detected a significant, negative heterozygosity-fitness correlation (HFC) between standardized multi-locus heterozygosity and body condition considering all samples in the global dataset $\left(p=0.032, R^{2}=0.035\right.$; Figure 5.3a). Although there was no significant interaction between admixture status groups ( $p=0.737)$, indicating no difference in slope, all groups showed a negative correlation (Figure 5.3b). HFC was not significant in Big Sugar Creek independently ( $p=0.206, R^{2}=0.041$; Figure 5.3c), and there were no differences in slopes between groups ( $p=0.649$; Figure $5.3 \mathrm{~d}$ ). HFC was approaching significance in the Elk River $\left(p=0.068, R^{2}=0.052\right.$; Figure 5.3e), although no differences in slope between groups were detected ( $p=0.843$; Figure $5.3 \mathrm{f}$ ). In both rivers, all groups showed negative HFCs, with admixed fish exhibiting the highest negative slope.

Big Sugar Creek $(p<0.001)$, the Elk River $(p<0.001)$, and the Northern reference population $(p<0.001)$ all had significantly higher average standardized multi-locus heterozygosity than the Neosho reference population, but did not differ from each other, based on a post-hoc Tukey test from our linear mixed effect model (Figure A3.7a). Heterozygosity was not significantly different between admixture status groups within rivers; however, admixed $(p=0.010)$ and Neosho $(p<0.001)$ fish within Big Sugar Creek differed significantly from the Neosho reference, and admixed $(p<0.001)$, Neosho 
$(p=0.008)$, and Northern $(p<0.001)$ fish all differed significantly from the Neosho reference (Figure A3.7b).

\section{Discussion}

Smallmouth Bass (Micropterus dolomieu) in the Central Interior Highlands (CIH) are characterized by complex, hierarchical genetic structure distributed between the known subspecies, the Neosho Smallmouth Bass (M. d. velox) and the Northern Smallmouth Bass (M. d. dolomieu Stark and Echelle 1998; Taylor et al. 2018; Gunn et al. 2020), within river drainages (Gunn et al. 2020; This Dissertation, Chapter 4), and among populations. While the subspecies are evolutionarily distinct, they have also intermixed in some parts of the Neosho subspecies range through a likely combination of historic stream connections and recent anthropogenic introductions (This Dissertation, Chapter 4). We know little about how these patterns and processes affect fitness and their longterm consequences for the preservation of endemic diversity.

Genetic composition of Smallmouth Bass in two Neosho subspecies rivers, Big Sugar Creek and the Elk River, has been strongly influenced by the introduction of alleles from the Northern subspecies range, specifically tributaries of the White River drainage. Northern and Neosho Smallmouth Bass have successfully interbred in these streams, which could be a function of incomplete reproductive barriers resulting from divergence due to drift rather than selection (Vijay et al. 2016; Mack and Nachman 2017; Ravinet et al. 2017). Many individuals were found to be either of pure Northern ancestry or are of admixed origin. Additionally, there was no difference in heterozygosity between the Elk River and Big Sugar Creek populations compared to the Northern reference, even though 
both rivers had significantly higher average heterozygosity than the Neosho reference. Further, there were no differences in average heterozygosity between admixture status groups within these two rivers. Allelic diversity in the Elk River and Big Sugar Creek is clearly elevated, which has likely occurred through continued, multi-generational introgression.

We expected that fish assigned as Northern Smallmouth Bass would exhibit genetic signatures of a founder effect. Population genetic theory predicts that a newly introduced species should experience a severe bottleneck, as colonizing individuals would retain a limited subset of genetic variation from the source population (Dlugosch and Parker 2008). Absence of phenotypic adaptations in the new habitat should compound the effects of low genetic diversity, resulting in reduced relative fitness (Estoup et al. 2016). In fact, most attempted introductions should, and do, fail (Veltman 1996; Sax and Brown 2000). Our hypothesis was rejected; we found that there was no difference in genetic diversity between Northern Smallmouth Bass in the Neosho range compared to those in the source population.

Although Northern Smallmouth Bass in the Neosho range have not undergone a bottleneck, they have not shown signs of swamping out ancestral Neosho genotypes. Neither average assignment to the Northern cluster, nor the frequency of non-admixed Northern individuals, increased moving downstream from Deep Ford Access (DFA) on Big Sugar Creek to Mount Shira Access (MSA) on the Elk River. We therefore have no evidence that introduced Northern Smallmouth Bass are more fit than native Neosho, making these populations possibly indicative of a relatively stable hybrid zone (Arnold 1997). 
We also found that individual growth is highly variable between rivers, but less so between males and females. Based on our parameterizations of the von Bertalanffy growth model, Smallmouth Bass in Big Sugar Creek and the Elk River reach an average maximum length of approximately $416 \mathrm{~mm}$. Males and females were nearly identical in maximum length and were in line with the sample-wide average. This result was not surprising, since there is no known sexual dimorphism in this species (Brown et al. 2009). However, it is important to note that our estimate of maximum length is considerably lower than estimates in nearby river systems within the Northern Smallmouth Bass range, including the North Fork of the White River (maximum length $551 \mathrm{~mm}$; Sterling et al. 2019).

Variation in maximum size between White River Northern Smallmouth Bass and Neosho Smallmouth Bass may be attributed to overall body size differences that have evolved in the process of local adaptation. Hubbs and Bailey (1940) originally described the subspecies as morphologically distinct, noting that the Northern Smallmouth Bass is larger and more rotund than the Neosho. However, to our knowledge, no rigorous assessments of body size differentiation between the subspecies have been conducted. Size and growth patterns may also be a function of stream ecology. This is especially likely given that growth rate and maximum individual length were substantially different in Big Sugar Creek and the Elk River in our study. It is known that Smallmouth Bass growth is variable among streams (Brewer and Long 2015); the relationship between age and size is largely dependent on water temperature (Serns 1982; King et al. 1999; Dunlop and Shuter 2006; Whitledge et al. 2006; Brewer 2013), flow rate (Paragamian and Wiley 1987) and type of prey resources available (Steinhart and Marschall 2004). Any of these 
factors may differentially influence productivity and contribute to the patterns we observed.

Along with growth variation, we found a negative heterozygosity-fitness correlation for Smallmouth Bass body condition across the Big Sugar Creek and Elk River, refuting our hypothesis of heterosis and suggesting instead a deleterious effect of genomic heterozygosity on fish health and therefore fitness in these populations.

Although there were no significant correlations in either river individually, both sample sets exhibited a similar downward trend in condition. It is also important to note that average heterozygosity was similar between pure Neosho, pure Northern, and admixed fish, which indicates that individuals of admixed origin did not necessarily possess a greater degree of heterozygosity in the microsatellite loci we analyzed.

However, given the significant identity disequilibrium we detected in the global dataset, we propose that there is a general effect of heterozygosity on fitness; the magnitude of heterozygosity in our neutral microsatellites is likely indicative of heterozygosity in the genome as a whole, including functional genes (Chapman et al. 2009; Szulkin et al. 2010; Brambilla et al. 2014). This result was accompanied by a lower average maximum length of admixed fish compared to both Neosho and Northern fish in the Elk River. Admixture between the Smallmouth Bass subspecies may, to some extent, be contributing to decreased overall fitness (Chapman et al. 2009). Outbreeding depression has been previously observed in experimental populations of Largemouth Bass (Micropteus salmoides). Goldberg et al. (2005) found significantly lower survival in first and second-generation hybrids of two distinct Largemouth Bass strains inoculated with Largemouth Bass Virus (LBV) compared to the non-admixed parents. If a similar 
process is decreasing condition among Smallmouth Bass in the Elk River and Big Sugar Creek, it may reduce endemic genetic diversity in the Neosho Smallmouth Bass native range. These results should be interpreted cautiously. It is critical to corroborate these findings with additional data in these and other admixed rivers before using them as a basis for management decisions.

\section{Conclusions}

Even though the Northern Smallmouth Bass does not appear to be replacing Neosho genotypes through introgression, the observed negative effect of heterozygosity on body condition of populations in Big Sugar Creek and the Elk River, which appears to have been facilitated by admixture, may call for managers to treat the Northern Smallmouth Bass as invasive in the Neosho range. With such a classification, it will become increasingly important to address the potential conservation concerns of prolonged admixture in these rivers.

Biological invasion - the rapid spread of a species into a novel environment after natural barriers to movement have been removed (Valéry et al. 2008) — has become a common, destructive feature of the Anthropocene (Simberloff 2013; Estoup et al. 2016). Researchers have extensively detailed the criteria that should be met for a species to qualify as invasive (Richardson et al. 2000; Colautti and MacIsaac 2004; Richardson and Pyšek 2006), and they have long known that the process can usually be attributed to human-mediated introductions of species outside their native ranges, whether or not it happens deliberately. Many studies (e.g., Reznick and Ghalambor 2001; Blair and Wolfe 2004; Rogers and Siemann 2004) suggest that successful invasion can occur because of 
rapid adaptive evolution on an ecological time scale (see Schoener 2011 for a review). Such quick evolution may be aided by multiple introductions (Allendorf and Lundquist 2003), purging of deleterious alleles through inbreeding depression (Facon et al. 2011), or plasticity. Each of these may perhaps be attributed to broad environmental tolerances across the invader species' native distribution (e.g., Rejmánek 1996). The Northern Smallmouth Bass inhabits an expansive geographic range, possibly making it a broadly adapted subspecies that may readily invade non-native habitat.

The consequences of invasion extend beyond admixture. One is economic; when introduced species reduce populations of high commercial value, i.e., crops, aquaculture, or game species, damages can exceed billions of dollars (Anaman et al. 1994; Pimentel et al. 2000; Watkinson et al. 2000). The more far-reaching problem is the ecological impact. The effects of invasion on species diversity may be enough to disturb the fundamental biotic functions of an entire ecosystem (Vitousek 1986; Vitousek et al. 1987). Predation and herbivory (Pouget 1989; Lockwood et al. 2007; Pringle 2011), transmission of new pathogens (Bertolino and Genovesi 2003; Rushton et al. 2006; Lodge et al. 2012), and competitive exclusion (Adams et al. 2000; Sans et al. 2008) are all mechanisms that can allow introduced species to dominate, driving locally specialized native species to extinction and eliminating the critical ecological services they provide.

Mitigating invasion is a pressing concern in the conservation of species. Admixture between the Northern and Neosho Smallmouth Bass subspecies may reflect an ongoing biological invasion with direct impacts on fitness of a range-restricted, endemic subspecies. Focusing on the dynamics of admixture between these subspecies in the Central Interior Highlands, and ultimately reducing the negative effects of the 
Northern subspecies on Neosho fitness, should be a priority in the conservation and management of this species.

\section{Acknowledgments}

We thank the University of Missouri for providing the equipment and resources needed to complete this project, and we thank the Missouri Department of Conservation for providing permits for sample collection. We appreciate the numerous faculty and graduate students in the Division of Biological Sciences at the University of Missouri who advised us on the design and analysis of this experiment. In particular, we thank M. Schultz, D.Y.S. Hall, A. Gunn, G. Gunn, C. Forck, G. Schmitz, and R. Horton for assistance with field sampling. Additionally, we thank D. Tillitt, J. Candrl, S. Clements, C. Forck, and G. Schmitz for help with otolith processing and data curation. We thank K. Budd and K. Storey for their assistance in design, data interpretation, and analysis of the experiment and in revisions of the manuscript. This project was supported financially by

the Trans World Airlines Scholarship fund and a Graduate Professional Council Research Development Award through the University of Missouri. 


\section{References}

Adams SB, Frissell CA, Rieman BE (2000) Movements of nonnative Brook Trout in relation to stream channel slope. Trans Am Fish Soc 129:623-638.

Aday D, Parkos J, Wahl D (2009) Population and community ecology of Centrarchidae. In: Cooke S, Philipp D (eds) Centrarchid Fishes: Diversity, Biology, and Conservation. Wiley-Blackwell, Chichester, UK, pp 134-164.

Ahlert J, Barkley S, Claybrok L, et al (1995) The Arkansas Smallmouth Bass management plan. Little Rock, AR.

Allendorf F, Leary R (1988) Conservation and distribution of genetic variation in a polytypic species, the Cutthroat Trout. Conserv Biol 2:170-184.

Allendorf FW, Leary RF, Spruell P, Wenburg JK (2001) The problems with hybrids: Setting conservation guidelines. Trends Ecol Evol 16:613-622.

Allendorf FW, Lundquist LL (2003) Introduction: Population biology, evolution, and control of Invasive Species. Conserv Biol 17:24-30.

Anaman KA, Atzeni MG, Mayer DG, Walthall JC (1994) Economic assessment of preparedness strategies to prevent the introduction or the permanent establishment of screwworm fly in Australia. Prev Vet Med 20:99-111.

Arnold ML (1997) Natural hybridization and evolution. New York: Oxford University Press.

Arnold M (2006) Evolution Through Genetic Exchange. Oxford University Press, Oxford, UK

Avise JC, Pierce PC, Van Den Avyle MJ, et al (1997) Cytonuclear lntrogressive swamping and species turnover of bass after an introduction. J Hered 88:14-20.

Bateson W (1909) Heredity and variation in modern lights. In: Seward A (ed) Darwin and Modern Science. Cambridge University Press, Cambridge, UK, pp 85-101.

Bensch S, Andren H, Hansson B, Hans CP, Sand H, Sejberg D, Wabakken P, Akesson M, Liberg O (2006) Selection for heterozygosity gives hope to a wild population of inbred wolves. PloS ONE:e72.

Bertolino S, Genovesi P (2003) Spread and attempted eradication of the grey squirrel (Sciurus carolinensis) in Italy, and consequences for the red squirrel (Sciurus vulgaris) in Eurasia. Biol Conserv 109:351-358. 
Beverton R, Holt S (1957) On the dynamics of exploited fish populations. Great Britain Ministry of Agriculture.

Blair AC, Wolfe LM (2004) The evolution of an invasive plant: An experimental study with Silene latifolia. Ecology 85:3035-3042.

Bock DG, Caseys C, Cousens RD, et al (2015) What we still don't know about invasion genetics. Mol Ecol 24:2277-2297.

Bolger T, Connolly PL (1989) The selection of suitable indices for the measurement and analysis of fish condition. J Fish Biol 34:171-182.

Botero-Delgadillo E, Quirici V, Vásquez RA, Kempenaers B (2020) Heterozygosityfitness correlations in a continental island population of thorn-tailed rayadito. $\mathrm{J}$ Hered 111:628-639.

Brambilla A, Biebach I, Bassano B, et al (2014) Direct and indirect causal effects of heterozygosity on fitness-related traits in Alpine ibex. Proc R Soc B Biol Sci 282:.

Brewer S (2013) Groundwater influences on the distribution and abundance of riverine Smallmouth Bass, Micropterus dolomieu, in pasture landscapes of the Midwestern USA. River Res Appl 29:269-278.

Brewer S, Long J (2015) Biology and ecology of Neosho Smallmouth Bass and the genetically distinct Ouachita lineage. In: Tringali, MD; Long, JM; Birdson, TW; Allen M (ed) Black Bass Diversity: Multidisciplinary Science for Conservation. Bethesda, pp 281-295.

Brewer S, Orth D (2015) Smallmouth Bass Micropterus dolomieu Lacepede, 1802. In: Tringali, MD; Long, JM; Birdsong, TW; Allen M (ed) Black Bass Diversity: Multidisciplinary Science for Conservation. Bethesda, pp 9-26.

Brown J (1989) Patterns, modes and extents of invasions by vertebrates. In: Drake J, Mooney H, di Castri F, et al. (eds) Biological invasions, a global perspective. Wiley, New York, NY, pp 85-109.

Brown T, Runciman B, Pollard S, et al (2009) Biological synopsis of Smallmouth Bass (Micropterus dolomieu). Nanaimo, BC.

Buckmeier DL, Howells R (2003) Validation of otoliths for estimating ages of Largemouth Bass to 16 years. North Am J Fish Manag 32:590-593.

Burton RS, Pereira RJ, Barreto FS (2013) Cytonuclear genomic interactions and hybrid breakdown. Annu Rev Ecol Evol Syst 44:281-302. 
Campana SE, Thorrold SR (2001) Otoliths, increments, and elements: Keys to a comprehensive understanding of fish populations? Can J Fish Aquat Sci 58:3038.

Carey MP, Sanderson BL, Friesen TA, et al (2011) Smallmouth Bass in the pacific northwest: A threat to native species; a benefit for anglers. Rev Fish Sci 19:305315.

Case T (1990) Invasion resistance arises in strongly interacting species-rich model competition communities. Proc Natl Acad Sci USA 24:9610-9614.

Chapman JR, Nakagawa S, Coltman DW, et al (2009) A quantitative review of heterozygosity-fitness correlations in animal populations. Mol Ecol 18:27462765.

Colautti RI, MacIsaac HI (2004) A neutral terminology to define "invasive" species. Divers Distrib 10:135-141.

Coltman D, Slate J (2009) Microsatellite measures of inbreeding: A meta-analysis. Evolution 57:971-983.

Crispo E, Moore JS, Lee-Yaw JA, et al (2011) Broken barriers: Human-induced changes to gene flow and introgression in animals: An examination of the ways in which humans increase genetic exchange among populations and species and the consequences for biodiversity. BioEssays 33:508-518.

David P (1998) Heterozygosity-fitness correlation: New perspectives on old problems. Heredity 80:531-537.

David P, Delay B, Berthou P, Jarne P (1995) Alternative models for allozyme-associated heterosis in the marine bivalve Spisula ovalis. Genetics 139:1719-1726.

DeVries D, Frie R (1996) Determination of age and growth. In: Murphy B, Willis D (eds) Fisheries Techniques, 2nd edn. American Fisheries Society, Bethesda, MD, pp 483-508.

Dlugosch KM, Parker IM (2008) Founding events in species invasions: Genetic variation, adaptive evolution, and the role of multiple introductions. Mol Ecol 17:431-449.

Dobzhansky T (1934) Studies on hybrid sterility. I. Spermatogenesis in pure and hybrid Drosophila pseudoobscura. Zeitschrift fur Zellforsch und mikroskopische Anat 21:169-221.

Dowling T, Childs M (1992) Impact of hybridization on a threatened Ttout of the southwestern United States. Conserv Biol 6:355-364. 
Dunlop E, Shuter B (2006) Native and introduced populations of Smallmouth Bass differ in concordance between climate and somatic growth. Trans Am Fish Soc 135:1175-1190.

Dyer R (2016) gstudio: Tools related to the spatial analysis of genetic marker data.

Earl DA, vonHoldt BM (2012) Structure Harvester: A website and program for visualizing STRUCTURE output and implementing the Evanno method. Conserv Genet Resour 4:359-361.

Ellstrand NC, Schierenbeck KA (2006) Hybridization as a stimulus for the evolution of invasiveness in plants? Euphytica 148:35-46.

Estoup A, Guillemaud T (2010) Reconstructing routes of invasion using genetic data: Why, how and so what? Mol Ecol 19:4113-4130.

Estoup A, Ravigné V, Hufbauer R, et al (2016) Is there a genetic paradox of biological invasion? Annu Rev Ecol Evol Syst 47:51-72.

Evanno G, Regnaut S, Goudet J (2005) Detecting the number of clusters of individuals using the software STRUCTURE: A simulation study. Mol Ecol 14:2611-2620.

Facon B, Hufbauer RA, Tayeh A, et al (2011) Inbreeding depression is purged in the invasive insect harmonia axyridis. Curr Biol 21:424-427.

Fitzpatrick BM, Shaffer B (2007) Hybrid vigor between native and introduced salamanders raises new challenges for conservation. Proc Natl Acad Sci U S A 104:15793-15798.

Fox J, Weisberg S (2019) An $\{\mathrm{R}\}$ companion to applied regression.

Francis R (1990) Back-calculation of fish lengths: A critical review. J Fish Biol 36:883902.

Frie R (1982) Measurement of fish scales and back calculation of body lengths using a digitizing pad and microcomputer. Fisheries 7:5-8.

Goldberg TL, Grant EC, Inendino KR et al. (2005) Increased infectious disease susceptibility resulting from outbreeding depression. Conserv Biol, 19, 455-462.

Gunn JC, Berkman LK, Koppelman J, et al (2020) Complex patterns of genetic and morphological differentiation in the Smallmouth Bass subspecies (Micropterus dolomieu dolomieu and M. d. velox) of the Central Interior Highlands. Conserv Genet 21:891-904. 
Hales L, Belk M (1991) Validation of otolith annuli of Bluegills in a southeastern thermal reservoir. Trans Am Fish Soc 121:823-830.

Hansson B, Westerdahl H, Hasselquist D, et al (2004) Does linkage disequilibrium generate heterozygosity-fitness correlations in great reed warblers? Evolution 58:870-879.

Heidinger R, Clodfelter K (1987) Validity of the otolith for determining age and growth of Walleye, Striped Bass, and Smallmouth Bass in power-plant cooling ponds. In: Summerfelt R, Hall G (eds) Age and Growth of Fishes. Iowa State University Press, Ames, IA, pp 241-251.

Hubbard A, McOris S, Jones T, et al (1992) Is survival of European wildcats Felis silvestris in Britain threatened by interbreeding with domestic cats? Biol Conserv 61:203-208.

Hubbs CL, Bailey RM (1940) A Revision of the Black Basses (Micropterus and Huro) with Descriptions of Four New Forms. Misc Publ Univeristy Michigan Museum Zool

Iguchi K, Matsuura K, McNyset KM, et al (2004) Predicting invasions of North American basses in Japan using native range data and a genetic algorithm. Trans Am Fish Soc 133:845-854.

Jakobsson M, Rosenberg NA (2007) CLUMPP: A cluster matching and permutation program for dealing with label switching and multimodality in analysis of population structure. Bioinformatics 23:1801-1806.

Keller SR, Fields PD, Berardi AE, Taylor DR (2014) Recent admixture generates heterozygosity-fitness correlations during the range expansion of an invading species. J Evol Biol 27:616-627.

Keller SR, Taylor DR (2010) Genomic admixture increases fitness during a biological invasion. J Evol Biol 23:1720-1731.

King J, Shuter B, Zimmerman A (1999) Empirical links between thermal habitat, fish growth, and climate change. Trans Am Fish Soc 128:656-665.

Kolbe J, Glor R, Schettino L, et al (2004) Genetic variation increases during biological invasion by a Cuban lizard. Nature 431:177-181.

Kopelman NM, Mayzel J, Jakobsson M, et al (2015) Clumpak: A program for identifying clustering modes and packaging population structure inferences across K. Mol Ecol Resour 15:1179-1191. 
Lavretsky P, Janzen T, McCracken KG (2019) Identifying hybrids \& the genomics of hybridization: Mallards \& American black ducks of Eastern North America. Ecol Evol 9:3470-3490.

Li YL, Liu JX (2018) StructureSelector: A web-based software to select and visualize the optimal number of clusters using multiple methods. Mol Ecol Resour 18:176-177.

Lockwood J, Hoopes M, Marchetti M (2007) Invasion ecology. Blackwell Publishing, Malden, MA.

Lodge DM, Deines A, Gherardi F, et al (2012) Global introductions of crayfishes: Evaluating the impact of species invasions on ecosystem services. Annu Rev Ecol Evol Syst 43:449-472.

Long JM, Fisher WL (2001) Precision and bias of Largemouth, Smallmouth, and Spotted Bass ages estimated from scales, whole otoliths, and sectioned otoliths. North Am J Fish Manag 21:636-645.

Loppnow GL, Vascotto K, Venturelli PA (2013) Invasive smallmouth bass (Micropterus dolomieu): History, impacts, and control. Manag Biol Invasions 4:191-206.

Lynch M, Walsh J (1998) Genetics and Analysis of Quantitative Traits. Sinauer Associates, Inc., Sunderland, MA.

Maceina MJ, Boxrucker J, Buckmeier DL, et al (2007) Current status and review of freshwater fish aging procedures used by state and provincial fisheries agencies with recommendations for future directions. Fisheries 32:329-340.

Maceina MJ, Sammons SM (2006) An evaluation of different structures to age freshwater fish from a northeastern US river. Fish Manag Ecol 13:237-242.

Mack K, Nachman M (2017) Gene regulation and speciation. Trends Genet 33:68-80

Meneau K (2010) Stream black bass special management area summary for Smallmouth Bass. Jefferson City, MO.

Miller JM, Coltman DW (2014) Assessment of identity disequilibrium and its relation to empirical heterozygosity fitness correlations: A meta-analysis. Mol Ecol 23:1899-1909.

Mitton J (1997) Selection in Natural Populations. Oxford University Press, Oxford, UK. Muller H (1942) Isolating mechanisms, evolution, and temperature. Biol Symp 6:71-125. Nigh T, Schroeder W (2002) Atlas of Missouri ecoregions. 
O’Sullivan AM, Samways KM, Perreault A, et al (2020) Space invaders: Searching for invasive Smallmouth Bass (Micropterus dolomieu) in a renowned Atlantic Salmon (Salmo salar) river. Ecol Evol 10:2588-2596.

Ogle D, Wheeler P, Dinno A (2021) FSA: Fisheries stock analysis. R PackagE. version 0.8 .32

Paragamian V, Wiley M (1987) Effects of variable stream flows on growth of Smallmouth Bass in Maquoketa River, Iowa. North Am J Fish Manag 7:357-362.

Pfaff CL, Parra EJ, Bonilla C, et al (2001) Population structure in admixed populations: Effect of admixture dynamics on the pattern of linkage disequilibrium. Am J Hum Genet 68:198-207.

Pimentel D, Lach L, Zuniga R, Morrison D (2000) Environmental and economic costs of nonindigenous species in the United States. Bioscience 50:53-65.

Popper AN, Lu Z (2000) Structure-function relationships in fish otolith organs. Fish Res $46: 15-25$.

Popper AN, Ramcharitar J, Campana SE (2005) Why otoliths? Insights from inner ear physiology and fisheries biology. Mar Freshw Res 56:497-504.

Pouget R (1989) Historie de la lutte contre le phylloxera de la vigne en France (18681895). Institut National de la Recherche Agronomique, Paris, France.

Pringle R (2011) Nile perch. In: Simberloff D, Rejmanek M (eds) Encyclopedia of biological invasions. University of California Press, Berkeley, CA, pp 484-488.

Pritchard JK, Stephens M, Donnelly P (2000) Inference of population structure using multilocus genotype data. Genetics 155:945-959.

Puechmaille SJ (2016) The program structure does not reliably recover the correct population structure when sampling is uneven: Subsampling and new estimators alleviate the problem. Mol Ecol Resour 16:608-627.

Ravinet M, Faria R, Butlin RK, et al (2017) Interpreting the genomic landscape of speciation: a road map for finding barriers to gene flow. J Evol Biol 30:14501477.

Raymond M, Rousset F (1995) GENEPOP (Version 1.2): Population genetics software for exact tests and ecumenicism. J Hered 86:248-249.

Rejmánek M (1996) A theory of seed plant invasiveness: The first sketch. Biol Conserv 78:171-181. 
Reznick DN, Ghalambor CK (2001) The population ecology of contemporary adaptations: What empirical studies reveal about the conditions that promote adaptive evolution. Genetica 112-113:183-198.

Rhymer JM, Simberloff D (1996) Extinction by hybridization and introgression. Annu Rev Ecol Syst 27:83-109.

Richardson DM, Pyšek P (2006) Plant invasions: Merging the concepts of species invasiveness and community invasibility. Prog Phys Geogr 30:409-431.

Richardson DM, Pyšek P, Rejmánek M, et al (2000) Naturalization and invasion of alien plants: Concepts and definitions. Divers Distrib 6:93-107.

Rogers C, Thompson T, Seiler G (1982) Sunflower species of the United States. National Sunflower Association, Bismark, ND.

Rogers WE, Siemann E (2004) Invasive ecotypes tolerate herbivory more effectively than native ecotypes of the Chinese tallow tree Sapium sebiferum. J Appl Ecol 41:561570 .

Rohlf F (2004) tpsDIG, digitize landmarks and outlines.

Rousset F (2008) GENEPOP'007: A complete re-implementation of the GENEPOP software for Windows and Linux. Mol Ecol Resour 8:103-106.

Rushton SP, Lurz PWW, Gurnell J, et al (2006) Disease threats posed by alien species: The role of a poxvirus in the decline of the native red squirrel in Britain. Epidemiol Infect 134:521-533.

Sans X, Cano L, Green A (2008) Las especies invasoras reducen la diversidad de especies nativas y su integridad genetica. In: Vila M, Valladares F, Traveset A, et al. (eds) Invasiones biologicas. Consejo Superior de Investigaciones Cientificas, Madrid, Spain, pp 103-116.

Santure AW, Stapley J, Ball AD, et al (2010) On the use of large marker panels to estimate inbreeding and relatedness: Empirical and simulation studies of a pedigreed zebra finch population typed at 771 SNPs. Mol Ecol 19:1439-1451.

Sax DF, Brown JH (2000) The paradox of invasion. Glob Ecol Biogeogr 9:363-371

Schoener TW (2011) The newest synthesis: Understanding the interplay of evolutionary and ecological dynamics. Science 331:426-429.

Seehausen O, Takimoto G, Roy D, Jokela J (2008) Speciation reversal and biodiversity dynamics with hybridization in changing environments. Mol Ecol 17:30-44. 
Serns S (1982) Relation of temperature and population density to first-year recruitment and growth of Smallmouth Bass in a Wisconsin lake. Trans Am Fish Soc 111:570-574.

Shi J, Macel M, Tielbörger K, Verhoeven KJF (2018) Effects of admixture in native and invasive populations of Lythrum salicaria. Biol Invasions 20:2381-2393.

Simberloff D (2013) Biological invasions: Much progress plus several controversies. Contrib to Sci 9:7-16.

Stark WJ, Echelle AA (1998) Genetic structure and systematics of Smallmouth Bass, with emphasis on Interior Highlands populations. Trans Am Fish Soc 127:393416.

Steinhart G, Marschall E (2004) Round Goby predation on Smallmouth Bass offspring in nests during simulated catch-and-release angling. Trans Am Fish Soc 133:121131.

Sterling EM, Sterling KB, Phelps QE, et al (2019) Smallmouth Bass population demographics in Missouri Ozark streams and an evaluation of a statewide 305mm minimum length limit. North Am J Fish Manag 39:1175-1191.

Stoffel M, Esser M, Kardos M, et al (2016) inbreedR: An R package for the analysis of inbreeding based on genetic markers. Methods Ecol Evol 7:1331-1339

Suarez AV, Bolger DT, Case TJ (1998) Effects of fragmentation and invasion on native ant communities in coastal southern California. Ecology 79:2041-2056.

Szulkin M, Bierne N, David P (2010) Heterozygosity-fitness correlations: A time for reappraisal. Evolution 64:1202-1217.

Szulkin M, David P (2011) Negative heterozygosity-fitness correlations observed with microsatellites located in functional areas of the genome

Taubert B, Tranquilli J (1982) Verification of the formation of annuli in otoliths of Largemouth Bass. Trans Am Fish Soc 111:531-534.

Taylor AT, Long JM, Schwemm MR, Brewer SK (2018a) Hybridization and genetic structure of Neosho Smallmouth Bass in the Ozark Highlands. North Am J Fish Manag. https://doi.org/10.1002/nafm.10225

Townsend SM, Jamieson IG (2013) Molecular and pedigree measures of relatedness provide similar estimates of inbreeding depression in a bottlenecked population. $\mathbf{J}$ Evol Biol 26:889-899. h 
Valéry L, Fritz H, Lefeuvre JC, Simberloff D (2008) In search of a real definition of the biological invasion phenomenon itself. Biol Invasions 10:1345-1351.

Valière N (2002) a computer program for analyzing genetic GIMLET. Mol Ecol Notes 2:377-379.

Veltman S (1996) Correlates of introduction success in exotic New Zealand birds. Am Nat 147:542-557.

Verhoeven KJF, MacEl M, Wolfe LM, Biere A (2011) Population admixture, biological invasions and the balance between local adaptation and inbreeding depression. Proc R Soc B Biol Sci 278:2-8.

Vermeij G (1982) Phenotypic evolution in a poorly dispersing snail after arrival of a predator. Nature 299:349-350.

Vijay N, Bossu CM, Poelstra JW, et al (2016) Evolution of heterogeneous genome differentiation across multiple contact zones in a crow species complex. Nat Commun 7:1-10.

Vitousek P (1986) Biological invasions and ecosystem properties: Can species make a difference? In: Mooney H, Drake J (eds) Ecology of biological invasions of North America and Hawaii. Springer, New York, NY, pp 163-176.

Vitousek P, Walker L, Whiteaker L, et al (1987) Biological invasion by Myrica faya alters ecosystem development in Hawaii. Science 238:802-804.

Von Bertalanffy L (1938) A quantitative theory of organic growth (inquiries on growth laws II). Hum Biol 10:181-213.

Wahl N, Phelps QE, Garvey JE, et al (2009) Comparison of scales and sagittal otoliths to back-calculate lengths-at-age of crappies collected from midwestern waters. J Freshw Ecol 24:469-475.

Watkinson A, Freckleton R, Dowling P (2000) Weed invasions of Australian farming systems: from ecology to economics. In: Perrings C, Williamson M, Dalmazzone $\mathrm{S}$ (eds) The

Economics of Biological Invasion. Edward Elgar Publishing, Cheltenham, UK, pp 94-116.

Weigel DE, Peterson JT, Spruell P (2018) Introgressive hybridization between Native Cutthroat Trout and introduced Rainbow Trout. Ecol Appl 13:38-50. 
Weir BS, Cockerham CC (1973) Mixed self and random mating at two loci. Genet Res 21:247-262.

Weisberg S (1986) A linear model approach to back-calculation of fish length. J Am Stat Assoc 81:922-929.

Whitledge G, Rabeni C, Annis G, Sowa S (2006) Riparian shading and groundwater enhance growth potential for Smallmouth Bass in Ozark streams. Ecol Appl 16:1461-1473.

Xiao J, Li J, Yuan L, Tanksley SD (1995) Dominance is the major genetic basis of heterosis in rice as revealed by QTL analysis using molecular markers. Genetics 140:745-754. 


\section{Tables and Figures}

Table 5.1. (a) Rivers and associated sample sizes $(N)$ for Northern Smallmouth Bass samples used to calculate cluster membership in STRUCTURE. (b) Rivers, distance from Deep Ford Access (DFA), starting (1) and ending (2) easting (East) and northing (North) coordinates, and sample sizes $(N)$ for 10 groups of samples in our study populations of interest, Big Sugar Creek and the Elk River.

\begin{tabular}{|c|c|c|c|c|c|c|c|}
\hline Site & River & $\begin{array}{l}\text { Dist. from } \\
\text { DFA (m) }\end{array}$ & East 1 & East 2 & North 1 & North 2 & $N$ \\
\hline \multicolumn{8}{|c|}{ a. Northern Smallmouth Bass populations run in STRUCTURE } \\
\hline 1 & Tablerock Lake & -- & -- & -- & -- & -- & 8 \\
\hline 2 & Crooked Creek & -- & -- & -- & -- & -- & 10 \\
\hline 3 & White River & -- & -- & -- & -- & -- & 2 \\
\hline \multicolumn{8}{|c|}{ b. Study Populations } \\
\hline 4 & Big Sugar Creek & $0-943$ & 0379133 & 0379139 & 4053309 & 4052702 & 14 \\
\hline 5 & Big Sugar Creek & $1083-1982$ & 0379129 & 0379166 & 4052558 & 4051735 & 13 \\
\hline 6 & Big Sugar Creek & $2078-2349$ & 0379076 & 0378827 & 4051716 & 4051813 & 10 \\
\hline 7 & Big Sugar Creek & $3168-6287$ & 0378068 & 0376074 & 4051795 & 4050105 & 8 \\
\hline 8 & Elk River & $6317-7868$ & 0376062 & 0374719 & 4050104 & 4049649 & 16 \\
\hline 9 & Elk River & $8053-8614$ & 0374572 & 0374192 & 4049528 & 4049186 & 20 \\
\hline 10 & Elk River & $9083-9584$ & 0373737 & 0373349 & 4049186 & 4048916 & 9 \\
\hline 11 & Elk River & $10074-10929$ & 0373222 & 0372779 & 4048646 & 4047966 & 9 \\
\hline 12 & Elk River & $11139-13945$ & 0372584 & 0370741 & 4047930 & 4048793 & 8 \\
\hline 13 & Elk River & $14313-17916$ & 0370412 & 0369028 & 4048635 & 4049626 & 8 \\
\hline
\end{tabular}


Table 5.2. Individual growth parameters from von Bertalanffy growth models within Big Sugar Creek and the Elk River for (a) sexes, and (b) admixture status groups (Neosho, Northern, Admixed). $L_{\infty}$ is theoretical average maximum length $(\mathrm{mm}), K$ is the Brody growth coefficient (rate at which total length (TL) approaches $L_{\infty}$, and $t_{0}$ is theoretical age at which length is $0 \mathrm{~mm}$. Average estimates that fall outside of the $95 \%$ confidence interval of other groups are marked delineated with "**.

\begin{tabular}{|c|c|c|c|c|c|c|}
\hline \multirow{2}{*}{ Group } & \multicolumn{3}{|c|}{ Big Sugar Creek } & \multicolumn{3}{|c|}{ Elk River } \\
\hline & $L_{\infty}(\mathrm{mm})$ & $K$ & $t_{0}$ & $L_{\infty}(\mathrm{mm})$ & $K$ & $t_{0}$ \\
\hline \multicolumn{7}{|l|}{ a. $\operatorname{Sex}$} \\
\hline Male & $\begin{array}{c}448.35 \\
(408.36-534.31)\end{array}$ & $\begin{array}{c}0.29 \\
(0.17-0.38)\end{array}$ & $\begin{array}{c}-0.23 \\
(-1.05-0.07)\end{array}$ & $\begin{array}{c}418.42 \\
(375.65-481.30)\end{array}$ & $\begin{array}{c}0.43 \\
(0.27-0.58)\end{array}$ & $\begin{array}{c}0.05 \\
(-0.56-0.30)\end{array}$ \\
\hline Female & $\begin{array}{c}512.55 \\
(435.42-763-16)\end{array}$ & $\begin{array}{c}0.21 \\
(0.11-0.32)\end{array}$ & $\begin{array}{c}-0.53 \\
(-1.16--0.15)\end{array}$ & $\begin{array}{c}385.99 \\
(359.86-429.17)\end{array}$ & $\begin{array}{c}0.40 \\
(0.29-0.54)\end{array}$ & $\begin{array}{c}-0.08 \\
(-0.55-0.25)\end{array}$ \\
\hline \multicolumn{7}{|c|}{ b. Admixture Status } \\
\hline Neosho & $\begin{array}{c}466.32 \\
(410.01-558.37)\end{array}$ & $\begin{array}{c}0.27 \\
(0.17-0.39)\end{array}$ & $\begin{array}{c}-0.29 \\
(-0.78-0.05)\end{array}$ & $\begin{array}{c}406.15 \\
(353.78-616.30)\end{array}$ & $\begin{array}{c}0.39 \\
(0.12-0.69)\end{array}$ & $\begin{array}{c}-0.21 \\
(-2.21-0.43)\end{array}$ \\
\hline Northern & $\begin{array}{c}347.20 \\
(272.48-938.38)\end{array}$ & $\begin{array}{c}0.44 \\
(0.07-1.19)\end{array}$ & $\begin{array}{c}-0.15 \\
(-2.17-0.44)\end{array}$ & $\begin{array}{c}438.20 \\
(399.51-531.83)\end{array}$ & $\begin{array}{c}0.33 \\
(0.19-0.46)\end{array}$ & $\begin{array}{c}-0.07 \\
(-0.65-0.24)\end{array}$ \\
\hline Admixed & $\begin{array}{c}474.54 \\
(428.10-575.47)\end{array}$ & $\begin{array}{c}0.26 \\
(0.18-0.35)\end{array}$ & $\begin{array}{c}-0.31 \\
(-0.80--0.02)\end{array}$ & $\begin{array}{c}353.19 * \\
(322.12-384.12)\end{array}$ & $\begin{array}{c}0.57 \\
(0.41-0.80)\end{array}$ & $\begin{array}{c}0.13 \\
(-0.35-0.38)\end{array}$ \\
\hline
\end{tabular}



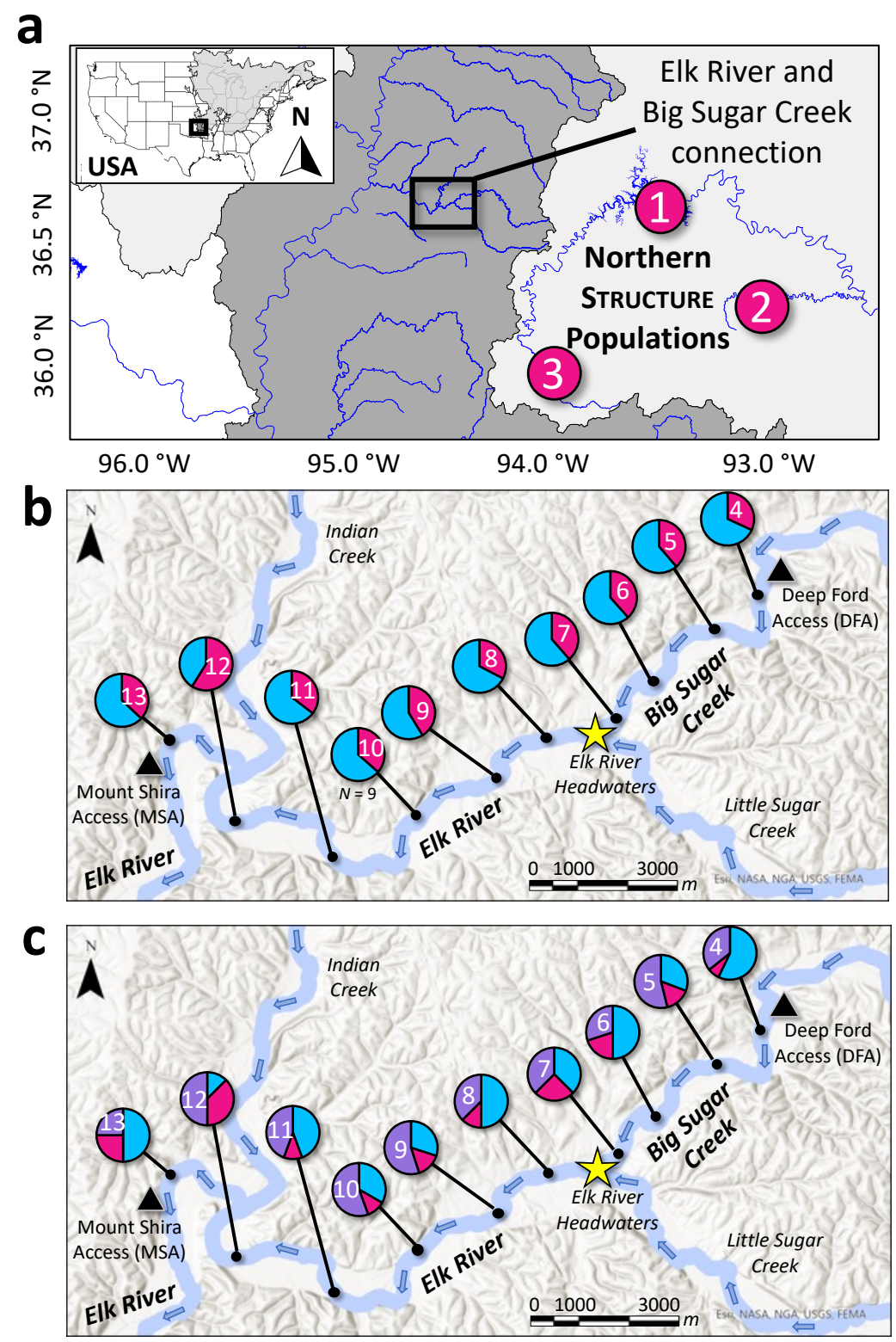

Figure 5.1. (a) Smallmouth Bass collection sites for reference Neosho and Northern Smallmouth Bass. The inset shows the approximate geographic location of the sampling distribution in the Central Interior Highlands, USA. (b) The distribution of samples collected from Big Sugar Creek and the Elk River, grouped roughly every 1000 linear stream meters, between the Deep Ford Access (DFA) and the Mount Shira Access (MSA), with pie charts indicating average group proportion $(q)$ of Northern Smallmouth Bass (dark pink) and Neosho Smallmouth Bass (light blue) cluster membership. (c) The distribution of samples collected from Big Sugar Creek and the Elk River, with pie charts indicating the proportion of individuals assigned as pure Neosho Smallmouth Bass (light blue), Northern Smallmouth Bass (dark pink), and admixed (light purple). Blue arrows overlaid on rivers indicate direction of water flow, and yellow stars indicate the location of the Elk River headwaters. 

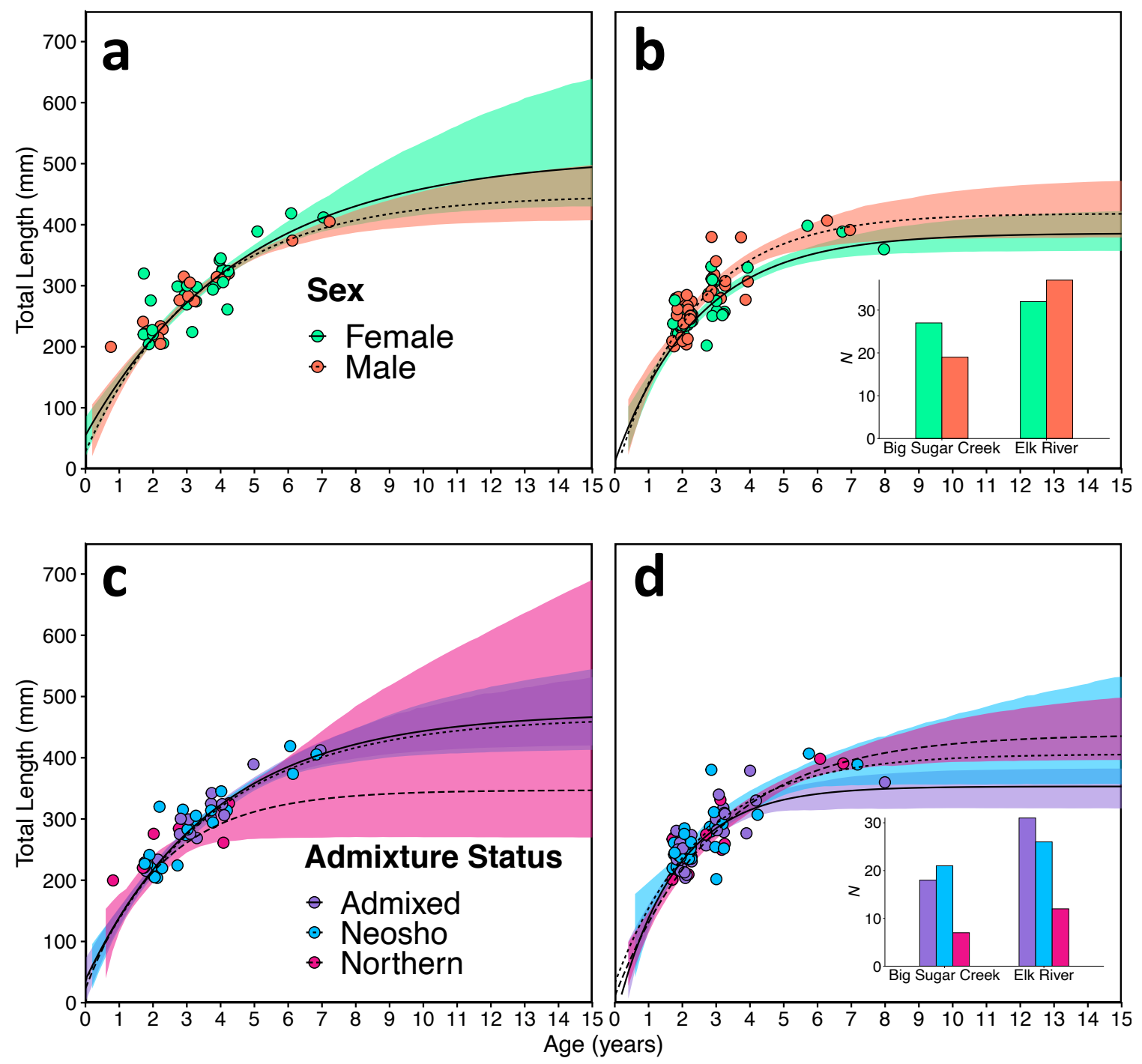

Figure 5.2. Von Bertalanffy growth models within Big Sugar Creek (at left) and the Elk River (at right), with lines indicating average length-at-age and ribbons delineating 95\% confidence intervals for 1000 bootstrap replicates, for (a-b) admixture statuses (Neosho, Northern, or Admixed), and (c-d) sexes. Color legends are provided as insets in the upper left-hand corner of (a) and (c). Lower right-hand insets in (b) and (d) represent the number of samples included per group per river in each growth model. 

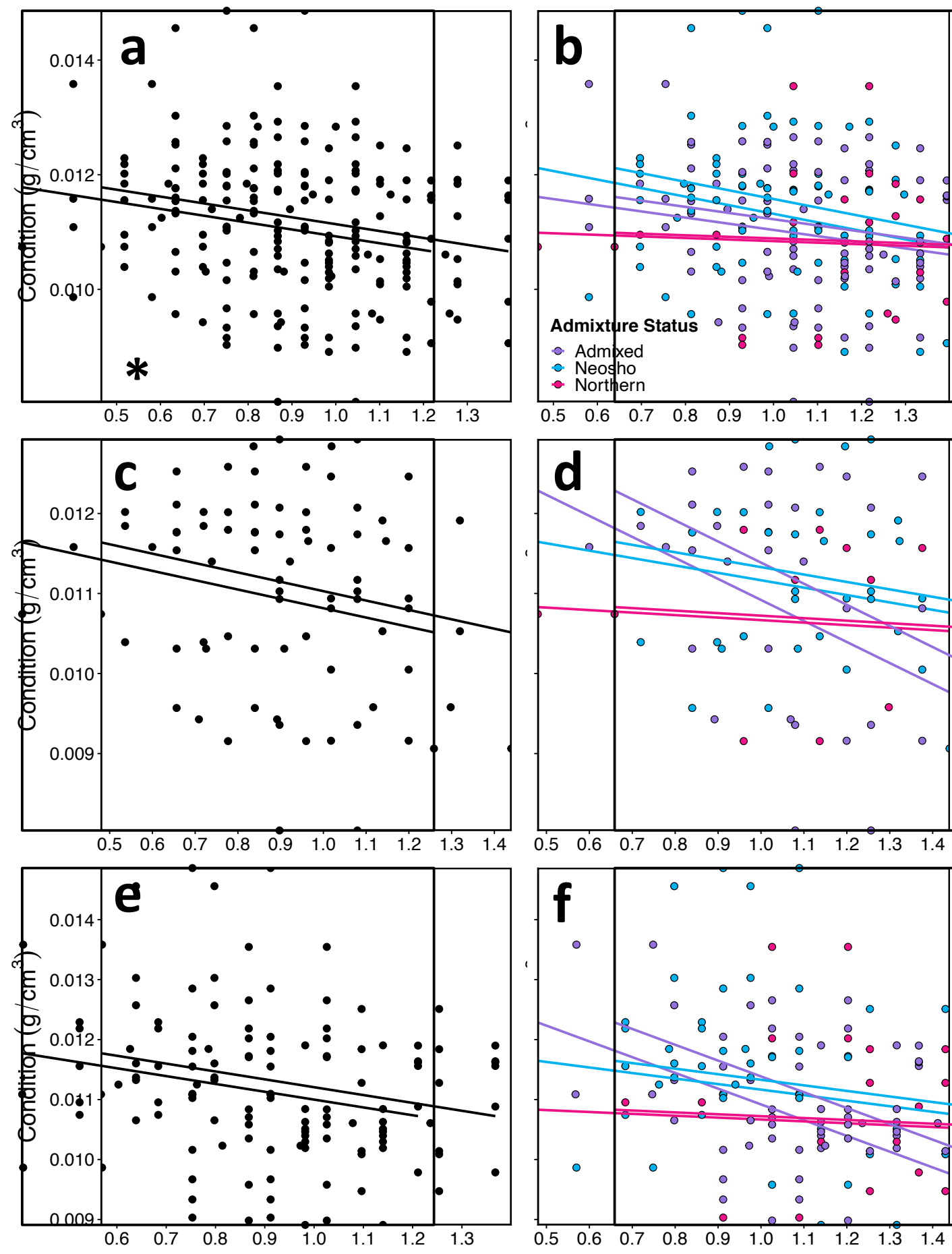

Standardized multilocus heterozygosity

Standardized multilocus heterozygosity

Figure 5.3. Heterozygosity-fitness correlations (HFCs) between standardized multi-locus heterozygosity and fish body condition (condition, $\mathrm{g} / \mathrm{cm}^{3}$ ) overall (at left) and broken down by admixture status (at right) for samples in $(\mathrm{a}, \mathrm{b})$ the global dataset, (c,d) Big Sugar Creek, and (e,f) the Elk River. Significance at $p<0.05$ is indicated with “*”. 


\section{CHAPTER 6}

\section{Genetic and Morphological Patterns, Ecological and Evolutionary Processes, and Fitness Consequences in the Conservation of the Smallmouth Bass (Micropterus dolomieu)}

Joe C. Gunn

Division of Biological Sciences, University of Missouri, 226 Tucker Hall, Columbia, MO 65211, USA, ORCID: 0000-0001-6916-8678

\section{Why and how do we Conserve?}

A variety of arguments have been made for why wildlife conservation is necessary: to maintain the beauty of biological diversity (aesthetics), to ensure the continued availability and cultural significance of natural resources (socioeconomics), to stabilize ecosystem dynamics (ecology), or perhaps just because all organisms have the right to share this planet, having endured through billions of years of evolution (moral philosophy; Primack 1993; Meffe and Caroll 1994; Beattie 1995; Frankham 1995). While all of these are good reasons, some are more pertinent than others in specific contexts. For example, there is often economic and social value in preserving native game or sport animals (reviewed in Gren et al. 2018), both by increasing regional or community revenue through recreation and by providing food. Biodiversity has perhaps an even more important relationship with ecosystem function (Loreau et al. 2001; Tilman et al. 2012, 2014). Removal or replacement of a keystone species from its native habitat not only results in its own local extinction, but it can also lead to predictable, negative, cascading effects on the survivability of co-occurring organisms that may be dependent on 
symbiosis or other ecosystem services (Strecker and Arnott 2008; Gaston et al. 2018; Baker et al. 2019).

The one critical element that each of these reasons shares is us, humans. We benefit directly from biodiversity. We cherish the splendor of life; we profit by exchanging natural resources; we survive using the nutrients produced and cycled through the environment; and we appreciate the inherent value of existence. But even though we owe our survival and well-being to biodiversity, we are also largely culpable for its destruction. As we continue to alter, fragment, and eliminate viable habitat (Pimm and Raven 2000; Marvier et al. 2004), introduce exotic species around the world (Marvier et al. 2004), overexploit species for our own use, and pollute the environment (Frankham 1995), we contribute to global-scale biodiversity loss. So, because of our dependence and simultaneous destructive impact, it is clear that conservation is not just important for any one reason. It is a responsibility. It is the responsibility of scientists and citizens of the world to use our agency to strive for the preservation of species.

The challenge lies in how we accomplish our goals in conservation. Genetic and, with ever-increasing accessibility, genomic methods offer powerful tools for quantifying the variation that exists within and among populations and species. Observing the distribution of genetic and genomic diversity on the landscape allows us to infer the ecological factors mediating population dynamics, such as inbreeding, hybridization, or local adaptation (Frankham 1995). In some cases, it allows us to infer the evolutionary processes, historic and recent, natural and anthropogenic, that have generated contemporary diversity. Finally, understanding how ecology and evolution affect the vital demographic characteristics that underlie individual fitness gives us the ability to predict 
the extent to which populations and species will adapt and evolve in a changing environment.

I propose that the discipline of conservation genetics has a three-fold imperative: to characterize the patterns of genetic variation in populations and species, to infer the ecological and evolutionary processes driving diversification, admixture and adaptation, and to quantify the fitness consequences of those patterns and processes. Data from each of these areas allow us design and carry out effective management and conservation plans that will ensure the long-term persistence of biological diversity.

The goal of my dissertation research was to elucidate genetic and morphological patterns, ecological and evolutionary processes, and fitness consequences in a North American endemic freshwater sport fish, the Smallmouth Bass (Micropterus dolomieu). I focused on populations at the convergence of the native ranges of the two recognized subspecies in the Central Interior Highlands (CIH): the Neosho Smallmouth Bass $(M . d$. velox) and the Northern Smallmouth Bass $(M . d$. dolomieu). Below, I summarize the major findings of my work, specifically outlining the patterns of genetic and genomic diversity within and among the Smallmouth Bass subspecies, the natural historic and recent anthropogenic forces driving contemporary patterns, and the potential consequences of these forces on individual growth and fitness in two highly admixed rivers within the Neosho Smallmouth Bass range. Based on those findings, I offer several potential avenues for future research that will be important for discovering the evolutionary basis of genetic patterns and fitness. Finally, I discuss the importance and practical application of my findings. 


\section{Brief Overview of Dissertation Findings}

\section{Genetic and Morphological Patterns}

In my assessment of both neutral microsatellite markers (Chapter 3 of this dissertation) and genome-wide single nucleotide polymorphisms (SNPs; Chapter 4 of this dissertation), I found that the Neosho and Northern Smallmouth Bass, although long considered to be minimally differentiated and perhaps even intergraded in parts of the $\mathrm{CIH}$, constitute diverged, independently evolving lineages that form monophyletic clades in a phylogenetic analysis. These clades may represent evolutionary significant units (Ryder 1986; Moritz 1994) that should be considered for conservation priority. The original concept of the evolutionary significant unit stipulates that, to be considered for conservation priority, populations need to be highly differentiated at nuclear loci and reciprocally monophyletic in their mitochondrial DNA (Ryder 1986). I do not provide information on mitochondrial divergence between the Smallmouth Bass subspecies, but previous studies have shown phylogenetic clustering of Neosho, Ouachita, and Northern Smallmouth Bass based on mitochondrial haplotypes (Borden and Krebs 2009).

Within the two Smallmouth Bass subspecies clades, distinct lineages emerge, corresponding to tributaries of the upper Arkansas River Basin and south-flowing streams in the Boston Mountains within the Neosho range and corresponding to tributaries of the Missouri River and the White River drainage within the Northern range. These lineages can be delineated further into populations at a finer scale, which may represent viable management units (Moritz 1994) that contain important and representative species-level genetic variation. 
Clear signatures of evolutionary divergence within the Smallmouth Bass are interspersed with evidence of substantial, heterogenous admixture within the Neosho subspecies native range. While some rivers remain largely non-admixed, including Honey Creek, Sycamore Creek, Caney Creek, Baron Fork, Lee Creek, and the Mulberry River, other rivers exhibit allele sharing with Northern Smallmouth Bass genetic clusters. We found that one river system in the Neosho range, the Illinois River, is admixed with Northern Smallmouth Bass derived from a hatchery strain, colloquially known as the "Tennessee Lake Strain." This finding is consistent with the known stocking history of this river system; Smallmouth Bass were introduced in the Illinois River in the early 1990s (Taylor et al. 2018). Other rivers, including the Elk River, Big Sugar Creek, Little Sugar Creek, Indian Creek, the Buffalo River, the Elk River, Spavinaw Creek, the Illinois River, the Illinois Bayou River, and Big Piney Creek, are admixed with Northern Smallmouth Bass derived from a genetic cluster in the White River drainage. Patterns of admixture differ among rivers; some populations appear to be highly introgressed, while others show relatively low levels of intermixing. However, in all rivers, the extent and origins of admixture have affected genetic diversity.

In Chapter 3, I found that the Neosho and Northern Smallmouth Bass are morphologically distinct based on five morphometric traits - total length, standard length, orbital length, head length, and body depth—and one meristic trait, the number of soft dorsal fin rays. While the original subspecies descriptions noted morphological differences (Hubbs and Bailey 1940), my study provides the first evidence that when all traits are analyzed together the subspecies are differentiated; however, the only individual trait that differs significantly between subspecies is head length (Gunn et al 2020). This 
adds to the previous notion that the subspecies were differentiated primarily in the number soft dorsal rays (the Neosho Smallmouth Bass is thought to have 13, while the Northern Smallmouth Bass is thought to have 14). While we found a significant association between the number of soft dorsal rays and the proportion of the genome assigned as Neosho, we did not find this meristic trait to be diagnostic of subspecies distinction. The Neosho Smallmouth Bass, relative to total length, show greater head length than the Northern Smallmouth Bass, perhaps reflecting a level of phenotypic adaptation to the environment that has not been previously established.

\section{Ecological and Evolutionary Processes}

In Chapter 4 of this dissertation, results from my analysis of 50,828 SNPs showed that patterns of population structure and differentiation in the Smallmouth Bass subspecies have been driven by complex diversification processes, likely during and after the Pleistocene. Specifically, I found that the Northern and Neosho subspecies form two distinct monophyletic clades, suggesting historic divergence between them which may have occurred through vicariance as a result of river channel changes, habitat fragmentation, and climate shifts amid post-Pleistocene glacial recessions (Miller 1965; Mayden 1988; Bermingham et al. 1992). Climate shifts and habitat fragmentation may have also contributed significantly to periods of allopatry. While I was not able to estimate the precise timing of divergence between subspecies, previous studies suggest that the Smallmouth Bass subspecies likely split from sister taxa between four and six million years ago (Near and Kim 2021), likely placing the subspecies divergence on a much more recent timeframe. 
Along with their divergence, we found that the Neosho and Northern Smallmouth Bass subspecies are locally adapted based on a set of 156 SNPs under diversifying selection. While they have also been influenced by drift, as shown by divergence at neutral SNPs, it is likely that they are differentially adapted to their respective native environments. None of the populations of the Northern subspecies exhibited signatures of strong selection. Conversely, populations in the Boston Mountains of Arkansas, including the Illinois Bayou, Big Piney Creek, Mulberry River, and Lee Creek, were all highly diverged from other Neosho populations based on 29 SNPs under strong diversifying selection. This suggests that certain alleles within the Boston Mountains populations may be under selection in response to unique factors in their environment.

Using a combination of moment statistics and diffusion analysis of joint site frequency spectra, I was able to resolve admixture dynamics between the Neosho and Northern Smallmouth Bass within the Neosho range. Moment statistics show that the admixed populations shared an ancestral Neosho "source" derived from a non-admixed genomic cluster identified in tributaries of the mid-Arkansas River Basin, including Honey Creek, Sycamore Creek, Caney Creek, and Baron Fork. This result offers evidence that populations in these rivers of pure genomic origin may represent the ancestral Neosho genotype, which may prove useful in defining true Neosho genetic variation for the conservation of the subspecies' genomic integrity. Concordant with the genetic results, one admixed population, the Illinois River system, was significantly mixed with a genomic cluster identified in Skiatook Lake, an impoundment outside the native ranges of both subspecies that is known to have been stocked with Tennessee Lake strain hatchery-raised fish. All other admixed populations, including the Elk River, the 
Illinois Bayou Rive and Big Piney Creek, and tributaries of the upper Arkansas River Basin, were mixed with a Northern Smallmouth Bass "source" derived from the White River drainage.

Diffusion analysis of the joint site frequency spectra for admixed populations allowed me to ascertain the most likely demographic scenarios that have generated admixture patterns in a demographic model testing framework. All admixed populations experienced asymmetric migration over evolutionary time, with migration always occurring from parts of the Northern Smallmouth Bass range or the Tennessee Lake strain into the Neosho native range. My results indicate that the Illinois River system has been admixed through recent secondary contact. This result confirms my hypothesis that admixture in this river system is of recent anthropogenic origin caused by deliberate Smallmouth Bass introductions. The Illinois Bayou River and Big Piney Creek were found to be similarly admixed through secondary contact; although I do not know of any specific introduction events in this part of the Neosho range, I hypothesize that, like the Illinois River system, these populations have been impacted by human-mediated introductions. Interestingly, both the Elk River and tributaries of the upper Arkansas River Basin experienced admixture differentially over the course of two distinct “epochs." These results lead me to propose that, in both populations, there has been a combination of historic admixture through periodic river connections (i.e., stream capture) and recent anthropogenic introductions, creating complex allele-sharing patterns. 


\section{Fitness Consequences}

To determine whether intermixing has affected individual fitness in Chapter 5 of this dissertation, I focused on two rivers within the Neosho Smallmouth Bass native range, Big Sugar Creek and the Elk River, which were found to be substantially admixed. I found that individual fish growth is significantly different between these two rivers, possibly due to differences in ecological conditions (i.e., temperature, flow rate, and habitat structure) that may affect nutrient consumption and productivity. Within Big Sugar Creek, there was no difference in growth between fish that were inferred to be pure Neosho, pure Northern, or admixed. However, within the Elk River there were differences in growth among admixture status groups; specifically, admixed fish reached a lower average maximum length than both Neosho and Northern fish, suggesting a possible genetic influence on growth.

We also found a significant, negative general effect heterozygosity-fitness correlation (HFC) between standardized multi-locus heterozygosity and body condition across both Big Sugar Creek and the Elk River, which we used as a proxy for individual fitness. There was not a significant negative HFC in either Big Sugar Creek or the Elk River independently, although both rivers exhibited a negative trend between heterozygosity and body condition, and the lack of significance could be attributed to lack of statistical power. Furthermore, HFCs for each admixture status group (Neosho, Northern, and Admixed) were all negative, though not significant, across the global dataset and within Big Sugar Creek and the Elk River independently HFCs appeared to be more negative in admixed fish compared to either pure Neosho or Northern fish in both rivers, but we did not see a significant effect. 
Overall, these results run contrary to the expectation that increased heterozygosity leads to heterosis, or increased fitness of hybrids, through mechanisms of overdominance or associative overdominance. In these rivers, we provide evidence that admixture may be contributing to outbreeding depression, perhaps by dissolving adaptive gene complexes in locally adapted Neosho Smallmouth Bass.

\section{Open Questions and Future Directions}

Researchers have studied the ecology, including everything from diet, behavior, distribution, reproduction, movement, and population dynamics, of Smallmouth Bass for over a century (Brewer and Orth 2015) and have learned a great deal. However, much less is known about their evolutionary history. In the past few decades, we have begun to address the largely unknown realm of genetic diversity within the species, which has led to the recognition of distinct lineages (Stark and Echelle 1998; Stepien et al. 2017; Taylor et al. 2018; Gunn et al. 2020). There is much yet to be learned about the levels and distribution of genetic and genomic diversity across the Smallmouth Bass range, both within the Interior Highlands and extending to the northeastern boundary of the distribution. Here, I briefly outline three specific avenues of future research-exploration of population structure across the Ouachita Lineage at the southern-most edge of the species range, genomics, and reproductive isolation and speciation - that I believe will be critical in defining Smallmouth Bass diversity and their evolutionary capacity to adapt in the face of global climate change. 


\section{The Ouachita Lineage}

Along with the Northern Smallmouth Bass, whose range broadly stretches from central Missouri north and east to the Lawrentian Great Lakes (Nigh and Schroeder 2002; Brewer and Orth 2015), and the Neosho Smallmouth Bass inhabiting the Arkansas River drainage, a third potentially distinct lineage occupies the Red River and Ouachita River drainages in the Ouachita Mountains of eastern Oklahoma and central Arkansas, USA (the Ouachita Smallmouth Bass; Brewer and Long 2015). Recognition of the Ouachita lineage was initially motivated by a study of allozyme loci, which found Smallmouth Bass in the Ouachita Mountains to be distinct from both the Northern and Neosho subspecies (Stark and Echelle 1998). Divergence among these lineages is consistent with the expectation that both genetic drift (due to allopatry of their ranges) and diversifying selection (due to unique ecological characteristics in the Ouachita Mountains ecoregion (Brewer and Long 2015)) may have led to the fixation of distinct alleles.

Although recent analysis of a low-density, genome-wide SNP panel (Long et al. 2020) found the Ouachita Smallmouth Bass to be reciprocally monophyletic with respect to both the Northern and Neosho subspecies (and sister to the Northern Smallmouth Bass), very little research has been conducted to resolve population structure and potential signatures of admixture within the Ouachita Mountains. Long et al. (2020) also determined that, even within the Ouachita lineage, fish in the Red River and Ouachita River Basins formed monophyletic clades, suggesting strong allopatric differentiation between them. Management agencies in this ecoregion, including the Arkansas Game and Fish Commission (AGFC; Ahlert et al. 1995) and the Oklahoma Department of Wildlife Conservation (OWDC; Boxrucker et al. 2004) already recognize the Ouachita 
Smallmouth Bass as a unit of potential conservation value. With evidence of genomewide divergence, it will be important to comprehensively investigate population structure, local adaptation, and admixture within this additional Smallmouth Bass lineage, and to resolve its distinction with respect to the known subspecies.

\section{Genomics}

One of the next critical steps in understanding contemporary patterns of diversity and the evolutionary history of the Smallmouth Bass lineages is to sequence the full genome. Surprisingly, whole-genome sequencing has only recently been leveraged for the study of diversity within the black bass genus. Sun et al (2021) published the first chromosome-level, annotated genome of the Largemouth Bass (Micropterus salmoides), which, although a congener, is a relatively distant relative of the Smallmouth Bass. According to fossil and nuclear gene data, the lineages containing both species likely diverged over 6 million years ago (Near and Kim 2021). The Largemouth Bass genome will undoubtedly prove useful for understanding fine-scale processes of hybridization, selection, and speciation among the black basses. It may even be possible to map RAD tags or short-read sequences of other black bass species, including the Smallmouth Bass, to these annotated chromosome scaffolds, offering valuable linkage and functional locus information. However, to fully understand genome-level diversity in the Smallmouth Bass, it will be necessary to ascertain a full genome. These data will provide much greater power to resolve the timing of admixture among Smallmouth Bass lineages, the specific functional genes underlying local adaptation among and within the subspecies, and the dynamics of speciation. 


\section{Reproductive Isolation}

One potentially critical step in the long-term conservation of distinct genetic units within the Smallmouth Bass, including the Neosho, Northern, and Ouachita lineages, is to consider species delimitation. With this dissertation and evidence from previous studies (Hubbs and Bailey 1940; Taylor et al. 2018; Gunn et al. 2020; Long et al. 2020; This Dissertation, Chapter 4), there is morphological, genetic, and genomic evidence for distinction between the Northern and Neosho subspecies. One additional piece of evidence that may support or refute the appropriateness of species-level designation for these subspecies is the degree of reproductive isolation between them.

Like other black bass species, the Smallmouth Bass mate through external fertilization. In the spawning season — mid-to-late Spring (Ridgway and Friesen 1992) sexually mature males swiftly fan their caudal fin to excavate a circular nest near the littoral zone of their riverine or lacustrine habitat (Warren 2009). Following courtship, females lay a clutch of eggs in the nest, the male fertilizes them by externally depositing milt, and he aggressively defends them until well after the fry have hatched, typically six days later (Shuter et al. 1980). Although Smallmouth Bass have long been thought to exhibit iteroparous monogamy (Avise et al. 2002), meaning they keep the same reproductive partner during spawning seasons, recent evidence shows that they will engage in more promiscuous, multiple mating depending on demographic and environmental conditions (Franckowiak et al. 2017). With external fertilization, and with the possibility of multiple mating, prezygotic gametic isolation, or incompatibilities between non-conspecific sperm and eggs, may play an important role in segregating distinct lineages, particularly when allopatric populations come into contact. 
To determine whether the Neosho and Northern Smallmouth Bass are incipient species, it will be important to test for reproductive isolation. In conjunction with our current understanding of genetic and morphological divergence, the detection of gametic isolation may provide further evidence for allopatric speciation. This could be done in a laboratory setting by measuring differential proportions of hybrid and non-hybrid progeny after females are fertilized with both heterospecific and homospecific sperm, and by measuring differential survival of hybrid and non-hybrid offspring over three months after reciprocal crosses between subspecies. Results from these experiments would greatly contribute to the species delimitation question.

\section{Conservation Needs}

Applying appropriate conservation and management strategies to maintain Smallmouth Bass diversity in the Central Interior Highlands will require careful interpretation of the genetic, morphological, genomic, and fitness data. The strong population structure, morphological and genomic divergence, and outbreeding depression I found in this study need to be considered in any future agency decisions for fish stocking in streams within the Central Interior Highlands. This will be particularly important in the Neosho range, which is geographically constrained to a single drainage and contains relatively low genetic diversity compared to the Northern range.

Because of the negative fitness effects of admixture in the Neosho range, future stocking into any stream should ideally be carried out using broodstock from the same genomic lineage that exists in that stream. Furthermore, to begin a propagation program, wild, native brood fish sampling should be focused on streams that are unadmixed. 
Honey Creek, Sycamore Creek, Caney Creek, and Baron Fork are strong candidates for this purpose. Such restrictive regulations would unfortunately preclude sampling from several highly productive stream fisheries, such as the Elk River, Big Sugar Creek, and the Illinois River. However, it would increase the long-term sustainability of the unique Neosho Smallmouth Bass genomic signature by preventing introgression of Northern alleles.

Currently, Neosho Smallmouth Bass in the Arkansas River Basin and Northern Smallmouth Bass within the White River and Missouri River drainages are treated as potentially interbreeding populations of a single species. My study does not address the question of elevating the Neosho and Northern subspecies to distinct species. However, future studies will need to address the need, or lack thereof, for further taxonomic delimitation.

\section{Concluding Remarks}

The findings in this dissertation shed light on patterns of population structure, divergence, admixture, local adaptation, and fitness between both subspecies' ranges, ultimately revealing that Smallmouth Bass phylogeography in this ecoregion is far more complex than previously suspected. The results provide data that can be used to understand patterns of variation among and within the subspecies and to identify areas with potentially important genetic diversity. They provide valuable information that can be used by conservation managers to avoid non-native Northern Smallmouth Bass introductions and mitigate the effects of already-present admixture. Ultimately, the findings and methods in this dissertation can be applied to other managed species, in 
particular those that have been and are currently being influenced by anthropogenic introductions and admixture.

Perhaps, someday, this work will inspire another emerging scientist to use genetics and genomics to explore much more intricate and profound concepts in ecology, evolution, and conservation. 


\section{References}

Ahlert J, Barkley S, Claybrok L, et al (1995) The Arkansas Smallmouth Bass management plan. Little Rock, AR.

Avise J, Jones A, Walker D, DeWoody J (2002) Genetic mating systems and reproductive natural histories of fishes: Lessons for ecology and evolution. Annu Rev Genet 36:19-45

Baker D, Garnett S, O’Connor JO, et al (2019) Conserving the abundance of nonthreatened species. Conserv Biol 33:319-328.

Beattie A (1995) Biodiversity: Australia’s Living Wealth. Reed, Chastwood, Australia.

Bermingham E, Rohwer S, Freeman S, Wood C (1992) Vicariance biogeography in the Pleistocene and speciation in North American wood warblers: A test of Mengel's model. Proc Natl Acad Sci 89:6624-6628.

Borden WC, Krebs RA (2009) Phylogeography and postglacial dispersal of Smallmouth Bass (Micropterus dolomieu) into the Great Lakes. Can J Fish Aquat Sci 66:2142-2156.

Boxrucker J, Echelle A, Van Den Bussche R (2004) Determining the degree of hybridization in the Smallmouth Bass population of Broken Bow Reservoir and the Mountain Fork River. Oklahoma City, OK.

Brewer SK, Long JM (2015) Biology and ecology of Neosho Smallmouth Bass and the genetically distinct Ouachita lineage. In: Tringali MD, Long JM, Birdsong TW, Allen MS (eds) Black Bass Diversity: Multidisciplinary Science for Conservation. Transactions of the American Fisheries Society, Bethesda, MD, pp 281-295.

Brewer SK, Orth DJ (2015) Smallmouth Bass Micropterus dolomieu Lacepede, 1802. In: Tringali MD, Long JM, Birdsong TW, Allen MS (eds) Black Bass Diversity: Multidisciplinary Science for Conservation. Transactions of the American Fisheries Society, Bethesda, MD, pp 9-26.

Franckowiak RP, Ridgway MS, Wilson CC (2017) Genetic mating system and mate selection in Smallmouth Bass. Ecol Evol 8864-8875.

Frankham R (1995) Conservation genetics. Annu Rev Genet 29:305-327.

Gaston K, Cox D, Canavelli S, et al (2018) Population abundance and ecosystem service provision: The case of birds. BioScience 68:264-272. 
Gren IM, Häggmark-Svensson T, Elofsson K, Engelmann M (2018) Economics of wildlife management—an overview. Eur J Wildl Res 64: 22.

Gunn JC, Berkman LK, Koppelman J, et al (2020) Complex patterns of genetic and morphological differentiation in the Smallmouth Bass subspecies (Micropterus dolomieu dolomieu and $M . d$. velox) of the Central Interior Highlands. Conserv Genet 21:891-904.

Hubbs CL, Bailey RM (1940) A revision of the Black Basses (Micropterus and Huro) with descriptions of four new forms. Misc Publ Univeristy Michigan Museum Zool 1940:1-72.

Long JM, Taylor AT, Buonaccorsi V (2020) A conservation-oriented SNP panel for Smallmouth Bass (Micropterus dolomieu), with emphasis on Interior Highlands lineages. Conserv Genet Resour 13: 47-59.

Loreau M, Naeem S, Inchausti P, et al (2001) Ecology: Biodiversity and ecosystem functioning: Current knowledge and future challenges. Science 294:804-808.

Marvier M, Kareiva P, Neubert MG (2004) Habitat destruction, fragmentation, and disturbance promote invasion by habitat generalists in a multispecies metapopulation. Risk Anal 24:869-878.

Mayden R (1988) Vicariance biogeography, parsimony, and evolution in North American freshwater fishes. Syst Zool 37:329-355.

Meffe G, Caroll C (1994) Principles of Conservation Biology. Sinauer Associates, Inc., Sunderland, MA.

Miller R (1965) Quaternary freshwater fishes of North America. In: Wright J, Frey D (eds) The Quaternary of the United States. Princeton University Press, Princeton, NJ, pp 569-581.

Moritz C (1994) Defining 'Evolutionarily Significant Units.' Trends Ecol Evol 9:373375.

Near TJ, Kim D (2021) Phylogeny and time scale of diversification in the fossil-rich sunfishes and black basses (Teleostei: Percomorpha: Centrarchidae). Mol Phylogenet Evol 161:107156.

Nigh TA, Schroeder WA (2002) Atlas of Missouri ecoregions. Jefferson City, MO.

Pimm SL, Raven P (2000) Extinction by numbers. Nature 403:843-845. 
Primack R (1993) Essentials of Conservation Biology. Sinauer Associates, Inc., Sunderland, MA.

Ridgway M, Friesen T (1992) Annual variation in parental care in Smallmouth Bass, Micropterus dolomieu. Environ Biol Fishes 35:243-255.

Ryder OA (1986) Species conservation and systematics: The dilemma of the subspecies. Trends Ecol Evol 1:9-10.

Shuter B, MacLean J, Fry F, Regier H (1980) Stochastic simulation of temperature effects on first year survival of Smallmouth Bass. Trans Am Fish Soc 109:1-34.

Stark WJ, Echelle AA (1998) Genetic structure and systematics of Smallmouth Bass, with emphasis on interior highlands populations. Trans Am Fish Soc 127:393416.

Stepien CA, Karsiotis SI, Sullivan TJ, Klymus KE (2017) Population genetic structure and comparative diversity of smallmouth bass Micropterus dolomieu: congruent patterns from two genomes. J Fish Biol 90:2125-2147.

Strecker AL, Arnott SE (2008) Biodiversity and ecosystem functioning: current knowledge and future challenges. Ecosystems 11:804-808.

Sun C, Li J, Dong J, et al (2021) Chromosome-level genome assembly for the largemouth bass Micropterus salmoides provides insights into adaptation to fresh and brackish water. Mol Ecol Resour 21:301-315.

Taylor AT, Long JM, Schwemm MR, Brewer SK (2018) Hybridization and genetic structure of Neosho Smallmouth Bass in the Ozark Highlands. North Am J Fish Manag 38:1226-1240.

Tilman D, Isbell F, Cowles JM (2014) Biodiversity and ecosystem functioning. Annu Rev Ecol Evol Syst 45:471-493.

Tilman D, Reich PB, Isbell F (2012) Biodiversity impacts ecosystem productivity as much as resources, disturbance, or herbivory. Proc Natl Acad Sci U S A 109:10394-10397.

Warren M (2009) Micropterus dolomieu (Lacepede). In: Cooke S, Philipp D (eds) Centrarchid Fishes: Diversity, Biology, and Conservation. Blackwell Publishing, pp 439-446. 


\section{APPENDIX 1}

\section{Supplementary tables and figures for chapter 3}

Table A1.1. Metadata for Neosho and Northern Smallmouth Bass and Spotted Bass samples, including source ID, source name, site, date collected, collecting agencies, approximate northing UTM coordinates, and approximate easting UTM coordinates.

\begin{tabular}{|c|c|c|c|c|c|c|}
\hline ID & Source & Site & Date Collected & Collector(s) & Easting & Northing \\
\hline 1 & Center Creek & 1 & July, 2016 & MU, MDC & 399822 & 4105564 \\
\hline \multirow[t]{3}{*}{2} & Shoal Creek & 1 & August, 2016 & MU, MDC & 406353 & 4075344 \\
\hline & & 2 & August, 2016 & MU, MDC & 400556 & 4083565 \\
\hline & & 3 & August, 2016 & MU, MDC & 376784 & 4087311 \\
\hline 3 & Sycamore Creek & 1 & May, 2016 & OSU & 349193 & 4070742 \\
\hline 4 & Buffalo Creek & 1 & April, May 2016 & OSU & 358813 & 4062302 \\
\hline \multirow[t]{2}{*}{5} & Indian Creek & 1 & June, 2016 & MU, MDC & 372799 & 4057508 \\
\hline & & 2 & July, 2016 & MU, MDC & 389049 & 4072508 \\
\hline \multirow[t]{3}{*}{6} & Big Sugar Creek & 1 & June, 2016 & MU, MDC & 387730 & 4053187 \\
\hline & & 2 & July, 2016 & MU, MDC & 399202 & 4044930 \\
\hline & & 3 & October, 2015 & MU, MDC & 394297 & 4052947 \\
\hline 7 & Little Sugar Creek & 1 & June, 2016 & MU, MDC & 385947 & 4040944 \\
\hline \multirow[t]{3}{*}{8} & Elk River & 1 & October, 2016 & MU, MDC & 370131 & 4049760 \\
\hline & & 2 & October, 2016 & MU, MDC & 370131 & 4049760 \\
\hline & & 3 & May, 2016 & OSU & 358576 & 4054916 \\
\hline 9 & Honey Creek & 1 & November 2016 & OSU & 347033 & 4045379 \\
\hline 10 & Spavinaw Creek & 1 & June, 2015 & OSU & 346210 & 4020948 \\
\hline \multirow[t]{4}{*}{11} & Illinois River & 1 & October, 2016 & MU, MDC, OSU & 361940 & 3997121 \\
\hline & & 2 & August, 2015 & OSU & 335216 & 3995949 \\
\hline & & 3 & September, 2015 & OSU & 326757 & 3967482 \\
\hline & & 4 & August, 2015 & OSU & 326416 & 3977013 \\
\hline \multirow[t]{2}{*}{12} & Baron Fork & 1 & July, August 2015 & OSU & 328745 & 3971216 \\
\hline & & 2 & August, 2015 & OSU & 335135 & 3978455 \\
\hline \multirow[t]{3}{*}{13} & Caney Creek & 1 & August, 2015 & OSU & 339905 & 3967820 \\
\hline & & 2 & August, 2015 & OSU & 333144 & 3962593 \\
\hline & & 3 & July, August 2015 & OSU & 333693 & 3963121 \\
\hline 14 & Lee Creek & 1 & Unknown & OSU & 361138 & 3936676 \\
\hline 15 & Mulberry River & 1 & September, 2017 & MU & 437524 & 3948610 \\
\hline 16 & Big Piney Creek, AR & 1 & September, 2017 & MU, AGFC & 478700 & 3949057 \\
\hline \multirow[t]{2}{*}{17} & Illinois Bayou & 1 & September, 2017 & MU, ATU & -- & -- \\
\hline & & 2 & September, 2017 & MU, AGFC & 505007 & 3933999 \\
\hline 18 & Genoa Hatchery & 1 & November, 2018 & CERC & -- & -- \\
\hline 19 & Meramec River & 1 & June, August 2016 & MU, MDC & 634864 & 4195767 \\
\hline 20 & Stockton Lake & 1 & October, November 2017 & $\mathrm{MDC}$ & 434043 & 4167685 \\
\hline \multirow[t]{2}{*}{21} & Big Piney River, MO & 1 & November, 2016 & MU, MDC & 582956 & 4179624 \\
\hline & & 2 & September, 2017 & MU, MDC & 585518 & 4157157 \\
\hline 22 & Tablerock Lake & 1 & October, November 2017 & MDC & 471594 & 4046542 \\
\hline 23 & Crooked Creek & 1 & September, 2015 & OSU & 507007 & 4009904 \\
\hline 24 & White River & 1 & September, 2015 & OSU & 507007 & 4009904 \\
\hline 25 & Skiatook Lake & 1 & May, 2014 & OSU & 757815 & 4024174 \\
\hline 26 & Illinois River & 1 & September, 2015 & OSU & 326757 & 3967482 \\
\hline 27 & Illinois/Elk River & 2 & September, 2015 & OSU & 344772 & 4046030 \\
\hline 28 & Spring River & 3 & Unknown & OSU & -- & -- \\
\hline
\end{tabular}


Table A1.2. PCR multiplexes (Mplex) for 15 polymorphic microsatellite loci known to cross-amplify in M. dolomieu and M. punctulatus. Multiplex, locus name (Locus), fluorescent label (Label), annealing temperature (Anneal T.), primer sequences (top forward, bottom - reverse), and source are listed for each locus. Locus $m d o 8$ was omitted from genetic analyses due to a high rate of amplification failure and a high incidence of null alleles and is therefore bolded and starred for reference.

\begin{tabular}{|c|c|c|c|c|c|}
\hline Mplex & Locus & Label & $\begin{array}{l}\text { Anneal } \\
\text { T. }\left({ }^{\circ} \mathrm{C}\right)\end{array}$ & Primer Sequence & Source \\
\hline \multirow[t]{10}{*}{1} & Mdo5 & FAM & 55 & CAGGTTCCCTCTCACCTTCA & Malloy et al., 2001 \\
\hline & & & & ATGGTCTCACCAGGGACAAA & \\
\hline & Mdo6 & PET & 55 & TGAAATGTACGCCAGAGCAG & Malloy et al., 2001 \\
\hline & & & & TGTGTGGGTGTTTATGTGGG & \\
\hline & Mdo7 & VIC & 55 & TCAAACGCACCTTCACTGAC & Malloy et al., 2001 \\
\hline & & & & GTCACTCCCATCATGCTCCT & \\
\hline & Mdo9 & FAM & 55 & TTTGATGGGCGTTTTGTGTA & Malloy et al., 2001 \\
\hline & & & & GACCGGTCCTGCATATGATT & \\
\hline & Mdo10 & PET & 55 & GTGTCTCCGTGTGTTGATGG & Malloy et al., 2001 \\
\hline & & & & AACACCAGAGGCAAACAAGC & \\
\hline \multirow[t]{8}{*}{2} & Lma21 & PET & 55 & CAGCTCAATAGTTCTGTCAGG & Colbourne et al., 1995 \\
\hline & & & & ACTACTGCTGAAGATATTGTAG & \\
\hline & Mdo2 & NED & 55 & GCCCTTTCATATTGGGACAA & Malloy et al., 2001 \\
\hline & & & & CTGCTCTGGCGTACATTTCA & \\
\hline & Mdo3 & NED & 55 & AGGTGCTTTGCGCTACAAGT & Malloy et al., 2001 \\
\hline & & & & CTGCATGGCTGTTATGTTGG & \\
\hline & Mdo8 & FAM & 55 & GTGAGGACCAGCCAAAATGT & Malloy et al., 2001 \\
\hline & & & & GGAAGATTGAGGTCCCAACA & \\
\hline \multirow[t]{8}{*}{3} & Msaf05 & VIC & 58 & CGTCACCTCAGCCTCTGATT & Seyoum et al., 2013 \\
\hline & & & & TCAGCAGCAACCAAAACAAC & \\
\hline & Msaf14 & NED & 58 & GAAAGAAAGGTCCAGTCATGTAGAA & Seyoum et al., 2013 \\
\hline & & & & ATGTTATTGAGTAGATCCCAATGGA & \\
\hline & Msafl7 & PET & 58 & AGGTTGCAGGAGCAGCAGCTAGAGCA & Seyoum et al., 2013 \\
\hline & & & & ACGATGAGCCCTGTTGGGAGCTGT & \\
\hline & Msaf 29 & FAM & 58 & CGTTCTCTGAAAATGTTTCACTTC & Seyoum et al., 2013 \\
\hline & & & & ATACAATTTCTCACATTGTCTCTGTAG & \\
\hline \multirow[t]{4}{*}{4} & Msaf06 & PET & 58 & GACAGTGCACCAGGCCAAG & Seyoum et al., 2013 \\
\hline & & & & ATCTGCAGGAGATTCTAGAGGATG & \\
\hline & Msaf09 & VIC & 58 & CACACTCCAGCTACAACGCACCT & Seyoum et al., 2013 \\
\hline & & & & CTTGGGGCTATAGAGACATGGAA & \\
\hline
\end{tabular}


Table A1.3. Observed heterozygosity $\left(H_{\mathrm{O}}\right)$, expected heterozygosity $\left(H_{\mathrm{E}}\right)$, rarefied allelic richness $\left(A_{\mathrm{R}}\right)$, number of non-rare alleles $\left(A_{95}\right)$, and private allele frequency $\left(A_{\mathrm{P}}\right)$ for 43 sampling sites of Neosho Smallmouth Bass, Northern Smallmouth Bass, and Spotted Bass. Metrics that were significant are denoted with $* * *(p<0.005)$ or $*(p<0.05)$.

\begin{tabular}{|c|c|c|c|c|c|c|c|}
\hline ID & Source & Site & $H_{0} * * *$ & $\boldsymbol{H}_{\mathrm{E}}{ }^{*}$ & $A_{\mathrm{R}}$ & $A_{95} *$ & $A_{\mathrm{P}} * * *$ \\
\hline 1 & Center Creek & 1 & 0.246 & 0.421 & 2.170 & 3.000 & 0.000 \\
\hline \multirow[t]{3}{*}{2} & Shoal Creek & 1 & 0.571 & 0.426 & 2.430 & 2.429 & 0.000 \\
\hline & & 2 & 0.548 & 0.567 & 3.570 & 4.643 & 0.010 \\
\hline & & 3 & 0.557 & 0.646 & 3.720 & 4.571 & 0.020 \\
\hline 3 & Sycamore Creek & 1 & 0.396 & 0.386 & 2.470 & 2.714 & 0.030 \\
\hline 4 & Buffalo Creek & 1 & 0.545 & 0.589 & 3.440 & 4.000 & 0.030 \\
\hline \multirow[t]{2}{*}{5} & Indian Creek & 1 & 0.435 & 0.617 & 3.740 & 4.429 & 0.040 \\
\hline & & 2 & 0.477 & 0.455 & 2.930 & 4.071 & 0.030 \\
\hline \multirow[t]{3}{*}{6} & Big Sugar Creek & 1 & 0.522 & 0.639 & 3.780 & 4.786 & 0.030 \\
\hline & & 2 & 0.384 & 0.456 & 3.010 & 4.071 & 0.010 \\
\hline & & 3 & 0.568 & 0.598 & 3.540 & 3.357 & 0.090 \\
\hline 7 & Little Sugar Creek & 1 & 0.546 & 0.705 & 4.310 & 5.286 & 0.180 \\
\hline \multirow[t]{3}{*}{8} & Elk River & 1 & 0.670 & 0.634 & 3.750 & 4.500 & 0.050 \\
\hline & & 2 & 0.617 & 0.673 & 3.930 & 4.000 & 0.060 \\
\hline & & 3 & 0.600 & 0.634 & 3.760 & 4.214 & 0.030 \\
\hline 9 & Honey Creek & 1 & 0.341 & 0.368 & 2.500 & 2.429 & 0.010 \\
\hline 10 & Spavinaw Creek & 1 & 0.516 & 0.520 & 3.200 & 4.071 & 0.070 \\
\hline \multirow[t]{4}{*}{11} & Illinois River & 1 & 0.465 & 0.523 & 3.470 & 4.286 & 0.050 \\
\hline & & 2 & 0.603 & 0.604 & 3.660 & 4.714 & 0.050 \\
\hline & & 3 & 0.569 & 0.563 & 3.820 & 4.714 & 0.010 \\
\hline & & 4 & 0.589 & 0.624 & 3.840 & 4.143 & 0.060 \\
\hline \multirow[t]{2}{*}{12} & Baron Fork & 1 & 0.457 & 0.470 & 2.900 & 3.000 & 0.020 \\
\hline & & 2 & 0.401 & 0.434 & 2.720 & 2.714 & 0.030 \\
\hline \multirow[t]{3}{*}{13} & Caney Creek & 1 & 0.342 & 0.397 & 2.410 & 2.500 & 0.050 \\
\hline & & 2 & 0.417 & 0.425 & 2.650 & 3.214 & 0.000 \\
\hline & & 3 & 0.449 & 0.467 & 2.840 & 2.929 & 0.020 \\
\hline 14 & Lee Creek & 1 & 0.403 & 0.458 & 2.770 & 3.214 & 0.140 \\
\hline 15 & Mulberry River & 1 & 0.361 & 0.356 & 2.340 & 2.786 & 0.000 \\
\hline 16 & Big Piney Creek, AR & 1 & 0.532 & 0.574 & 3.500 & 4.000 & 0.050 \\
\hline \multirow[t]{3}{*}{17} & Illinois Bayou & 1 & 0.518 & 0.555 & 3.300 & 4.500 & 0.030 \\
\hline & & 2 & 0.514 & 0.485 & 3.140 & 3.429 & 0.010 \\
\hline & Neosho Average & & 0.489 & 0.525 & 3.213 & 3.765 & 0.039 \\
\hline 18 & Genoa Hatchery & 1 & 0.616 & 0.542 & 3.020 & 3.571 & 0.100 \\
\hline 19 & Meramec River & 1 & 0.574 & 0.628 & 3.770 & 4.500 & 0.010 \\
\hline 20 & Stockton Lake & 1 & 0.695 & 0.622 & 3.830 & 5.643 & 0.190 \\
\hline \multirow[t]{2}{*}{21} & Big Piney River, MO & 1 & 0.601 & 0.579 & 3.290 & 3.286 & 0.130 \\
\hline & & 2 & 0.651 & 0.650 & 3.760 & 5.357 & 0.040 \\
\hline 22 & Tablerock Lake & 1 & 0.688 & 0.736 & 4.340 & 5.429 & 0.130 \\
\hline 23 & Crooked Creek & 1 & 0.711 & 0.674 & 4.020 & 4.500 & 0.140 \\
\hline 24 & White River & 1 & 0.690 & 0.587 & 2.860 & 3.214 & 0.140 \\
\hline \multirow[t]{2}{*}{25} & Skiatook Lake & 1 & 0.578 & 0.581 & 3.580 & 5.000 & 0.210 \\
\hline & Northern Average & & 0.645 & 0.622 & 3.608 & 4.500 & 0.121 \\
\hline 26 & Illinois River & 1 & 0.311 & 0.441 & 2.780 & 3.214 & 0.230 \\
\hline 27 & Illinois/Elk River & 1 & 0.304 & 0.384 & 2.500 & 2.500 & 0.170 \\
\hline \multirow[t]{2}{*}{28} & Spring River & 1 & 0.468 & 0.522 & 3.500 & 4.429 & 0.350 \\
\hline & Spotted Bass Average & & 0.361 & 0.449 & 2.927 & 3.381 & 0.250 \\
\hline
\end{tabular}


Table A1.4. Pairwise $F_{\mathrm{ST}}$ values for all populations following Table 3.1. Significant $F_{\mathrm{ST}}$ after Bonferroni correction are bolded and shaded.

\begin{tabular}{|c|c|c|c|c|c|c|c|c|c|c|c|c|c|c|c|c|c|c|c|c|c|c|c|c|c|c|c|}
\hline POP & 1 & 2 & 3 & 4 & 5 & 6 & 7 & 8 & 9 & 10 & 11 & 12 & 13 & 14 & 15 & 16 & 17 & 18 & 19 & 20 & 21 & 22 & 23 & 24 & 25 & 26 & 27 \\
\hline 2 & 0.07 & & & & & & & & & & & & & & & & & & & & & & & & & & \\
\hline 3 & 0.08 & 0.12 & & & & & & & & & & & & & & & & & & & & & & & & & \\
\hline 4 & 0.05 & 0.03 & 0.06 & & & & & & & & & & & & & & & & & & & & & & & & \\
\hline 6 & 0.03 & 0.02 & 0.07 & 0 & 0 & & & & & & & & & & & & & & & & & & & & & & \\
\hline 7 & 0.16 & 0.07 & 0.25 & 0.08 & 0.07 & 0.06 & & & & & & & & & & & & & & & & & & & & & \\
\hline 8 & 0.1 & 0.03 & 0.12 & 0.02 & 0.02 & 0.02 & 0.03 & & & & & & & & & & & & & & & & & & & & \\
\hline 10 & 0.09 & 0.07 & 0.06 & 0.03 & 0.04 & 0.04 & 0.14 & 0.07 & 0.06 & & & & & & & & & & & & & & & & & & \\
\hline 11 & 0.11 & 0.06 & 0.09 & 0.04 & 0.03 & 0.04 & 0.1 & 0.06 & 0.1 & 0.04 & & & & & & & & & & & & & & & & & \\
\hline 12 & 0.14 & 0.13 & 0.07 & 0.07 & 0.08 & 0.09 & 0.22 & 0.12 & 0.09 & 0.06 & 0.05 & & & & & & & & & & & & & & & & \\
\hline 13 & 0.17 & 0.16 & 0.1 & 0.1 & 0.11 & 0.12 & 0.24 & 0.14 & 0.13 & 0.08 & 0.06 & 0.01 & & & & & & & & & & & & & & & \\
\hline 14 & 0.16 & 0.15 & 0.21 & 0.14 & 0.13 & 0.12 & 0.22 & 0.15 & 0.21 & 0.14 & 0.13 & 0.16 & 0.19 & & & & & & & & & & & & & & \\
\hline 15 & 0.07 & 0.11 & 0.09 & 0.07 & 0.06 & 0.06 & 0.19 & 0.11 & 0.06 & 0.07 & 0.09 & $\mathbf{0 . 0 7}$ & 0.11 & 0.11 & & & & & & & & & & & & & \\
\hline 20 & 0.27 & 0.11 & 0.33 & 0.17 & 0.15 & 0.16 & 0.13 & 0.14 & 0.34 & 0.21 & 0.16 & 0.3 & 0.33 & 0.3 & 0.3 & 0.2 & 0.21 & 0.11 & 0.08 & & & & & & & & \\
\hline 21 & 0.22 & 0.1 & 0.28 & 0.13 & 0.13 & 0.13 & 0.08 & 0.09 & 0.29 & 0.18 & 0.14 & 0.25 & 0.28 & 0.26 & 0.23 & 0.15 & 0.16 & 0.09 & 0.01 & 0.05 & & & & & & & \\
\hline 22 & 0.22 & 0.12 & 0.28 & 0.12 & 0.12 & 0.1 & 0.02 & 0.08 & 0.3 & 0.17 & 0.12 & 0.23 & 0.25 & 0.21 & 0.21 & 0.12 & 0.13 & 0.18 & 0.11 & 0.14 & 0.1 & & & & & & \\
\hline 23 & 0.23 & 0.11 & 0.27 & 0.11 & 0.1 & 0.1 & 0.03 & 0.07 & 0.29 & 0.17 & 0.11 & 0.23 & 0.26 & 0.25 & 0.23 & 0.13 & 0.15 & 0.21 & 0.14 & 0.16 & 0.11 & 0.03 & & & & & \\
\hline 24 & 0.31 & 0.12 & 0.38 & 0.15 & 0.12 & 0.13 & 0.04 & 0.09 & 0.4 & 0.25 & 0.16 & 0.32 & 0.34 & 0.34 & 0.35 & 0.16 & 0.19 & 0.26 & 0.15 & 0.16 & 0.11 & 0.07 & 0.04 & & & & \\
\hline 25 & 0.29 & 0.15 & 0.33 & 0.18 & 0.16 & 0.17 & 0.11 & 0.13 & 0.35 & 0.22 & 0.14 & 0.29 & 0.31 & 0.31 & 0.3 & 0.19 & 0.2 & 0.19 & 0.16 & 0.15 & 0.14 & 0.13 & 0.14 & 0.16 & & & \\
\hline 26 & 0.38 & 0.29 & 0.4 & 0.3 & 0.29 & 0.29 & 0.26 & 0.27 & 0.42 & 0.34 & 0.29 & 0.39 & 0.42 & 0.4 & 0.4 & 0.29 & 0.32 & 0.36 & 0.28 & 0.31 & 0.28 & 0.26 & 0.3 & 0.36 & 0.34 & & \\
\hline 27 & 0.47 & 0.32 & 0.46 & 0.34 & 0.31 & 0.32 & 0.25 & 0.3 & 0.5 & 0.38 & 0.32 & 0.45 & 0.47 & 0.45 & 0.48 & 0.33 & 0.36 & 0.4 & 0.27 & 0.3 & 0.29 & 0.24 & 0.3 & 0.35 & 0.37 & 0.08 & \\
\hline 28 & 0.34 & 0.26 & 0.41 & 0.28 & 0.26 & 0.26 & 0.21 & 0.25 & 0.42 & 0.31 & 0.25 & $\mathbf{0 . 3 7}$ & 0.39 & 0.35 & 0.36 & 0.24 & 0.28 & 0.33 & 0.24 & 0.25 & 0.24 & 0.21 & 0.26 & 0.32 & 0.3 & 0.04 & -0.02 \\
\hline
\end{tabular}


Table A1.5. $K$, STRUCTURE replicates, replicates with major clusters, mean and standard deviation of posterior probability $(\operatorname{LnP}(K))$, and second order rate of change of log likelihood (Delta $K$ ) for 10 replicates in STRUCTURE using Default Parameters for (a) all black bass samples, (b) all samples from the Northern Smallmouth Bass range and all Spotted Bass, and (c) all samples from the Neosho Smallmouth Bass range.

\begin{tabular}{rrcrrr}
\hline $\boldsymbol{K}$ & Reps & $\begin{array}{c}\text { Reps with Major } \\
\text { Clusters }\end{array}$ & Mean LnP(K) & $\begin{array}{c}\text { St. Dev. } \\
\text { LnP(K) }\end{array}$ & DeltaK \\
\hline a. & All black bass samples & & & \\
1 & 10 & 10 & -33993.25 & 0.07 & $N A$ \\
2 & 10 & 10 & -31341.39 & 1.02 & 1502.55 \\
3 & 10 & 5 & -30220.94 & 3.10 & 116.55 \\
4 & 10 & 7 & -29461.66 & 2.27 & 98.45 \\
5 & 10 & 5 & -28925.64 & 3.22 & 38.90 \\
6 & 10 & 10 & -28514.88 & 4.83 & 12.60 \\
7 & 10 & 10 & -28043.27 & 4.02 & 73.71 \\
8 & 10 & 10 & -27868.22 & 6.68 & 3.57 \\
9 & 10 & 10 & -27669.35 & 4.88 & 25.31 \\
10 & 10 & 8 & -27593.92 & 6.48 & 28.16 \\
11 & 10 & 9 & -27700.91 & 604.09 & 0.07 \\
12 & 10 & 9 & -27847.74 & 781.95 & 0.09 \\
13 & 10 & 9 & -27922.37 & 240.75 & 1.41 \\
14 & 10 & 9 & -28336.57 & 585.61 & 0.06 \\
15 & 10 & 9 & -28783.52 & 581.27 & $N A$
\end{tabular}

b. All samples from the Northern Smallmouth Bass range and all Spotted Bass

\begin{tabular}{rrrrrr}
1 & 10 & 10 & -7726.92 & 0.66 & $N A$ \\
2 & 10 & 10 & -6780.68 & 0.16 & 3459.83 \\
3 & 10 & 10 & -6394.70 & 27.70 & 4.75 \\
4 & 10 & 10 & -6140.41 & 1.18 & 194.81 \\
5 & 10 & 10 & -6116.34 & 434.48 & $N A$ \\
\multicolumn{5}{c}{ c. } & All samples from the Neosho Smallmouth Bass range \\
1 & 10 & 10 & -24359.86 & 0.08 & \\
2 & 10 & 10 & -23037.04 & 1.20 & NA \\
3 & 10 & 5 & -22736.92 & 9.98 & 11.31 \\
4 & 10 & 5 & -22549.74 & 43.11 & 10.65 \\
5 & 10 & 10 & -21903.53 & 6.27 & 68.93 \\
6 & 10 & 7 & -21689.34 & 4.51 & 56.87 \\
7 & 10 & 7 & -21731.67 & 15.76 & 1.04 \\
8 & 10 & 7 & -21790.46 & 22.62 & 2.62 \\
9 & 10 & 9 & -21790.00 & 39.96 & 4.32 \\
10 & 10 & 6 & -21616.93 & 37.42 & $N A$ \\
\hline
\end{tabular}


Table A1.6 $K$, STRUCTURE replicates, replicates representing major clusters, mean and standard deviation of posterior probability $(\operatorname{LnP}(K))$, and second order rate of change of $\log$ likelihood (Delta $K$ ) for 10 replicates in STRUCTURE using Wang Parameters for all black bass samples.

\begin{tabular}{cccccr}
\hline $\boldsymbol{K}$ & Reps & $\begin{array}{c}\text { Reps with Major } \\
\text { Clusters }\end{array}$ & Mean LnP(K) & St. Dev. LnP(K) & DeltaK \\
\hline 1 & 10 & 10 & -33997.63 & 0.05 & $N A$ \\
2 & 10 & 7 & -31859.06 & 3.47 & 277.25 \\
\hline
\end{tabular}




\begin{tabular}{rrrrrr}
\hline 3 & 10 & 6 & -30681.82 & 2.59 & 1689.06 \\
4 & 10 & 8 & -33879.76 & 11262.89 & 0.66 \\
5 & 10 & 4 & -29646.95 & 4.79 & 819.77 \\
6 & 10 & 5 & -29343.60 & 55.23 & 7.82 \\
7 & 10 & 5 & -29472.00 & 448.45 & 1.31 \\
8 & 10 & 7 & -29013.77 & 34.11 & 13.80 \\
9 & 10 & 8 & -29026.06 & 15.36 & 46.82 \\
10 & 10 & 8 & -29757.30 & 1361.20 & 0.98 \\
11 & 10 & 6 & -29147.77 & 4.51 & 145.16 \\
12 & 10 & 7 & -29193.59 & 16.78 & 0.49 \\
13 & 10 & 5 & -29231.12 & 11.99 & 0.47 \\
14 & 10 & 9 & -29274.26 & 11.81 & 0.82 \\
15 & 10 & 8 & -29327.11 & 18.13 & $N A$ \\
\hline
\end{tabular}


Table A1.7. Table of Puechmaille (2016) estimators: median of medians (MedMed $K$ ), median of means (MedMean $K)$, maximum of medians (MaxMed $K)$, and maximum of means (MaxMeanK), based on STRUCTURE Puechmaille Metrics for all black bass samples.

\begin{tabular}{cccccc}
\hline $\boldsymbol{K}$ & MedMed & MedMean & MaxMed & MaxMean & Reps \\
\hline 1 & 1 & 1 & 1 & 1 & 10 \\
2 & 2 & 2 & 2 & 2 & 10 \\
3 & 3 & 3 & 3 & 3 & 10 \\
4 & 4 & 4 & 4 & 4 & 10 \\
5 & 5 & 5 & 5 & 5 & 10 \\
6 & 6 & 6 & 6 & 6 & 10 \\
7 & 7 & 7 & 7 & 7 & 10 \\
8 & 8 & 8 & 8 & 8 & 10 \\
9 & 9 & 9 & 9 & 9 & 10 \\
10 & 8 & 8 & 9 & 8 & 10 \\
11 & 9 & 9 & 9 & 9 & 10 \\
12 & 8 & 8 & 9 & 9 & 10 \\
13 & 8 & 8 & 9 & 9 & 10 \\
14 & 7 & 8 & 8 & 8 & 10 \\
15 & 7 & 7 & 8 & 8 & 10
\end{tabular}

MedMedK MedMeaK MaxMedK MaxMeaK

9

9

9

9 
Table A1.8. Back-calculated grand mean of total length and ANCOVA coefficients calculated for log-transformed, adjusted means of standard length (SL), orbital length (OL), head length (HL), and body depth for a) Neosho and Northern Smallmouth Bass assessed by taxonomic range and b) Neosho and Northern Smallmouth Bass assessed by genetic assignment.

\begin{tabular}{|c|c|c|c|c|c|c|}
\hline \multirow{2}{*}{ Trait Grand Mean (mm) } & \multirow{2}{*}{$R^{2}$} & \multirow{2}{*}{ Error } & \multicolumn{2}{|r|}{$\beta$} & \multicolumn{2}{|r|}{$\alpha$} \\
\hline & & & Neosho & Northern & Neosho & Northern \\
\hline \multicolumn{7}{|l|}{ a. Taxonomic Range } \\
\hline \multirow{4}{*}{283.139} & 0.961 & 0.038 & 1.007 & 0.977 & -0.103 & -0.019 \\
\hline & 0.284 & 0.036 & 0.576 & -0.033 & -0.264 & 1.237 \\
\hline & 0.799 & 0.059 & 0.949 & 0.974 & -0.426 & -0.523 \\
\hline & 0.841 & 0.015 & 1.129 & 1.269 & -0.950 & -1.299 \\
\hline \multicolumn{7}{|l|}{ b. Genetic Assignment } \\
\hline \multirow{4}{*}{279.898} & 0.963 & 0.014 & 1.145 & 0.996 & -0.435 & -0.066 \\
\hline & 0.026 & 0.066 & 0.452 & 0.122 & 0.056 & 0.862 \\
\hline & 0.624 & 0.053 & 0.945 & 1.019 & -0.412 & -0.620 \\
\hline & 0.804 & 0.043 & 1.407 & 1.219 & -1.618 & -1.177 \\
\hline
\end{tabular}


Table A1.9. Sample sizes and results from Discriminant Function Analysis (DFA) for total length (TL), standard length (SL), orbital length (OL), head length (HL), and body depth (BD) grouped by taxonomic range ("Range") or genetic assignment ("Assignment"). Mean accuracy of assignment overall and coefficients for individual morphometrics are listed.

\begin{tabular}{|c|c|c|c|c|c|c|c|c|c|c|}
\hline \multirow{2}{*}{ Group } & \multicolumn{2}{|r|}{$N$} & \multicolumn{8}{|c|}{ Coefficients from Discriminant Function Analysis (DFA) } \\
\hline & Neosho & Northern & Accuracy & TL & SL & OL & HL & BD & $X^{2}$ & $p-v a l$ \\
\hline Range & 184 & 65 & $79.92 \%$ & -2.858 & 35.529 & 0.277 & -21.645 & -8.764 & 43.750 & $<0.001$ \\
\hline Assignment & 17 & 71 & $81.82 \%$ & -11.588 & 38.414 & 1.117 & -5.669 & -8.716 & 6.981 & 0.008 \\
\hline
\end{tabular}




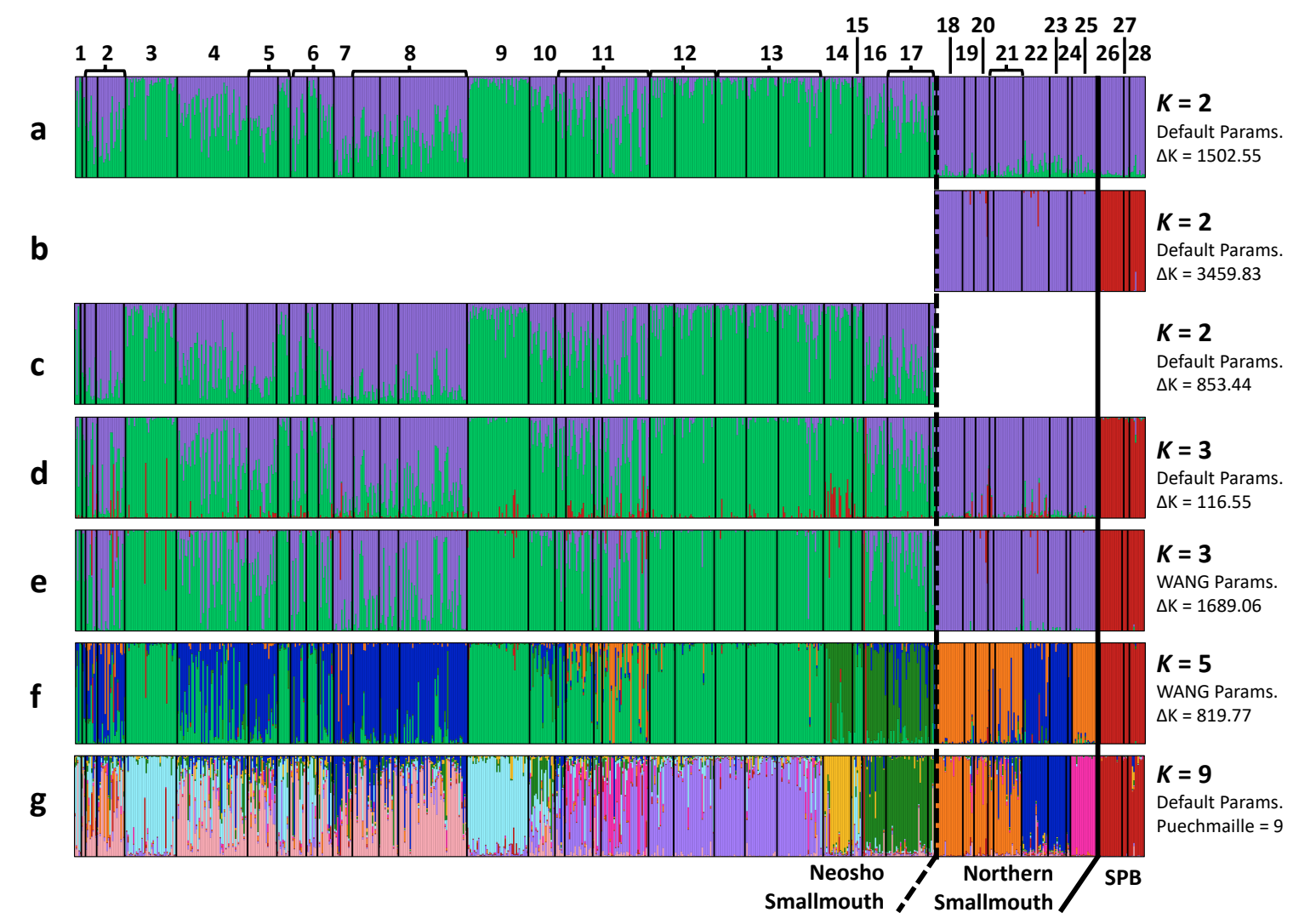

Figure A1.1. $q$-plots of major clusters from STRUCTURE. Within sources (upper horizontal), sites are presented north to south from left to right and correspond to Table 1, with the exception of Skiatook Lake, which lies outside both subspecies ranges. Species distinction is delineated by a bold black line; subspecies distinction is delineated by a dotted black line. Number of clusters $(K)$, parameters utilized, and $\Delta K$ are listed to the right of each plot. Plots a-d show genotypic assignments based on Default Parameters to (a) 2 clusters; (b) 2 clusters for Northern Smallmouth Bass and Spotted Bass (SPB) only; (c) 2 clusters for Neosho Smallmouth Bass only; and (d) 3 clusters. Plots e and f show assignments based on Wang Parameters to (e) 3 clusters, and (f) 5 clusters. Plot (g) shows assignment based on Puechmaille Metrics. 


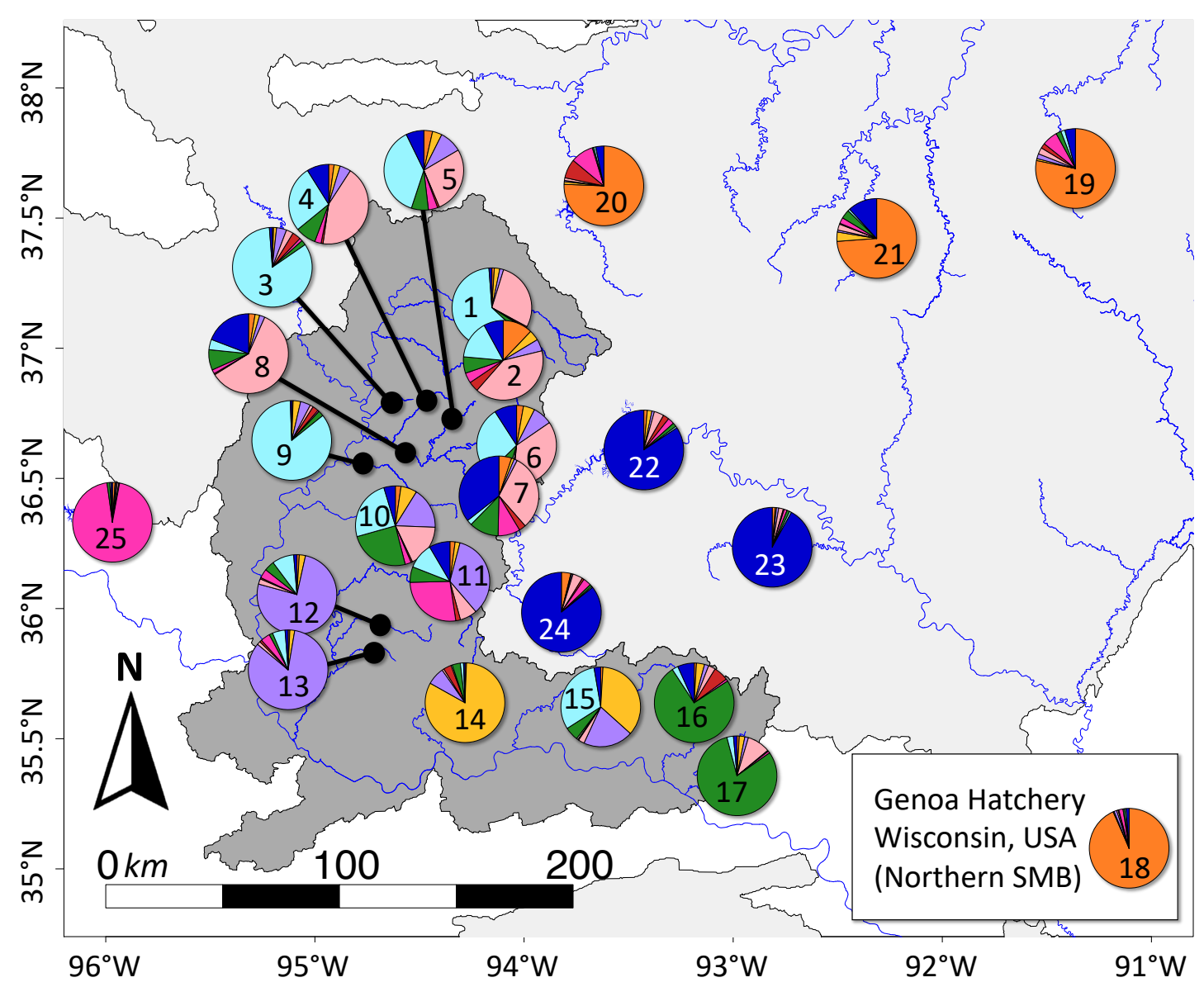

Figure A1.2. Geographic distribution of cluster assignments for Smallmouth Bass. Individual charts show average membership coefficients of 25 Smallmouth Bass populations to $K=9$ major clusters based on Puechmaille Metrics. Genoa Hatchery, Wisconsin (Population 18), is shown in the lower right. 

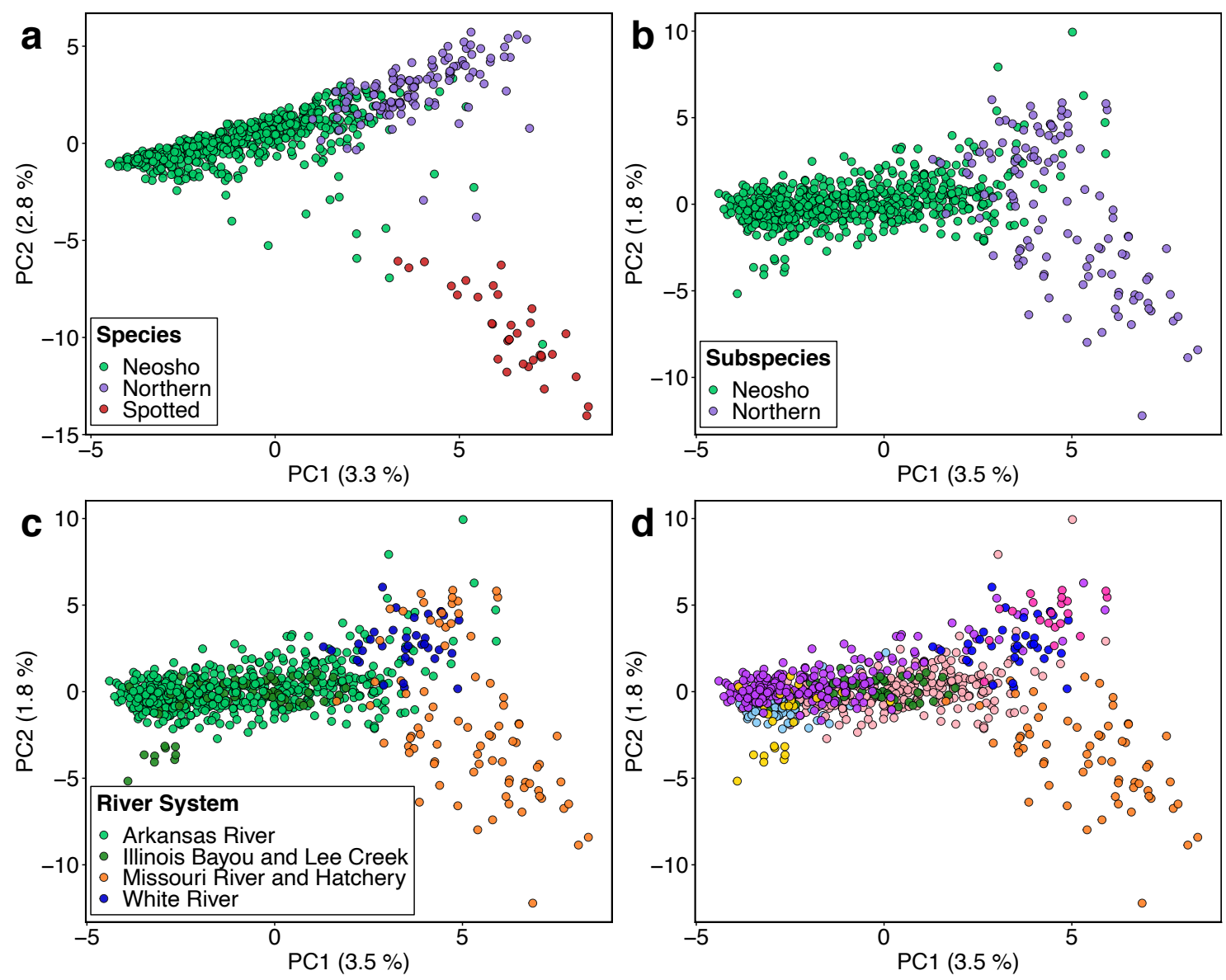

Figure A1.3. PCA of 14 microsatellites showing clustering at the a) taxonomic, (b) subspecies, (c) river system, and (d) population levels. Panel (a) includes Spotted Bass data. Panels $(b-d)$ include only Smallmouth Bass data and therefore depict groupings at or below subspecies level. Panel c shows groupings among river systems of the CIH. Panel d corresponds with population clusters shown in Figure 3.3f and Figure 3.4c; individuals were grouped according to highest membership coefficient. Populations were unnamed, so a figure legend is not included. 

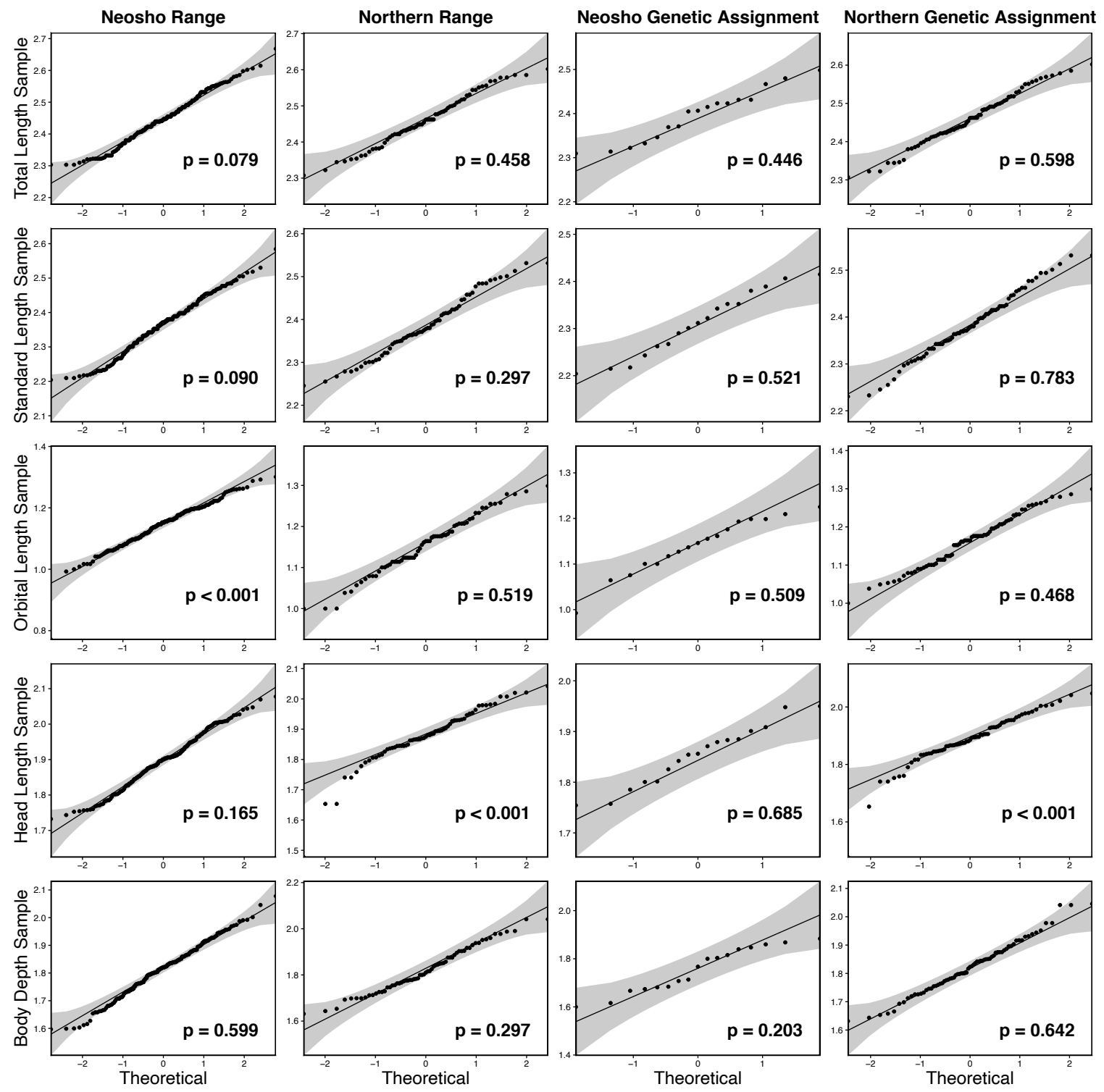

Figure A1.4. $q q$-plots showing adherence to a normal distribution for all log-transformed morphometric traits (top to bottom: total length, standard length, orbital length, head length, and body depth) across taxonomic ranges and genetic assignments (left to right: Neosho range samples, Northern range samples, Neosho non-admixed samples, Northern non-admixed samples). $p$-values from Shapiro-Wilk normality tests are listed for each trait. 

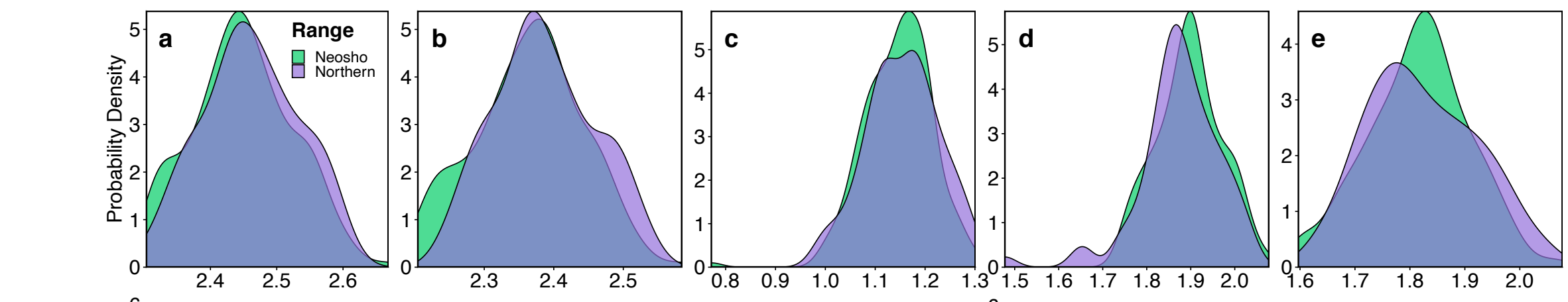

w
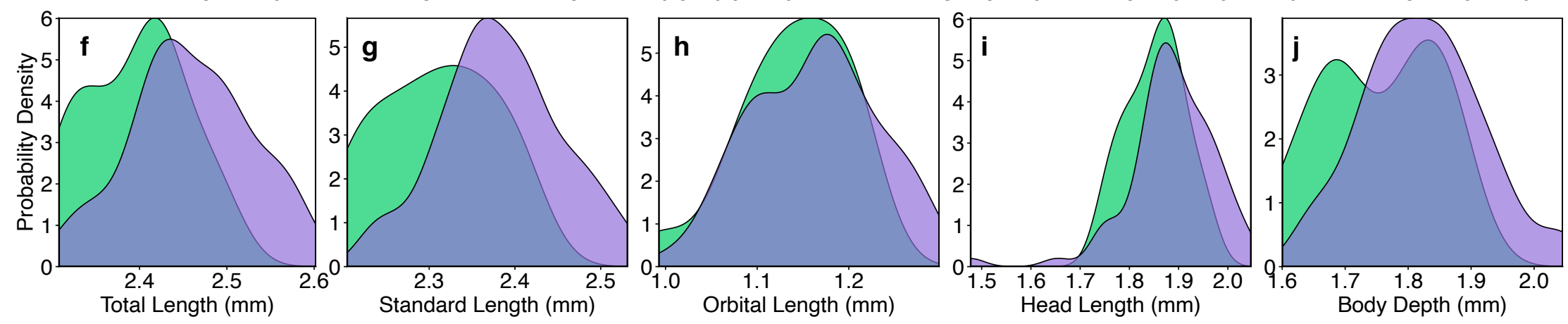

Figure A1.5. Probability density distributions for all log-transformed morphometrics (right to left: total length, standard length, orbital length, head length, and body depth), colored by taxonomic range ("Range"; a-e) and by genetic assignment ("Assignment"; f-g). 


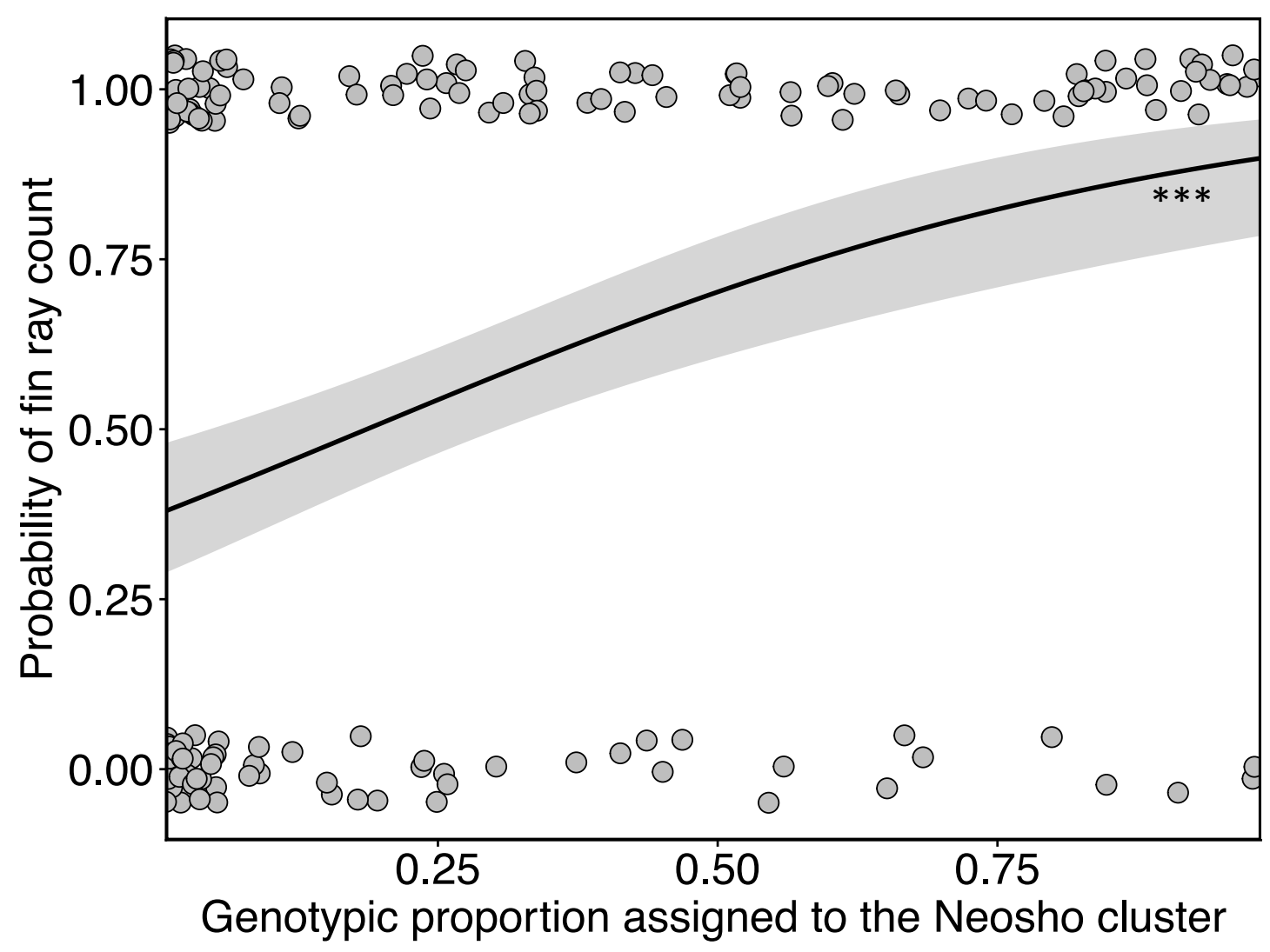

Figure A1.6. Logistic regression of soft dorsal fin ray count. Values of 0 represent samples possessing 14 soft dorsal rays, and values of 1 represent samples possessing 13 soft dorsal rays. The red trend line indicates the probability of possessing either 14 or 13 soft dorsal rays based on the proportion of genetic assignment to the Neosho cluster from STRUCTURE analysis. Logistic regression showed a significant association with a $p R^{2}$ value of 0.115 and is therefore marked with ***. 


\section{APPENDIX 2 \\ Supplementary tables and figures for chapter 4}

Table A2.1. References (with respect to Figure A2.2), ID codes, and descriptions of nine two-population diversification demographic models tested for admixed populations in $\delta a \delta i$.

\begin{tabular}{cll}
\hline $\begin{array}{c}\text { Model } \\
\text { Ref }\end{array}$ & Code & \\
\hline $\mathbf{a}$ & NM & Divergence, no migration \\
b & SM & Divergence, continuous symmetric migration \\
c & AM & Divergence, continuous asymmetric migration \\
d & SCSM & Divergence, isolation, secondary contact with symmetric migration \\
e & SCAM & Divergence, isolation, secondary contact with asymmetric migration \\
f & ASM & Divergence, ancient symmetric migration, isolation \\
g & AAM & Divergence, ancient asymmetric migration, isolation \\
h & SM2E & Divergence, symmetric migration between two distinct epochs \\
i & AM2E & Divergence, asymmetric migration between two distinct epochs \\
\hline
\end{tabular}


Table A2.2. Description of parameters estimated in $\delta a \delta i$.

\begin{tabular}{cl}
\hline Parameter & \multicolumn{1}{c}{ Parameter Description } \\
\hline $\boldsymbol{n} \boldsymbol{u}_{\mathbf{1}}$ & Size of population 1 at present \\
$\boldsymbol{n} \boldsymbol{u}_{\mathbf{2}}$ & Size of population 2 at present \\
$\boldsymbol{m}_{\mathbf{1 2}}$ & Continuous migration rate from population 2 to population 1 \\
$\boldsymbol{m}_{\mathbf{2 1}}$ & Continuous migration rate from population 1 to population 2 \\
$\boldsymbol{m}_{\mathbf{1 2}}$ & Migration rate from population 2 to population 1 during first epoch \\
$\boldsymbol{m}_{\mathbf{2 1}}$ & Migration rate from population 1 to population 2 during first epoch \\
$\boldsymbol{m}_{\mathbf{1 2 b}}$ & Migration rate from population 2 to population 1 during second epoch \\
$\boldsymbol{m}_{\mathbf{2 1}}$ & Migration rate from population 1 to population 2 during second epoch \\
$\boldsymbol{T}_{\mathbf{1}}$ & Scaled time between split and ancient migration \\
$\boldsymbol{T}_{\mathbf{2}}$ & Scaled time between ancient migration and present \\
\hline
\end{tabular}


Table A2.3. Maximum likelihood, AIC, and BIC results for phylogenetic substitution models (General Time Reversible; GTR and TN93) and possible decorations (Dec) tested in PHYML.

\begin{tabular}{lllrrcrc}
\hline Model Dec & K & Likelihood & AIC & AAIC & BIC & $\Delta$ BIC \\
\hline GTR & G & 108 & $-19,484,754,373$ & 389911.874 & 0.000 & 390734.155 & 0.000 \\
GTR & G + I & 109 & $-19,484,856,089$ & 389915.122 & 3.247 & 390745.810 & 11.655 \\
GTR & & 107 & $-19,488,923,330$ & 389992.467 & 80.592 & 390807.913 & 73.758 \\
TN93 & G & 105 & $-19,511,468,744$ & 390439.375 & 527.500 & 391239.579 & 505.424 \\
GTR & I & 108 & $-19,513,952,051$ & 390495.410 & 583.535 & 391318.108 & 583.953 \\
\hline
\end{tabular}


Table A2.4. Results of three-population tests for $p$-Admixed populations (UPPARK, ILLI, ELK, BAYOU). Combinations of parents (Source 1 and Source 2) with the most negative $f_{3}$ value are inferred as most likely parents of the corresponding admixed population (Admixed Pop). Source populations with highest $f_{3}$ for each population are highlighted in grey for emphasis. Corresponding standard errors and $z$-scores are given.

\begin{tabular}{|c|c|c|c|c|c|}
\hline Admixed Pop & Source 1 & Source 2 & $f_{3}$ & Standard Error & $z$-score \\
\hline UPPARK & MIDARK & MISS & -0.01365 & 0.00017 & -78.92 \\
\hline UPPARK & MIDARK & SKIA & -0.01220 & 0.00017 & -72.51 \\
\hline UPPARK & MIDARK & ELK & -0.00490 & 0.00008 & -59.63 \\
\hline UPPARK & MIDARK & WHITE & -0.01446 & 0.00017 & -83.78 \\
\hline UPPARK & MIDARK & BAYOU & -0.00172 & 0.00010 & -16.87 \\
\hline UPPARK & MISS & LMULB & -0.00463 & 0.00028 & -16.27 \\
\hline UPPARK & SKIA & LMULB & -0.00353 & 0.00030 & -11.97 \\
\hline UPPARK & ELK & LMULB & -0.00190 & 0.00016 & -11.81 \\
\hline UPPARK & LMULB & WHITE & -0.00522 & 0.00027 & -19.62 \\
\hline ILLI & MIDARK & MISS & -0.01452 & 0.00020 & -73.98 \\
\hline ILLI & MIDARK & SKIA & -0.01647 & 0.00021 & -80.31 \\
\hline ILLI & MIDARK & ELK & -0.00311 & 0.00010 & -30.07 \\
\hline ILLI & MIDARK & WHITE & -0.01322 & 0.00019 & -68.41 \\
\hline ILLI & MIDARK & BAYOU & -0.00174 & 0.00010 & -17.83 \\
\hline ILLI & MISS & LMULB & -0.00583 & 0.00026 & -22.08 \\
\hline ILLI & SKIA & UPPARK & -0.00209 & 0.00018 & -11.79 \\
\hline ILLI & SKIA & LMULB & -0.00813 & 0.00028 & -28.54 \\
\hline ILLI & ELK & LMULB & -0.00044 & 0.00015 & -2.97 \\
\hline ILLI & LMULB & WHITE & -0.00431 & 0.00027 & -15.92 \\
\hline ELK & MIDARK & MISS & -0.02100 & 0.00029 & -72.97 \\
\hline ELK & MIDARK & SKIA & -0.01820 & 0.00030 & -60.57 \\
\hline ELK & MIDARK & WHITE & -0.02240 & 0.00024 & -94.07 \\
\hline ELK & MISS & UPPARK & -0.01225 & 0.00021 & -57.99 \\
\hline ELK & MISS & ILLI & -0.00959 & 0.00022 & -43.31 \\
\hline ELK & MISS & LMULB & -0.01498 & 0.00028 & -52.68 \\
\hline ELK & MISS & BAYOU & -0.00427 & 0.00021 & -20.61 \\
\hline ELK & SKIA & UPPARK & -0.0109 & 0.00023 & -46.99 \\
\hline ELK & SKIA & ILLI & -0.00485 & 0.00023 & -20.97 \\
\hline ELK & SKIA & LMULB & -0.01254 & 0.00031 & -41.00 \\
\hline ELK & SKIA & BAYOU & -0.00281 & 0.00025 & -11.25 \\
\hline ELK & UPPARK & WHITE & -0.01284 & 0.00017 & -76.54 \\
\hline ELK & ILLI & WHITE & -0.01230 & 0.00021 & -59.69 \\
\hline ELK & LMULB & WHITE & -0.01616 & 0.00023 & -71.61 \\
\hline ELK & WHITE & BAYOU & -0.00511 & 0.00021 & -24.73 \\
\hline BAYOU & MIDARK & MISS & -0.01140 & 0.00027 & -41.99 \\
\hline BAYOU & MIDARK & SKIA & -0.01005 & 0.00028 & -35.50 \\
\hline BAYOU & MIDARK & WHITE & -0.01195 & 0.00026 & -46.28 \\
\hline BAYOU & MISS & LMULB & -0.01053 & 0.00030 & -35.54 \\
\hline BAYOU & SKIA & LMULB & -0.00955 & 0.00029 & -32.58 \\
\hline BAYOU & ILLI & WHITE & -0.00047 & 0.00024 & -1.99 \\
\hline BAYOU & LMULB & WHITE & -0.01087 & 0.00027 & -40.57 \\
\hline
\end{tabular}


Table A2.5. Best-fitting models (highlighted in grey), log-likelihood, AIC, $\Delta$ AIC, and parameter estimates inferred in $\delta a \delta i$.

\begin{tabular}{|c|c|c|c|c|c|c|c|c|c|c|c|c|c|c|c|}
\hline Model & $\log ($ LIK $)$ & AIC & $\Delta \mathbf{A I C}$ & $X^{2}$ & $\theta$ & $n u_{1}$ & $n u_{2}$ & $m_{12}$ & $m_{21}$ & $m_{12 \mathrm{a}}$ & $m_{21 a}$ & $m_{12 b}$ & $m_{21 b}$ & $T_{1}$ & $T_{2}$ \\
\hline \multicolumn{16}{|c|}{ ELK-WHITE } \\
\hline AM & -1680.740 & 3371.480 & 0.000 & 2845.700 & 6367.420 & 0.362 & 0.690 & 4.903 & 0.026 & -- & -- & -- & -- & 0.878 & -- \\
\hline SCAM & -1686.190 & 3384.380 & 12.900 & 2805.280 & 10355.270 & 0.200 & 0.417 & 7.872 & 0.291 & -- & -- & -- & -- & 2.532 & 0.772 \\
\hline AM2E & -2015.220 & 4046.440 & 674.960 & 3520.880 & 3682.220 & 0.870 & 0.972 & -- & -- & 3.766 & 1.587 & 1.998 & 0.250 & 2.084 & 0.756 \\
\hline AAM & -2587.250 & 5186.500 & 1815.020 & 5447.180 & 487.070 & 6.119 & 8.419 & 0.370 & 0.085 & -- & -- & -- & -- & 25.239 & 0.416 \\
\hline ASM & -2939.020 & 5888.040 & 2516.560 & 6020.250 & 507.130 & 7.755 & 5.287 & 0.176 & 0.176 & -- & -- & -- & -- & 24.728 & 0.135 \\
\hline SM & -2970.100 & 5948.200 & 2576.720 & 6226.700 & 2105.330 & 1.871 & 1.286 & 0.643 & 0.643 & -- & -- & -- & -- & 4.853 & -- \\
\hline SM2E & -2983.360 & 5978.720 & 2607.240 & 6331.740 & 4844.120 & 0.759 & 0.576 & -- & -- & 5.847 & 5.847 & 1.349 & 1.349 & 1.023 & 0.302 \\
\hline SCSM & -3075.980 & 6161.960 & 2790.480 & 6047.350 & 23253.430 & 0.150 & 0.099 & 8.110 & 8.110 & -- & -- & -- & -- & 0.166 & 4.984 \\
\hline NM & -3296.110 & 6598.220 & 3226.740 & 7179.420 & 6360.550 & 0.445 & 0.410 & -- & -- & -- & -- & -- & -- & 0.087 & -- \\
\hline \multicolumn{16}{|c|}{ ILLI-SKIA } \\
\hline SCAM & -1782.330 & 3576.660 & 0.000 & 3050.590 & 2854.340 & 0.962 & 0.957 & 3.434 & 0.276 & -- & -- & -- & -- & 1.143 & 0.091 \\
\hline $\mathrm{AM}$ & -3374.100 & 6758.200 & 3181.540 & 7183.260 & 5031.200 & 0.405 & 0.501 & 1.988 & 0.035 & -- & -- & -- & -- & 0.998 & -- \\
\hline AM2E & -3426.530 & 6869.060 & 3292.400 & 7194.670 & 8356.110 & 0.248 & 0.349 & -- & -- & 12.606 & 0.223 & 3.296 & 0.049 & 1.172 & 2.678 \\
\hline SCSM & -3995.760 & 8001.520 & 4424.860 & 8600.030 & 1325.630 & 2.540 & 1.121 & 0.497 & 0.497 & -- & -- & -- & -- & 4.277 & 0.578 \\
\hline AAM & -4061.900 & 8135.800 & 4559.140 & 9271.600 & 5738.750 & 0.394 & 0.335 & 2.780 & 0.418 & -- & -- & -- & -- & 0.590 & 0.013 \\
\hline SM & -4362.920 & 8733.840 & 5157.180 & 9799.840 & 15555.610 & 0.175 & 0.086 & 3.592 & 3.592 & -- & -- & -- & -- & 2.738 & -- \\
\hline SM2E & -4362.890 & 8737.780 & 5161.120 & 9781.380 & 3482.880 & 0.780 & 0.393 & -- & -- & 9.060 & 9.060 & 0.800 & 0.800 & 0.485 & 5.548 \\
\hline ASM & -4536.060 & 9082.120 & 5505.460 & 10882.700 & 457.150 & 6.675 & 3.124 & 0.112 & 0.112 & -- & -- & -- & -- & 27.211 & 0.118 \\
\hline NM & -5777.170 & 11560.340 & 7983.680 & 14792.680 & 5681.110 & 0.312 & 0.131 & -- & -- & -- & -- & -- & -- & 0.077 & -- \\
\hline \multicolumn{16}{|c|}{ UPPARK-WHITE } \\
\hline AM2E & -6121.950 & 12259.900 & 0.000 & 11792.280 & 3135.310 & 0.637 & 1.508 & -- & -- & 1.656 & 0.096 & 1.413 & 0.011 & 3.076 & 16.128 \\
\hline $\mathrm{AM}$ & -6144.990 & 12299.980 & 40.080 & 11783.010 & 1554.960 & 1.259 & 3.043 & 0.687 & 0.010 & -- & -- & -- & -- & 16.249 & -- \\
\hline SCAM & -6215.650 & 12443.300 & 183.400 & 12124.500 & 10236.050 & 0.218 & 0.411 & 4.126 & 0.245 & -- & -- & -- & -- & 4.664 & 3.213 \\
\hline AAM & -6645.750 & 13303.500 & 1043.600 & 13734.960 & 2276.210 & 1.062 & 1.837 & 0.950 & 0.044 & -- & -- & -- & -- & 10.348 & 0.010 \\
\hline SCSM & -7521.570 & 15053.140 & 2793.240 & 17579.200 & 5409.540 & 0.600 & 0.518 & 2.140 & 2.140 & -- & -- & -- & -- & 0.588 & 0.090 \\
\hline SM2E & -7528.020 & 15068.040 & 2808.140 & 18231.120 & 1798.340 & 1.913 & 1.683 & -- & -- & 0.062 & 0.062 & 0.607 & 0.607 & 4.240 & 0.324 \\
\hline SM & -8651.010 & 17310.020 & 5050.120 & 20386.740 & 1535.130 & 2.096 & 1.702 & 0.296 & 0.296 & -- & -- & -- & -- & 9.468 & -- \\
\hline ASM & -9020.850 & 18051.700 & 5791.800 & 21859.010 & 3329.230 & 0.876 & 0.782 & 0.775 & 0.775 & -- & -- & -- & -- & 8.007 & 0.011 \\
\hline NM & -12410.300 & 24826.600 & 12566.700 & 37087.760 & 7016.920 & 0.332 & 0.289 & -- & -- & -- & -- & -- & -- & 0.091 & -- \\
\hline \multicolumn{16}{|c|}{ BAYOU-WHITE } \\
\hline SCAM & -1049.790 & 2111.580 & 0.000 & 1127.730 & 4965.440 & 0.437 & 0.867 & 19.782 & 0.775 & -- & -- & -- & -- & 0.750 & 0.019 \\
\hline $\mathrm{AM} 2 \mathrm{E}$ & -1853.650 & 3723.300 & 1611.720 & 3005.520 & 10102.310 & 0.185 & 0.411 & -- & -- & 0.029 & 0.571 & 5.001 & 0.131 & 0.322 & 0.835 \\
\hline $\mathrm{AM}$ & -1858.620 & 3727.240 & 1615.660 & 2973.110 & 15135.790 & 0.115 & 0.275 & 8.156 & 0.143 & -- & -- & -- & -- & 0.784 & -- \\
\hline AAM & -3482.480 & 6976.960 & 4865.380 & 7610.390 & 6387.160 & 0.432 & 0.541 & 3.647 & 1.045 & -- & -- & -- & -- & 2.113 & 0.056 \\
\hline SM & -3498.620 & 7005.240 & 4893.660 & 6995.780 & 4861.830 & 0.696 & 0.594 & 0.864 & 0.864 & -- & -- & -- & -- & 1.220 & -- \\
\hline ASM & -3506.790 & 7023.580 & 4912.000 & 7058.010 & 2528.710 & 1.337 & 1.147 & 0.469 & 0.469 & -- & -- & -- & -- & 4.118 & 0.010 \\
\hline SM2E & -3541.000 & 7094.000 & 4982.420 & 6893.060 & 12839.690 & 0.242 & 0.210 & -- & -- & 8.279 & 8.279 & 2.361 & 2.361 & 7.109 & 0.218 \\
\hline SCSM & -3644.410 & 7298.820 & 5187.240 & 6932.470 & 6202.980 & 0.480 & 0.403 & 1.312 & 1.312 & -- & -- & -- & -- & 0.060 & 4.630 \\
\hline NM & -4374.010 & 8754.020 & 6642.440 & 9964.400 & 6765.700 & 0.341 & 0.375 & -- & -- & -- & -- & -- & -- & 0.112 & -- \\
\hline
\end{tabular}




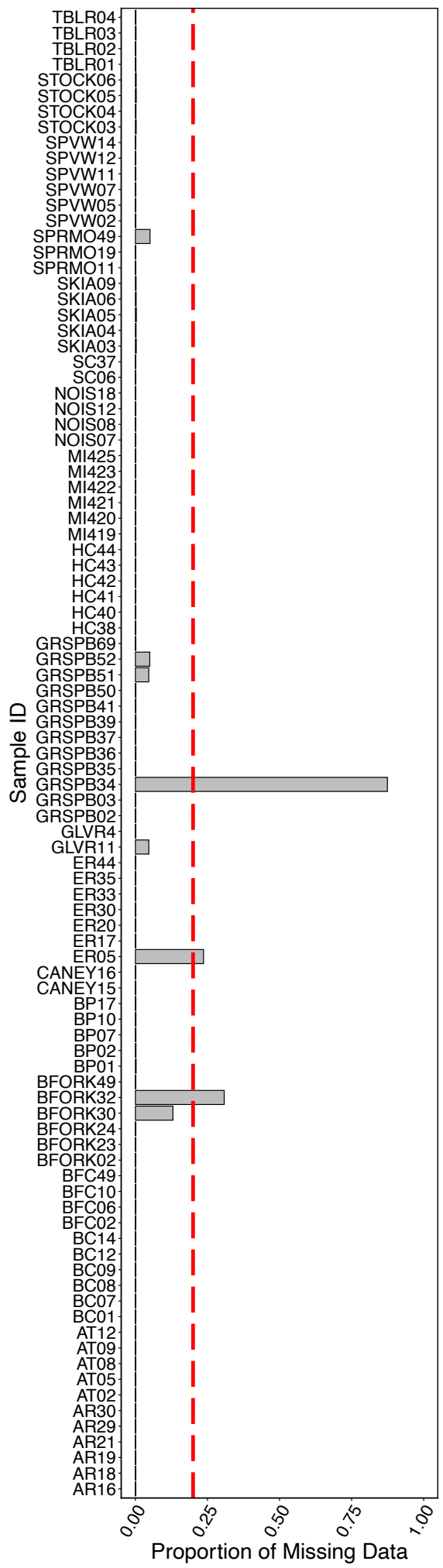

Figures A2.1. Proportion of missing genotype data per sample across all SNPs $(127,428)$ before filtering. The red dotted line indicates the threshold $(\leq 20 \%$ missing data) for keeping a sample. 

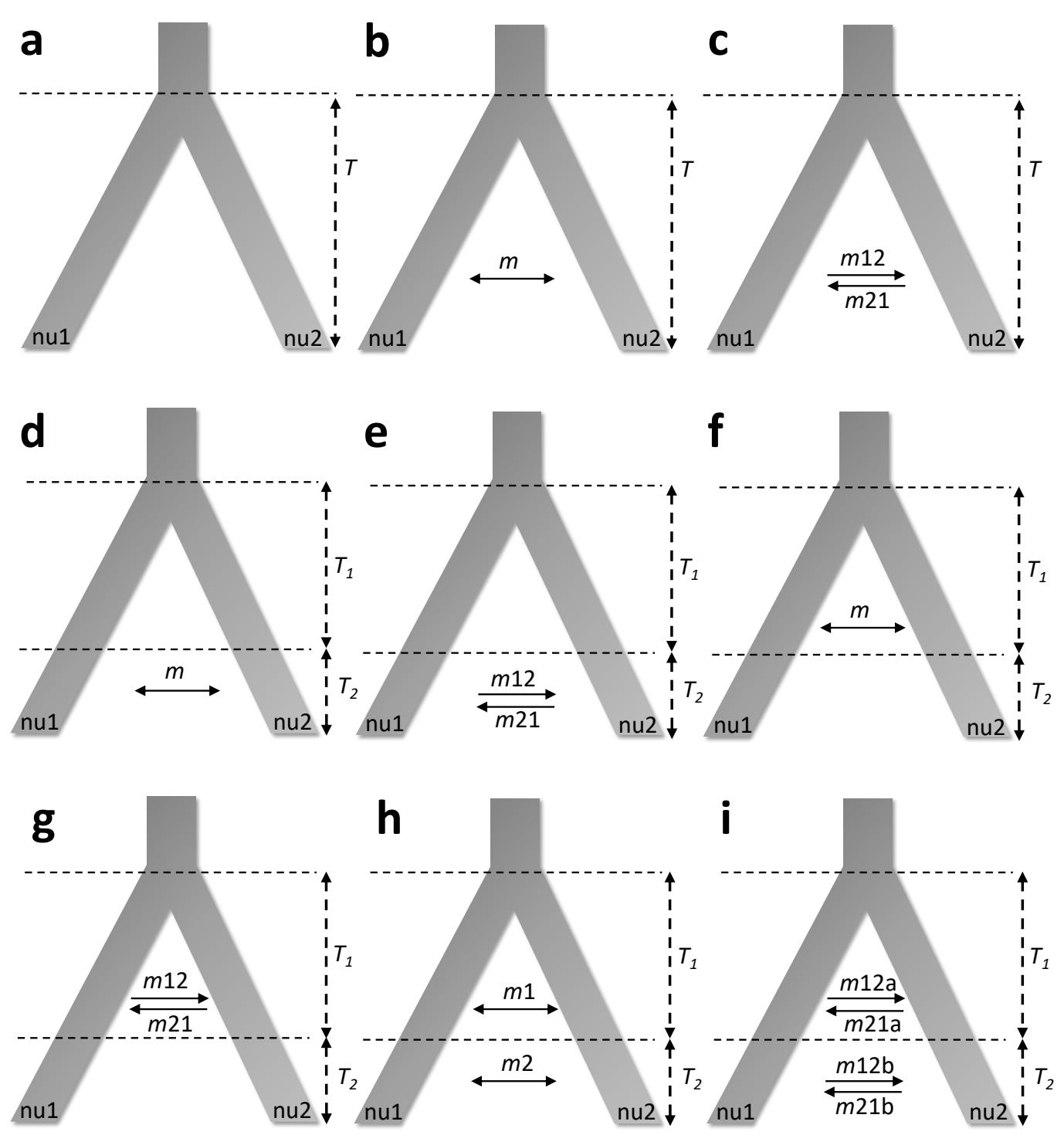

Figure A2.2. Two-population diversification demographic models tested in $\delta \mathrm{a} \delta$ i for each population pair (ELK and WHITE, BAYOU and WHITE, UPPARK and WHITE, and ILLI and SKIA), along with associated parameters. Models were fitted using 2D folded joint frequency spectra and represent (a) population divergence with no migration; (b) divergence with continuous symmetric migration; (c) divergence with continuous asymmetric migration; (d) divergence, isolation, and secondary contact with symmetric migration; (e) divergence, isolation, and secondary contact with asymmetric migration; (f) divergence, ancient symmetric migration, isolation; (g) divergence, ancient asymmetric migration, isolation; (h) divergence, symmetric migration over two distinct epochs; and (i) divergence, asymmetric migration over two distinct epochs. 


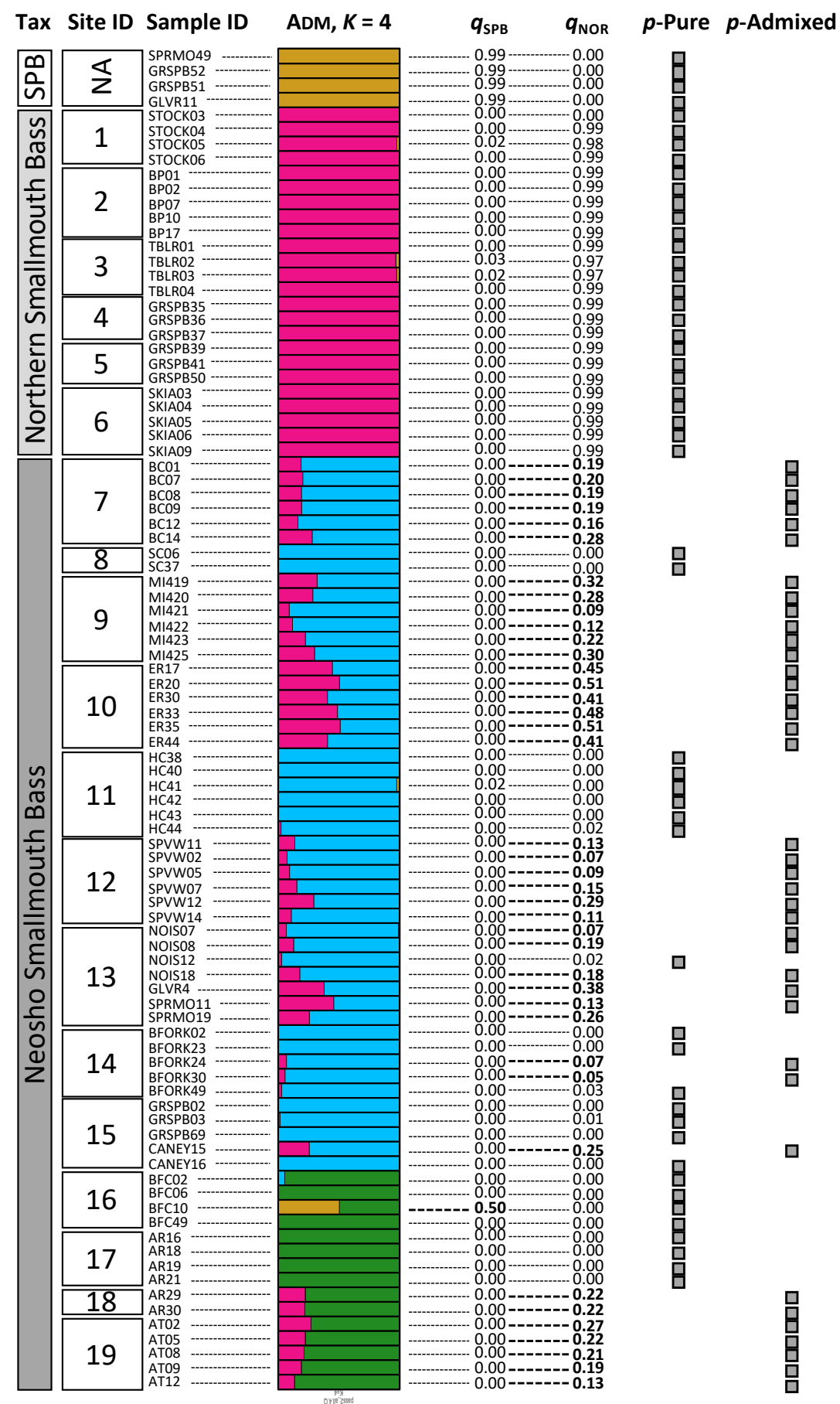

Figure A2.3. Population structure results for $K=4$ generated in ADMIXTURE for all samples $(N=92)$ and all SNPs $(50,828)$ passing quality filters. Individuals are labeled from left to right by taxon (Tax), Site ID, and Sample ID. Ancestry coefficients for Spotted Bass $\left(q_{\mathrm{SPB}}\right)$ and Northern Smallmouth Bass $\left(q_{\mathrm{NOR}}\right)$ are given and connected by thin dotted lines for ease of visualization. A check was placed in the $p$-Pure column if 
$q_{\mathrm{NOR}}<0.05$ and $q_{\mathrm{SPB}}<0.05$. Otherwise, a check was placed in the $p$-Admixed column, indicated a putatively admixed individual.

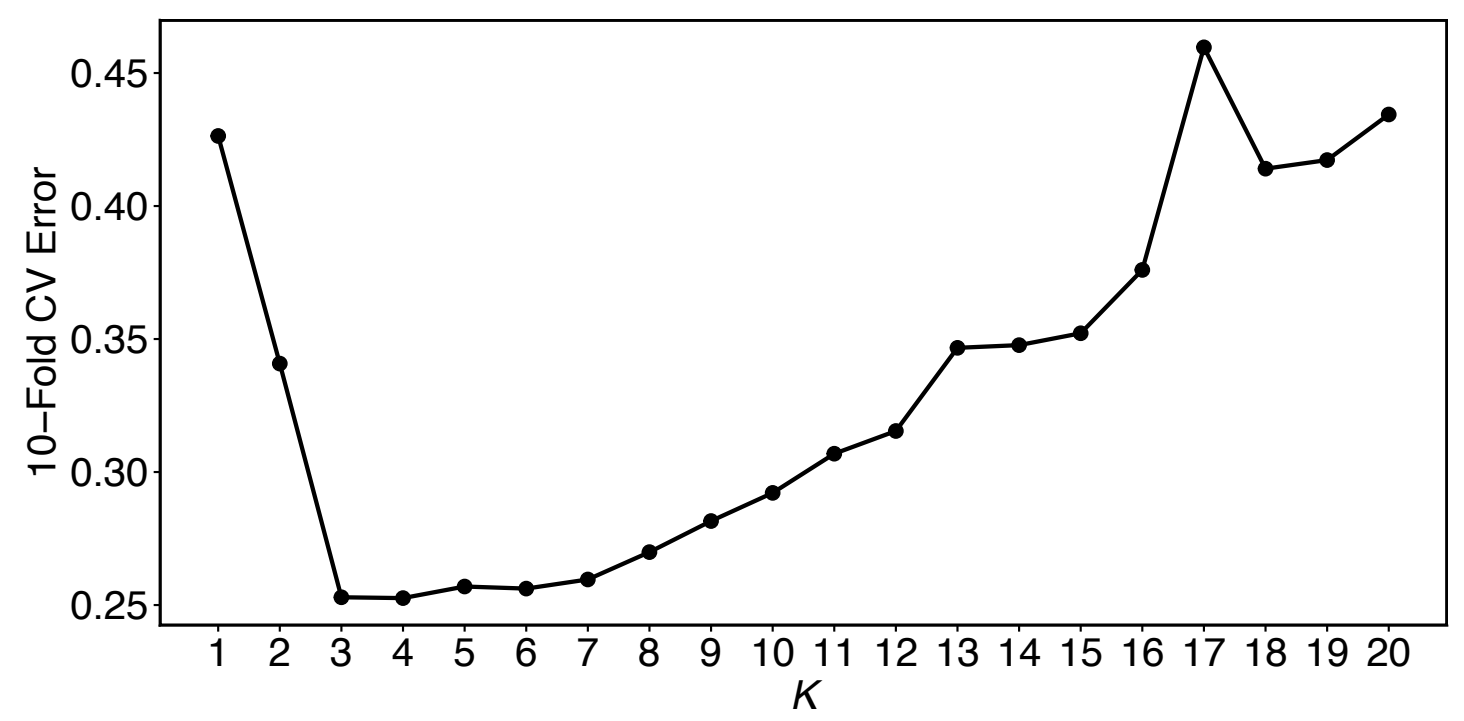

Figure A2.4. 10-fold cross-validation error results for admixture screening analysis of all Smallmouth Bass samples. 

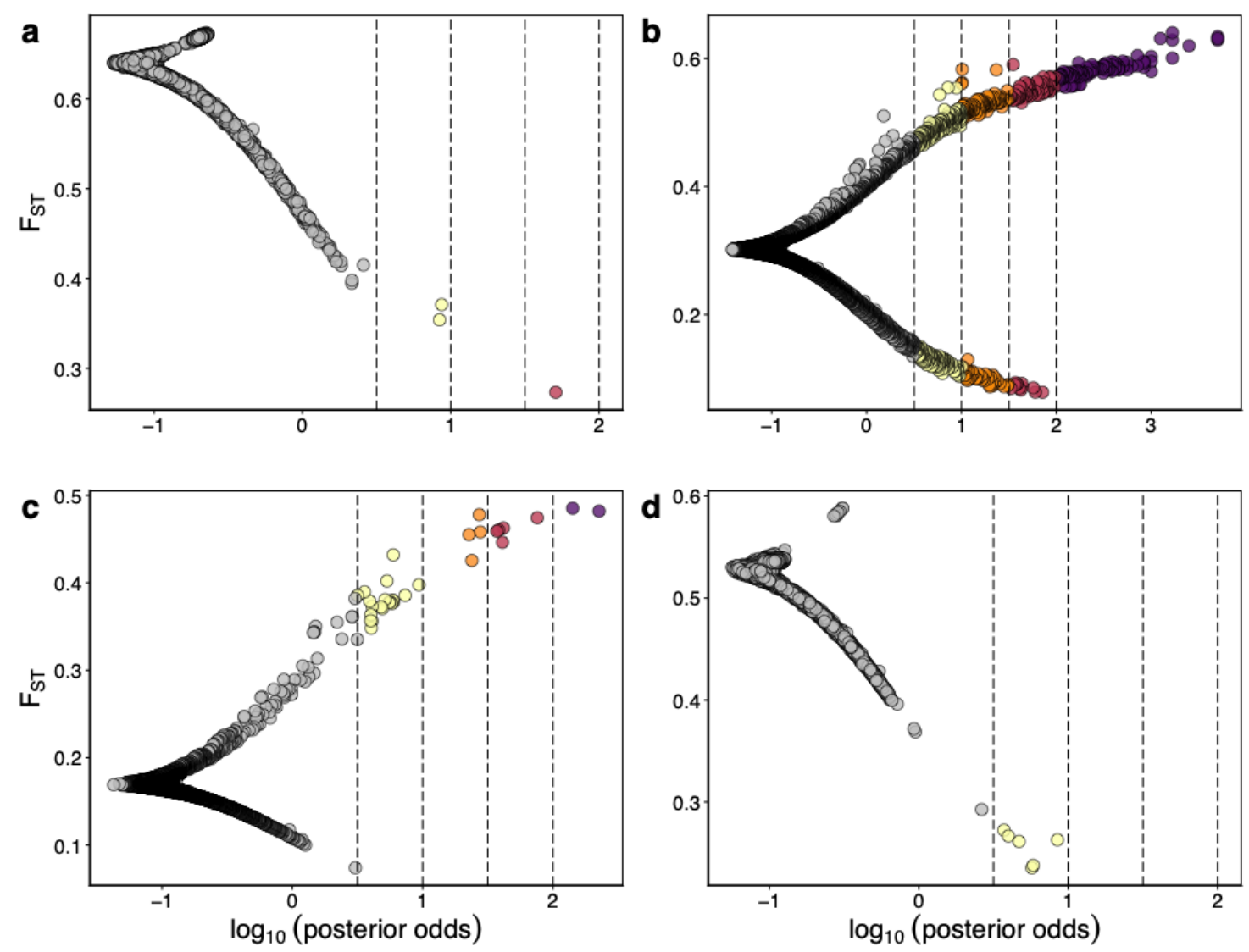

Figure A2.5. SNPs with outlier $F_{\mathrm{ST}}$ detected in BAYESCAN. (a) Outlier SNPs detected across Spotted Bass and Smallmouth Bass samples; (b) outlier SNPs detected across Smallmouth Bass only; (c) outlier SNPs detected across Neosho Smallmouth Bass only; and (d) outlier SNPs detected across Northern Smallmouth Bass only. Log 10 of the posterior odds for each SNP are plotted on the x-axis, and associated $F_{\mathrm{ST}}$ values are plotted on the y-axis. Dotted lines are plotted on the x-axis at 0.5, 1.0, 1.5, and 2.0, designating posterior odds corresponding to thresholds for substantial support, strong support, very strong support, and decisive support for outlier status, respectively, and dots are colored according to the threshold they meet. High outlier $F_{\mathrm{ST}}$ SNPs are under strong diversifying (positive) selection, whereas low outlier $F_{\mathrm{ST}}$ SNPs are under strong balancing (stabilizing) selection. SNPs with posterior odds above 1.5, colored in dark red and dark purple, were considered significant for downstream analyses. 

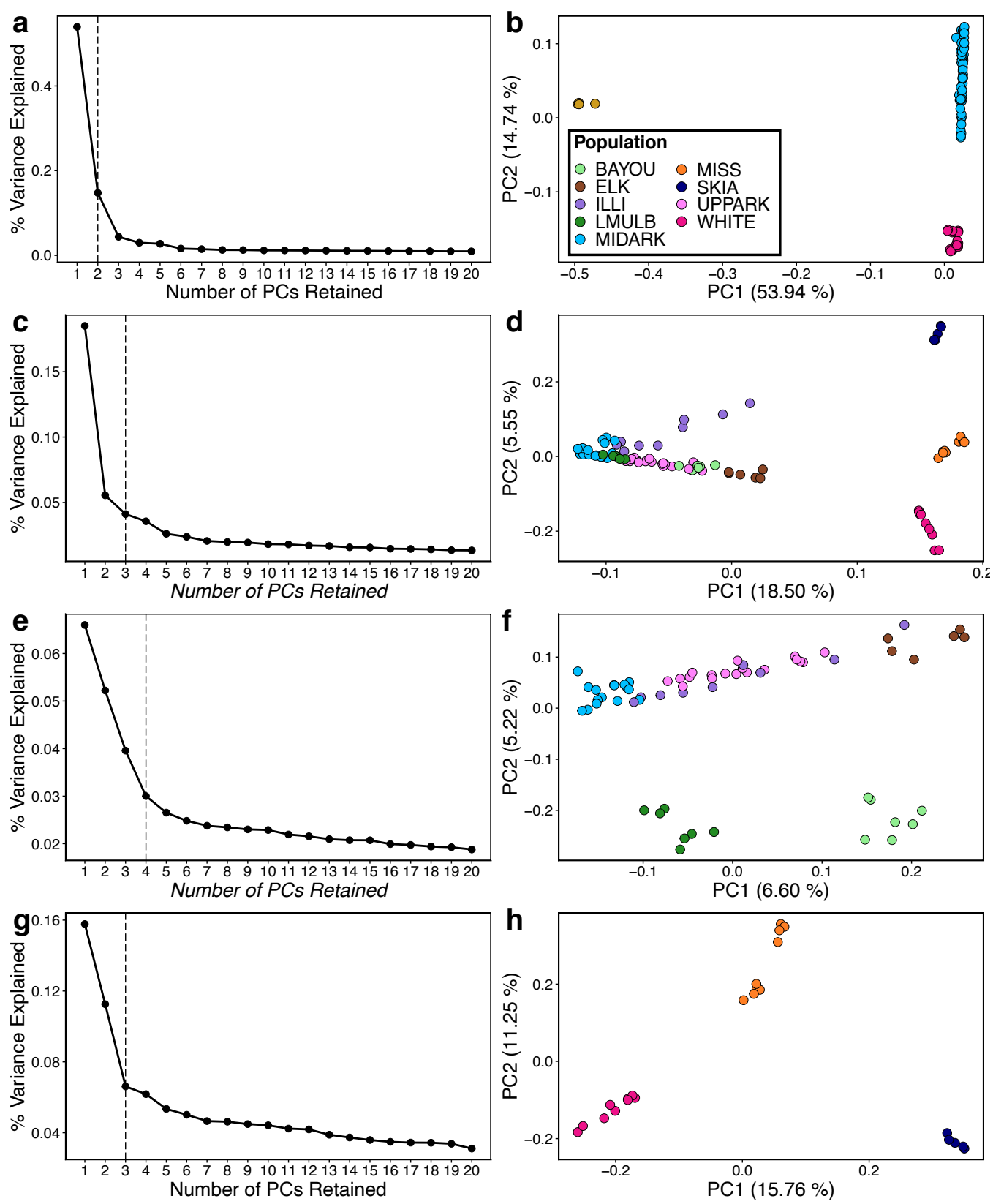

Figure A2.6. Scree plots (left column) and PCA score plots (right column) from outlier $F_{\text {ST }}$ analysis in PCADAPT for all Spotted Bass and Smallmouth Bass samples combined (a and b), Smallmouth Bass samples only (c and d), Neosho Smallmouth Bass samples only (e and f) and Northern Smallmouth Bass samples only ( $g$ and $h$ ). Dotted lines on the scree plot indicate the number of PCs used to calculate the PCA shown at right. Only the first 2 PCs (with proportion of explained variance listed for each) are shown. PCA plots were colored by the most prominent level population structure. 

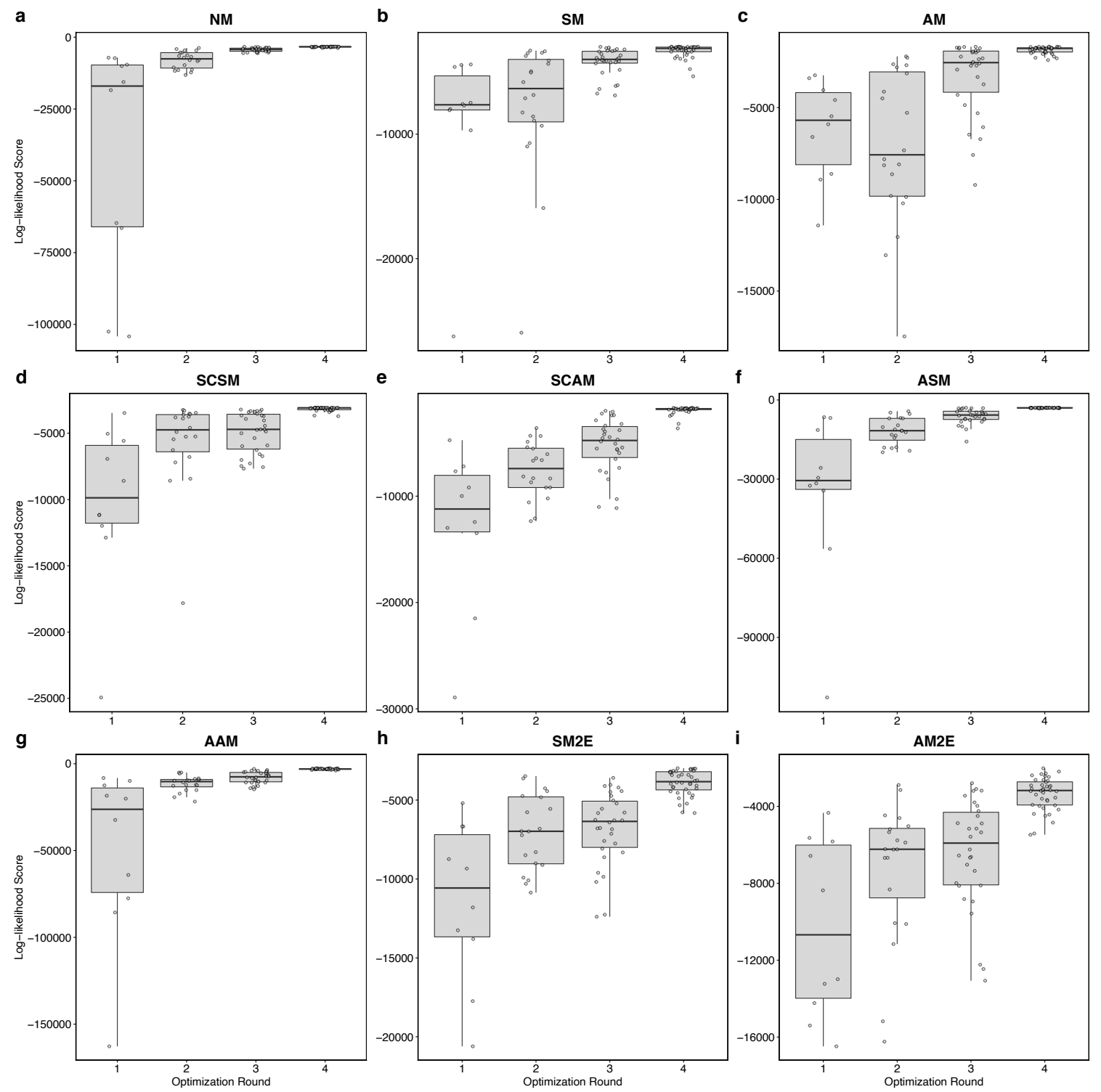

Figure A2.7. Optimization rounds for nine demographic models (a-i) run in $\delta a \delta i$ for the admixed Neosho Smallmouth Bass population in the Elk River (ELK) and its Northern Smallmouth Bass parent in the White River drainage (WHITE). Log-likelihood scores and associated box plots for 10 replicates in Round 1, 20 replicates in Round 2, 30 replicates in Round 3, and 40 replicates in Round 4, are shown for each model. Model codes are associated with the model descriptions in Table A2.1. Schematics for each model are given in Figure A2.2. 

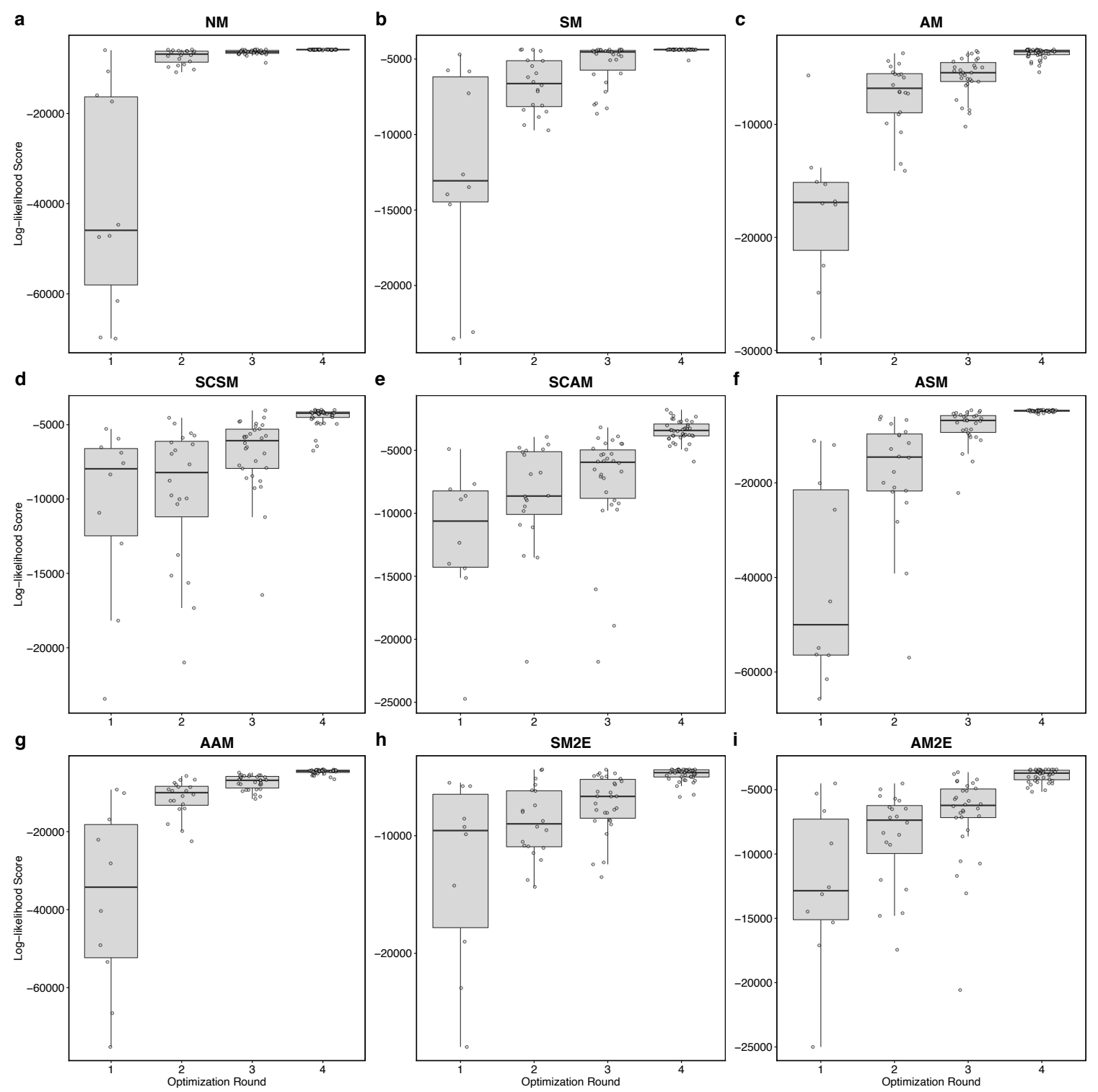

Figure A2.8. Optimization rounds for nine demographic models (a-i) run in $\delta a \delta i$ for the admixed Neosho Smallmouth Bass population in the Illinois River system (ILLI) and its Northern Smallmouth Bass parent in the hatchery strain represented by Skiatook Lake (SKIA). Log-likelihood scores and associated box plots for 10 replicates in Round 1, 20 replicates in Round 2, 30 replicates in Round 3, and 40 replicates in Round 4, are shown for each model. Model codes are associated with the model descriptions in Table A2.1. Schematics for each model are given in Figure A2.2. 

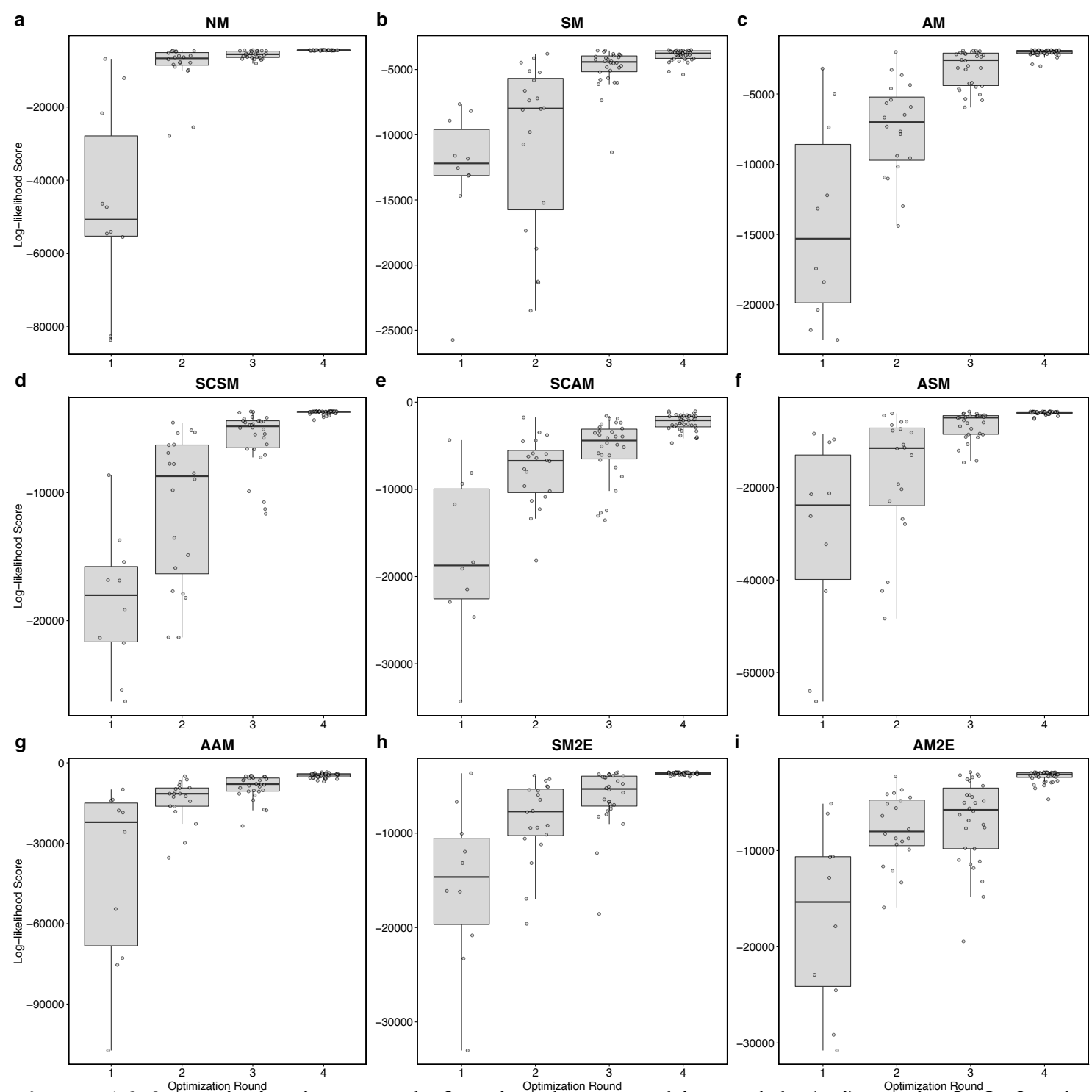

Figure A2.9. Optimization rounds for nine demographic models (a-i) run in $\delta a \delta i$ for the admixed Neosho Smallmouth Bass population in the Illinois Bayou River and Big Piney Creek, AR (BAYOU) and its Northern Smallmouth Bass parent in the White River drainage (WHITE). Log-likelihood scores and associated box plots for 10 replicates in Round 1, 20 replicates in Round 2, 30 replicates in Round 3, and 40 replicates in Round 4 , are shown for each model. Model codes are associated with the model descriptions in Table A2.1. Schematics for each model are given in Figure A2.2. 

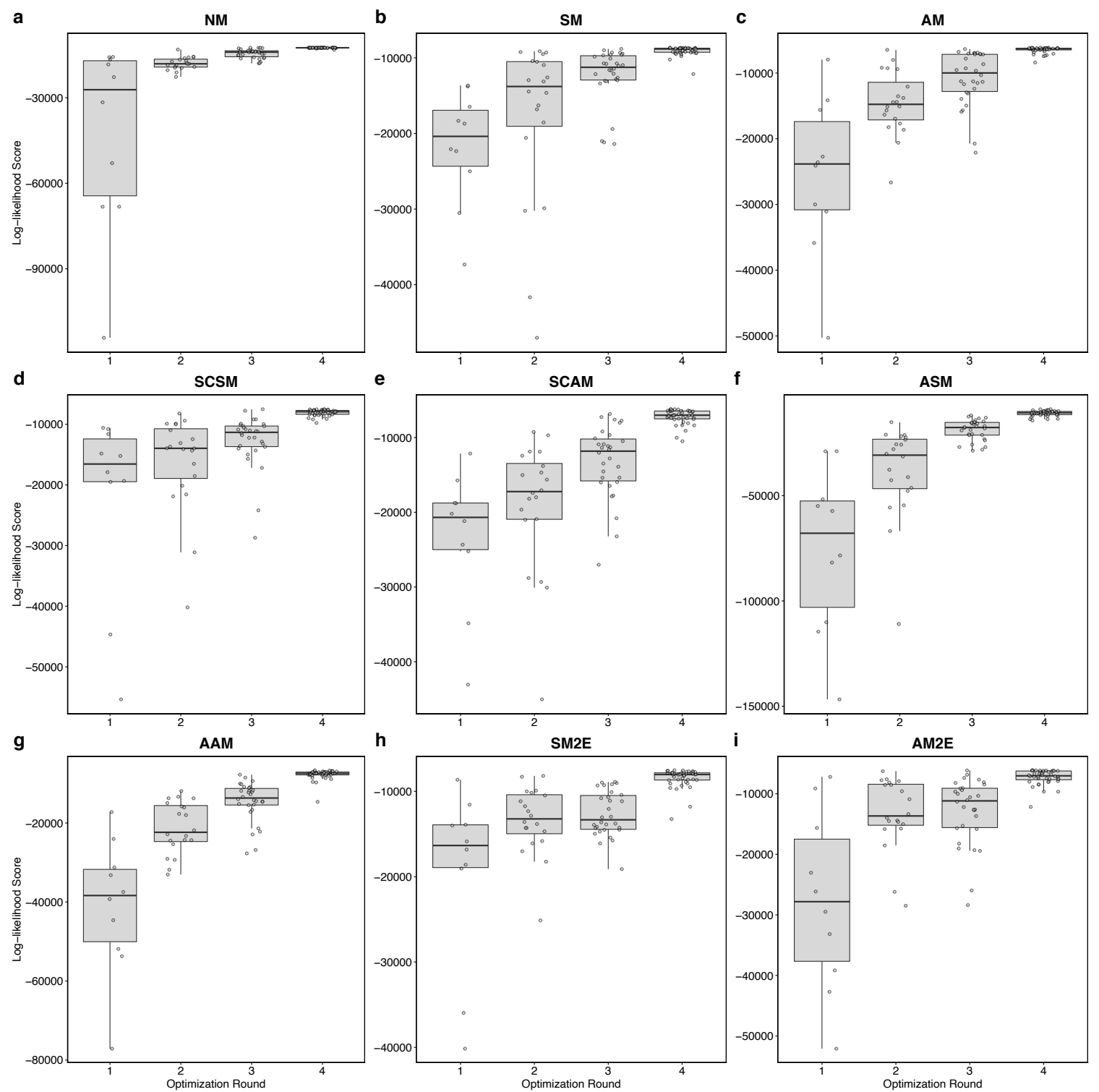

Figure A2.10. Optimization rounds for nine demographic models (a-i) run in $\delta a \delta i$ for the admixed Neosho Smallmouth Bass population in three streams of the upper Arkansas River Basin, including Buffalo Creek, Big Sugar Creek, and Spavinaw Creek (UPPARK) and its Northern Smallmouth Bass parent in the White River drainage (WHITE). Loglikelihood scores and associated box plots for 10 replicates in Round 1, 20 replicates in Round 2, 30 replicates in Round 3, and 40 replicates in Round 4, are shown for each model. Model codes are associated with the model descriptions in Table A2.1. Schematics for each model are given in Figure A2.2. 
Model Residuals

a

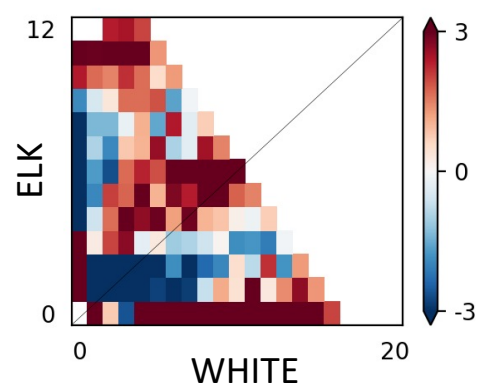

b

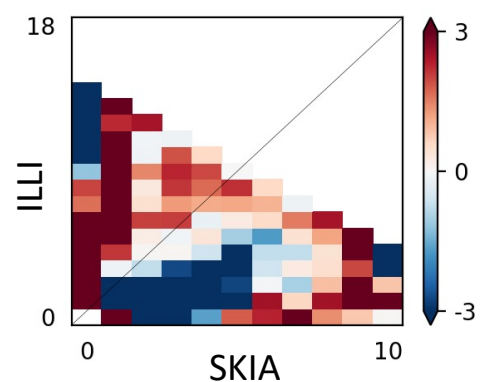

C

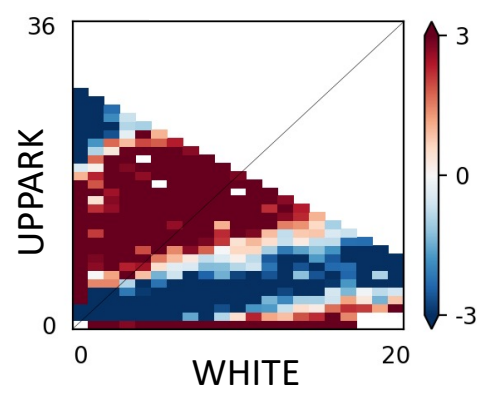

d

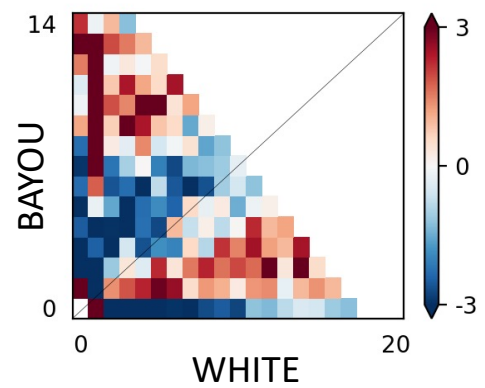

\section{Residual Distribution}
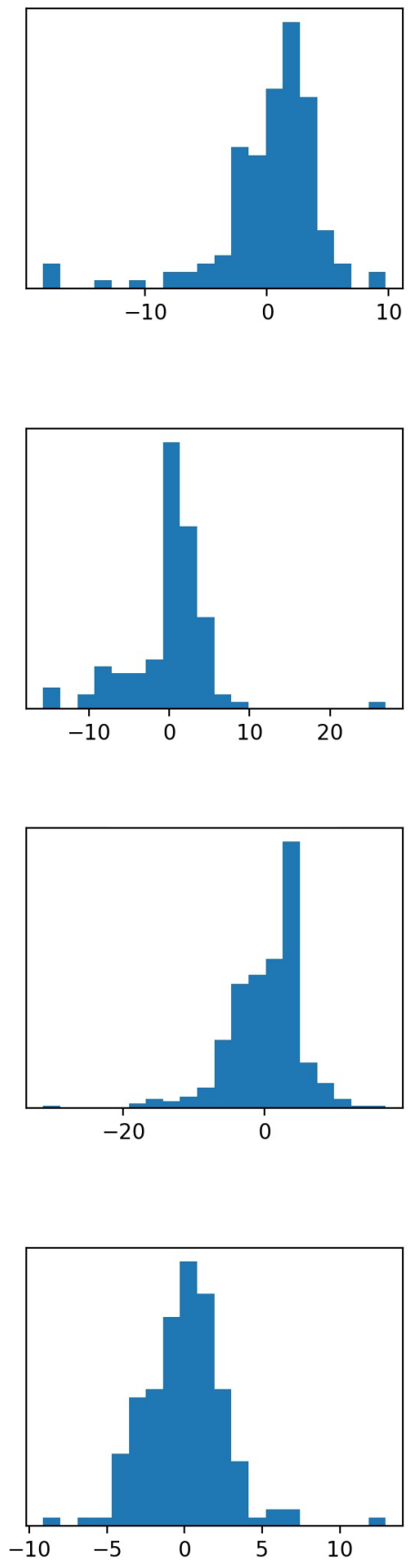

Figure A2.11. Residuals of empirical data (first column) and distribution of residuals (second column) with respect to the best fitting two-population demographic model for (a) ELK and WHITE, (b) ILLI and SKIA, (c) BAYOU and WHITE, and (d) UPPARK and WHITE. 

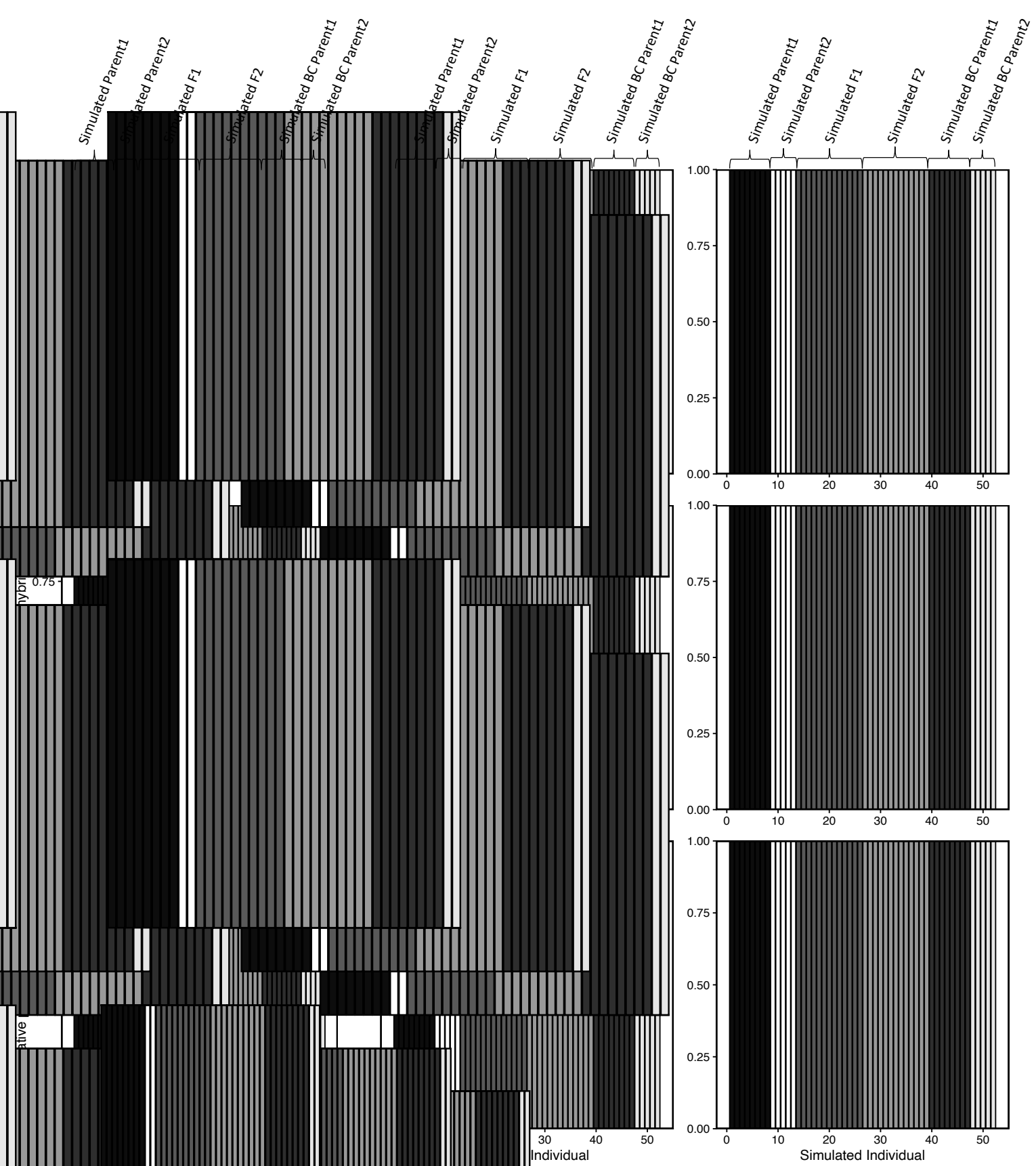

NewHYBRIDS Assignment

$\square \begin{array}{ll}\text { PARENT1 } \\ \text { PARENT2 }\end{array}$

Figure A2.12. Validation of 200 diagnostic SNPS generated with the validation set of samples from MIDARK and WHITE. Three replicates were run in each of three independent simulations: Simulation 1 (a-c), Simulation 2 (d-f), and Simulation 3 (g-i). Simulated hybrids from all replicates were assigned to hybrid categories with a posterior probability in NEWHYBRIDS. True, simulated hybrid categories are listed across the upper horizontal. Colors within each bar indicate the cumulative probability to which the individual sample is assigned to the corresponding hybrid category. 

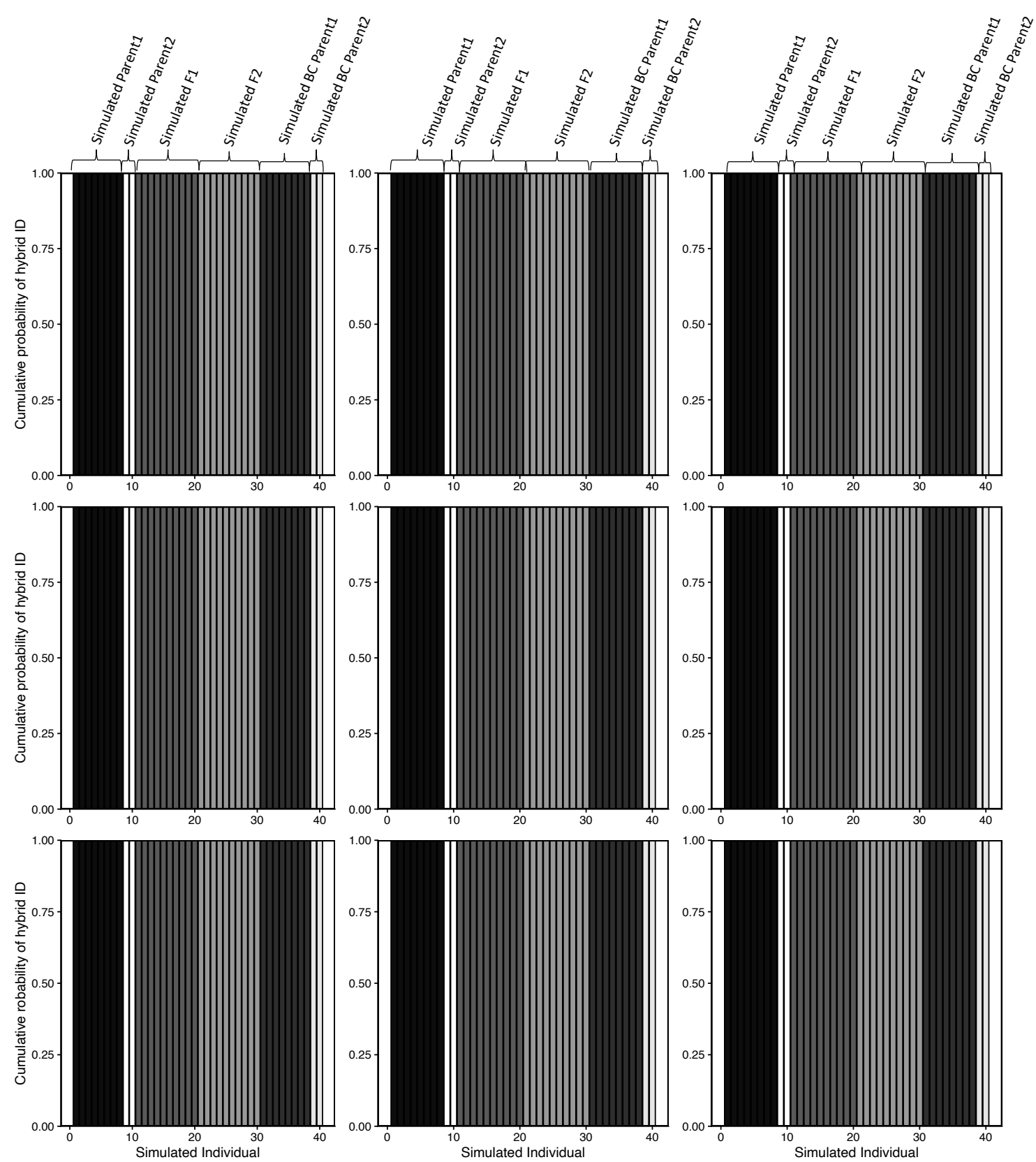

NeWHybrids Assignment

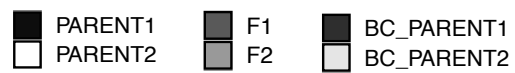

Figure A2.13. Validation of 200 diagnostic SNPS generated with the validation set of samples from MIDARK and SKIA. Three replicates were run in each of three independent simulations: Simulation 1 (a-c), Simulation 2 (d-f), and Simulation 3 (g-i). Simulated hybrids from all replicates were assigned to hybrid categories with a posterior probability in NEWHYBRIDS. True, simulated hybrid categories are listed across the upper horizontal. Colors within each bar indicate the cumulative probability to which the individual sample is assigned to the corresponding hybrid category. 


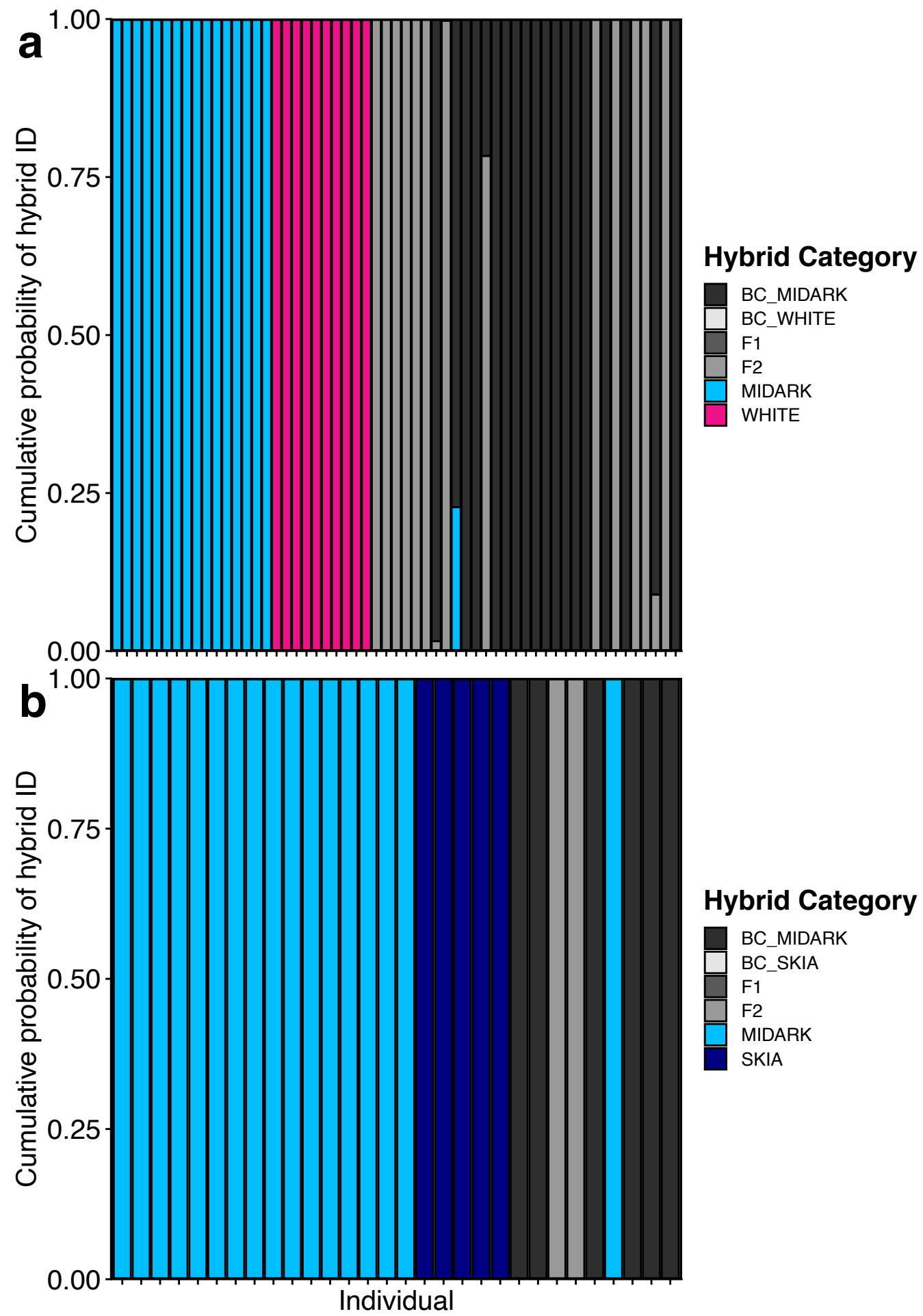

Figure A2.14. Hybrid category assignments for empirical data on (a) admixed populations with MIDARK and WHITE parents and (b) admixed populations with MIDARK and SKIA as parents in NEWHYBRIDS. Parent and admixed populations are labeled and color-coded along the upper horizontal. Colors in each bar indicate the probability that the individual sample is assigned to the corresponding category. 


\section{APPENDIX 3}

\section{Supplementary tables and figures for chapter 5}

Table A3.1. Sample sizes $(N)$ per $25 \mathrm{~mm}$ size bin $(200-400+\mathrm{mm})$ for females and males and for admixture status groups (Neosho, Northern, and Admixed) within Big Sugar Creek and the Elk River.

\begin{tabular}{lcccc}
\hline \multirow{2}{*}{$\begin{array}{l}\text { Size bin } \\
(\mathbf{m m})\end{array}$} & \multicolumn{2}{c}{$N$ (Female, Male) } & \multicolumn{2}{c}{$N$ (Neosho, Northern, Admixed) } \\
\cline { 2 - 5 } & Big Sugar Creek & Elk River & Big Sugar Creek & Elk River \\
\hline $200-225$ & $11(6,5)$ & $10(4,6)$ & $11(6,2,3)$ & $10(3,2,5)$ \\
$225-250$ & $4(1,3)$ & $15(9,6)$ & $4(2,0,2)$ & $15(6,3,6)$ \\
$250-275$ & $4(3,1)$ & $16(8,8)$ & $4(2,1,1)$ & $16(6,4,6)$ \\
$275-300$ & $8(6,2)$ & $12(4,8)$ & $8(3,2,3)$ & $12(6,0,6)$ \\
$300-325$ & $11(5,6)$ & $6(2,4)$ & $11(5,1,5)$ & $6(2,0,4)$ \\
$325-350$ & $4(3,1)$ & $4(3,1)$ & $4(2,1,1)$ & $4(0,1,3)$ \\
$350-375$ & $1(1,0)$ & $5(2,3)$ & $1(0,0,1)$ & $5(2,2,1)$ \\
$375-400+$ & $3(2,1)$ & $1(0,1)$ & $3(2,0,1)$ & $1(1,0,0)$ \\
Totals & $46(27,19)$ & $69(32,37)$ & $46(22,7,17)$ & $69(26,12,31)$ \\
\hline
\end{tabular}


Table A3.2. $K$, STRUCTURE replicates, mean and standard deviation of posterior probability $(\operatorname{LnP}(K))$, and second order rate of change of log likelihood (Delta $K)$ for 10 replicates in STRUCTURE. The best $K$ values (2) are highlighted in grey for convenience.

\begin{tabular}{ccccc}
\hline $\boldsymbol{K}$ & Reps & Mean LnP(K) & St. Dev LnP(K) & Delta $\boldsymbol{K}$ \\
\hline 1 & 10 & -6224.14 & 0.41 & -- \\
2 & 10 & -6272.80 & 9.21 & 27.60907 \\
3 & 10 & -6575.79 & 803.21 & 0.08767 \\
4 & 10 & -6949.20 & 228.24 & 0.06515 \\
5 & 10 & -7337.48 & 429.29 & -- \\
\hline
\end{tabular}


Table A3.3. Table of Puechmaille (2016) estimators: median of medians (MedMed $K$ ), median of means $(\operatorname{MedMean} K)$, maximum of medians $(\operatorname{MaxMed} K)$, and maximum of means (MaxMean $K$ ), for 10 replicates in STRUCTURE. The best $K$ values (2) are highlighted in grey for convenience.

\begin{tabular}{cccccc}
\hline $\boldsymbol{K}$ & MedMed & MedMean & MaxMed & MaxMean & Reps \\
\hline 1 & 1 & 1 & 1 & 1 & 10 \\
2 & 2 & 2 & 2 & 2 & 10 \\
3 & 1 & 1 & 1 & 1 & 10 \\
4 & 0 & 0 & 1 & 1 & 10 \\
5 & 0 & 0 & 0 & 0 & 10 \\
& $\operatorname{MedMed} K$ & MedMea $K$ & $\operatorname{MaxMed} K$ & $\operatorname{MaxMea} K$ & \\
& 2 & 2 & 2 & 2 & \\
\hline
\end{tabular}


Table A3.4. Allelic richness $(A)$, observed heterozygosity $\left(H_{\mathrm{O}}\right)$, expected heterozygosity $\left(H_{\mathrm{E}}\right)$, and the inbreeding coefficient $\left(F_{\mathrm{IS}}\right)$ across 14 microsatellite loci for Smallmouth Bass samples assigned as Northern grouped within rivers in the Neosho Smallmouth Bass range (Big Sugar Creek and the Elk River) and the Northern Smallmouth Bass samples used to calculate ancestry in STRUCTURE. Mean values for each metric across loci are given.

\begin{tabular}{|c|c|c|c|c|c|c|c|c|}
\hline \multirow[t]{2}{*}{ Locus } & \multicolumn{4}{|c|}{ Neosho Rivers } & \multicolumn{4}{|c|}{ Northern Rivers } \\
\hline & $A$ & $H_{\mathrm{O}}$ & $H_{\mathrm{E}}$ & $F_{\text {IS }}$ & $A$ & $H_{\mathrm{O}}$ & $H_{\mathrm{E}}$ & $F_{\text {IS }}$ \\
\hline mdo9 & 3.18 & 0.47 & 0.69 & 0.31 & 2.87 & 0.65 & 0.65 & 0.00 \\
\hline mdo5 & 1.84 & 0.47 & 0.46 & -0.04 & 2.36 & 0.65 & 0.58 & -0.13 \\
\hline mdo 7 & 1.97 & 0.53 & 0.49 & -0.07 & 2.48 & 0.55 & 0.60 & 0.08 \\
\hline mdo10 & 1.24 & 0.21 & 0.19 & -0.09 & 1.44 & 0.35 & 0.31 & -0.14 \\
\hline mdo6 & 2.18 & 0.63 & 0.54 & -0.17 & 1.78 & 0.05 & 0.44 & 0.89 \\
\hline mdo3 & 2.43 & 0.68 & 0.59 & -0.16 & 2.61 & 0.70 & 0.62 & -0.14 \\
\hline mdo2 & 3.37 & 0.74 & 0.70 & -0.05 & 3.49 & 0.65 & 0.71 & 0.09 \\
\hline $\operatorname{lma} 21$ & 5.05 & 0.74 & 0.80 & 0.08 & 4.65 & 0.80 & 0.79 & -0.02 \\
\hline msaf29 & 7.22 & 0.74 & 0.86 & 0.14 & 12.89 & 0.89 & 0.92 & 0.03 \\
\hline msaf05 & 6.88 & 0.68 & 0.85 & 0.20 & 5.69 & 0.68 & 0.82 & 0.17 \\
\hline msaf14 & 13.50 & 0.72 & 0.93 & 0.22 & 14.44 & 0.79 & 0.93 & 0.15 \\
\hline msaf17 & 9.50 & 1.00 & 0.89 & -0.12 & 8.20 & 0.84 & 0.88 & 0.04 \\
\hline msaf09 & 4.95 & 0.68 & 0.80 & 0.14 & 5.10 & 0.90 & 0.80 & -0.12 \\
\hline msaf06 & 7.15 & 0.95 & 0.86 & -0.10 & 9.09 & 0.95 & 0.89 & -0.07 \\
\hline Mean & 5.03 & 0.66 & 0.69 & 0.02 & 5.51 & 0.68 & 0.71 & 0.06 \\
\hline
\end{tabular}


Table A3.5. Genetic diversity values including allelic richness $(A)$, observed heterozygosity $\left(H_{\mathrm{O}}\right)$, expected heterozygosity $\left(H_{\mathrm{E}}\right)$, and the inbreeding coefficient $\left(F_{\text {IS }}\right)$ across 14 microsatellite loci for Smallmouth Bass samples assigned as Northern in Big Sugar Creek and the Elk River within the Neosho Smallmouth Bass range and in Tablerock Lake and tributaries of the White River (including White River and Crooked Creek) for the Northern Smallmouth Bass samples used to calculate ancestry in STRUCTURE.

\begin{tabular}{|c|c|c|c|c|c|c|c|c|c|c|c|c|c|c|c|c|}
\hline \multirow{2}{*}{ Locus } & \multicolumn{4}{|c|}{ Big Sugar Creek } & \multicolumn{4}{|c|}{ Elk River } & \multicolumn{4}{|c|}{ Tablerock Lake } & \multicolumn{4}{|c|}{ White River } \\
\hline & $A$ & $H_{\mathrm{O}}$ & $H_{\mathrm{E}}$ & $F_{\text {IS }}$ & $A$ & $H_{\mathrm{O}}$ & $H_{\mathrm{E}}$ & $F_{\text {IS }}$ & $A$ & $H_{\mathrm{O}}$ & $H_{E}$ & $F_{\text {IS }}$ & $A$ & $H_{\mathrm{O}}$ & $H_{\mathrm{E}}$ & $F_{\text {IS }}$ \\
\hline mdo9 & 4.00 & 0.29 & 0.66 & 0.57 & 3.00 & 0.58 & 0.56 & -0.04 & 3.00 & 0.50 & 0.53 & 0.06 & 3.00 & 0.75 & 0.66 & -0.13 \\
\hline mdo5 & 3.00 & 0.29 & 0.45 & 0.36 & 3.00 & 0.58 & 0.45 & -0.30 & 3.00 & 0.88 & 0.63 & -0.38 & 3.00 & 0.50 & 0.52 & 0.03 \\
\hline mdo 7 & 2.00 & 0.57 & 0.41 & -0.40 & 3.00 & 0.50 & 0.53 & 0.06 & 3.00 & 0.88 & 0.62 & -0.42 & 3.00 & 0.33 & 0.50 & 0.33 \\
\hline mdo10 & 2.00 & 0.14 & 0.13 & -0.08 & 3.00 & 0.25 & 0.23 & -0.11 & 3.00 & 0.50 & 0.40 & -0.25 & 4.00 & 0.25 & 0.23 & -0.09 \\
\hline mdo6 & 3.00 & 0.71 & 0.52 & -0.37 & 3.00 & 0.58 & 0.53 & -0.10 & 2.00 & 0.00 & 0.50 & 1.00 & 2.00 & 0.08 & 0.33 & 0.75 \\
\hline mdo3 & 4.00 & 0.43 & 0.53 & 0.19 & 5.00 & 0.83 & 0.61 & -0.36 & 5.00 & 0.63 & 0.63 & 0.01 & 4.00 & 0.75 & 0.60 & -0.26 \\
\hline mdo2 & 3.00 & 0.57 & 0.62 & 0.08 & 5.00 & 0.83 & 0.72 & -0.17 & 5.00 & 0.88 & 0.73 & -0.20 & 3.00 & 0.50 & 0.66 & 0.25 \\
\hline $\operatorname{lma} 21$ & 5.00 & 0.86 & 0.74 & -0.15 & 7.00 & 0.67 & 0.78 & 0.14 & 5.00 & 0.63 & 0.76 & 0.18 & 6.00 & 0.92 & 0.78 & -0.18 \\
\hline msaf29 & 9.00 & 0.71 & 0.86 & 0.17 & 9.00 & 0.75 & 0.82 & 0.08 & 9.00 & 0.75 & 0.85 & 0.12 & 12.00 & 1.00 & 0.90 & -0.12 \\
\hline msaf05 & 7.00 & 0.57 & 0.80 & 0.28 & 10.00 & 0.75 & 0.85 & 0.12 & 4.00 & 0.63 & 0.67 & 0.07 & 8.00 & 0.73 & 0.84 & 0.13 \\
\hline msaf14 & 7.00 & 0.50 & 0.83 & 0.40 & 13.00 & 0.83 & 0.91 & 0.08 & 8.00 & 0.63 & 0.84 & 0.26 & 14.00 & 0.91 & 0.91 & 0.00 \\
\hline msaf17 & 9.00 & 1.00 & 0.87 & -0.15 & 11.00 & 1.00 & 0.87 & -0.15 & 8.00 & 0.75 & 0.79 & 0.05 & 12.00 & 0.91 & 0.88 & -0.03 \\
\hline msaf09 & 3.00 & 0.57 & 0.56 & -0.02 & 8.00 & 0.75 & 0.82 & 0.08 & 5.00 & 0.88 & 0.72 & -0.22 & 7.00 & 0.92 & 0.81 & -0.14 \\
\hline msaf06 & 9.00 & 1.00 & 0.87 & -0.15 & 10.00 & 0.92 & 0.82 & -0.12 & 8.00 & 0.88 & 0.84 & -0.05 & 12.00 & 1.00 & 0.89 & -0.13 \\
\hline Mean & 5.00 & 0.59 & 0.63 & 0.05 & 6.64 & 0.70 & 0.68 & -0.06 & 5.07 & 0.67 & 0.68 & 0.02 & 6.64 & 0.68 & 0.68 & 0.03 \\
\hline
\end{tabular}


Table A3.6. Individual growth parameters from von Bertalanffy growth models for all individuals in (a) the global dataset, (b) rivers, (c) sexes, and (d) admixture status groups (Neosho, Northern, Admixed). $L_{\infty}$ is theoretical average maximum length $(\mathrm{mm}), K$ is the Brody growth coefficient (rate at which total length (TL) approaches $L_{\infty}$, and $t_{0}$ is theoretical age at which length is $0 \mathrm{~mm}$.

\begin{tabular}{lccc}
\hline \multirow{2}{*}{ Group } & \multicolumn{3}{c}{ Growth Model Parameters } \\
\cline { 2 - 4 } a. Global & $L_{\infty}$ & $K$ & $t_{0}$ \\
All samples & 416.41 & 0.36 & -0.14 \\
b. River & $(394.96-447.61)$ & $(0.29-0.43)$ & $(-0.38-0.05)$ \\
Big Sugar Creek & & & \\
& $433.41-547.02)$ & $(0.18-0.33)$ & $(-0.80--0.13)$ \\
Elk River & 391.04 & 0.44 & 0.01 \\
& $(366.87-419.29)$ & $(0.34-0.55)$ & $(-0.31-0.23)$ \\
c. Sex & & & \\
Male & 417.86 & 0.38 & -0.06 \\
& $(390.70-451.43)$ & $(0.30-0.49)$ & $(-0.42-0.18)$ \\
Female & 418.71 & 0.33 & -0.22 \\
d. Admixture Status & $(383.84-465.44)$ & $(0.25-0.42)$ & $(-0.54-0.02)$ \\
Neosho & 431.07 & & \\
Northern & $(392.13-504.83)$ & $(0.19-0.47)$ & $(-1.02-0.14)$ \\
Admixed & 446.26 & 0.29 & -0.26 \\
& $(374.76-566.75)$ & $(0.16-0.45)$ & $(-0.88-0.11)$ \\
& 393.58 & 0.42 & -0.05 \\
& $(362.53-434.59)$ & $(0.31-0.54)$ & $(-0.33-0.19)$ \\
\hline
\end{tabular}




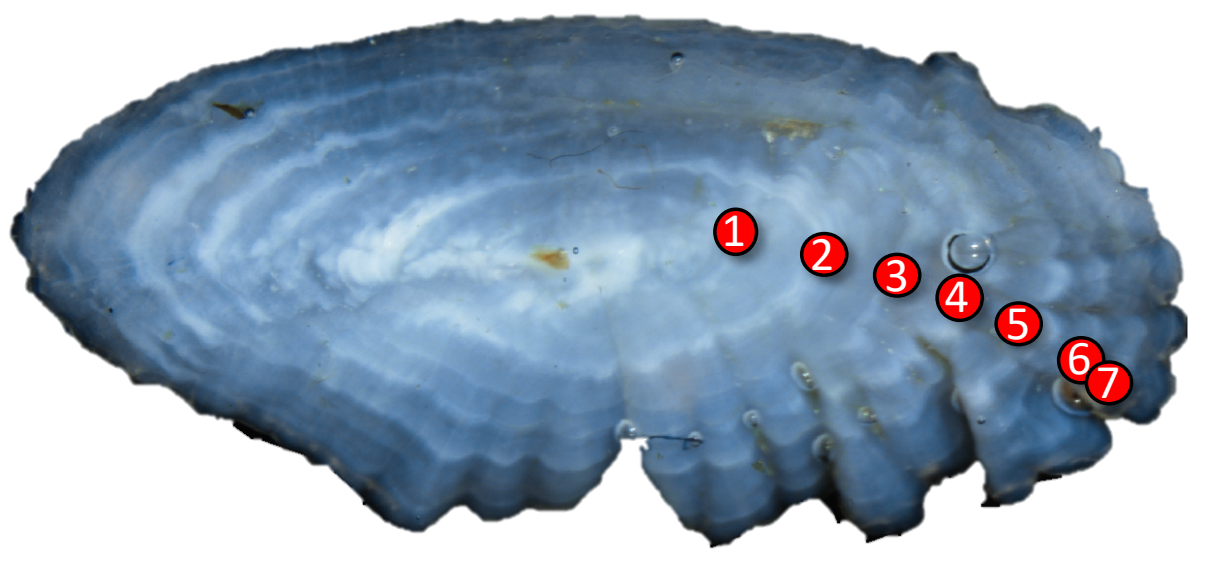

Figure A3.1. Microscope image of a representative sagittal otolith from the full dataset, with red, numbered circles indicating opaque growth annuli that were counted to determine consensus age (7). 


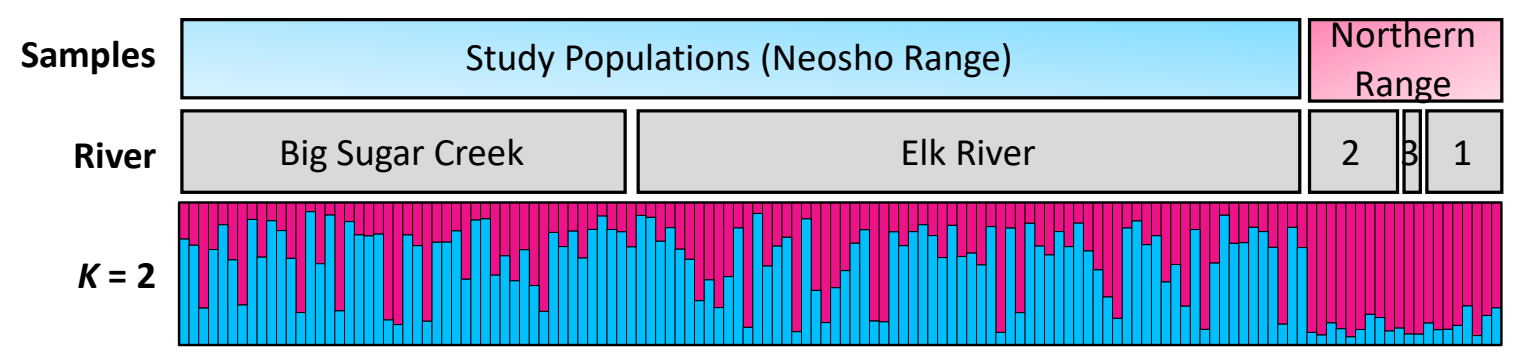

Figure A3.2. Population structure results from STRUCTURE. (a) The $q$-value plot for $K=2$, with samples labeled by their experimental status (Admixed populations or Northern reference) and by river on the upper horizontal. River ID numbers within the Northern reference correspond to Table 5.1. (b) Number of samples $(N)$ across eight $25 \mathrm{~mm}$ size bins for samples assigned to each admixture status. 

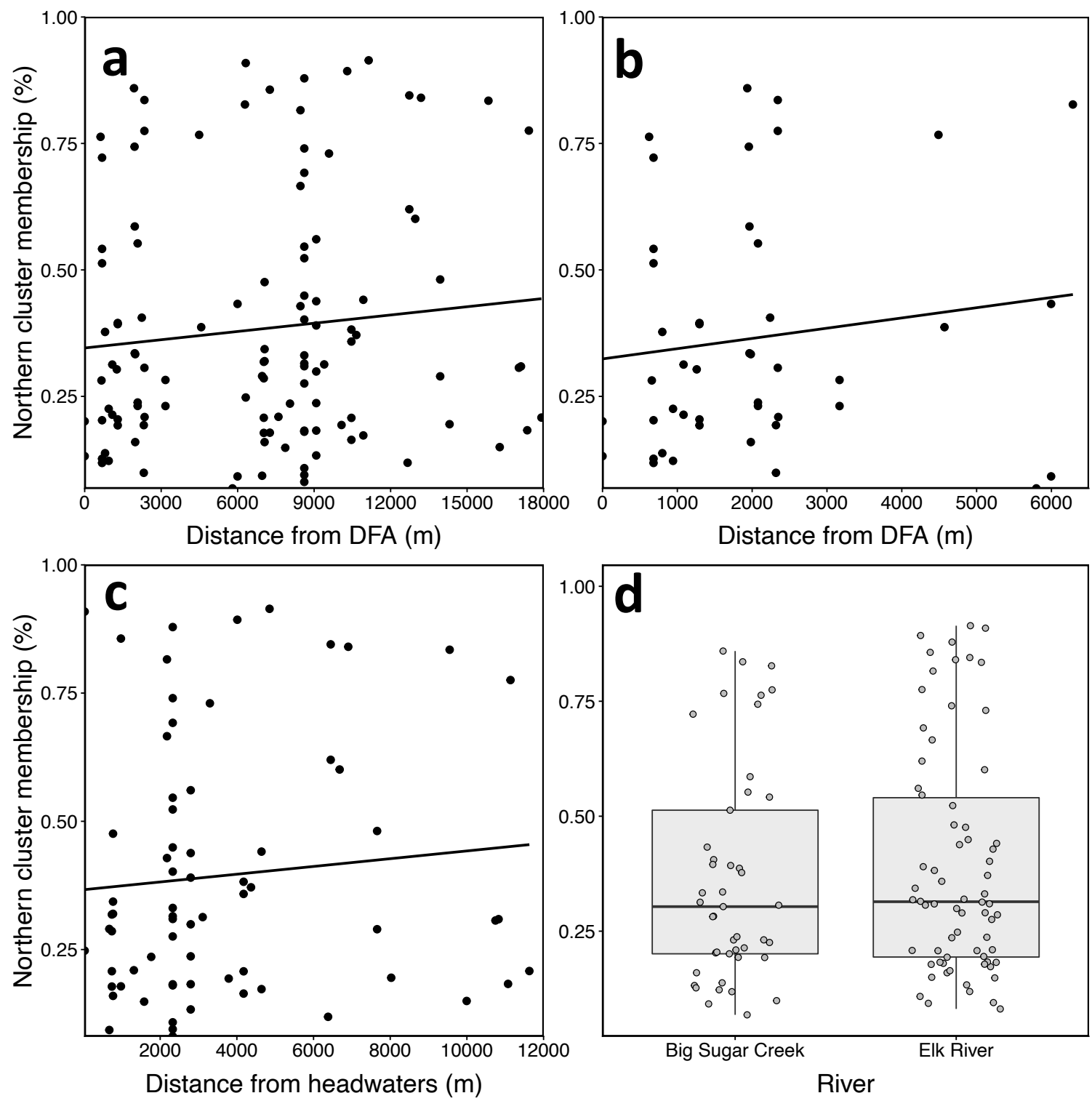

Figure A3.3. Linear mixed regression models for proportion of Northern ancestry (\%) by linear stream distance (m), with lines of best fit shown for each model, (a) for all sites in the global dataset between Deep Ford Access (DFA) and Mount Shira Access (MSA), (b) sites within Big Sugar Creek between DFA and the Elk River headwaters, and (c) sites within the Elk River between the Elk River headwaters and MSA. (d) Comparison of average Northern ancestry between Big Sugar Creek and the Elk River. 

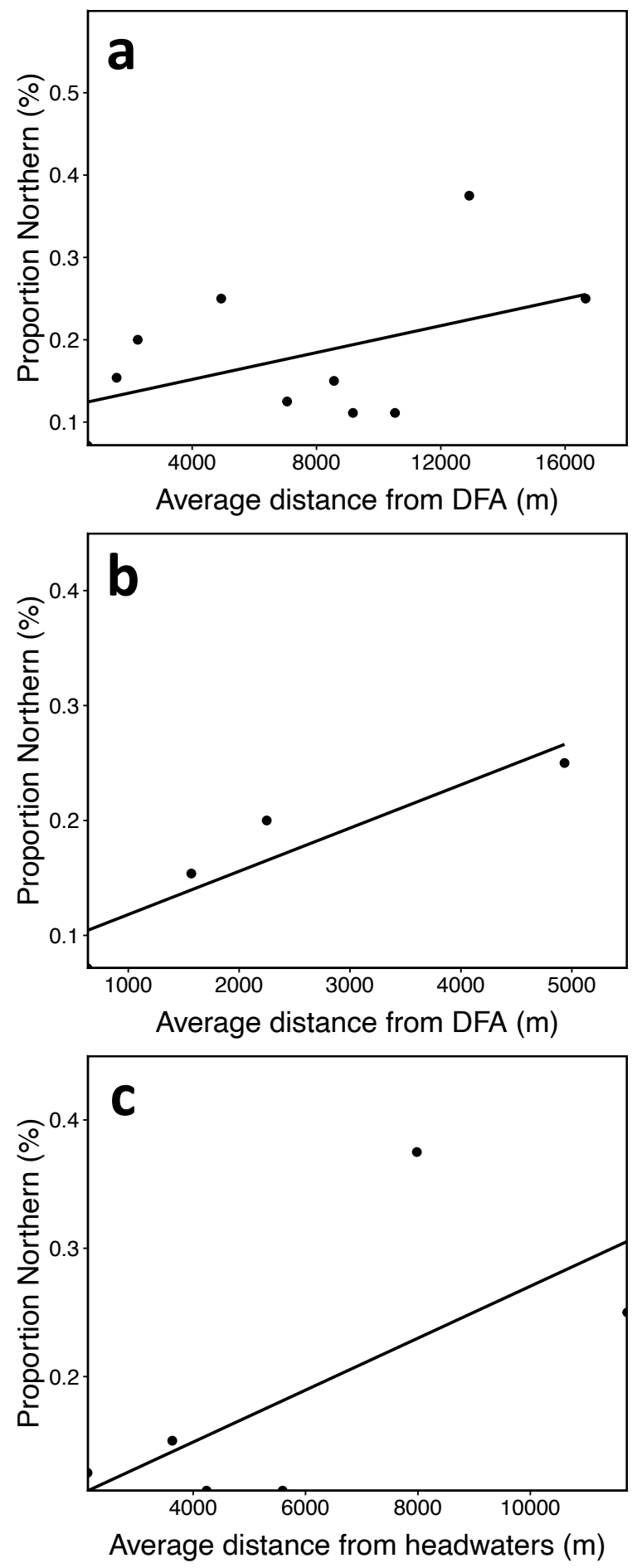

Figure A3.4. Linear regression models for the proportion of individuals assigned to the Northern genetic cluster (\%) in STRUCTURE by linear stream distance (m), with lines of best fit shown for each model, for (a) all sites in the global dataset between Deep Ford Access (DFA) and Mount Shira Access (MSA), (b) sites within Big Sugar Creek between DFA and the Elk River headwaters, and (c) sites within the Elk River between the Elk River headwaters and MSA. 

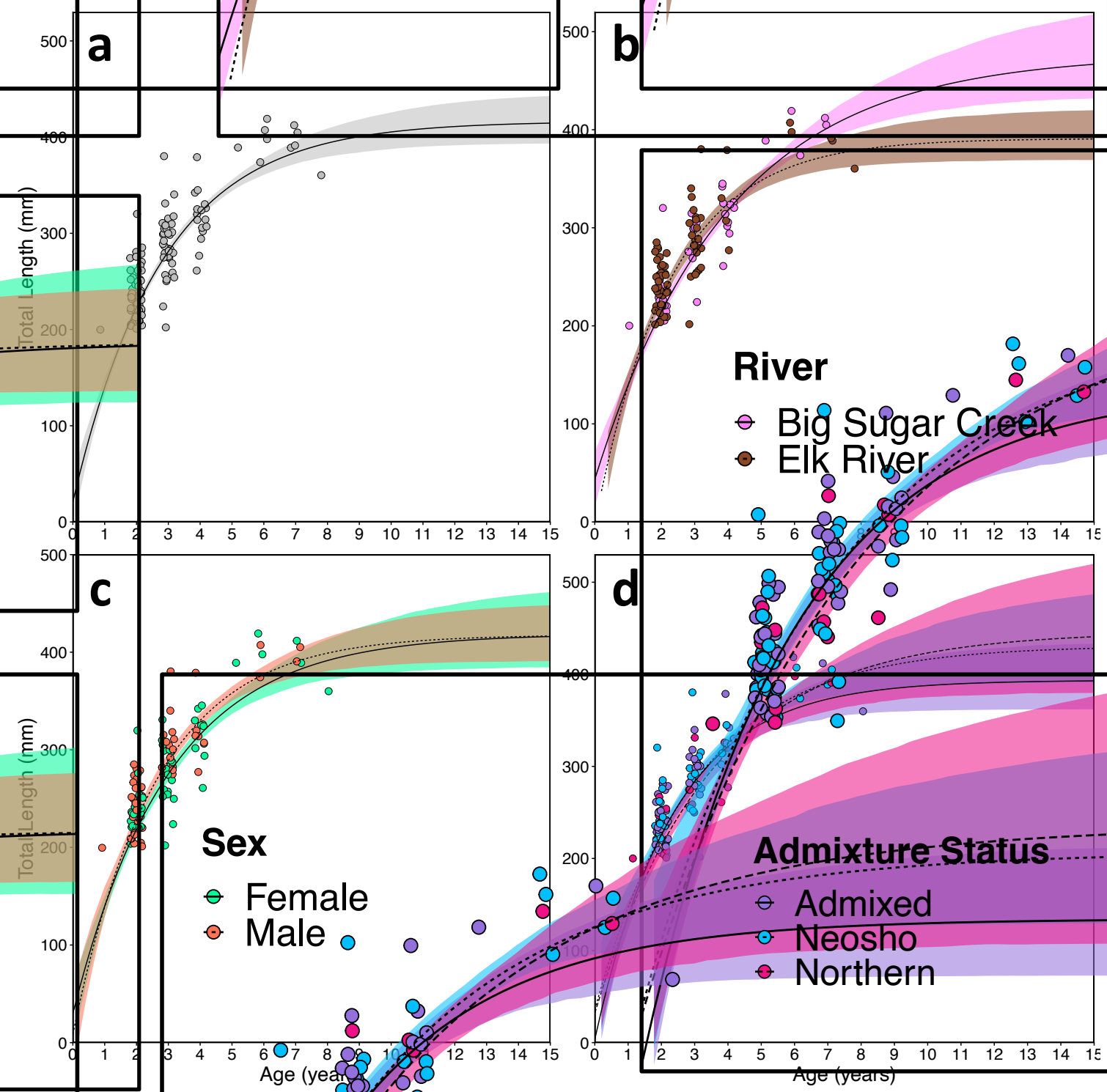

Figure A3.5. Von Bertalanffy growth models, with lines indicating average length-at-age and ribbons delineating 95\% confidence intervals for 1000 bootstrap replicates, for (a) all samples in the global dataset, (b) rivers, (c) sex, and (d) admixture statuses (Neosho, Northern, or Admixed). 

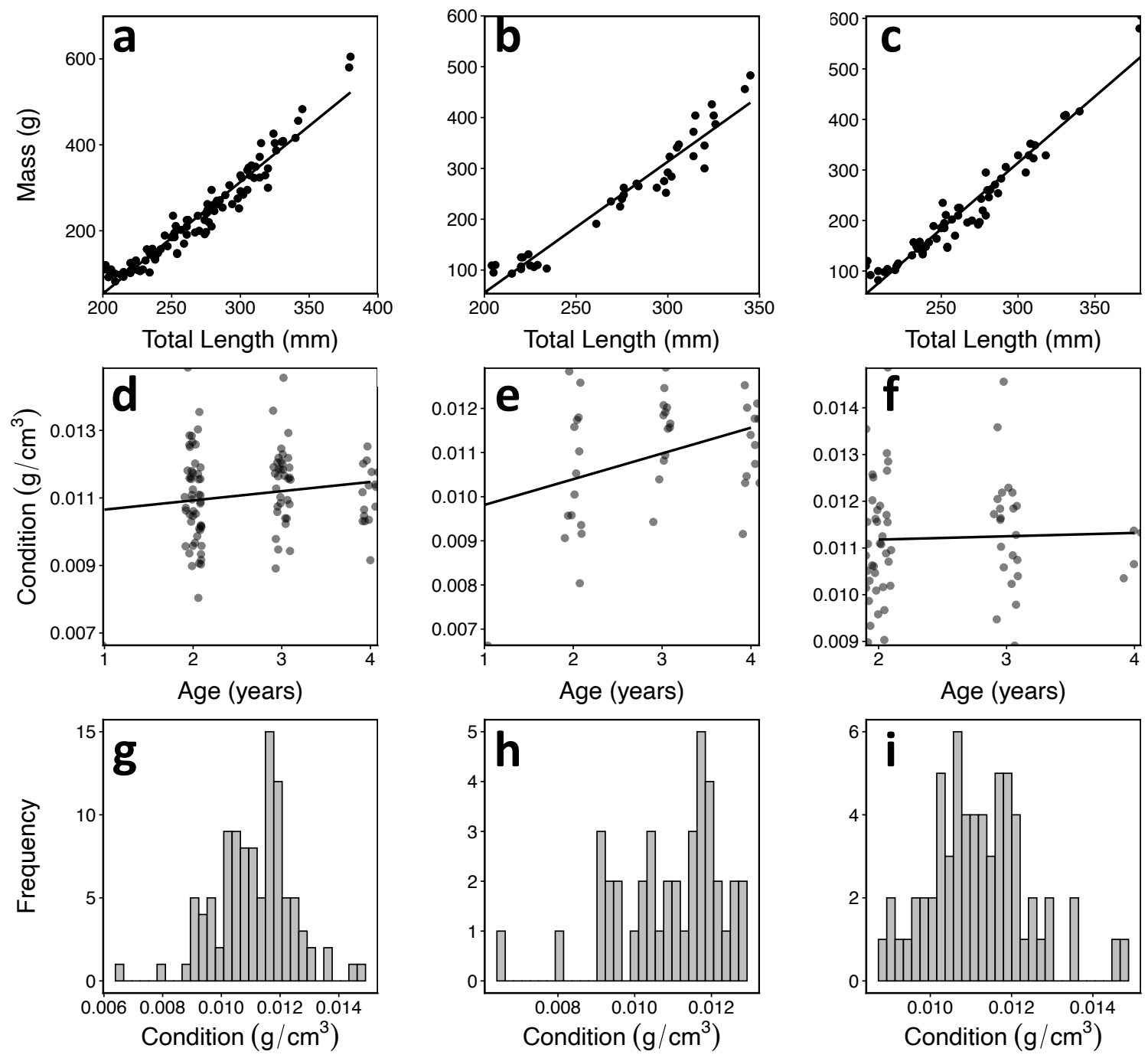

Figure A3.6. Check of suitability of the Fulton Condition Index as a proxy for fitness in Smallmouth Bass, including linear regression analysis of mass (g) and total length (TL) for samples in (a) the global dataset, (b) Big Sugar Creek, and (c) the Elk River; linear regression analysis of age (years) and condition $\left(\mathrm{g} / \mathrm{cm}^{3}\right)$ for samples in $(\mathrm{d})$ the global dataset, (e) Big Sugar Creek, and (f) the Elk River; and Shapiro-Wilk tests for deviations from normality for samples in (g) the global dataset, (h) Big Sugar Creek, and (i) the Elk River. 

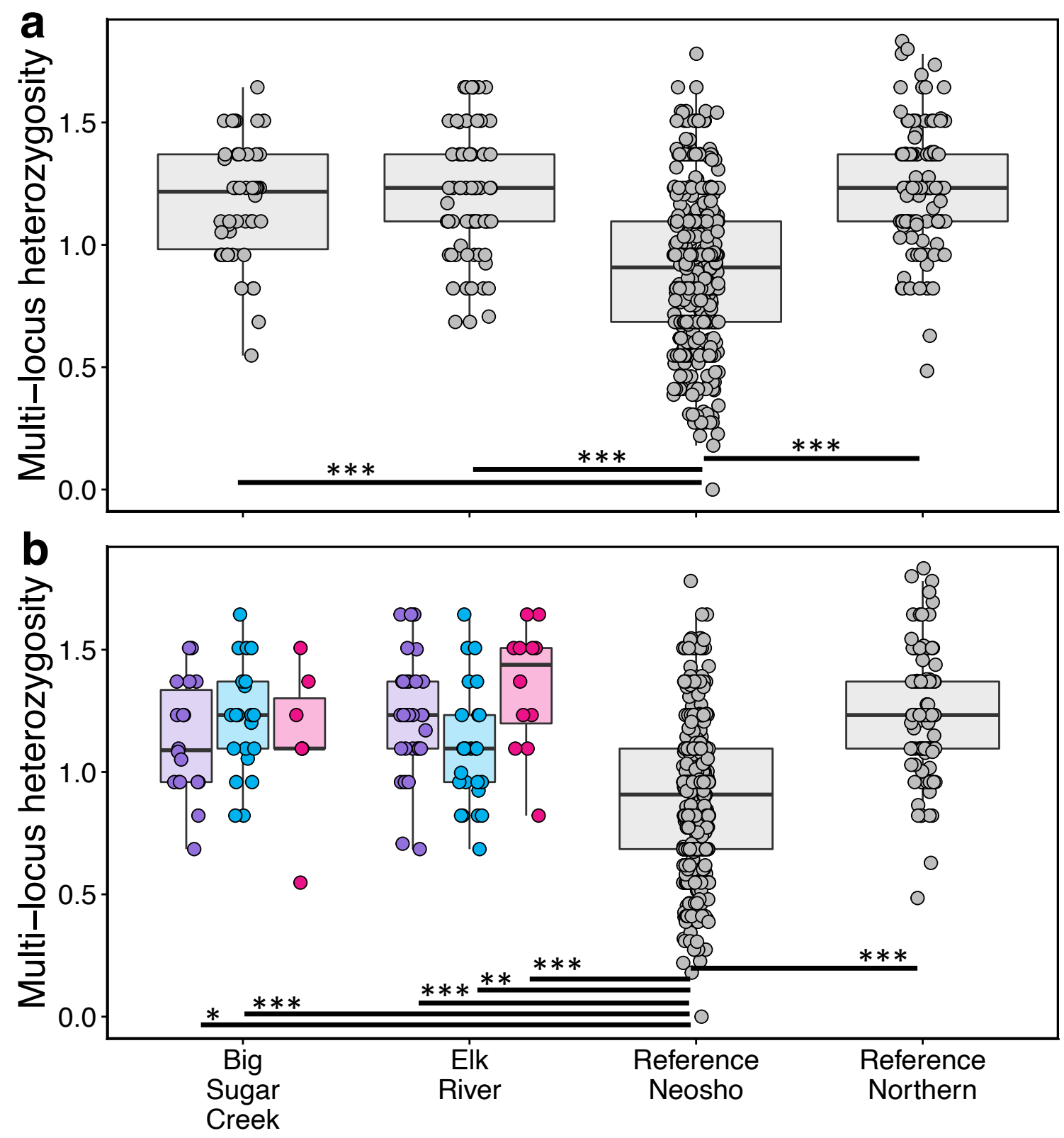

River/Population

Figure A3.7. Comparison of average multi-locus heterozygosity between rivers (Big Sugar Creek and the Elk River) and the reference Neosho and reference Northern populations. (a) Post hoc results for significant differences among rivers and reference populations. (b) Post-hoc results for significant differences among admixture status groups and reference populations. Significance at $p<0.05$ is indicated with “*”, and $p<0.001$ is indicated with “***". 


\section{VITA}

Joseph (Joe) C. Gunn was born on September 21, 1992, in Columbia, Missouri. He attended Apple School, Rock Bridge Elementary School, Gentry Middle School, Jefferson Junior High School, and Rock Bridge Senior High School, graduating in May 2011. In High School, he was fortunate to have had the best teachers he has ever known. Joe attended William Jewell College in August 2011, where he formed life-long friendships and learned to think deeply and critically about the world. He initially studied Spanish; he uses any opportunity to continue honing his skills. He eventually decided to pursue Math and Biology. In January 2014, Joe served as a volunteer for the Parque Nacional de Ecuador on the island of San Cristóbal, Galápagos, surveying sea lion populations, upkeeping the giant tortoise nature sanctuary, and removing invasive plants. That experience solidified his determination to pursue graduate training in conservation biology and to continue contemplating big questions in the evolution of species.

Joe graduated from William Jewell College with dual B.A. degrees in Math and Biology in May 2015, receiving the Doniphan Award for Graduating Senior with the Greatest Potential for Success. After graduation, he worked as a field technician in Dr. Deborah Finke's insect ecology lab at the University of Missouri. He began his PhD in Dr. Lori Eggert's lab at the University of Missouri in Fall 2016, where he found his passion for conservation and teaching. As a graduate student, he served as treasurer for the Biology Graduate Student Association for three years. He hopes to use the skills and knowledge he has gained to work for the conservation of species and to teach.

Joe spends most of his time outside of research and teaching either playing volleyball and tennis, doing crossword puzzles, hanging with good friends, or traveling. 